Electrochemical Reduction of $\mathrm{CO}$ to Ethylene

Spectroscopic Evaluation of Copper Electrodes

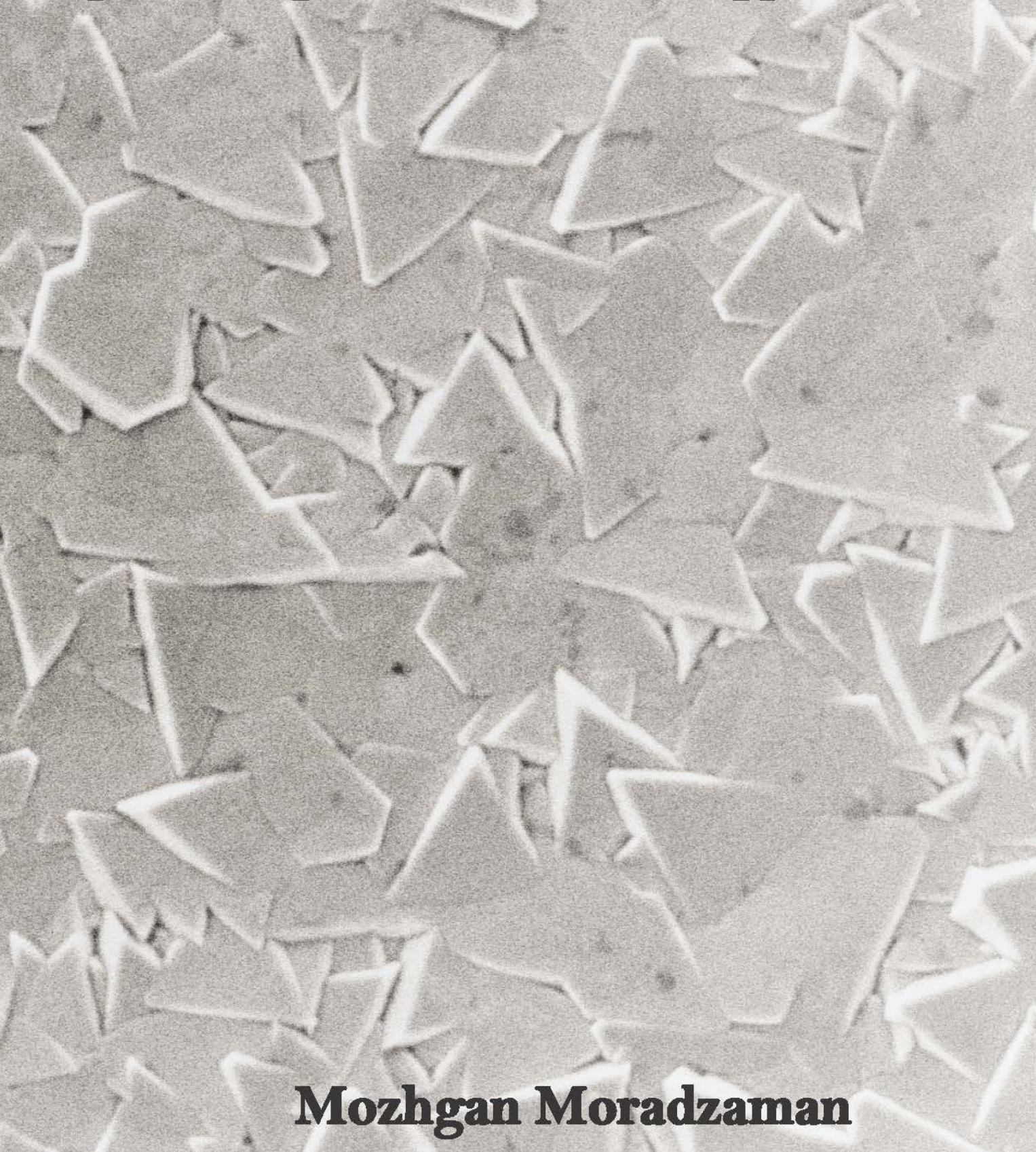





\section{Electrochemical Reduction of}

$\mathrm{CO}_{2}$ to Ethylene

Spectroscopic Evaluation of Copper Electrodes 


\section{Graduation Committee:}

\section{Chairman/secretary}

Prof. dr. J. L. Herek University of Twente

\section{Supervisor}

Prof. dr. G. Mul University of Twente

\section{Committee Members:}

Prof. dr. M. T. M. Koper ～Leiden University

Prof. dr. ir. E. L. V. Goetheer Delft University of Technology / TNO

Dr. H. Frei Lawrence Berkeley National Laboratory

Prof. dr. S. J. G. Lemay University of Twente

Prof. dr. S. R. A. Kersten University of Twente 


\title{
ELECTROCHEMICAL
}

\section{REDUCTION OF $\mathrm{CO}_{2} \mathrm{TO}$}

\section{ETHYLENE}

\section{SPECTROSCOPIC EVALUATION OF COPPER ELECTRODES}

\author{
Dissertation
}

to obtain

the degree of doctor at the Universiteit Twente,

on the authority of the rector magnificus,

prof. dr. ir. A. Veldkamp,

on account of the decision of the Doctorate Board

to be publicly defended

on Friday 23 April 2021 at 12.45 hours

by

Mozhgan Moradzaman

born on the $4^{\text {th }}$ of February 1988

in Shiraz, Iran 
This dissertation has been approved by:

Supervisor

Prof. Dr. Guido Mul

The research in this thesis was performed in the PhotoCatalytic Synthesis group within the faculty of Science and Technology, and the MESA+ Institute for Nanotechnology at the University of Twente. This research was financed by the Solar to Products project 733.000.008 "Electrochemical reduction of $\mathrm{CO}_{2}$ to ethylene” of the Netherlands Organization for Scientific Research (NWO).

\section{ELECTROCHEMICAL REDUCTION OF $\mathrm{CO}_{2}$ TO ETHYLENE - SPECTROSCOPIC EVALUATION OF COPPER ELECTRODES}

ISBN: 978-90-365-5151-9

DOI: $10.3990 / 1.9789036551519$

Cover: SEM image of copper oxide structure, by Mozhgan Moradzaman

Printed by: Gildeprint

(C) 2021 Mozhgan Moradzaman, The Netherlands. All rights reserved. No parts of this thesis may be reproduced, stored in a retrieval system or transmitted in any form or by any means without permission of the author. Alle rechten voorbehouden. Niets uit deze uitgave mag worden vermenigvuldigd, in enige vorm of op enige wijze, zonder voorafgaande schriftelijke toestemming van de auteur. 


\section{Contents}

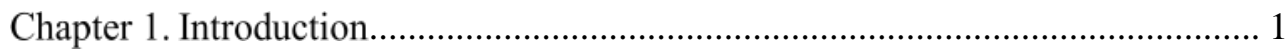

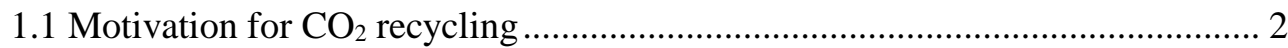

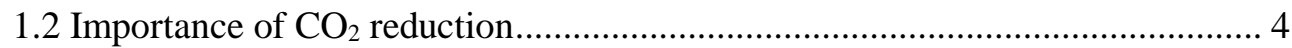

1.3 Heterogeneous catalysis in aqueous media at metal electrodes.......................... 6

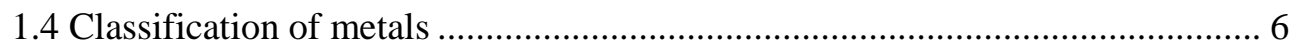

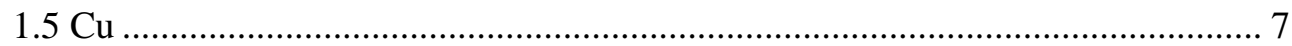

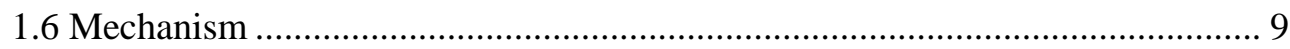

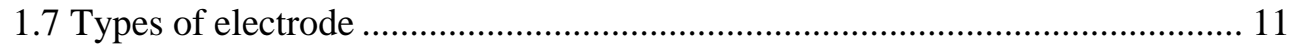

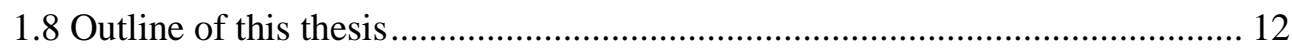

Chapter 2. Theory and experimental methods...................................................... 15

2.1 Gas chromatography................................................................................ 16

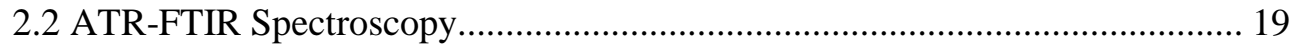

2.3 Raman Spectroscopy ……………........................................................... 22

2.4 Electrochemical surface area determination..................................................... 24

2.5 Electrode preparation................................................................................. 24

Chapter 3. Effect of partial pressure on product selectivity in Cu-catalyzed

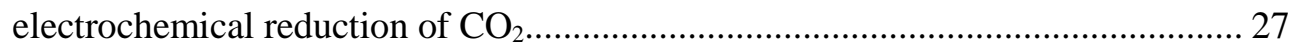

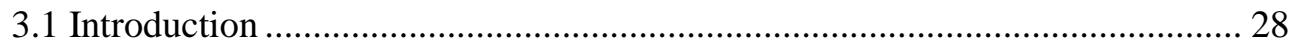

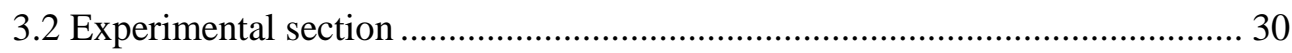

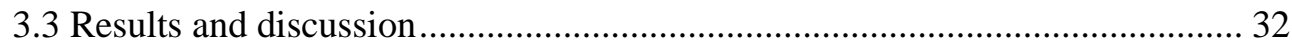

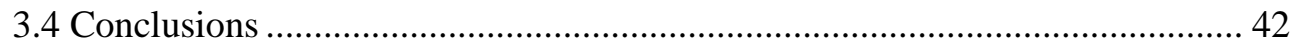

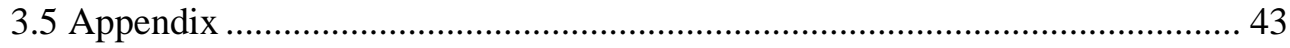


Chapter 4. Optimizing CO coverage on rough copper electrodes: effect of the partial pressure of $\mathrm{CO}$ and electrolyte anions $(\mathrm{pH})$ on selectivity toward ethylene 45

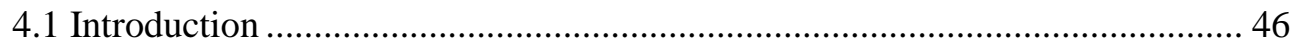

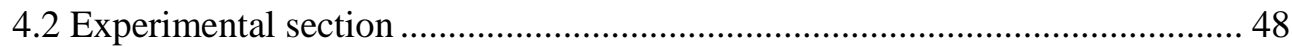

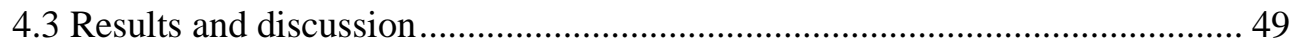

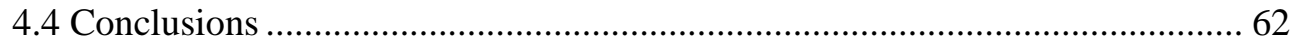

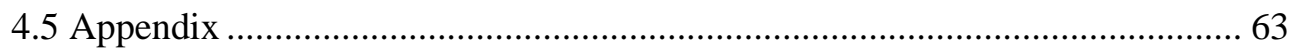

Chapter 5. Infrared analysis of interfacial phenomena during electrochemical reduction of $\mathrm{CO}_{2}$ over polycrystalline copper electrodes .................................... 67

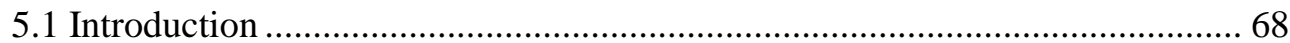

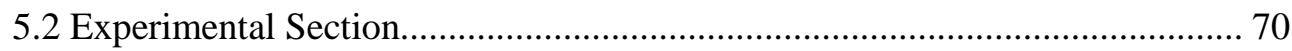

5.3 Results and Discussion .............................................................................. 71

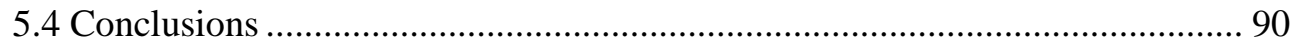

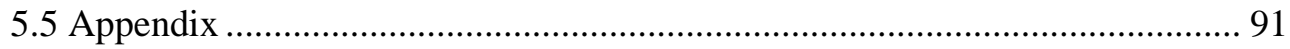

Chapter 6. Correlating the surface structure and composition of copper to high

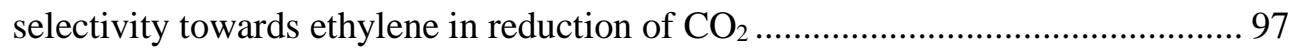

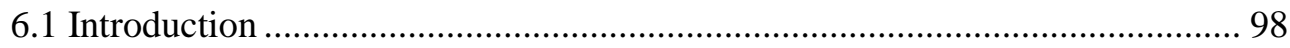

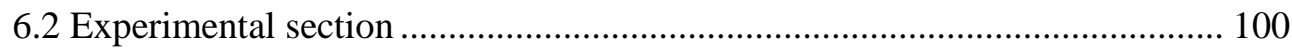

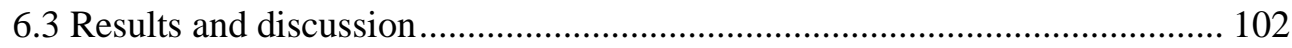

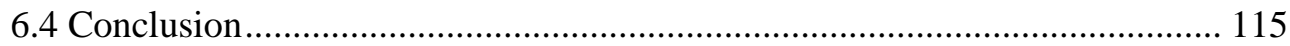

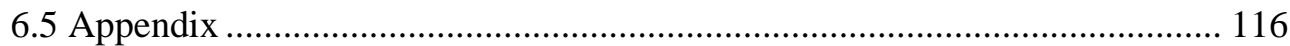

Chapter 7. In situ Raman study of potential dependent surface adsorbed carbonate, $\mathrm{CO}, \mathrm{OH}$ and $\mathrm{C}$-species on Cu-electrodes during electrochemical reduction of $\mathrm{CO}_{2}$ 


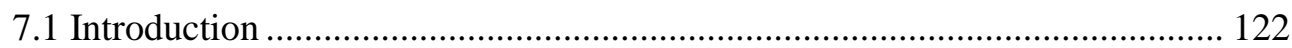

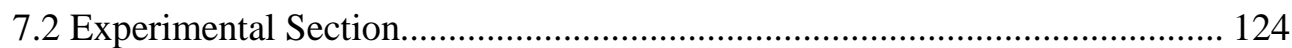

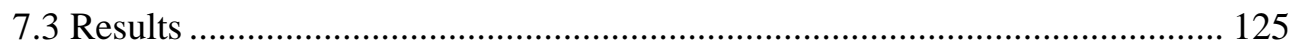

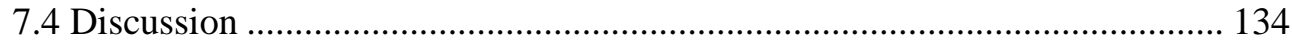

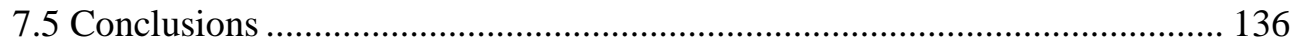

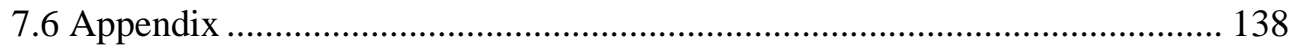

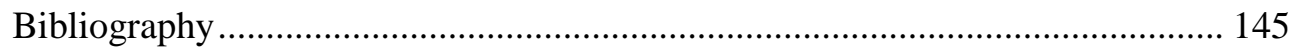

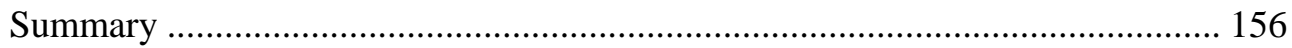

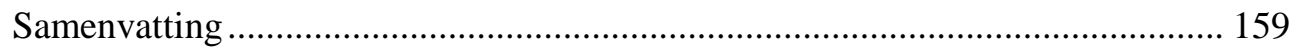

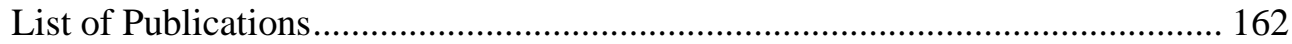

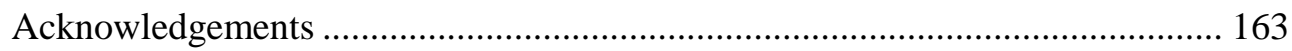





\section{Chapter 1.}

\section{Introduction}

This chapter provides motivation and background information for the work in the field of electrochemical reduction of $\mathrm{CO}_{2}$. After stating the importance of the subject, reaction mechanism on $\mathrm{Cu}$ electrodes is discussed. Finally, a brief overview of the thesis outline is given. 


\section{Chapter 1}

\subsection{Motivation for $\mathrm{CO}_{2}$ recycling}

Excessive $\mathrm{CO}_{2}$ emission by human activities is a serious environmental threat and a leading cause of global climate change ${ }^{1}$. Anthropogenic emissions of $\mathrm{CO}_{2}$ accelerated at the start of the industrial age in the mid-18th century and are now increasing the atmospheric concentration of $\mathrm{CO}_{2}$ by $1-2$ parts per million by volume (ppmv) annually ${ }^{2}$. As can be seen from figure 1, due to the tremendous consumption of fossil fuels, the annual $\mathrm{CO}_{2}$ emission steadily increased in the past 60 years. The continuously increasing concentration of $\mathrm{CO}_{2}$ in the atmosphere to levels as high as $410.31 \mathrm{ppm}$ has created serious environmental, social and global ecological issues. Consequently, this has resulted in global warming, acid rain, acidification of soils and rising of sea levels ${ }^{3-5}$.

This makes it imperative to find methods to mitigate $\mathrm{CO}_{2}$ emissions and also to replace an increasing portion of fossil fuels by renewable sources to meet global energy demand. Therefore, control and utilization of $\mathrm{CO}_{2}$ have become urgent issues to the entire international community.

Different strategies to reduce $\mathrm{CO}_{2}$ emissions must be employed and can be divided in three categories. These categories include 1) improving energy efficiency of the chemical industry, 2) carbon capture and storage, and 3) using non- or lowcarbon renewable energy sources, (e.g., solar, wind). Of these technologies, in the second option, $\mathrm{CO}_{2}$ is used as a carbon source to produce new, high-value products and in essence zero $\mathrm{CO}_{2}$ emission is feasible.

$\mathrm{CO}_{2}$ can be converted through diverse routes, including chemical ${ }^{6}$, biochemical ${ }^{7}$, photochemical ${ }^{8}$, electrochemical ${ }^{9}$, or biological ${ }^{10}$ transformations. Among these $\mathrm{CO}_{2}$ conversion technologies, electrochemical reduction has numerous advantages over others and is considered to be the most promising ${ }^{11}$. These advantages include ${ }^{12}: 1$ ) operating under ambient temperature and pressure, 2) possibility of driving the electrochemical conversion of $\mathrm{CO}_{2}$ toward the desired products via controlling 


\section{Introduction}

external potential, electrocatalysts and electrolyte, 3) minimal chemical consumption by recycling the electrolytes, 4) straightforward scale-up and low cost equipment, and 5) direct consumption of electrons for product formation and possibility of using renewable sources like solar and wind energies.

In electrochemical $\mathrm{CO}_{2}$ reduction, the electrochemical reaction is independent of the electricity source. To avoid extra $\mathrm{CO}_{2}$ emissions and replace the use of fossil fuels, the electrocatalytic reduction of $\mathrm{CO}_{2}$ should be powered by electricity from renewable energy sources such as solar energy, hydropower and wind energy. In this way, the anthropogenic carbon cycle can be closed and intermittent renewable electricity can be stored, resulting in net reduction of greenhouse gas emissions. In this way, carbon-based chemicals could be produced to replace those currently derived from petroleum. Significant technical progress has been made in recent years, and preliminary technoeconomic analysis of $\mathrm{CO}_{2}$ electrochemical reduction has demonstrated the commercial feasibility of the technology.

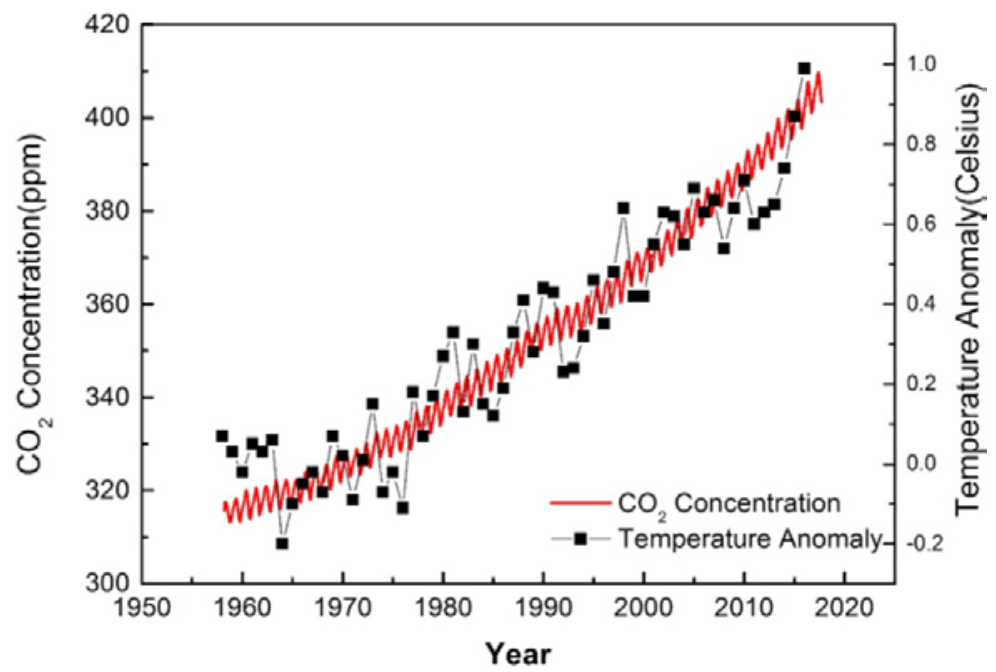

Figure 1. Correlation of global temperature with $\mathrm{CO}_{2}$ concentration from 1958 to $2017^{13}$. 


\section{Chapter 1}

\subsection{Importance of $\mathrm{CO}_{2}$ reduction}

Several important products can be formed during heterogeneous electrochemical reduction of $\mathrm{CO}_{2}$ including $\mathrm{CO}$, formic acid, oxalic acid, methanol, methane, formaldehyde, ethanol and ethylene ${ }^{14}$. These products can be used as commodity chemicals as well as fuels, thus allowing $\mathrm{CO}_{2}$ to be recycled into compounds that can act as energy carriers. Among these products, ethylene has the highest commercial value.

The performance of a catalyst is commonly evaluated by the following crucial parameters $^{15}$ : (1) onset potential or overpotential $(\eta)$, which is the difference between the onset potential and the standard reduction potential. As the reduction reaction has to overcome the kinetic energy barrier, the onset potential is always more negative than the standard potential of $\mathrm{CO}_{2} \mathrm{RR}$. (2) Faradaic efficiency (FE). This is defined as the ratio between the useful energy output (energy stored in a desired product) and total energy input. FE describes the product selectivity during the reduction reaction, which is closely related to the reduction mechanism. (3) Current density (CD), calculated as current divided by the geometric surface area of working electrode, reflects the transformation rate of $\mathrm{CO}_{2}$. This parameter is a crucial indicator of the performance of the cell. More importantly, the partial current density for a specific product is calculated via multiplying the overall current density by the FE of the product and is a measure of the product formation rate. (4) Stability, degradation rate of CD over the period of system operation. (5) Tafel slope, derived from the Tafel plot, which represents overpotential verses logarithm of the partial current density of a specific product. It is an indicator for the reaction pathway and the rate-determining step. (6) turnover frequency (TOF), a measure of per-site activity of catalyst.

Note that these parameters are not only dependent on the properties of the catalyst as the working electrode, but also on experimental parameters related to electrolyte, $\mathrm{CO}_{2}$ pressure, reaction temperature, etc. 


\section{Introduction}

To be feasible, the activation barrier for $\mathrm{CO}_{2}$ reduction should be minimized compared to hydrogen evolution, driving $\mathrm{CO}_{2}$ reduction selectively at low overpotential (high energy efficiency) with high reaction rates (high turnover number). High energetic efficiency is achieved through a combination of high selectivity (high FE) and low overpotentials (Figure 2). One hypothesis is that this can be achieved by use of a catalyst that can lower the energy of formation of the $\mathrm{CO}_{2}^{-}$radical anion intermediate.

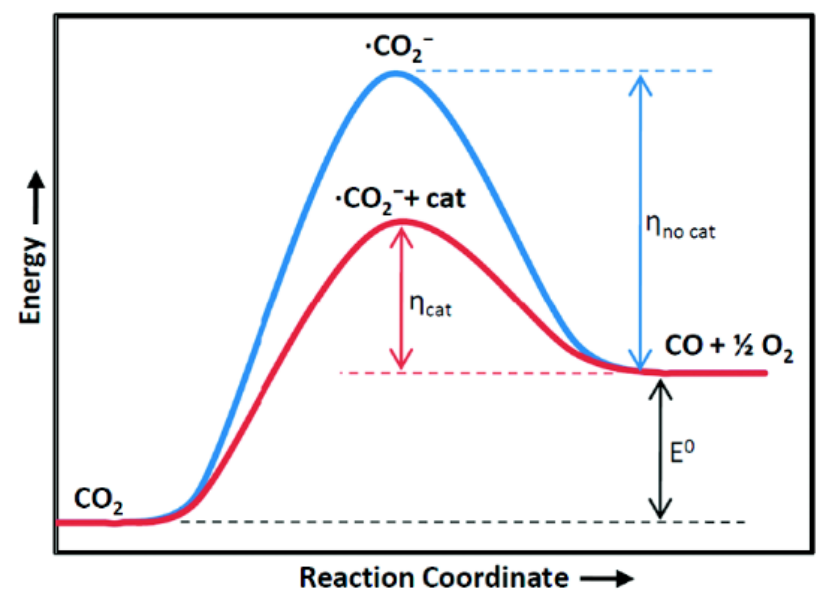

Figure 2. Qualitative reaction scheme for $\mathrm{CO}_{2}$ conversion. $\eta$ represents the overpotential. ${ }^{16}$

Though electrocatalytic reduction of $\mathrm{CO}_{2}$ possesses many advantages, this field still faces challenges of (1) large overpotential (low energy efficiency), (2) slow electron transfer kinetics even at high electrode potential resulting in low current densities, (3) unsatisfactory selectivity and costly separation steps, and (4) rapid deactivation of the catalyst (lifetime of less than $100 \mathrm{~h}$ ) leading to a shift in the product selectivity towards hydrogen evolution reaction, restricting practical use and commercialization. Over the last few years, researchers have focused on the exploration of different electrocatalysts with the aim of addressing these key challenges. Despite reports of new studies showing improved Faradaic efficiencies and lower overpotentials, the conditions to enable implementation of a large-scale 


\section{Chapter 1}

industrial process are still unclear. Generally, in order to minimize investment costs, industrial reactors are operated at commercially relevant geometric current densities above $100 \mathrm{~mA} / \mathrm{cm}^{2}$ with at least $50 \%$ Faradaic efficiency for the required products ${ }^{17}$. To date, efforts to increase the current densities have been very successful, with current densities exceeding $600 \mathrm{~mA} / \mathrm{cm}^{2}$ achieved using gas diffusion electrodes(GDEs). High $\mathrm{CO}_{2}$ reduction selectivity is important for future commercialization of these technologies because expensive separation processes can be avoided, decreasing the overall cost of scale-up.

\subsection{Heterogeneous catalysis in aqueous media at metal electrodes}

In effort to find catalysts to lower the overpotentials and control the selectivity, both homogeneous and heterogeneous catalysts have been applied to the electrochemical reduction of $\mathrm{CO}_{2}{ }^{18-19}$. Most homogeneous catalysts suffer from significant drawbacks, such as i) leaching from the electrode posing difficulty to separate the catalyst from the products and to recycle, ii) high cost, iii) toxicity and iv) poor chemical stability, which hinders their practical application. They are, however, usually more selective than heterogeneous catalysts ${ }^{20}$. Nevertheless, due to the disadvantages of homogeneous catalysts, development has been mainly focused on heterogeneous catalysts such as metal/metal alloys and non-metal catalysts.

\subsection{Classification of metals}

The first study to quantify both gaseous and liquid products, was reported by Hori and co-workers. ${ }^{21}$ This led to a classification of metal electrodes into four groups. Based on this, metals electrodes are classified depending on the tendency to bind various intermediates and final products.

$\mathrm{Pb}, \mathrm{Hg}$, In, Sn, Cd, and Bi give formate as a major product. These metals have moderate binding affinity toward the formate intermediates ( ${ }^{*} \mathrm{OCHO}$ and ${ }^{*} \mathrm{COOH}$ ). 


\section{Introduction}

$\mathrm{Au}, \mathrm{Ag}, \mathrm{Zn}, \mathrm{Pd}$, and Ga primarily produce $\mathrm{CO}$ as final product of $\mathrm{CO}_{2} \mathrm{RR}$. Such selective production of $\mathrm{CO}$ requires strong adsorption of $* \mathrm{COOH}$ while possessing low binding energy of * $\mathrm{CO}$ species. As a result of weakly bound * $\mathrm{CO}$ to the electrode surface, $\mathrm{CO}$ desorbs from the electrode as a major product. On Ni, Fe, Pt, and $\mathrm{Ti}, \mathrm{CO}$ is strongly adsorbed and highly stabilized on the electrode surface. This practically inhibits further reduction of $\mathrm{CO}_{2}$ under atmospheric pressure in aqueous media and instead almost exclusively reduction of water to hydrogen is observed.

Among various metals, $\mathrm{Cu}$ stands out in uniquely producing a number of hydrocarbons such as ethylene and methane, aldehydes, and alcohols with high current density. The product distribution on $\mathrm{Cu}$ ranges widely, depending on electrolyte, potential and temperature. This distinct behavior can be explained on the basis of heat of adsorption ${ }^{22}$. Pt and $\mathrm{Ni}$, for instance, have high heats of $\mathrm{CO}$ adsorption while $\mathrm{Au}$ and $\mathrm{Ag}$ have much smaller heat of adsorption. The heat of adsorption on $\mathrm{Cu}$ is intermediate among these metals, leading to $\mathrm{CO}$ adsorption with moderate strength. Thus, achieving a balance of the barriers for activation of $\mathrm{CO}_{2}$ and hydrogenation of *CO lead to effective formation of hydrocarbons. $\mathrm{Cu}$ is thus the only pure metal that reduces $\mathrm{CO}_{2}$ to products requiring more than two electron transfers with substantial Faradaic efficiencies.

\section{$1.5 \mathrm{Cu}$}

Polycrystalline $\mathrm{Cu}$ electrodes uniquely reduce $\mathrm{CO}_{2}$ to high value-added hydrocarbon and alcohols, which are widely used industrially. Since Hori et al. ${ }^{21}$ found that $\mathrm{CO}_{2} \mathrm{RR}$ on copper electrodes leads to formation of hydrocarbons, mainly ethylene and methane, different types of products and the reaction mechanisms have been investigated. Besides these hydrocarbons, $\mathrm{CO}$, formic acid and oxygenates such as ethanol and propanol are also formed on $\mathrm{Cu}$. In a study by Jaramillo and coworkers $^{23}$, using more sensitive product detection techniques for liquid products, a total of 16 products were observed with five detected for the first time. This included 


\section{Chapter 1}

the formation of eleven distinct $\mathrm{C}_{2}$ oxygenated products including aldehydes, ketones, alcohols, and carboxylic acids. Figure 3 provides an overview of the current efficiency of each product as a function of applied potential and is divided into three groups to distinguish between major, intermediate, and minor products. Despites these efforts, poor selectivity and activity degradation are still two remaining challenges for practical application of $\mathrm{Cu}$ electrodes.

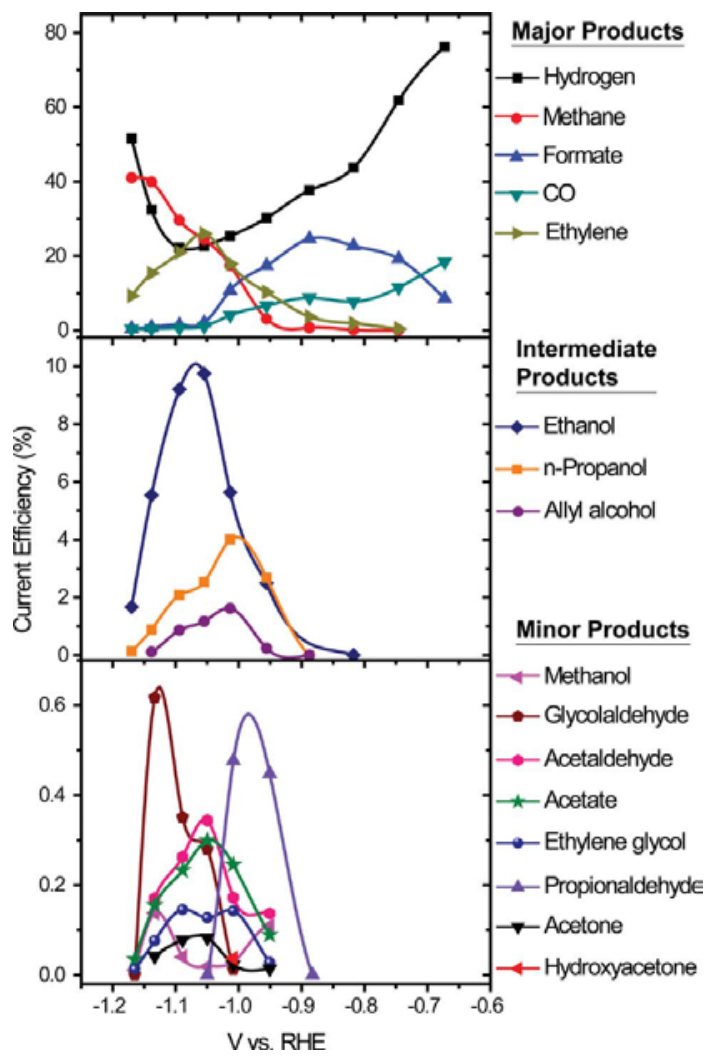

Figure 3. Product current efficiency on polycrystalline copper in $\mathrm{CO}_{2}$-saturated $0.1 \mathrm{M}$ $\mathrm{KHCO}_{3}$ as a function of potential is shown for major, intermediate range, and minor products $^{23}$.

As discussed above, numerous carbon-containing products can be produced during the electrochemical $\mathrm{CO}_{2} \mathrm{RR}$, among which ethylene has a high commercial value. Ethylene is a key building block of the chemical industry and representative 


\section{Introduction}

for products with a reasonably high added value. It is produced on a large scale as an important precursor for commercially useful chemical products such as ethylene oxide, ethylene glycol, ethyl benzene, etc. and much of it is turned into polyethylene, which is used in plastic packaging. Ethylene has a global production volume of 158 million tons in the year 2020. Much effort has been devoted to advance the prospects of producing ethylene from $\mathrm{CO}_{2}$ electroreduction.

\subsection{Mechanism}

In $\mathrm{CO}_{2} \mathrm{RR}$, water acts as the source of protons, and $\mathrm{CO}_{2}$ is reduced at the cathode, while the oxygen evolution reaction takes place at the anode. However, $\mathrm{CO}_{2}$ activation and reduction at the cathode is a significant challenge and does not take place easily due to the high heat of formation of $-393 \mathrm{~kJ} / \mathrm{mol}$. Furthermore, as the first electron transfer step, i.e. the formation of the intermediate species $\mathrm{CO}_{2}{ }^{-{ }^{-}}$by an electron transfer to a $\mathrm{CO}_{2}$ molecule, is highly unfavorable. The consequence is that, due to the enormous energy requirement to rearrange a linear molecule to a bent radical anion, the single electron reaction of $\mathrm{CO}_{2}$ to $\mathrm{CO}_{2}{ }^{--}$occurs only at a highly negative potential of $-1.9 \mathrm{~V}$ versus the standard hydrogen electrode (SHE) in aqueous media under standard conditions ${ }^{24}$. The high overpotential would lead to a serious waste of electric power and formation of hydrogen during the reaction, reducing the selectivity of $\mathrm{CO}_{2}$ reduction. Following this key reaction step, there are several concerted proton $\left(\mathrm{H}^{+}\right)$and electron transfer processes that are more favorable to occur at less negative potentials. The primary reactions for the major products and important intermediates that occur at the copper electrode during the reduction of $\mathrm{CO}_{2}$ are given below (all potentials are given with respect to the reversible hydrogen electrode (RHE)). These values are estimated from thermodynamics data in aqueous media at $25^{\circ} \mathrm{C}^{25}$. The actual electrode potentials to drive the reductions are much more negative than these equilibrium values, mainly due to formation of $\mathrm{CO}_{2}{ }^{\cdot-}$. 


\section{Chapter 1}

$$
\begin{array}{cc}
\mathrm{CO}_{2}+\mathrm{e}^{-} \rightarrow \mathrm{CO}_{2}{ }^{--} & \mathrm{E}_{0}=-1.49 \mathrm{~V} \\
\mathrm{CO}_{2}+2 \mathrm{H}^{+}+2 \mathrm{e}^{-} \rightarrow \mathrm{CO}+\mathrm{H}_{2} \mathrm{O} & \mathrm{E}_{0}=-0.103 \mathrm{~V} \\
2 \mathrm{H}^{+}+2 \mathrm{e}^{-} \rightarrow \mathrm{H}_{2} & \mathrm{E}_{0}=0 \mathrm{~V} \\
\mathrm{CO}_{2}+\mathrm{H}^{+}+2 \mathrm{e}^{-} \rightarrow \mathrm{HCOO}_{(\mathrm{l})}^{-} & \mathrm{E}_{0}=-0.225 \mathrm{~V} \\
\mathrm{CO}_{2}+6 \mathrm{H}^{+}+6 \mathrm{e}^{-} \rightarrow \mathrm{CH}_{3} \mathrm{OH}_{(\mathrm{l})}+\mathrm{H}_{2} \mathrm{O} & \mathrm{E}_{0}=0.03 \mathrm{~V} \\
\mathrm{CO}_{2}+8 \mathrm{H}^{+}+8 \mathrm{e}^{-} \rightarrow \mathrm{CH}_{4}+2 \mathrm{H}_{2} \mathrm{O} & \\
2 \mathrm{CO}_{2}+12 \mathrm{H}^{+}+12 \mathrm{e}^{-} \rightarrow \mathrm{C}_{2} \mathrm{H}_{4}+4 \mathrm{H}_{2} \mathrm{O} & \\
2 \mathrm{CO}_{2}+14 \mathrm{H}^{+}+14 \mathrm{e}^{-} \rightarrow \mathrm{C}_{2} \mathrm{H}_{6}+4 \mathrm{H}_{2} \mathrm{O} & \mathrm{E}_{0}=0.079 \mathrm{~V}
\end{array}
$$

Heterogeneous electrochemical reduction of $\mathrm{CO}_{2}$ occurs at electrode-electrolyte interfaces. This heterogeneous catalytic reaction contains three main steps: (1) adsorption of $\mathrm{CO}_{2}$ on the surface of a catalyst, (2) electron and proton transfer to $\mathrm{CO}_{2}$, (3) rearrangement of product species followed by desorption.

In the first step, tremendous energy is needed to reorganize the linear $\mathrm{CO}_{2}$ molecule to a bent radical anion. To overcome this, proton-assisted approach to $\mathrm{CO}_{2}$ reduction, lowers the thermodynamic barrier significantly. Transition-metal complexes can have accessible multiple redox states that promote such protonassisted, multi-electron pathways. In addition, in the aqueous system, hydrogen dominates as the major side-product of $\mathrm{CO}_{2} \mathrm{RR}$. This is in fact due to lower overpotentials of the hydrogen evolution reaction compared to $\mathrm{CO}_{2} \mathrm{RR}$. Therefore, 


\section{Introduction}

owing to the small difference in thermodynamic potential of the above equations, it is a great challenge to reduce $\mathrm{CO}_{2}$ to desirable products with considerable selectivity.

At less negative potentials, $\mathrm{CO}_{2}$ is reduced to $\mathrm{CO}$ and $\mathrm{HCOOH}$. Then, at morenegative potentials, the absorbed $\mathrm{CO}$ is further reduced to hydrocarbons and alcohols. Contrary to $\mathrm{CO}, \mathrm{HCOOH}$ is not further reduced at a $\mathrm{Cu}$ electrode. The electrochemical reduction of $\mathrm{CO}$ with a similar product distribution to $\mathrm{CO}_{2}$ reduction suggest that the $\mathrm{CO}_{2} \mathrm{RR}$ proceeds via $\mathrm{CO}$ as intermediate species ${ }^{26}$. The exact reaction mechanism of carbon monoxide reduction to either ethylene or methane is still subject of dispute.

\subsection{Types of electrode}

Bulk metals have been studied intensively as $\mathrm{CO}_{2}$ reduction electrocatalysts and their properties have been reviewed in detail by $\mathrm{Hori}^{26}$. Due to the several attractive qualities over bulk catalysts, nanostructured metallic electrocatalysts have been subject of several recent investigations. To improve the electrocatalytic $\mathrm{CO}_{2}$ reduction performance, diverse morphologies of $\mathrm{Cu}$ nanostructures including oxidederived electrodes, nanoparticles, nanocubes, nanowires, porous hollow fibers, roughened surfaces prepared by electrodeposition, electropolishing, or plasma treatments have been investigated. The main advantage of nanostructured catalysts is that they are capable of providing more active sites because of their enhanced surface areas compared to smooth $\mathrm{Cu}^{27}$. Under-coordinated surface sites are usually abundant on nanostructured materials, such as corners, edges and steps, and defects, such as vacancies and grain boundaries. Since the catalytic activity of heterogeneous catalysts is proportional to the number of surface active sites, greater abundance of active surface sites can boost the performance. Moreover, various types of lowcoordinated sites have different catalytic behavior than smooth surfaces. Thus, they can have a role in shifting the selectivity. According to recent studies, $\mathrm{Cu}$ nanostructures can have a promoting effect on ethylene formation ${ }^{28-29}$. In addition to 


\section{Chapter 1}

catalytic activity, nanostructured electrocatalysts have been shown to improve catalytic stability ${ }^{30}$. This is due to the fact that nanostructured electrocatalysts are able to accommodate impurities much better because of their enhanced surface area.

\subsection{Outline of this thesis}

The focus of this thesis is on the improvement of ethylene selectivity in electrochemical reduction of $\mathrm{CO}_{2}$ on copper electrodes. With the help of in situ spectroscopy techniques, mechanistic aspects of this reaction are carefully examined.

First, the experimental procedures and details of the equipment and set-ups is described in chapter 2. Besides, a brief theoretical background about the fundamentals of each technique is provided. The techniques discussed mainly includes gas chromatography, ATR-FTIR Spectroscopy, Raman Spectroscopy. Other characterization techniques are also discussed briefly, which include electrochemical surface area measurements. Finally, the methods for preparation of various electrodes are reviewed extensively.

In chapter 3 , the effect of partial pressure of $\mathrm{CO}_{2}\left(\mathrm{P}_{\mathrm{CO}}\right)$ on the product distribution of $\mathrm{CO}_{2} \mathrm{RR}$ on rough $\mathrm{Cu}_{2} \mathrm{O}$ films is investigated. Interestingly, enhanced selectivity towards formation of hydrocarbons was observed at low $\mathrm{P}_{\mathrm{CO} 2}$. After extensive examination of the effect of potential, film roughness and electrolyte buffer capacity, we concluded that this observation is due to an effect of the local $\mathrm{pH}$. We concluded that the $\mathrm{P}_{\mathrm{CO} 2}$ affects the local $\mathrm{pH}$ and plays a determining role in selectivity.

In chapter 4, the previous chapter was extended to a study of the partial pressure of $\mathrm{CO}\left(\mathrm{P}_{\mathrm{CO}}\right)$ and investigation of the effect of $\mathrm{CO}_{2} / \mathrm{CO}$ mixtures on product selectivity. Moreover, the effect of the electrolyte anion (directly affecting electrolyte $\mathrm{pH}$ ) on CORR product distribution was studied. To further understand the effect of anion on mechanism, ATR-SEIRAS was employed to monitor the $\mathrm{CO}$ adoption on $\mathrm{Cu}$ electrodes. 


\section{Introduction}

In chapter 5, in situ ATR-SEIRAS was employed to study the interfacial phenomena on $\mathrm{Cu}$ electrode during $\mathrm{CO}_{2} \mathrm{RR}$. With the help of isotopic labeling $\left({ }^{13} \mathrm{CO}_{2}\right.$ and $\left.\mathrm{D}_{2} \mathrm{O}\right)$, various intermediates and products were identified at different potentials. A highly detailed interpretation of spectra is presented in this chapter, and the presence of the $\mathrm{CO}_{2}$ dimer radical-anion on roughened copper surfaces is explored.

In chapter 6, effects of addition of $\mathrm{CuSO}_{4}$ to the electrolyte on surface morphology, roughness and product distribution was investigated. It was revealed that due to addition of $\mathrm{CuSO}_{4}$, during $\mathrm{CO}_{2} \mathrm{RR}$, in situ electrodeposition of rough $\mathrm{Cu}$ nano-structures occurs. As a result, an improved selectivity towards ethylene at an optimum $\mathrm{CuSO}_{4}$ concentration was observed. In situ Raman spectroscopy was employed and a correlation between CO coverage and activation of ethylene pathways was observed. In addition, $\mathrm{Cu}-\mathrm{OH}$, present at highly negative potentials, was found to have detrimental effects on ethylene formation.

In chapter 7, in situ Raman spectroscopy was applied to reveal the mechanistic pathways and oxidation state of the $\mathrm{Cu}$ electrode during $\mathrm{CO}_{2} \mathrm{RR}$. Employing isotopic labeling $\left({ }^{13} \mathrm{CO}_{2}\right.$ and $\left.\mathrm{D}_{2} \mathrm{O}\right)$ allowed to distinguish oxides, hydroxide and a stable Ccontaining species on $\mathrm{Cu}$ at highly negative potentials. In addition potentialdependent features associated with carbonates, bicarbonates, $\mathrm{CO}$, and most importantly hydroxide species were resolved.

Finally, in chapter 8 , a summary of the findings and a perspective is provided. 
Chapter 1 


\section{Chapter 2.}

\section{Theory and experimental methods}

This chapter outlines the principles and details of experimental setups of the most important used techniques in this thesis. The techniques include (micro) gas chromatography, ATR- Infrared spectroscopy and Surface Enhanced Raman spectroscopy. 


\section{Chapter 2}

\subsection{Gas chromatography}

\section{Fundamentals}

Gas chromatography is one of the most widely used separation techniques for analyzing hydrocarbon mixtures. The basic units of a gas chromatograph include the chromatographic column and the detector. The column separates the gas mixture into its components and the detector records the concentrations of the separated components.

The basis of the separation is the difference in the interactions of individual compounds with the stationary phase as they are moved through a long column by a carrier gas, usually helium or nitrogen. The time taken from injection to emergence is known as the retention time, and is characteristic for each substance under any given set of conditions. Compounds with greater affinity for the stationary phase spend more time in the column and have a longer retention time than samples with a higher affinity for the mobile phase. This affinity mainly depends on the intermolecular interactions and the polarity of the stationary phase. As a result, each component moves along the chromatographic column with different speed.

To measure a sample with an unknown concentration, a standard sample with known concentration (calibration gas) is injected into the instrument. This is repeated for at least 3 various concentrations for each compound. The standard sample peak retention time and the obtained areas are used to make a calibration graph. By using this calibration curve, the concentration of test sample can be calculated.

The Faradaic efficiency (FE) is defined as the ratio between the amount of product actually detected by the GC and the amount of product theoretically formed based on the charge passed through the cell during electrolysis. The FE or selectivity for each product in $\mathrm{CO}_{2} \mathrm{RR}$ was calculated according to the following equation:

$$
\mathrm{FE}(\%)=\frac{n Z F}{Q} \times 100
$$




\section{Theory and experimental methods}

$\mathrm{n}$ is the amount of the generated products (number of moles, mol); $\mathrm{Q}$ is the total charge passed through the cell (coulombs, C); F is the Faraday constant (96 485 $\mathrm{C} / \mathrm{mol}$ ); $\mathrm{Z}$ is the number of electrons required to obtain 1 molecule of the product. The number of electrons required to form 1 molecule of $\mathrm{CO}, \mathrm{CH}_{4}, \mathrm{C}_{2} \mathrm{H}_{4}$ and $\mathrm{C}_{2} \mathrm{H}_{6}$ are 2, 8, 12 and 14, respectively.

\section{Setup}

All electrochemical measurements were carried out using a Bio-Logic VSP potentiostat. A home-made two compartment electrochemical cell using a three electrode assembly was used to carry out the electrochemical reduction of $\mathrm{CO}_{2}$ (See figure 1). The as-prepared cuprous oxide films with the thickness equivalent to a total charge of 3C (Coulomb) were used as the working electrode, unless another thickness is mentioned. Glassy carbon (SIGRADUR ${ }^{\circledR} \mathrm{G}$ ) was used as the counter electrode and was separated from the working electrode using an anion exchange membrane (Selemion AMV, AGC, Inc.). $\mathrm{Ag} / \mathrm{AgCl}$ in $3 \mathrm{M} \mathrm{NaCl}$ was used as a reference electrode. The distance between the working and reference electrodes was kept small $(3 \mathrm{~mm})$ to reduce solution resistance. The IR compensation was automatically applied by using ohmic drop determination-current interrupt technique. All potentials were converted to the Reversible Hydrogen Electrode (RHE) scale by:

$$
\mathrm{V}_{\text {vs. RHE }}=\mathrm{V}_{\text {measured vs. Ag/AgCl }}+0.198+0.059 *(\mathrm{pH} \text { of solution }) \text {. }
$$

The electrolyte solutions of $\mathrm{KHCO}_{3}$ (Sigma- Aldrich, 99.99\% metals basis) were prepared with deionized water (Millipore MilliQ, $18.2 \mathrm{M} \Omega \mathrm{cm}$ ), in concentrations ranging from $0.05 \mathrm{M}$ to $0.5 \mathrm{M}$. The gas mixture $\left(\mathrm{CO}_{2} \backslash \mathrm{CO}\right.$ and $\left.\mathrm{He}\right)$ was continuously purged through a glass frit at a rate of $20 \mathrm{ml} \mathrm{min}^{-1}$ for 30 minutes before each experiment, using two mass flow controllers, to attain steady $\mathrm{CO}_{2}$ concentration in the electrolyte. The $\mathrm{pH}$ of the electrolytes of various concentrations of $\mathrm{KHCO}_{3}$ and

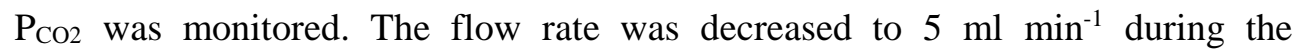




\section{Chapter 2}

electrochemical reduction experiments. The reactor effluent was then vented directly into the gas sampling loop of a micro-gas chromatograph (micro-GC) equipped with a pulsed discharge detector (PDD) every 4 minutes. The micro-GC was equipped with two different columns (Molsieve plot and Rt-Q Bond) for separation of $\mathrm{H}_{2}, \mathrm{O}_{2}$, $\mathrm{CO}, \mathrm{CO}_{2}$ and hydrocarbons. The mass balance was typically closed within $+90 \%$, and therefore the electrolyte was not analyzed for liquid phase products, which based on other studies most likely contains some formate/formic acid, as will be further addressed in the description of the results in various chapters.

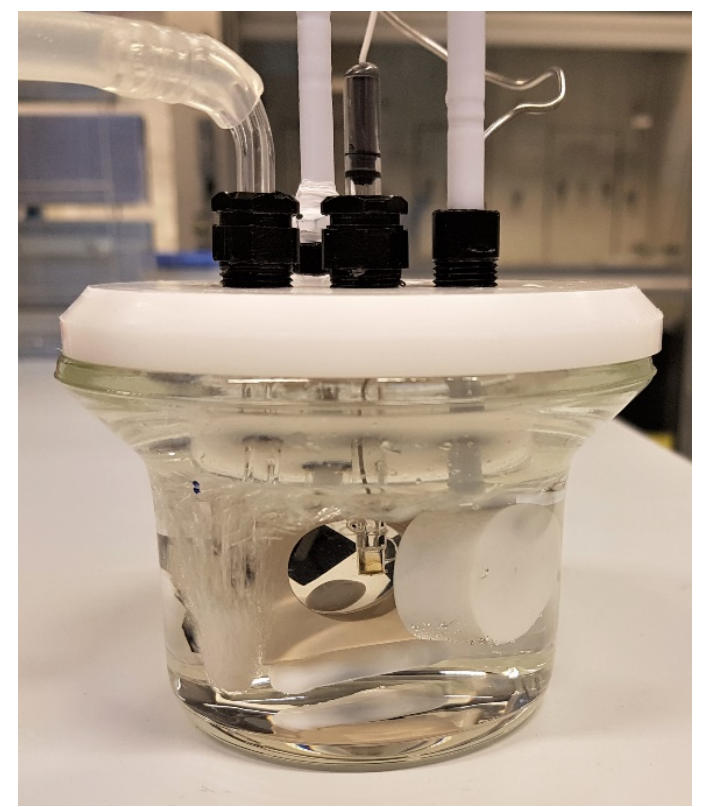

Figure 1. Experimental setup used to evaluate the electrochemical $\mathrm{CO}_{2}$ reduction of the $\mathrm{Cu}$ foils. Inside the reactor, from right to left, the $\mathrm{Cu}$ electrode Teflon holder is seen from back (The $\mathrm{Cu}$ foil is facing the $\mathrm{CE}$ ). In the middle, the reference electrode is visible by the yellowish capillary. Next, to the left, is the holder for glassy carbon CE, which can be seen as the black square behind the membrane. To the far left, a frit bubbler is seen while purging the electrolyte with $\mathrm{CO}_{2}$. 


\subsection{ATR-FTIR Spectroscopy \\ Fundamentals}

Surface enhanced infrared absorption spectroscopy (SEIRAS) is based on the phenomenon that a significant increase in intensity of $10-10^{3}$ times can be obtained on roughened surfaces of metals, as compared to polished surfaces. Such enhancement factors are enough to enable detection of sub-monolayer adsorbates and intermediates and their configurations on metallic electrode surfaces under operando conditions. In addition, infrared spectroscopy is a suitable technique to provide important experimental evidence to address preferred reaction pathways, selectivity and effects of the reaction environment on $\mathrm{CO}_{2} \mathrm{RR}$ catalysis.

This enhancement effect is based on the similar well established mechanism of surface enhanced Raman spectroscopy (SERS) and is attributed to electromagnetic and chemical origins ${ }^{31}$. However, unlike SERS, the SEIRA phenomenon is much less substrate specific.

IR absorption spectroscopy, uses the absorption of IR photons to detect molecular vibrations with a changing dipole moment. IR spectra can be measured in transmission mode, reflection mode or attenuated total reflection (ATR) mode. To enable operando IR spectroscopy under potential control, the experiment is typically conducted in ATR mode in a Kretschmann-like configuration ${ }^{32}$.

In the ATR mode, the electrocatalyst is deposited on an ATR crystal which serves as an internal reflection element (IRE) made of high-refractive materials ( $\mathrm{Si}$, Ge, or ZnSe). The IR beam is illuminated from below and undergoes a reflection at the interface of sample with the IRE. This results in formation of an evanescent wave with a low penetration depth $\left(\mathrm{d}_{\mathrm{p}}\right.$, see figure 3 ) of typically $0.5-2.0 \mu \mathrm{m}$ into the sample, depending on the angle of incident of IR beam and refractive index of the IRE and the sample. The evanescent wave penetrates the electrolyte medium and 


\section{Chapter 2}

decays exponentially with distance, enabling the selective monitoring of the catalytic interface.

Metal island thin films suitable for SEIRAS measurements have been deposited on the IREs in a wide variety of ways, such as chemical (electroless deposition) and sputtering techniques. The metal film must be thin enough so that the evanescent wave can reach the electrolyte. Moreover, the film should be non-uniform and made of islands, to enable the electromagnetic mechanism of SEIRA resulting from the polarization of these metal islands by the electromagnetic field of the incident radiation.

\section{Setup}

All electrochemical experiments were performed in a custom-made threeelectrode cell, with the $\mathrm{Cu}$ film being used as the working electrode. A graphite rod, rather than a Pt wire, was used as counter electrode to eliminate any possible Pt contaminations on the working electrode, while a $\mathrm{Ag} / \mathrm{AgCl}$ electrode $(3 \mathrm{M} \mathrm{NaCl}$, BASi) was used as reference electrode. A VersaSTAT 3 potentiostat was used to perform electrochemical measurements. The experiments were conducted in a Bruker Vertex 70 spectrometer equipped with a liquid nitrogen-cooled MCT detector and a Veemax III ATR accessory (See figure 2). Prior to each experiment, the electrolyte was bubbled with purging gas $\left(\mathrm{CO}_{2},{ }^{13} \mathrm{CO}_{2}\right.$ or $\left.\mathrm{CO}\right)$ for 15 minutes to saturate the solution. The $\mathrm{Cu}$ films were activated by three activation cycles between 0.6 and $-0.6 \mathrm{~V}$ in the electrolyte, in order to improve the signal. A reference spectrum was recorded and spectra were taken with $4 \mathrm{~cm}^{-1}$ resolution during a CV with a typical scan rate of $3 \mathrm{mV} / \mathrm{sec}$, under continuous purging. 


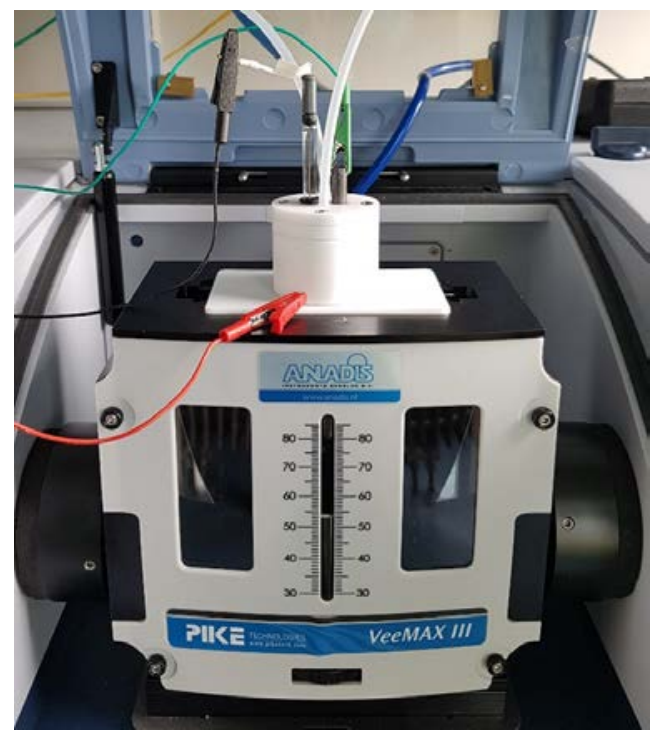

Figure 2. Experimental setup used for in-situ ATR-SEIRAS experiments. The Teflon cell in mounted on top of the Veemax III ATR accessory. On the top of cell, on the lid, gas inlet and outlet, and reference electrode and graphite rod as CE are observed.

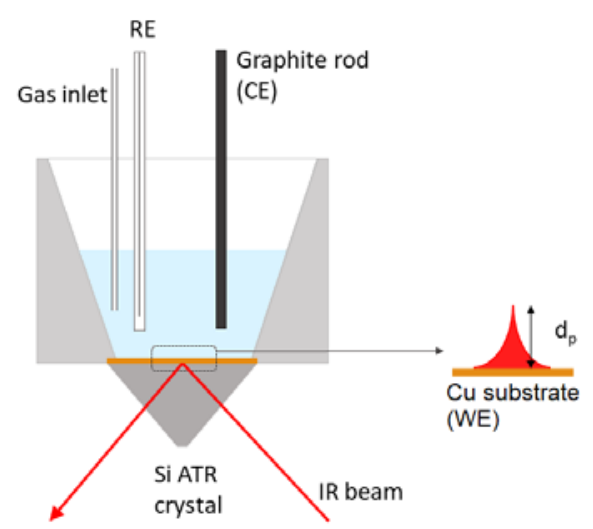

Figure 3. Schematic of the electrochemical cell used for in-situ ATR-SEIRAS experiments. Thin Cu film is deposited onto an infrared-transparent ATR crystal, and is used as the working electrode. The graphite rod, reference electrode and gas inlet are seen inserted into 


\section{Chapter 2}

the electrolyte. The penetration depth $\left(d_{p}\right)$ of evanescent wave resulting from the internal reflection of IR beam, is shown to surpass the $\mathrm{Cu}$ film and reach the electrode/electrolyte interface.

\subsection{Raman Spectroscopy}

\section{Fundamentals}

Raman spectroscopy detects the inelastically scattered light as a result of incident monochromatic light, typically provided by a laser. Following the interaction of the exciting laser light with the surface of the electrode, a small fraction of photons which undergo inelastic scattering contains information of the vibrational modes of the samples, i.e. the Raman spectrum.

Surface enhanced Raman Spectroscopy (SERS) offers a surface-enhancement of several orders of magnitude on certain rough metal surfaces, typically of metals such as Ag and Au. Such surface-enhancement mainly originates from enhanced local electromagnetic fields, which significantly decay with distance from the electrode and make this technique well suited to investigate interfacial electrochemical reactions. Electromagnetic enhancement is regarded as the major contributing mechanism with an enhancement contribution of $10^{4}-10^{6}$. On the other hand, chemical enhancement due to charge transfer between metal and adsorbed molecules on plasmonic nanostructures has a smaller contribution of $10-100^{33}$.

In addition to issues addressed by infrared spectroscopy, SERS is suitable to identify catalytically active sites due to its ability to probe the catalyst surface in higher oxidation states. For example, operando SERS can be used to discriminate the presence of $\mathrm{CuO}, \mathrm{Cu}_{2} \mathrm{O}, \mathrm{Cu}(\mathrm{OH})_{2}$ and $\mathrm{Cu}(0)$ as the active surface for $\mathrm{CO}_{2} \mathrm{RR}$. The Raman signals corresponding to metal-adsorbate modes are in the wavenumber range of $<1000 \mathrm{~cm}^{-1}$. 
In summary, SERS has been proven to be exceptionally useful for studying interfacial catalytic $\mathrm{CO}_{2} \mathrm{RR}$ by providing information on surface adsorbed species and transformations in oxidation state.

\section{Setup}

Raman spectroscopy was carried out using an Avantes AvaRaman spectrometer with an Intertec laser as excitation source at $\lambda=785 \mathrm{~nm}$. In-situ experiments were performed in a homemade Teflon flow cell with Pt mesh as counter electrode and $\mathrm{Ag} / \mathrm{AgCl}$ in $3 \mathrm{M} \mathrm{NaCl}$ as a reference electrode. The electrolyte was continuously purged externally (outside the cell) with $\mathrm{CO}_{2}$ throughout the experiment and was pumped using a Watson-Marlow $101 \mathrm{U}$ pump at $1 \mathrm{~mL} / \mathrm{min}$ (See figure 4). The Raman probe, separated from the electrolyte by a quartz window was mounted on a $\mu \mathrm{m}$ optical screw to optimize the distance to the electrode surface. The beam travels through $4 \mathrm{~mm}$ of solution to get to the catalyst surface. An acquisition time of 10 seconds was selected to record each spectrum.

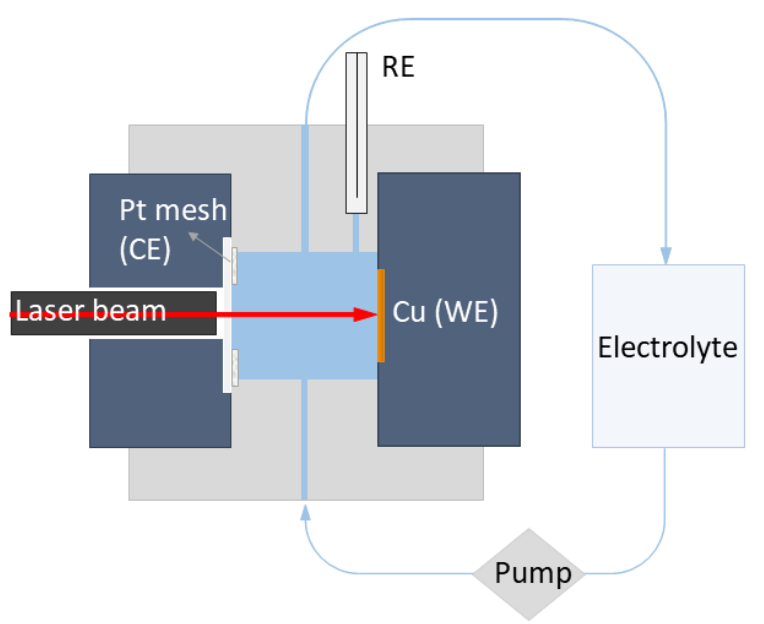

Figure 4. Schematic of the electrochemical setup used for in-situ SERS experiments. The electrolyte compartment placed outside the cell and before the pump, is continuously purged with $\mathrm{CO}_{2}$. 


\section{Chapter 2}

\subsection{Electrochemical surface area determination}

The relative surface roughness factors of the electrochemically active surfaces were calculated by measuring the double layer capacitance values in $0.1 \mathrm{M} \mathrm{KCl}$. Pt mesh was used as a counter electrode and $\mathrm{Ag} / \mathrm{AgCl}$ was used as reference electrode. After reducing the layers in $0.1 \mathrm{M} \mathrm{KHCO}_{3}$, cyclic voltammetry (CV) was performed with different scan rates $\left(5,20,40,60,80,100 \mathrm{mVs}^{-1}\right)$ in the potential range in which no Faradaic processes occur. The slope of the (difference in) current density vs. scan rate gave the capacitance value which was normalized to smooth copper, to obtain the surface roughness factors.

\subsection{Electrode preparation}

\section{Electrodeposition of $\mathrm{Cu}_{2} \mathrm{O}$ films}

Cuprous oxide films were electrodeposited onto copper foils (Alfa Aesar, 99.99\%) from $\mathrm{Cu}^{2+}$ containing solutions prepared using 0.4 $\mathrm{M} \mathrm{CuSO}_{4}$ (Sigma Aldrich, 99\%) and $3 \mathrm{M}$ lactic acid (Sigma Aldrich) at $60^{\circ} \mathrm{C}$, according to a published procedure described elsewhere ${ }^{34}$. A one-compartment, three electrode cell with $\mathrm{Cu}$ foil as working electrode, $\mathrm{Pt}$ mesh as counter electrode and $\mathrm{Ag} / \mathrm{AgCl}(3 \mathrm{M} \mathrm{NaCl})$ as the reference electrode were used (See figure 5). Copper foils were prepared by mechanical polishing and then electropolishing (in 85\% phosphoric acid, potentiostatically at $3 \mathrm{~V}$ vs. a graphite foil counter electrode), followed by cleaning ultrasonically in ethanol and water. The $\mathrm{pH}$ of the solution was adjusted to 12 using $\mathrm{NaOH}$ (Sigma Aldrich, 98\%). Galvanostatic deposition was performed at $0.8 \mathrm{~mA}$ $\mathrm{cm}^{-2}$ using a potentiostat/galvanostat (PAR, Versastat 3) until a desired film thickness was achieved. 


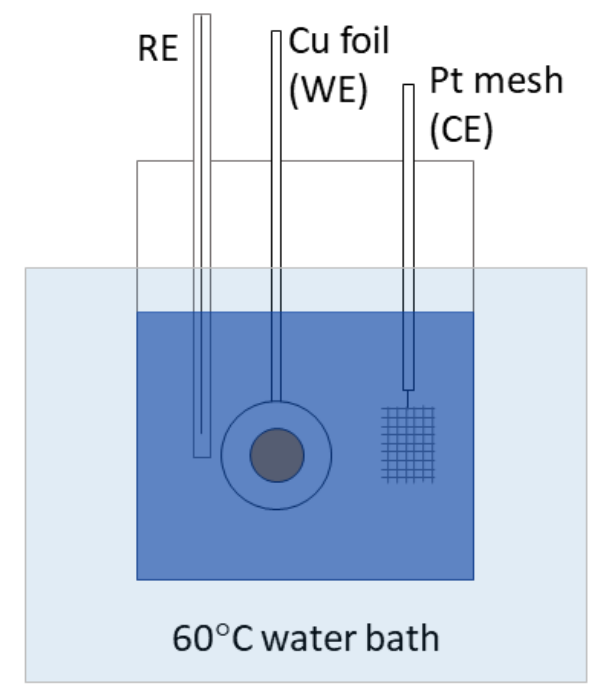

Figure 5. Schematic of the experimental setup used for electrodeposition of $\mathrm{Cu}_{2} \mathrm{O}$.

\section{Cu sputtering on ATR crystals}

$\mathrm{Cu}$ thin-film electrodes were prepared by magnetron sputtering from a copper source, directly onto the reflecting plane of a $45^{\circ}$ silicon ATR crystal. The sputtering was carried out using an argon flow of $25 \mathrm{ml} / \mathrm{min}$, and applying a power of $30 \mathrm{~W}$. These relatively mild conditions result in a sputtering rate of $0.044 \mathrm{~nm} / \mathrm{s}$. Since the time of sputtering was set at $270 \mathrm{~s}$, a film thickness of $12 \mathrm{~nm}$ was produced after 270 $\mathrm{s}$. The resistance of each film tested across a $1.5 \mathrm{~cm}$ length of the layer was around $8 \Omega$. Surface characterization of the copper film was carried out using atomic force microscopy (AFM). The working mode of the applied AFM system (Cypher, Oxford Instruments), was amplitude modulation, with a NSC36 double side probe coated cantilever, and the measurements were carried out in air. 
Chapter 2 


\section{Chapter 3.}

\section{Effect of partial pressure on product selectivity in Cu-catalyzed}

\section{electrochemical reduction of $\mathrm{CO}_{2}$}

\section{Abstract}

The influence of $\mathrm{CO}_{2}$ partial pressure on electrochemical reduction of $\mathrm{CO}_{2}$ using oxide-derived electrodeposited copper surfaces in a conventional two compartment cell configuration, is discussed. Contrary to what has been reported in the literature for polished copper surfaces, demonstrating a linear decrease in the Faradaic efficiency (FE) as a function of decreasing partial pressure, the (FE) and partial current density of both ethylene and methane are improved when the $\mathrm{CO}_{2}$ partial pressure is decreased below $1 \mathrm{~atm}$, and an optimized ethylene efficiency of $\sim 45 \%$ is 


\section{Chapter 3}

achieved in the range of $\sim 0.4-\sim 0.6$ atm at $-1.1 \mathrm{~V}$ vs. RHE. Such optimum in ethylene FE, ranging from $\sim 10-45 \%$, is obtained at a variety of applied voltages ( -0.7 to -1.1 $\mathrm{V}$ vs. RHE), but only at relatively low concentrations of $\mathrm{KHCO}_{3}$ of less than 0.25 M. Since a low $\mathrm{KHCO}_{3}$ concentration induces only a low buffer capacity, we conclude that a rise of local $\mathrm{pH}$ induced by a decreased $\mathrm{CO}_{2}$ partial pressure explains improved selectivity towards ethylene. If the $\mathrm{CO}_{2}$ partial pressure decreases below $\sim 0.4$ atm, not only the availability of $\mathrm{CO}_{2}$ limits ethylene selectivity, but also a fall in local $\mathrm{pH}$, associated with the decreasing partial current density in formation of ethylene. Calculations of local concentrations of $\mathrm{CO}_{2}$ and the $\mathrm{pH}$ corroborate these hypotheses. These findings contribute to, and substantiate the current understanding of the significant role of local $\mathrm{pH}$ conditions on the selectivity of $\mathrm{CO}_{2}$ electroreduction products, and suggest high ethylene selectivity over oxide derived $\mathrm{Cu}$ electrodes can be obtained for diluted $\mathrm{CO}_{2}$ feed compositions if the electrolyte has a relatively low buffer capacity.

\subsection{Introduction}

The accumulation of $\mathrm{CO}_{2}$ in the atmosphere is generally accepted to have significant impact on climate conditions. A promising methodology for reducing carbon dioxide is conversion of $\mathrm{CO}_{2}$ into fuels or commodity chemicals through an electrochemical process based on renewable electricity ${ }^{35}$. Among the metal electrodes used, copper is the most extensively studied since it is capable of producing hydrocarbons from $\mathrm{CO}_{2}$ with high Faradaic efficiencies ${ }^{21}$, 23, 36-37. Although a broad mix of hydrocarbons and minor products have been reported, the main products at relatively high potentials are ethylene and methane ${ }^{23,38-39}$. Ethylene is a desired product in electrochemical reduction of $\mathrm{CO}_{2}$, given the large market potential and use as feedstock for several industrial processes. In particular oxidederived copper electrodes have been reported to show a high Faradaic selectivity towards ethylene $\mathrm{e}^{40-43}$. Furthermore, significant progress has recently been made in increasing the current density towards ethylene by utilization of highly basic 
electrolytes in combination with advanced gas diffusion electrodes. Generally these studies have evaluated the cell performance using highly purified feeds ( $>98 \%)$. Yet direct utilization of flue gas would imply that the $\mathrm{CO}_{2}$ partial pressure is only $\sim 0.15$ Bar. Furthermore, the single-pass electrochemical conversion of $\mathrm{CO}_{2}$, even in gasdiffusion-based reactors, is still low ${ }^{44}$, and recycling is required to increase the overall process efficiency. Thus, in practical applications, diluted concentrations of $\mathrm{CO}_{2}$ can be expected.

Kenis et al. have nicely evaluated the effect of sub-atmospheric partial pressures on the performance of Ag-based gas diffusion electrodes, and showed that the decrease in partial current density for CO was less than $45 \%$ when switching from a pure $\mathrm{CO}_{2}$ feed to a feed of $10 \% \mathrm{CO}_{2}$ in inert gas ${ }^{44}$. Furthermore, Kyriacou et al. ${ }^{45}$ have conclusively shown that on smooth copper surfaces in $0.5 \mathrm{M} \mathrm{KHCO}_{3}$, the Faradaic efficiency (FE) and the rates of formation of the reduction products, including ethylene, diminish linearly with decreasing $\mathrm{P}_{\mathrm{CO} 2}$, while the efficiency in hydrogen evolution increases.

Lum et al. ${ }^{46}$, in their study focusing on the effect of surface roughness of copper electrodes in $0.1 \mathrm{M} \mathrm{KHCO}_{3}$, observed that the $\mathrm{FE}$ in methane formation improves when the $\mathrm{P}_{\mathrm{CO} 2}$ decreases from 1.0 to 0.8 or to $0.6 \mathrm{~atm}$.

Finally, the effect of CO partial pressure on the formation of several products of electroreduction, has been investigated in detail ${ }^{47-50}$. In a study by Wang et al. ${ }^{50}$, a major decrease in partial current densities of $\mathrm{CO}$ reduction products is observed as a function of decreasing partial pressure of $\mathrm{CO}$. Li et al. ${ }^{47}$ examined the effect of the local CO concentration on ethylene selectivity both theoretically and experimentally, and interestingly showed that constraining $\mathrm{CO}$, favored ethylene production.

As discussed above, research on the subject of variations in partial pressure of $\mathrm{CO}_{2}$ has been mostly restricted to smooth copper electrodes or gas diffusion electrodes. Herein, we examine for the first time the effect of partial pressure on 


\section{Chapter 3}

performance of rough, oxide-derived copper electrodes in the electrochemical reduction $\left(\mathrm{CO}_{2} \mathrm{R}\right)$ of $\mathrm{CO}_{2}$. This paper begins by investigating the effect of partial pressure at variable applied potential. It will then go on to correlate effects of partial pressure as a function of buffer $\left(\mathrm{KHCO}_{3}\right)$ concentration, which highly affects the local surface $\mathrm{pH}$. The third part deals with the effect of surface roughness, a factor also known to be responsible for the rise of local $\mathrm{pH}$. The impact of the mentioned factors on local $\mathrm{pH}$, proton activity and consequently hydrocarbon selectivity will be discussed on the basis of several results of calculation of the local concentration of $\mathrm{CO}_{2}$ and $\mathrm{pH}$ near the electrode.

\subsection{Experimental section}

Detailed description of materials and methods used for this study can be found in chapter 2.

\section{Modelling metholodogy}

The modelling approach was analogous to the one reported by Gupta et al. ${ }^{51}$. In such 1-D model, a 3-region system is considered, being 'Bulk', 'Boundary Layer' and 'Electrode Surface' in a batch, isothermal, and non-stationary situation. This is representative of the experimental set-up used in the present study. Only the cathodic half-cell is described in the model, as it is considered to be the limiting reaction in the whole electrochemical process (in the anodic half-cell, the oxygen evolution reaction takes place). The thickness of the 'Boundary Layer' region is given by the input parameter $\delta$, which is taken to be $100 \mu \mathrm{m}$, in accordance with previous literature ${ }^{51-52}$; for the current density $j$, the experimentally determined value of 25 $\mathrm{mA} \cdot \mathrm{cm}^{-2}$ was used.

At the 'Bulk' region, the equilibria of all dissolved species, $\mathrm{CO}_{2(\mathrm{aq})}$ and $\mathrm{KHCO}_{3}$, were considered. The equation of state for the calculation of the $\mathrm{CO}_{2}$ saturation concentration in pure water was taken from Duan et al. ${ }^{53}$. Then, the salt-out effect due to the presence of an electrolyte is also considered using the model from 
Schumpe ${ }^{54}$, having as output a saturated concentration of $\mathrm{CO}_{2 \text { (aq), given a certain }}$ pressure, temperature and initial $\mathrm{KHCO}_{3}$ concentration. Bulk equilibria for the buffered system $\mathrm{CO}_{2(\mathrm{aq})}-\mathrm{KHCO}_{3}$ were calculated having as input $\mathrm{CO}_{2(\mathrm{aq})}$ (after saltout effect) and $\mathrm{KHCO}_{3}$ initial concentrations. It is assumed that the 'Bulk' region is unaffected by the electrochemical reaction at the 'Electrode Surface', and neither by the transport effect in the 'Boundary Layer'.

At the 'Boundary Layer' region, two phenomena are taking place: diffusion of all species (modelled with Fick's $2^{\text {nd }} \mathrm{Law}$ ), and homogeneous equilibrium reactions for the buffered system $\mathrm{CO}_{2(\mathrm{aq})}-\mathrm{KHCO}_{3}$. All necessary data for these two effects were taken from Gupta et al. ${ }^{51}$, for a constant temperature. It is assumed that diffusion is the only transport mechanism for the reactive species to reach the 'Electrode Surface' region. Resulting equations are a set of Partial Differential Equations (PDE), solved with the PDE method in Matlab R2019A. Initial conditions (at instant zero and all spatial domains) consider that the concentration of all species is equal to the concentrations at the 'Bulk' region (from the equilibrium calculations). Boundary conditions at $\mathrm{x}=0$ (considering the border with ' $B u l k$ ' region to be $\mathrm{x}=0$, at all-time domains) assume that concentrations are equal to the 'Bulk' region equilibrium concentrations. Boundary conditions at $\mathrm{x}=\delta$ (considering the border with 'Electrode Surface' region to be $\mathrm{x}=\delta$, at all time domains) presume that a Neumann boundary condition is applied. Consumption or formation rates for the set of electrochemical reactions (only affecting $\mathrm{CO}_{2(\text { aq) }}$ and $\mathrm{OH}^{-}$) are used in this boundary layer.

At the 'Electrode Surface' region, the $\mathrm{CO}_{2(\text { aq) }}$ consumption and $\mathrm{OH}^{-}$formation rates are calculated from the given Faradic Efficiency values taken from the experimental data. All products formed at the electrode are considered not to affect the modelled system and have been neglected. Since Faradaic Efficiency values are constant with respect to current density, reactant concentration, or other variables, the $\mathrm{CO}_{2(\mathrm{aq})}$ consumption and $\mathrm{OH}^{-}$formation rates are therefore constant. The only 


\section{Chapter 3}

considered products are: $\mathrm{H}_{2}$ by hydrogen evolution, and $\mathrm{CH}_{4}, \mathrm{C}_{2} \mathrm{H}_{4}$, and $\mathrm{CO}$ by $\mathrm{CO}_{2} \mathrm{R}$.

\subsection{Results and discussion}

\section{Electrochemical deposition of $\mathrm{Cu}_{2} \mathrm{O}$ films}

The XRD patterns of the as prepared $\mathrm{Cu}_{2} \mathrm{O}$ films with varying thickness and a reduced electrode are shown in Figure 1. It can be seen that with an increase in thickness, the intensity of the $\mathrm{Cu}_{2} \mathrm{O}$ (110), (111), (100) and (220) diffraction lines increases while the intensity of the peaks associated with metallic copper (the substrate) decrease. The observed change in orientation (for the 9C sample) is believed to be the result of $\mathrm{pH}$ and $\mathrm{Cu}^{+}$variations during electrodeposition ${ }^{55}$. Furthermore, XRD patterns of the reduced copper electrode signify that the surface of the oxide film had been fully reduced to metallic copper during $\mathrm{CO}_{2} \mathrm{R}$, consisting of $\mathrm{Cu}$ (111), (220) and (200). The predominant orientation of $\mathrm{Cu}$ is (200). SEM images of oxide-derived copper with the thickness of 3C, before and after electrochemical reduction, are shown in Figure S1 of the supporting information. A rough surface is obtained consisting of pyramidal shapes, showing cracks after electrochemical reduction. This is in agreement with the observations of Kas et al. ${ }^{27}$. 


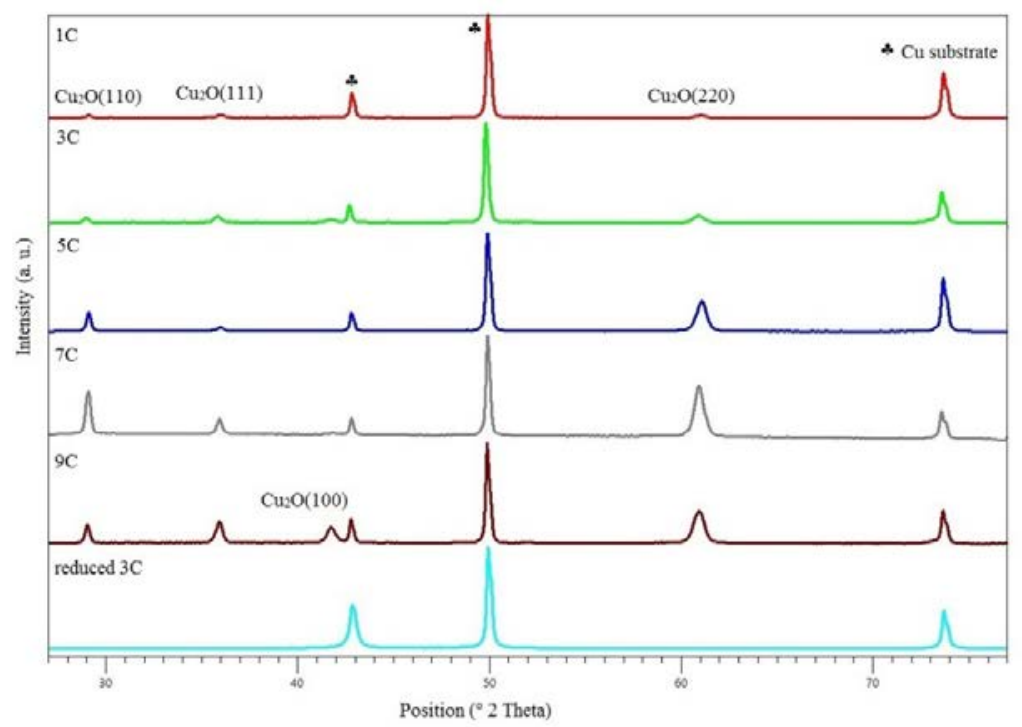

Figure 1. XRD of $\mathrm{Cu}_{2} \mathrm{O}$ electrodes with increase in thickness. The diffraction pattern shown at the bottom was obtained after electrochemical reduction.

\section{$\mathrm{CO}_{2} \mathrm{R}$ in $0.1 \mathrm{M} \mathrm{KHCO}_{3}$ at various partial pressures and potentials}

Electrochemical measurements were initially conducted at fixed potentials varying from $-0.7 \mathrm{~V}$ to $-1.1 \mathrm{~V}$ vs. RHE in $0.1 \mathrm{M} \mathrm{KHCO}_{3}$ electrolyte as function of a $\mathrm{P}_{\mathrm{CO} 2}$ ranging from 0.05 to $1 \mathrm{~atm}$. The most striking observation to emerge from this study is the trend of FE of $\mathrm{C}_{2} \mathrm{H}_{4}$ and $\mathrm{CH}_{4}$ as function of $\mathrm{P}_{\mathrm{CO} 2}$ (See Figures 2a and b). What stands out is that upon decreasing $\mathrm{P}_{\mathrm{CO} 2}$, the $\mathrm{FE}_{\mathrm{C} 2 \mathrm{H} 4}$ continuously increases until reaching a maximum at $\mathrm{P}_{\mathrm{CO} 2}=0.4 \mathrm{~atm}$, followed by a sharp drop at $\mathrm{P}_{\mathrm{CO} 2}=0.05 \mathrm{~atm}$. Furthermore, in the case of $\mathrm{CH}_{4}$, the $\mathrm{FE}_{\mathrm{CH} 4}$ strongly increases between 0.4 and 0.2 atm, until it sharply falls between $\mathrm{P}_{\mathrm{CO} 2}=0.2$ atm and $\mathrm{P}_{\mathrm{CO} 2}=0.05$ atm. On the other hand, the FE of CO linearly diminishes with decreasing $\mathrm{P}_{\mathrm{CO} 2}$, as previously reported in the literature $\mathrm{e}^{45-46}$. 


\section{Chapter 3}

(a)

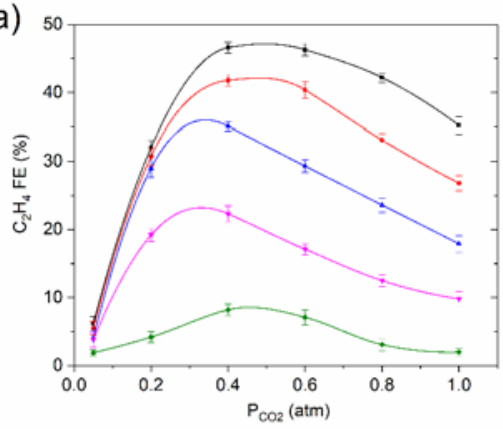

(c)

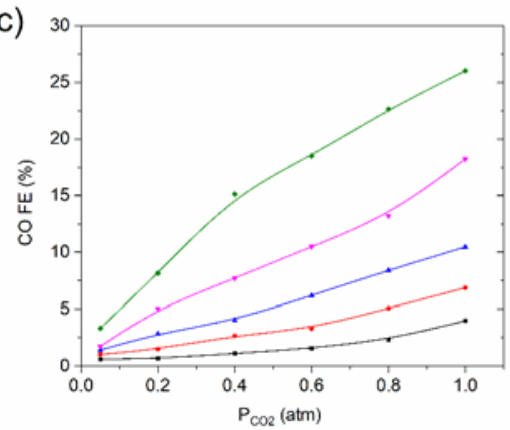

(b)

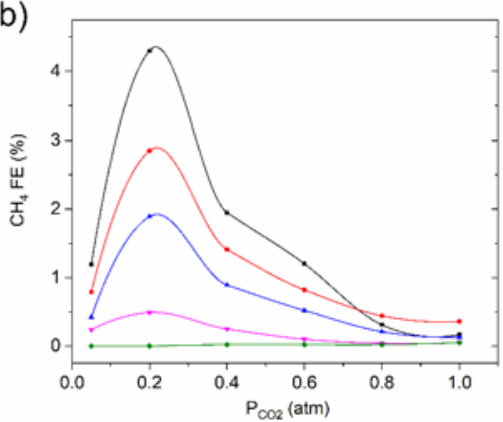

(d) 100

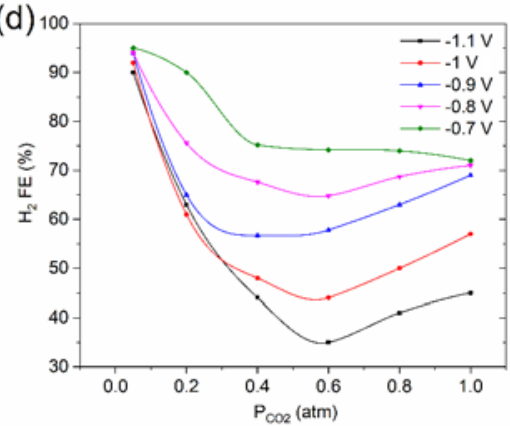

Figure 2. Faradaic efficiency vs. $\mathrm{P}_{\mathrm{CO} 2}$ of (a) $\mathrm{C}_{2} \mathrm{H}_{4}$, (b) $\mathrm{CH}_{4}$, (c) $\mathrm{CO}$ and (d) $\mathrm{H}_{2}$ under varying applied potentials (scale off-set to $30 \%$ for clarity) in $0.1 \mathrm{M} \mathrm{KHCO}_{3}$. The solid lines are there to guide the eye. Error bars represent the standard deviation from three independent measurements.

The sharp decline in FE of ethylene is correlating to a sharply increasing $\mathrm{H}_{2}$ efficiency below $0.4 \mathrm{~atm}$ (Figure 2d, note that the y-axis scales between 30-100\%). The trend in FE of hydrogen production approximately mirrors the $\mathrm{FE}$ of $\mathrm{C}_{2} \mathrm{H}_{4}$, suggesting an inverse correlation between hydrogen and ethylene production. Finally, the various results reported in Figure 2 indicate that the FE towards ethylene is strongly potential dependent, $-1.1 \mathrm{~V} v$ s RHE being optimal, while the formation of $\mathrm{CO}$ and hydrogen are favored at relatively low potential. This is further illustrated in Figure S2, which shows the partial current density vs. potential (V vs RHE) of $\mathrm{C}_{2} \mathrm{H}_{4}, \mathrm{CH}_{4}, \mathrm{CO}$ and $\mathrm{H}_{2}$ under varying $\mathrm{P}_{\mathrm{CO} 2}$ in $0.1 \mathrm{M} \mathrm{KHCO}_{3}$. Please note that the total 
current density during the experiments was relatively constant, at $28 \pm 2 \mathrm{~mA} \cdot \mathrm{cm}^{-2}$ (see Figure S2).

\section{$\mathrm{CO}_{2} \mathrm{R}$ in various $\mathrm{KHCO}_{3}$ electrolyte concentrations}

To evaluate whether the strong dependency of the ethylene FE shown in Figure 2 is depending on electrolyte concentration (and $\mathrm{pH}$ ), we varied the $\mathrm{KHCO}_{3}$ concentration and evaluated the $\mathrm{pH}$ as a function of $\mathrm{P}_{\mathrm{CO} 2}$, as shown in Figure 3. Figure 3 shows that the higher the $\mathrm{KHCO}_{3}$ concentration is, the stronger is the buffer capacity, leading to higher values of the bulk pH at variable partial pressure of $\mathrm{CO}_{2}$. At the same time, the higher the pressure of $\mathrm{CO}_{2}$, the lower the $\mathrm{pH}$ of the bulk solution appears to be, as expected from equilibrium calculations.

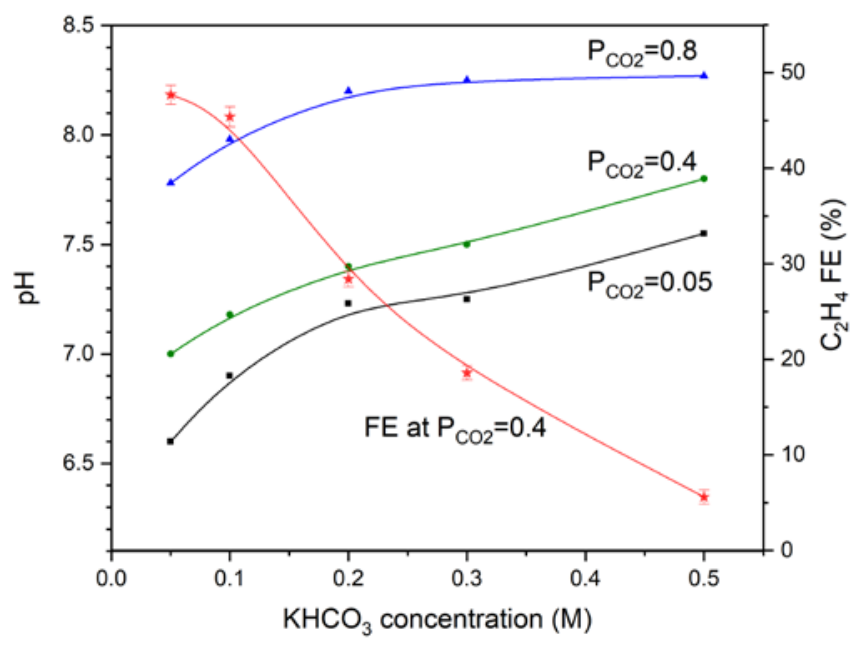

Figure 3. Dependency of $\mathrm{pH}$ of the $\mathrm{CO}_{2}$ saturated solutions on the $\mathrm{KHCO}_{3}$ concentrations at different partial pressures. The solid lines guide the eye and are second-order polynomial fits. The $\mathrm{FE}_{\mathrm{C} 2 \mathrm{H} 4}$ is also shown for $\mathrm{P}_{\mathrm{CO} 2}=0.4$ atm. and at $-1.1 \mathrm{~V}$ vs. RHE, demonstrating a significant drop as a function of increasing $\mathrm{KHCO}_{3}$ concentration. Error bars of faradaic efficiency curve represent the standard deviation from three independent measurements. 


\section{Chapter 3}

Figure 3 shows that an inverse trend between concentration of the $\mathrm{KHCO}_{3}$ solution (and solution $\mathrm{pH}$ ) and $\mathrm{FE}$ towards ethylene at $\mathrm{P}_{\mathrm{CO} 2}=0.4$ atm exists. While the $\mathrm{pH}$ of the solution increases as a function of increasing $\mathrm{KHCO}_{3}$ concentration, the $\mathrm{FE}_{\mathrm{C} 2 \mathrm{H} 4}$ decreases. However, the $\mathrm{pH}$ near the electrode surface significantly deviates from that of the solution, as will be discussed in more detail in the discussion of the model data. More experimental data of the combinations of $\mathrm{P}_{\mathrm{CO} 2}$ and concentration of electrolyte are shown in Figures 4a-d. With increasing buffer strength of the electrolyte, the trend in $\mathrm{FE}_{\mathrm{C} 2 \mathrm{H} 4}$ as a function of $\mathrm{P}_{\mathrm{CO} 2}$ changes from an optimum at $\sim 0.4 \mathrm{~atm}$, to an almost continuous trend with the highest $\mathrm{KHCO}_{3}$ concentration at $0.5 \mathrm{M}$.
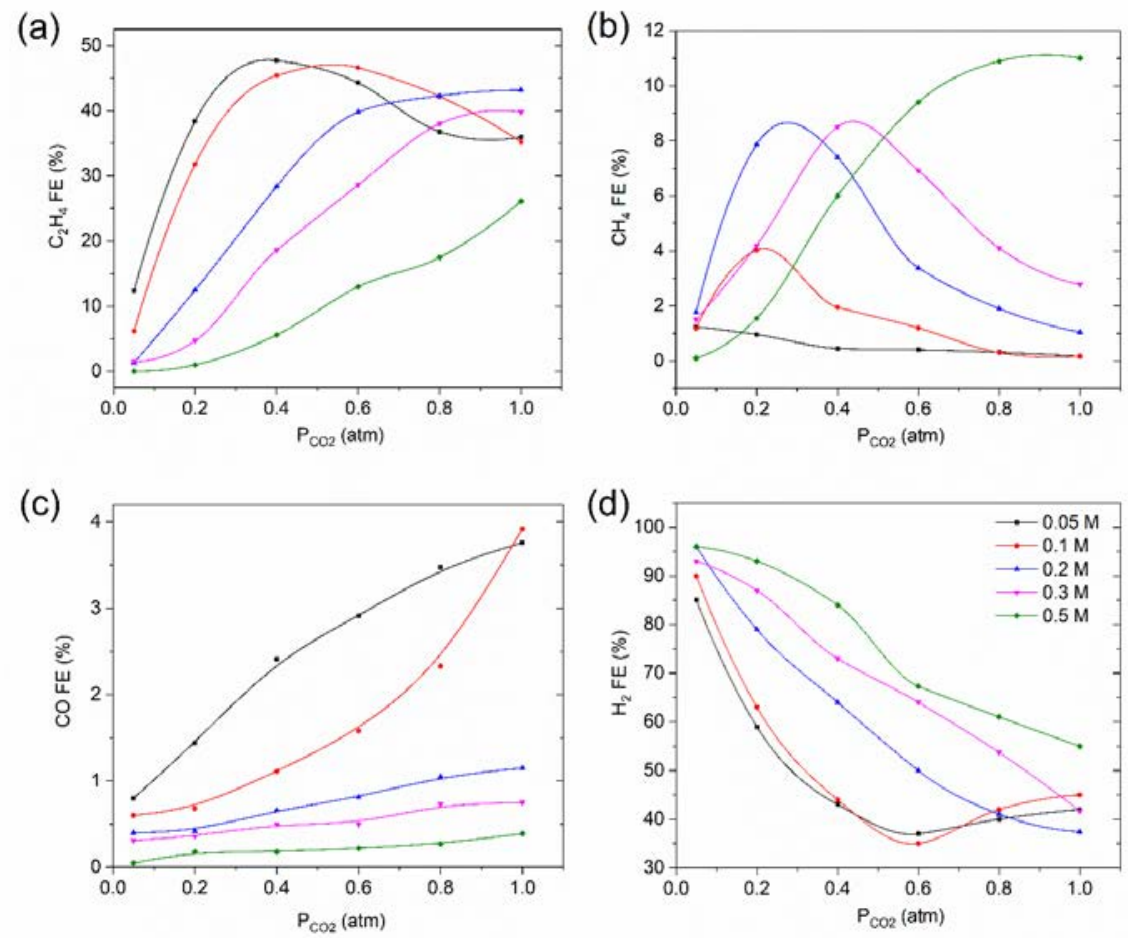

Figure 4. The effect of varying $\mathrm{KHCO}_{3}$ electrolyte concentrations at $-1.1 \mathrm{~V}$ vs. RHE on Faradaic efficiency of (a) $\mathrm{C}_{2} \mathrm{H}_{4}$, (b) $\mathrm{CH}_{4}$, (c) $\mathrm{CO}$ and (d) $\mathrm{H}_{2}$. The solid lines are there to guide the eye. 
Figure $4 \mathrm{~b}$ reveals that with increasing the electrolyte concentration, the maximum in $\mathrm{FE}_{\mathrm{CH} 4}$ increases, and takes place at gradually increasing values of $\mathrm{P}_{\mathrm{CO} 2}$ at higher $\mathrm{KHCO}_{3}$ concentrations. The $\mathrm{FE}_{\mathrm{CO}}$ decreases with decreasing $\mathrm{P}_{\mathrm{CO} 2}$ for all $\mathrm{KHCO}_{3}$ electrolyte concentrations investigated (Figure 3c), with the highest FE at the lowest concentrations. Again the FE of hydrogen evolution shows an inverse correlation with ethylene (Figure 3d), and is the lowest at the lowest concentration of $\mathrm{KHCO}_{3}$ electrolyte.

\section{$\mathrm{CO}_{2} \mathrm{R}$ on different cuprous oxide film thicknesses}

The third, and last correlation investigated, was how the combination of variation in surface roughness and $\mathrm{CO}_{2}$ partial pressure affect the FE. Sample surface roughness, relative to that of smooth copper, is reported in Table 2. As the oxide layer thickness increases, the roughness factors of the in-situ formed nanoparticulate copper surface increase as well, in agreement with the data of Kas et al. ${ }^{27}$.

Table 2. The capacitance values and surface roughness factors of the films as a function of initial thickness of the films

Charge passed through $\left(\mathrm{C} / \mathrm{cm}^{2}\right)$

Electropolished copper

1

3

5

7

9
Capacitance

(mF)

0.26

2.8

4.56

6.87

10.86

11.33
Surface Roughness

Factor

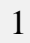

11

18

26

42

44 


\section{Chapter 3}

(a)

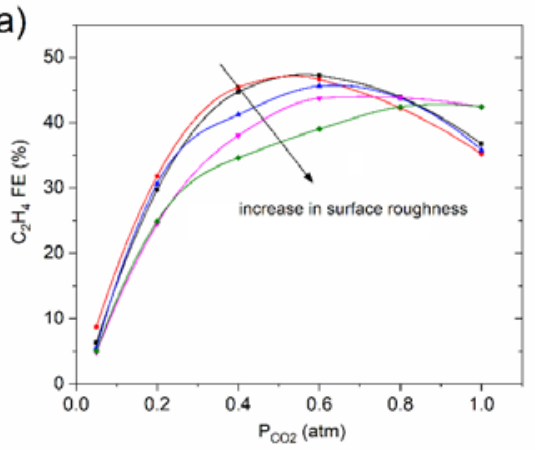

(c)

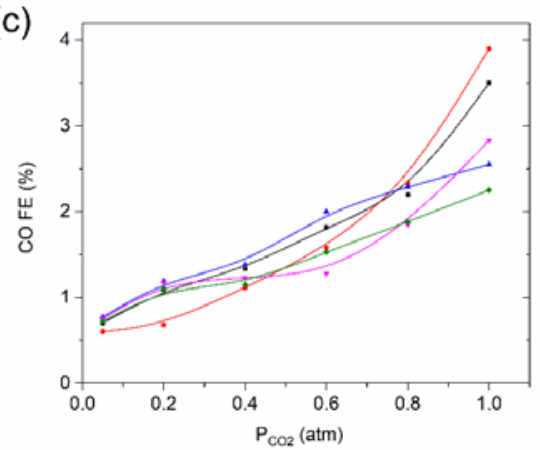

(b)

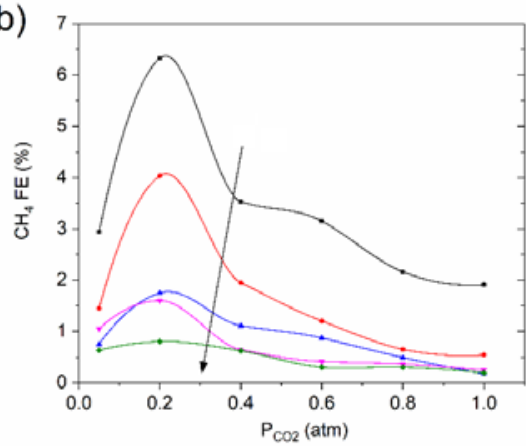

(d)

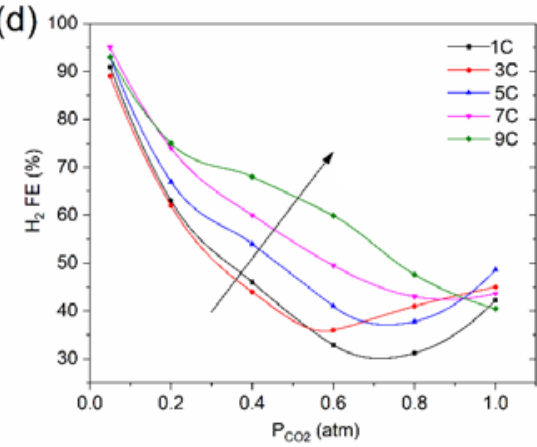

Figure 5. Faradaic efficiency vs. $\mathrm{P}_{\mathrm{CO} 2}$ of (a) $\mathrm{C}_{2} \mathrm{H}_{4}$, (b) $\mathrm{CH}_{4}$, (c) $\mathrm{CO}$ and (d) $\mathrm{H}_{2}$ for various oxide layer thicknesses at $-1.1 \mathrm{~V}$ vs. RHE in $0.1 \mathrm{M} \mathrm{KHCO}_{3}$. The solid lines are there to guide the eye.

$\mathrm{CO}_{2} \mathrm{R}$ on copper electrodes with different oxide thicknesses was conducted at $1.1 \mathrm{~V}$ vs. RHE in $0.1 \mathrm{M} \mathrm{KHCO}_{3}$ at various partial pressures of $\mathrm{CO}_{2}$. Figure 5 shows that a thicker film with higher surface roughness, leads to a lower optimum FE in ethylene and methane at partial pressures of $\mathrm{CO}_{2}$ in the range of $0.2-0.8$ atm or 0.05 to $0.3 \mathrm{~atm}$, respectively, while the formation of hydrogen is favored by the increasing thickness of the film. These observations are in agreement with previous studies, also showing a decrease in ethylene selectivity when the surface roughness increases 52, 56-578, but these have not been discussed in detail. We assume that multiple layers of copper, will lead to a certain porosity of the film, and therefore lower accessibility of $\mathrm{CO}_{2}$ towards the reduced copper sites closest to the electrode inner surface. While 
the local $\mathrm{pH}$ will be high in/near these porous films, the low concentration of $\mathrm{CO}_{2}$ likely limits the formation of ethylene. This is in agreement with the low amount of methane formed for thicker films, which is also restricted by the availability of $\mathrm{CO}_{2}$. Detailed studies and modeling of mass transport in porous layers is required to corroborate this hypothesis.

It remains striking that the FE of $\mathrm{C}_{2} \mathrm{H}_{4}$ and $\mathrm{CO}$ is much lower for smooth copper surfaces than obtained for the thinnest modified, oxide-derived film (See Figure 6 and compare to Figure 5). The methane FE is much higher than observed for exoxide derived surfaces, and in agreement with other $\mathrm{CO}_{2} / \mathrm{CO}$ electroreduction studies on smooth copper surfaces. A linear dependency of the ethylene selectivity as a function of partial pressure of $\mathrm{CO}_{2}$ is observed ${ }^{45,48,50}$.

Hydrogen evolution continuously increases with a decrease in $\mathrm{P}_{\mathrm{CO} 2}$ below $0.8 \mathrm{~atm}$.

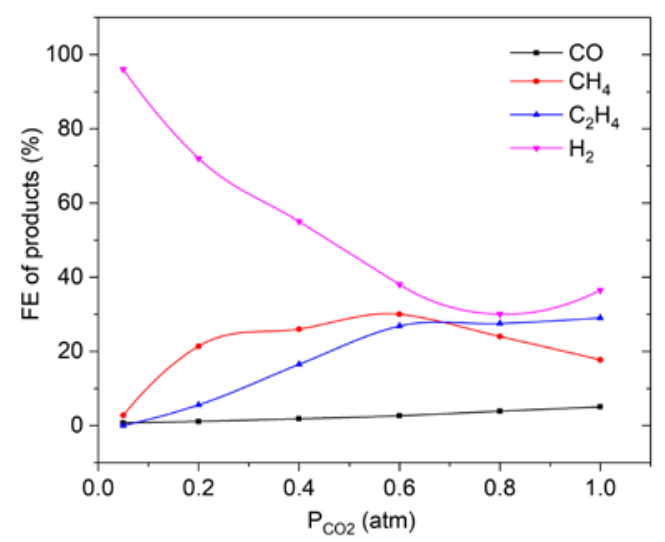

Figure 6. Faradaic efficiency vs. $\mathrm{P}_{\mathrm{CO} 2}$ of $\mathrm{C}_{2} \mathrm{H}_{4}, \mathrm{CH}_{4}, \mathrm{CO}$ and $\mathrm{H}_{2}$ for electropolished $\mathrm{Cu}$ electrode at $-1.1 \mathrm{~V}$ vs. RHE in $0.1 \mathrm{M} \mathrm{KHCO}_{3}$. The solid lines are there to guide the eye.

\section{Modelling}

To provide additional insight in the trends of local concentrations of $\mathrm{CO}_{2}$ and protons $(\mathrm{pH})$ near the electrode surface, several calculations were performed 


\section{Chapter 3}

following the modelling methodology described in the experimental procedures. For several concentrations of $\mathrm{KHCO}_{3}$, the concentration of $\mathrm{CO}_{2}$ at the electrode surface and the local proton concentration are plotted as a function of partial pressure of $\mathrm{CO}_{2}$ in Figures $7 \mathrm{a}$ and b, respectively.

(a)

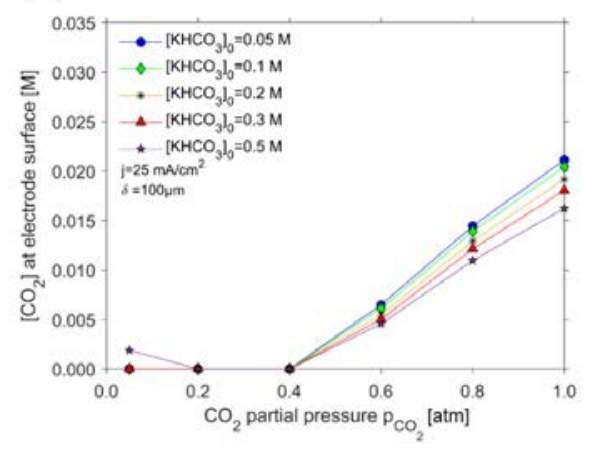

(b)

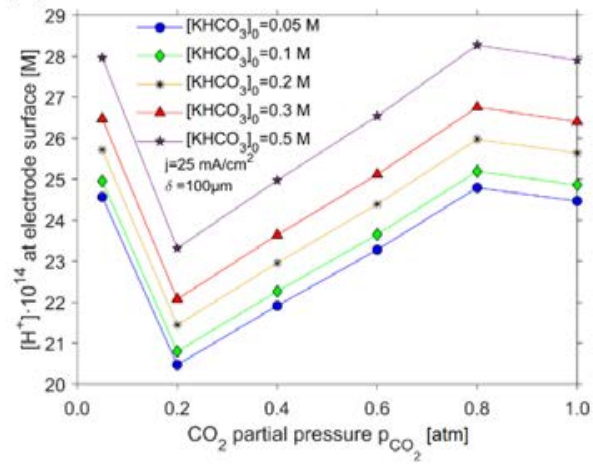

Figure 7. The effect of the $\mathrm{CO}_{2}$ partial pressure at a boundary layer condition of $100 \mu \mathrm{m}$ and total current density at the electrode of $25 \mathrm{~mA} \cdot \mathrm{cm}^{-2}$ on a) the concentration of $\mathrm{CO}_{2}$ near the electrode surface, and b) the local concentration of protons. Trend lines are provided for different initial $\mathrm{KHCO}_{3}$ concentrations.

As is demonstrated in Figure $7 \mathrm{a}$, the concentration of $\mathrm{CO}_{2}$ near the electrode surface decays as a function of partial pressure, and the trend is not strongly dependent on the initial $\mathrm{KHCO}_{3}$ concentration. Generally, for all $\mathrm{KHCO}_{3}$ concentrations taken into consideration, a depletion in the $\mathrm{CO}_{2}$ concentration can be discerned starting from a $\mathrm{CO}_{2}$ partial pressure of $0.4 \mathrm{~atm}$. For the $0.50 \mathrm{M} \mathrm{KHCO}_{3}$ series, depletion in $\mathrm{CO}_{2}$ concentration can be observed at $0.2-0.4$ atm, rising slightly at 0.05 atm. Depletion of $\mathrm{CO}_{2}$ can be correlated to the minimum in proton concentration at $\mathrm{CO}_{2}$ partial pressures of $0.2-0.6$ bar in Figure 7b. These two observed facts correlate to the high FE towards ethylene (and rise in methane FE) in the $\mathrm{CO}_{2}$ partial pressure range of $0.2-0.6 \mathrm{~atm}$, as is evident from the experimental results shown in Figures 2 and Figure 4. While decreasing the partial pressure 
evidently results in a lower local concentration of $\mathrm{CO}_{2}$ (which should lower ethylene selectivity), this also results in an increasing basicity (lower $\mathrm{H}^{+}$concentration in Figure $7 \mathrm{~b}$ ) near the electrode surface. This overcompensates for the lower $\mathrm{CO}_{2}$ concentration, and leads to better selectivity in ethylene. The decreasing trend in $\mathrm{H}^{+}$ concentration is further stimulated by the exceptionally high consumption of $\mathrm{H}^{+}$, which accompanies $\mathrm{CO}_{2} \mathrm{R}$ to $\mathrm{C}_{2} \mathrm{H}_{4}$ : 12 moles of $\mathrm{H}^{+}$per mole of $\mathrm{C}_{2} \mathrm{H}_{4}$ are consumed (or 12 moles of $\mathrm{OH}^{-}$formed), while hydrogen evolution only converts 2 moles of $\mathrm{H}^{+}$ per mole of $\mathrm{H}_{2}$ produced. Since the $\mathrm{CO}_{2}$ concentration depletes at low partial pressures, ethylene can no longer be formed, explaining the lower FE towards ethylene at partial pressure below $0.4 \mathrm{Bar}$, and the rise in local concentrations of $\mathrm{H}^{+}$, as shown in Figure 7b. It is interesting to note that for all studied concentrations of $\mathrm{KHCO}_{3}$, such minimum in proton concentration in Figure $7 \mathrm{~b}$ increases in absolute value of proton concentration as the buffer capacity goes up. This trend is in accordance with the experimental results for ethylene selectivity. A higher proton concentration results in a lower ethylene formation rate (and rate of $\mathrm{CH}_{4}$ formation, which also has a high $\mathrm{H}^{+}$consumption per mol of C-product).

The modeling results thus strongly suggest that the local $\mathrm{pH}$ (proton concentration) near the surface of the electrode is strongly correlated to the selectivity towards ethylene in the electrochemical reduction of $\mathrm{CO}_{2}$.

\section{Methane vs ethylene selectivity: surface coverage effects}

As indicated by the experimental and modeling results of the present study, surface coverages of $\mathrm{Cu}-\mathrm{H}$ and $\mathrm{Cu}-\mathrm{CO}$ appear to have a decisive role in determining methane and ethylene selectivity. Hydrocarbons are then formed through a Langmuir Hinshelwood-type of mechanism. The trends in formation of methane vs ethylene can be explained if we take a deeper look into two extreme conditions, namely electrolyte concentrations of $0.05 \mathrm{M}$ vs. $0.5 \mathrm{M}$. At the concentration of 0.05 $\mathrm{M}$, the highest $\mathrm{FE}_{\mathrm{CH} 4}$ Occurs at $\mathrm{P}_{\mathrm{CO} 2}=0.2$ atm. At such a low $\mathrm{P}_{\mathrm{CO} 2}$, sufficient amount of $\mathrm{H}_{\mathrm{ads}}$ can be formed (even though the local $\mathrm{pH}$ is high) relative to $\mathrm{CO}_{\mathrm{ads}}$. This 


\section{Chapter 3}

induces methane formation and reduces the rate of formation of ethylene (2 CO molecules are required per mole of ethylene). On the other hand, at a concentration of $0.5 \mathrm{M}$, where the local $\mathrm{pH}$ value is retained close to the bulk $\mathrm{pH}$ value (around 7.45), a much higher surface coverage with $\mathrm{H}_{\mathrm{ads}}$ can be expected, and the optimized value of $\mathrm{CO}_{\text {ads }}$ requires a higher $\mathrm{P}_{\mathrm{CO} 2}$. The significant increase of $\mathrm{FE}_{\mathrm{CH} 4}$ as a function of increasing bicarbonate concentration is consistent with the literature 26,58 .

An analogous reasoning can be proposed for the formation of ethylene, where the surface concentration of $\mathrm{CO}_{\text {ads }}$ (assuming $\mathrm{CO}$ dimerization is the limiting step for the formation of ethylene) needs to be significantly higher than for the formation of $\mathrm{CH}_{4}$. Therefore the optimum in production of ethylene occurs at relatively higher partial pressures of $\mathrm{CO}_{2}$, than the optimized formation of $\mathrm{CH}_{4}$. This is in agreement with existing literature, such as a previous study of Raciti et al. ${ }^{59}$, who also demonstrates a high local $\mathrm{pH}$ is needed for maximal selectivity toward multi-carbon products.

\subsection{Conclusions}

In general, our results confirm that the local $\mathrm{pH}$, i.e. the $\mathrm{pH}$ near the surface of the electrode, is largely affecting the selectivity of roughened, oxide-derived copper electrodes in the electrochemical reduction of $\mathrm{CO}_{2}$ towards ethylene. What is new, is that for the utilized roughened electrodes, the selectivity towards $\mathrm{C}_{2+}$ products does not depend linearly on partial pressure of $\mathrm{CO}_{2}$. We have demonstrated experimentally, and by modeling, that the partial pressure of $\mathrm{CO}_{2}$ has a small, yet significant effect on local $\mathrm{pH}$, in particular when the buffer capacity of the applied electrolyte $\left(\mathrm{KHCO}_{3}\right)$ is limited (at low concentrations of $\sim 0.05 \mathrm{M}$ ). This implies that the partial pressure not only directly affects the near-surface concentration of $\mathrm{CO}_{2}$ (required for the formation of $\mathrm{CO}$ and consecutively $\mathrm{CH}_{4}$ and $\mathrm{C}_{2} \mathrm{H}_{4}$ ), but also indirectly affects the local $\mathrm{pH}$, which is essential in determining product selectivity. 


\subsection{Appendix}
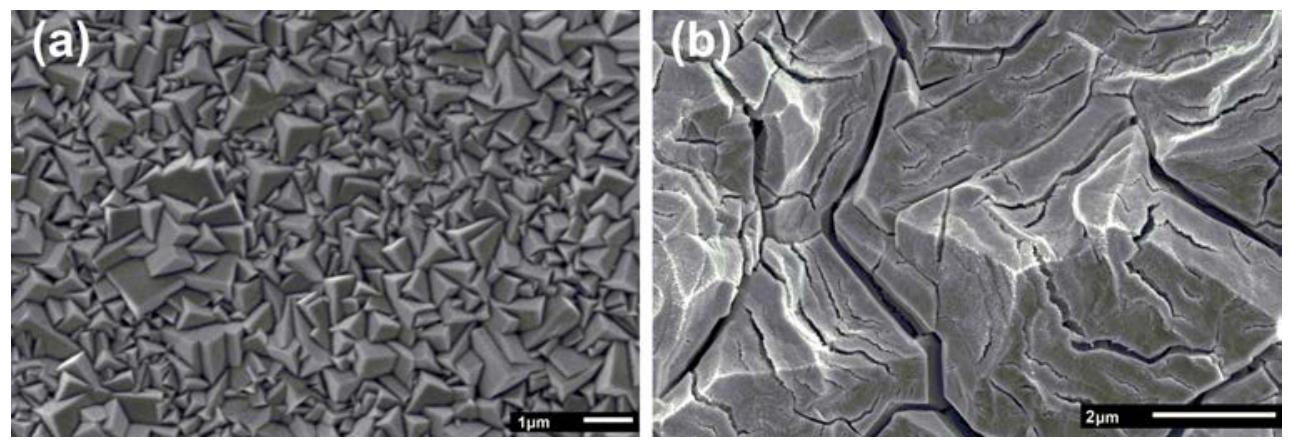

Figure S1. SEM images of oxide-derived copper with the thickness of 3C (a) before and (b) after electrochemical reduction.

(a)

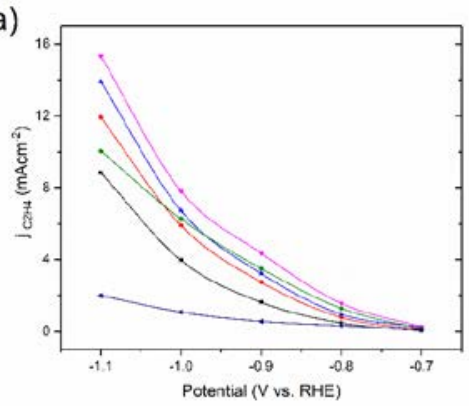

(c)

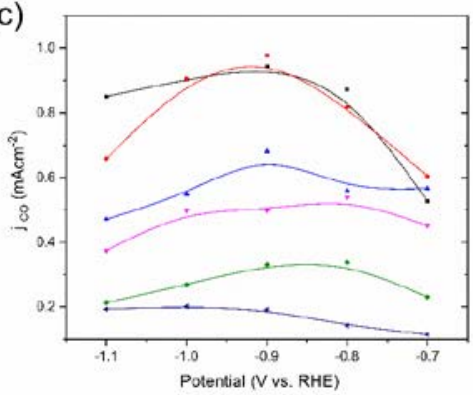

(b)

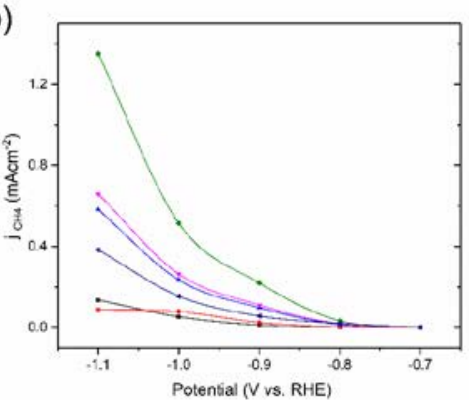

(d)

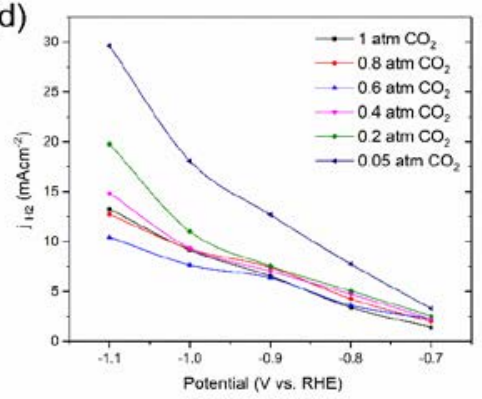

Figure S2. Partial current density vs. potential (V vs RHE) of $(a) \mathrm{C}_{2} \mathrm{H}_{4}$, (b) $\mathrm{CH}_{4}$,(c) $\mathrm{CO}$ and (d) $\mathrm{H}_{2}$ under varying $\mathrm{P}_{\mathrm{CO} 2}$ in $0.1 \mathrm{M} \mathrm{KHCO}_{3}$. The solid lines are there to guide the eye. 
Chapter 3 


\section{Chapter 4.}

\section{Optimizing CO coverage on rough}

\section{copper electrodes: effect of the partial}

pressure of $\mathrm{CO}$ and electrolyte anions

\section{(pH) on selectivity toward ethylene}

\section{Abstract}

Electrochemical reduction of $\mathrm{CO}$ on rough copper electrodes is known to produce commercially viable hydrocarbons and alcohols. In this study, we show that in inert gas, an increase in partial pressure of CO results in a linear increase in Faradaic Efficiency (FE) for ethylene, at various potentials ranging from -0.7 to $-1.1 \mathrm{~V} v \mathrm{~s}$ RHE. On the contrary, when the partial pressure of $\mathrm{CO}$ is increased in a mixture of $\mathrm{CO} / \mathrm{CO}_{2}$, a potential dependent optimum in ethylene formation is found for the partial pressure of $\mathrm{CO}$ in the range of 0.5 (at $-1.1 \mathrm{~V}$ ) to 0.8 (at $-0.8 \mathrm{~V}$ ) atm. We also present the result of $\mathrm{CO}$ reduction in electrolytes with different anions. The optimized FE towards ethylene increases from $5.2 \%$ in $\mathrm{KH}_{2} \mathrm{PO}_{4}$ to $43.2 \%$ in $\mathrm{KOH}$. The observed differences in selectivity are attributed to anion buffering capacity, $\mathrm{pH}$ 


\section{Chapter 4}

and conductivity of the electrolyte. Using in-situ attenuated total reflection surface enhanced infrared absorption spectroscopy (ATR-SEIRAS), we probed CO coverage in the presence of the different anions. Comparison of the adsorbed CO band area in different electrolytes revealed an increase of CO coverage with increase in $\mathrm{pH}$, confirming $\mathrm{CO}$ coverage and $\mathrm{pH}$ are coupled. Collectively, the data herein outline the critical role of reactant partial pressures and the significant effect of anion composition $(\mathrm{pH})$ on the surface coverage of $\mathrm{CO}$ and concomitant selectivity in electrochemical reduction of $\mathrm{CO}_{2}$.

\subsection{Introduction}

The electrochemical reduction of $\mathrm{CO}_{2}\left(\mathrm{CO}_{2} \mathrm{RR}\right)$ to hydrocarbons and alcohols has been subject of numerous studies since its discovery by Hori and coworkers ${ }^{21}$. Since the recognition of $\mathrm{CO}$ as the key intermediate in $\mathrm{CO}_{2} \mathrm{RR}$, many studies have also focused on reduction of CO. Studying CORR has the advantage that few reaction intermediates and steps are involved. In addition, with the elimination of dissolved $\mathrm{CO}_{2}$ acting as buffer, CORR allows for a wider range of $\mathrm{pH}$ conditions to be examined.

CO gas streams are industrially available in the form of syngas, and CO is also a side product of steel manufacturing, ranging in CO concentration from 10-60\%, often also consisting of $\mathrm{CO}_{2}{ }^{47,60-61}$. Conversion of these abundant gas mixtures to hydrocarbons avoids costly purification steps. This underlines the importance of investigating electrocatalytic activity of gas mixtures containing $\mathrm{CO}$ or $\mathrm{CO} / \mathrm{CO}_{2}$. A number of reports have investigated the effect of $\mathrm{CO}$ partial pressure $\left(\mathrm{P}_{\mathrm{CO}}\right)$ in inert gas on product selectivity of copper electrodes, with different outcomes. Schreier et al. ${ }^{48}$ or Li et al. ${ }^{49}$ demonstrated that with decreasing $\mathrm{P}_{\mathrm{CO}}$, ethylene partial current density either declined ${ }^{5}$ or was unvaried ${ }^{6}$, whereas both studies reported improved methane production rates as the $\mathrm{P}_{\mathrm{CO}}$ was decreased. Wang et al. ${ }^{62}$ found a major decrease in ethylene and methane partial current density at low $\mathrm{P}_{\mathrm{CO}}$. A recent study by Li et al. ${ }^{47}$ examined the effect of local CO concentrations on ethylene selectivity, 
both theoretically and experimentally. They showed that constraining CO, favored ethylene production. However, they also found that at certain small local CO concentrations, partial current density and selectivity towards ethylene decreases.

In CORR a wide range of $\mathrm{pH}$ values can be investigated. Different values of $\mathrm{pH}$ can be achieved by changes in the composition of anions in solution. The buffering strength of the anion in the electrolyte, highly influences selectivity towards hydrocarbons. CORR on copper is also known to greatly depend on $\mathrm{pH}$. However, the $\mathrm{pH}$ dependence varies for different products ${ }^{63}$. Increasing the electrolyte alkalinity is known to enhance the selectivity towards ethylene, while suppressing the competitive hydrogen evolution reaction ${ }^{64-66}$. The dramatic $\mathrm{pH}$ impact on selectivity towards $C_{2}$ or $C_{1}$ pathways has been explained by differences in ratedetermining proton-electron transfer steps ${ }^{67}$. Electron transfer during CO dimerization, or a second proton assisted electron transfer, are rate determining steps in formation of $\mathrm{C}_{2}$ products or methane, respectively ${ }^{68-69}$.

In our previous study, we studied the effect of $\mathrm{CO}_{2}$ partial pressure $\left(\mathrm{P}_{\mathrm{CO} 2}\right)$ on $\mathrm{CO}_{2} \mathrm{RR}$ using oxide-derived copper electrodes ${ }^{70}$ and reported improved ethylene formation by decreasing $\mathrm{P}_{\mathrm{CO}}$. So far, however, there is little published data on the performance of such electrodes in the reduction of $\mathrm{CO} / \mathrm{CO}_{2}$ gas mixtures ${ }^{71-72}$. The importance and originality of this study are the exploration of the effect of $\mathrm{CO} / \mathrm{CO}_{2}$ partial pressures on selectivity towards hydrocarbons. We also show that the electrolyte anion greatly influences the activity and selectivity towards $C_{1}$ and $C_{2}$ pathways. Besides, we employ ATR-SEIRAS to understand dynamic evolution of adsorbed CO, including atop-adsorbed and bridge-adsorbed CO, as a function of potential and applied anion in the electrolyte. We demonstrate that the CO surface coverage can be moderated by the ration of $\mathrm{CO}$ and $\mathrm{CO}_{2}$ in the feed gas, as well as the establishment of the local $\mathrm{pH}$ by variation of the anion. 


\section{Chapter 4}

\subsection{Experimental section}

\section{Materials and Film Deposition}

Cuprous oxide films were prepared by electropolishing (in 85\% phosphoric acid, potentiostatically at $2.1 \mathrm{~V}$ vs. a graphite foil counter electrode) of copper foils (Alfa Aesar, 99.99\%), followed by electrodeposition. $\mathrm{A} \mathrm{Cu}^{2+}$ containing electrodeposition solution was prepared using 0.4 $\mathrm{M} \mathrm{CuSO}_{4}$ (Sigma Aldrich, 99\%) and $3 \mathrm{M}$ lactic acid (Sigma Aldrich) at $60^{\circ} \mathrm{C}$, according to a published procedure ${ }^{34}$. A one-compartment, three electrode cell with $\mathrm{Cu}$ foil as working electrode, Pt mesh as counter electrode and $\mathrm{Ag} / \mathrm{AgCl}(3 \mathrm{M} \mathrm{NaCl})$ as the reference electrode were used. The $\mathrm{pH}$ of the solution was adjusted to 12 using $\mathrm{NaOH}$ (Sigma Aldrich, 98\%). Galvanostatic deposition was performed at $0.8 \mathrm{~mA} \mathrm{~cm}^{-2}$ using a potentiostat/galvanostat (PAR, Versastat 3) until a film thickness equivalent to 3 Coulomb was achieved. $\mathrm{Cu}$ thin-film electrodes were prepared by magnetron sputtering on a silicon ATR crystal, as described in our previous work ${ }^{73}$. The electrolyte solutions of $\mathrm{KHCO}_{3}$ (Sigma Aldrich, 99.99\% metals basis), $\mathrm{KClO}_{4}$ (Alfa Aesar, 99-100.5\%), KOH (Sigma Aldrich, 99.99\%), $\mathrm{K}_{2} \mathrm{HPO}_{4}$ (Sigma Aldrich, $\geq 98 \%$ ) and $\mathrm{KH}_{2} \mathrm{PO}_{4}$ (Sigma Aldrich, $\geq 98 \%$ ) were prepared using deionized water (Millipore MilliQ, 18.2 $\mathrm{M} \Omega \mathrm{cm}$ ). In order to prepare $0.1 \mathrm{M}$ phosphate buffer with $\mathrm{pH}=5.9,0.0098 \mathrm{M}$ of $\mathrm{K}_{2} \mathrm{HPO}_{4}$ was added to $0.0902 \mathrm{M}$ $\mathrm{KH}_{2} \mathrm{PO}_{4}$ in equivalent aliquots.

\section{Electrochemical Measurements}

All electrochemical measurements were carried out on a Bio-Logic VSP potentiostat. A home-made glass two compartment electrochemical cell using a three electrode assembly was used to carry out the $\mathrm{CO}_{2} / \mathrm{CO}$ electrochemical reduction. The as-prepared cuprous oxide films with the thickness of 3 Coulomb were used as the working electrode. Glassy carbon (SIGRADUR ${ }^{\circledR} \mathrm{G}$ ) was used as the counter electrode and was separated from the working electrode using an anion exchange membrane (Selemion AMV, AGC, Inc.). $\mathrm{Ag} / \mathrm{AgCl}$ in $3 \mathrm{M} \mathrm{NaCl}$ was used as a 
reference electrode and potentials were converted to the Reversible Hydrogen Electrode (RHE) scale by $\mathrm{V}_{\text {vs. } \mathrm{RHE}}=\mathrm{V}_{\text {measured vs. Ag/AgCl }}+0.198+0.059 *(\mathrm{pH}$ of solution).

The gas mixture $\left(\mathrm{CO}_{2}\right.$, $\mathrm{CO}$ and $\left.\mathrm{He}\right)$ was continuously purged through a glass frit at a rate of $20 \mathrm{ml} \mathrm{min}^{-1}$ for 30 minutes before each experiment using two mass flow controllers, to attain a steady $\mathrm{CO}_{2} / \mathrm{CO}$ concentration in the electrolyte. The flow rate was then decreased to $5 \mathrm{ml} \mathrm{min}{ }^{-1}$ during the electrochemical reduction. The reactor effluent was vented directly into the gas sampling loop of a micro-gas chromatograph (micro-GC) equipped with a pulsed discharge detector (PDD) every 4 minutes. The micro-GC was equipped with two different columns (Molsieve plot and Rt-Q Bond) for separation of $\mathrm{H}_{2}, \mathrm{CO}, \mathrm{CO}_{2}$ and hydrocarbons.

\section{In-situ ATR-SEIRAS}

All electrochemical experiments were performed in a custom-made threeelectrode cell, with the sputtered $\mathrm{Cu}$ film used as the working electrode. A graphite rod was used as counter electrode, while a $\mathrm{Ag} / \mathrm{AgCl}$ electrode (3 $\mathrm{M} \mathrm{NaCl}, \mathrm{BASi}$ ) was used as reference electrode. A VersaSTAT 3 potentiostat was used to perform the electrochemical measurements. The experiments were conducted in a Bruker Vertex 70 spectrometer equipped with a liquid nitrogen-cooled MCT detector and a Veemax III ATR accessory. Spectra were taken with $4 \mathrm{~cm}^{-1}$ resolution during a CV with a scan rate of $2 \mathrm{mV} / \mathrm{sec}$, under continuous purge of pure CO.

\subsection{Results and discussion}

\section{Effect of $P_{\text {CO }}$ on CORR}

To investigate the effect of $\mathrm{CO}$ coverage on product distribution, the CO partial pressure was varied at several fixed potentials. Figure 1 shows the faradaic efficiency of ethylene, ethane and methane as a function of $\mathrm{P}_{\mathrm{CO}}$ between $-1.1 \mathrm{~V}$ and $-0.7 \mathrm{~V}$. Based on Fig 1a, an increase in partial pressure of CO results in a linear increase in Faradaic Efficiency for ethylene. This is in line with theoretical and experimental studies that propose higher CO coverage to facilitate CO dimerization ${ }^{47,74-76}$. 


\section{Chapter 4}

Consequently, this favors formation of $\mathrm{C}_{2}$ products, in particular ethylene. Moreover, the highest FE was obtained at $-0.8 \mathrm{~V}$ and $1 \mathrm{~atm}$ of CO.

These observations for the trend in formation of ethylene are also valid for ethane (Figure 1b), a minor product with marginal Faradaic Efficiency (FE), with the exception that in the range of 0.8 to $1.0 \mathrm{~atm}$ the FE decreases, in particular at -0.7 and $-0.8 \mathrm{~V}$.
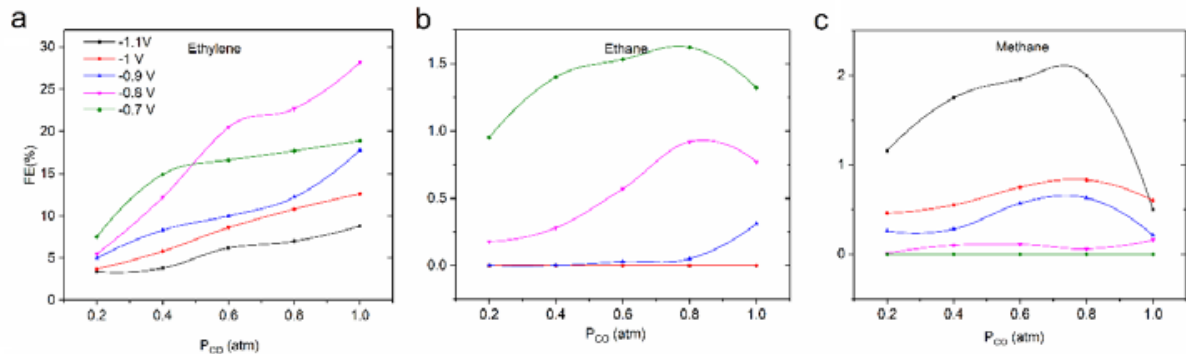

Figure 1. Faradaic efficiency vs. $\mathrm{P}_{\mathrm{CO}}$ in inert gas of a) ethylene, b) ethane and c) methane under varying applied potentials in $0.1 \mathrm{M} \mathrm{KHCO}_{3}$. The solid lines are there to guide the eye.

Similar to ethane, the other minor product, methane (Figure 1c), also displayed optimum selectivity at a $\mathrm{P}_{\mathrm{CO}}$ of $0.8 \mathrm{~atm}$, but now the highest FE is obtained at -1.1 V. Such trends in methane and ethane formation support previous observations implying that a Langmuir-Hinshelwood mechanism can be in play ${ }^{77}$. Based on this mechanism, both $\mathrm{CO}$ and $\mathrm{H}$ compete for surface sites and increasing the $\mathrm{P}_{\mathrm{CO}}$ improves coverage and activity towards formation of carbon-containing products. The optimum in $\mathrm{P}_{\mathrm{CO}}$ for ethane and methane formation is in agreement with the hypothesis that the formation of these products also requires a significant quantity of activated $\mathrm{H}$ on the surface.

\section{Reduction of mixtures of $\mathrm{CO}$ and $\mathrm{CO}_{2}$}

To assess the influence of $\mathrm{CO}_{2}$ on the electrochemical reduction of $\mathrm{CO}$, the partial pressure of $\mathrm{CO}$ was varied and the total pressure balanced to 1 atm with $\mathrm{CO}_{2}$, rather than He. When comparing Figs $1 \mathrm{a}$ and 2a, at the potentials of $-0.7 \mathrm{~V}$ and $-0.8 \mathrm{~V}$, a 
quite similar increasing trend in formation of ethylene is observed when the $\mathrm{P}_{\mathrm{Co}}$ is increased, and comparable FE towards ethylene are obtained (at $-0.8 \mathrm{~V}$ and $1 \mathrm{~atm}$ the $\mathrm{FE}$ is again $\sim 30 \%$ ). In agreement with literature, $\mathrm{CO}_{2}$ is not electrocatalytically activated at $-0.8 \mathrm{~V}$, and hence $\mathrm{CO}_{2}$ acts as an inert gas. As shown in Figure 2a, at potentials more negative than $-0.8 \mathrm{~V}$, an optimum in production of ethylene as a function of $\mathrm{P}_{\mathrm{CO}}$ becomes apparent, shifting towards lower $\mathrm{P}_{\mathrm{CO}}$ in the potential series of $-0.9,-1.0$ and $-1.1 \mathrm{~V}$, with the highest ethylene $\mathrm{FE}$ of $\sim 45 \%$ at $\mathrm{P}_{\mathrm{CO}}=0.5 \mathrm{~atm}$ and at $\mathrm{V}=-1.1 \mathrm{~V}$.
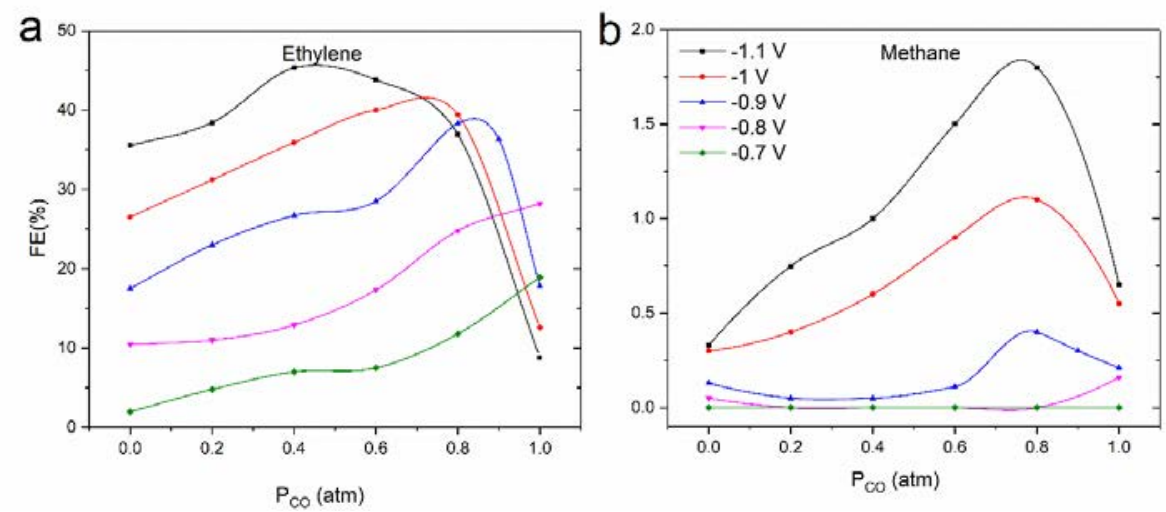

Figure 2. (a) Faradaic efficiency of ethylene vs. $\mathrm{P}_{\mathrm{CO}}\left(\mathrm{P}_{\mathrm{CO}}=0\right.$ equals $\left.\mathrm{P}_{\mathrm{CO} 2}=1\right)$, (b) Faradaic efficiency of methane vs. potential ( $\mathrm{V}$ vs. RHE). Experiments were performed in $0.1 \mathrm{M}$ $\mathrm{KHCO}_{3}$. Voltages indicated by the legend in Fig. $1 \mathrm{~b}$.

These data suggest that at potentials more negative than $-0.8 \mathrm{~V}$, the reduction of $\mathrm{CO}_{2}$ is dominating product formation. It is generally accepted that at values less negative than $-0.8 \mathrm{~V}$, only $\mathrm{CO}$ can be electrochemically activated over $\mathrm{Cu}$ surfaces, whereas activation of $\mathrm{CO}_{2}$ requires higher overpotentials. Turning to Fig 2b, methane formation was observed to be the highest at $\mathrm{P}_{\mathrm{CO}}=0.8$ atm (and $\mathrm{P}_{\mathrm{CO} 2}=0.2$ atm) at the two most negative potentials, again showing similar trends and values as compared to Fig. 1c. 


\section{Chapter 4}

The observations for the formation of ethylene at potentials more negative than $0.8 \mathrm{~V}$ are very similar to observed by varying the partial pressure of $\mathrm{CO}_{2}$ in inert balance gas $^{70}$, also showing an optimum in FE of ethylene at $\mathrm{P}_{\mathrm{CO} 2} \sim 0.5 \mathrm{~atm}$, see Fig. 3a. Fig 3a shows the results from this work and previously published data on $\mathrm{P}_{\mathrm{CO} 2}{ }^{70}$, measured at $-1.1 \mathrm{~V}$ vs RHE (see also Supplementary Figures S2 and S3). The relatively low FE towards ethylene induced by reduction of $\mathrm{CO}$, could be related to the large difference in aqueous solubility of $\mathrm{CO}(1 \mathrm{mM})$ and $\mathrm{CO}_{2}(33 \mathrm{mM})^{78}$.

The trend in ethylene production rate in Fig 3a is partly consistent with a recent study on $\mathrm{CO}_{2} / \mathrm{CO}$ co-feeds which assigned the highest rate of ethylene formation to reduction of $\mathrm{CO}_{2}$ in a mixture with $\mathrm{CO}$, followed by pure $\mathrm{CO}_{2}$ and finally pure $\mathrm{CO}^{71}$.

a

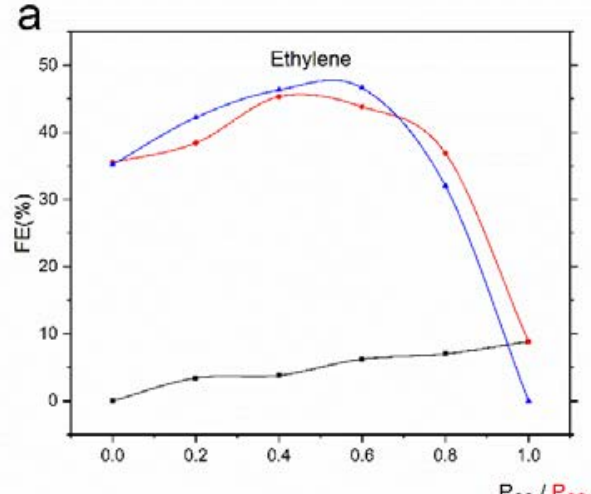

b

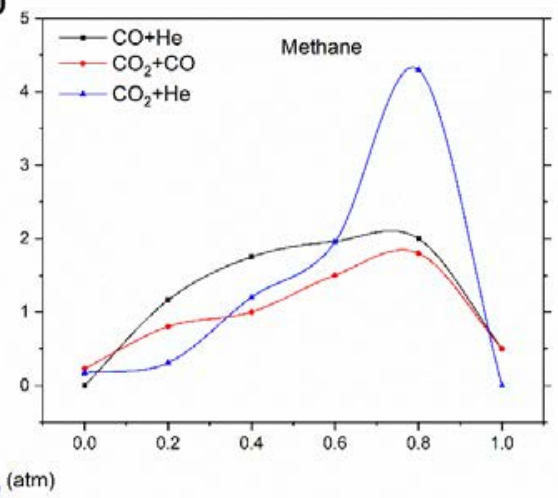

Figure 3. Comparison of Faradaic efficiency of (a) ethylene and (b) methane vs. $\mathrm{P}_{\mathrm{CO}}$ $\left(\mathrm{P}_{\mathrm{CO}}+\mathrm{P}_{\mathrm{HE}}=1\right)$ or $\mathrm{P}_{\mathrm{CO}}\left(\mathrm{P}_{\mathrm{CO}}+\mathrm{P}_{\mathrm{CO} 2}=1\right)$ or $\mathrm{P}_{\mathrm{He}}\left(\mathrm{P}_{\mathrm{He}}+\mathrm{P}_{\mathrm{CO} 2}=1\right)$ at $-1.1 \mathrm{~V}$ vs RHE in $0.1 \mathrm{M} \mathrm{KHCO}_{3}$.

However, Figure 3a shows that having $\mathrm{CO}$ added to $\mathrm{CO}_{2}$ at $-1.1 \mathrm{~V}$, rather than dilution of $\mathrm{CO}_{2}$ with $\mathrm{He}$, is only beneficial in the $\mathrm{P}_{\mathrm{CO}}$ range of 0.8 to $1.0 \mathrm{~atm}$, i.e. at relatively low partial pressure of $\mathrm{CO}_{2}$. On the contrary, below a $\mathrm{P}_{\mathrm{CO}}$ of $\sim 0.7$, dilution of $\mathrm{CO}_{2}$ with $\mathrm{CO}$ rather than $\mathrm{He}$ (somewhat) negatively affects the FE towards ethylene.

The positive effect of $\mathrm{CO}$ at high relative pressures, may be explained by the higher coverage of adsorbed $\mathrm{CO}$ which is then achieved on the $\mathrm{Cu}$ surface. As 
previously stated, a high CO surface coverage enhances the CO dimerization rate, and, due to the low solubility of $\mathrm{CO}$, the $\mathrm{P}_{\mathrm{CO}}$ needs to be relatively high for the $\mathrm{CO}$ feed to contribute to the optimized balance between surface $\mathrm{CO}$ and $\mathrm{H}^{48,74}$. Apparently at relatively low $\mathrm{P}_{\mathrm{CO}}$ (and thus high $\mathrm{P}_{\mathrm{CO}}$ ), the coverage of the surface with $\mathrm{CO}_{2}$-derived $\mathrm{CO}$ is already sufficient, and having additional $\mathrm{CO}$ leads to suboptimal deviation of the optimized $\mathrm{CO} / \mathrm{H}$ surface ratio.

A negative effect of $\mathrm{CO}$ on the conversion of $\mathrm{CO}_{2}$ to methane is apparent over the entire range of partial pressures, but most prominently apparent at a $\mathrm{P}_{\mathrm{CO}}$ of $\sim 0.8$. This is contrary to observations in ref. ${ }^{79}$, where CO reduction was determined to lead to the highest rate, rather than reduction of $\mathrm{CO}_{2}$. We discovered that this discrepancy could be attributed to the effect of the $\mathrm{pH}$ of the electrolyte on methane formation. The formation of methane is highly dependent on availability of protons or hydrogen ${ }^{80}$. The mentioned study ${ }^{71}$ was conducted in $0.1 \mathrm{M} \mathrm{K}_{2} \mathrm{HPO}_{4} / \mathrm{KH}_{2} \mathrm{PO}_{4}$ electrolyte ( $\mathrm{pH}=6.9$ ), while we used the more basic $0.1 \mathrm{M} \mathrm{KHCO}_{3}(\mathrm{pH}=8.4)$. Consequently, in our study the alkalinity of the electrolyte likely suppressed methane formation in the reduction of CO. This effect will be discussed in more detail in section 3.3.

\section{The effect of electrolyte anion on CORR}

Since not only the $\mathrm{P}_{\mathrm{Co}}$, but also the local $\mathrm{pH}$ is likely to affect the surface coverage of $\mathrm{CO}$, we studied the effect of the anion composition of the electrolyte on the performance of the oxide derived copper surface. To assess the effect of anionic species associated with potassium on the $\mathrm{CO}$ reduction activity, the Faradaic efficiencies and partial current densities (See Figures S4 and S5) of the reduction products were measured at the potential range of -0.4 to $-1.4 \mathrm{~V}$ in various electrolytes. Anionic species such as $\mathrm{ClO}_{4}^{-}, \mathrm{HCO}_{3}{ }^{-}$and $\mathrm{H}_{2} \mathrm{PO}_{4}{ }^{-}$greatly affect the selectivity of the CORR products due to their different buffering strengths ${ }^{80}$. Phosphate buffers and $0.1 \mathrm{M} \mathrm{KOH}$ were employed to minimize the changes of local $\mathrm{pH}$ due to the generated $\mathrm{OH}^{-}$at the electrode surface during the CORR from 


\section{Chapter 4}

hydrogen and hydrocarbon formation. In the presence of a buffering anion, the released $\mathrm{OH}^{-}$is instantly neutralized by the following reactions:

$$
\begin{aligned}
& \mathrm{OH}^{-}+\mathrm{HCO}_{3}^{-} \rightarrow \mathrm{H}_{2} \mathrm{O}+\mathrm{CO}_{3}^{2-} \\
& \mathrm{OH}^{-}+\mathrm{H}_{2} \mathrm{PO}_{4}^{-} \rightarrow \mathrm{H}_{2} \mathrm{O}+\mathrm{HPO}_{4}^{2-}
\end{aligned}
$$

On the other hand, the low buffer capacity of $0.1 \mathrm{M} \mathrm{KHCO}_{3}$ and non-buffering capacity of $\mathrm{KClO}_{4}$ solutions, would result in significant enhancement of the $\mathrm{pH}$ near the electrode surface during the CORR.

Table 1 shows the bulk $\mathrm{pH}$ and resistance of the $0.1 \mathrm{M}$ electrolyte solutions prior to electrochemical reactions.

Table 1. $\mathrm{pH}$ and resistance of various $0.1 \mathrm{M}$ electrolyte electrolytes.

$\begin{array}{cccccc}\text { electrolyte } & \mathbf{K H}_{2} \mathbf{P O}_{4} & \mathbf{K H}_{2} \mathbf{P O}_{4} / \mathbf{K}_{2} \mathbf{H P O}_{4} & \mathbf{K C l O}_{4} & \mathbf{K H C O}_{3} & \mathbf{K O H} \\ \mathrm{pH} & 4.6 & 5.9 & 5.9 & 8.4 & 13 \\ \text { Resistance } & 86 & 78 & 64 & 78 & 34\end{array}$

$(\Omega)$

Despite minimizing the $\mathrm{pH}$ changes at the electrode, phosphate which is a strongly adsorbing anion could act as hydrogen donor. As a result, it can negatively affect CORR and promote the hydrogen evolution reaction, based on the following reaction ${ }^{80}$ :

$$
2 \mathrm{H}_{2} \mathrm{PO}_{4}^{-}+2 e^{-} \rightarrow \mathrm{H}_{2}+2 \mathrm{HPO}_{4}^{2-}
$$

Turning now to the experimental evidence, Figure 4 compares the product distribution of CORR in various electrolytes. We begin by examining and explaining ethylene formation. 

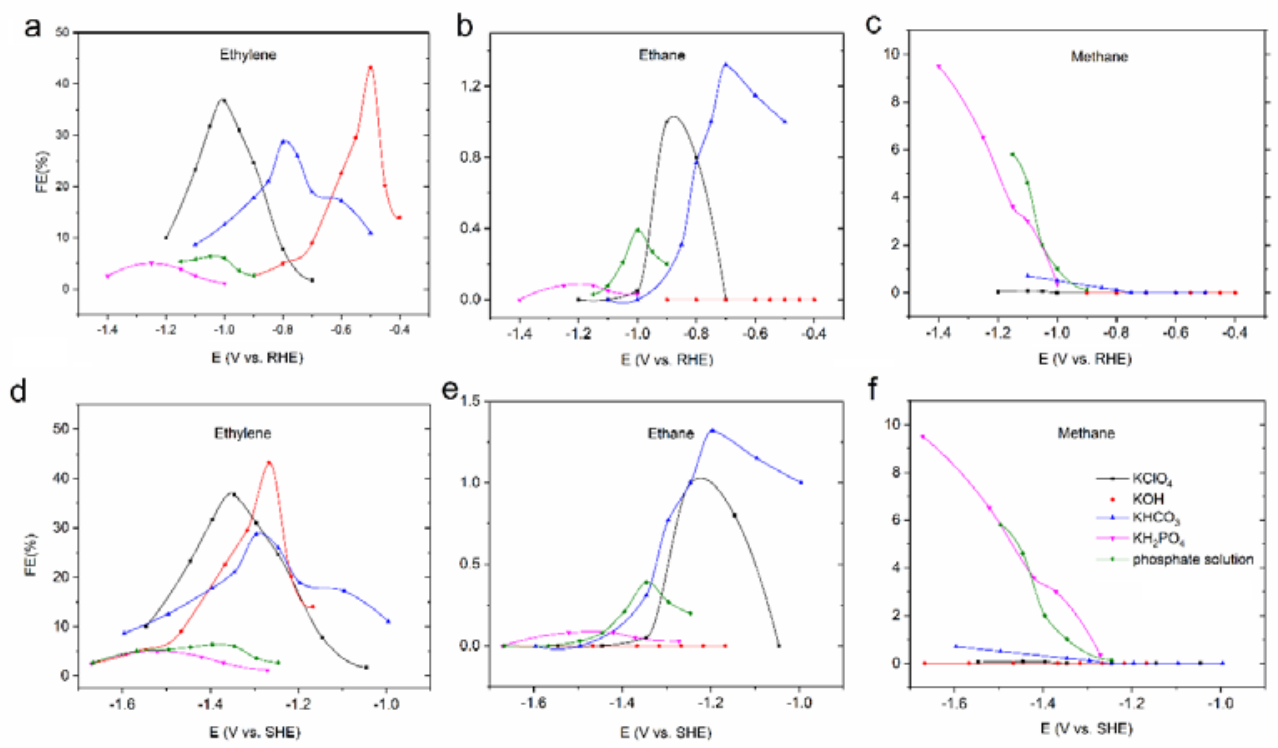

Figure 4. Faradaic efficiencies of ethylene, ethane and methane as a function of applied potential in (a, b and c) RHE and (d, e and f) SHE scale in various electrolytes. Potentials were converted to the Standard Hydrogen Electrode (SHE) scale by $V_{\text {vs. } S H E}=V_{\text {measured vs. }}$ $\mathrm{Ag} / \mathrm{AgCl}+0.197$.

Ethylene: In Figure 4a, we can see a significant difference in the position (potential) at which the ethylene optimizes. This is related to the way the data have been plotted, i.e. versus potential on the RHE scale. Figure 4d represents ethylene Faradaic efficiencies on the SHE scale. Comparing Figures 4a and d, it can be seen that ethylene formation is $\mathrm{pH}$ dependent on the RHE scale but (roughly) $\mathrm{pH}$ independent on SHE scale. These results reflect previous analyses of similar data by the groups of Hori and Koper ${ }^{81-83}$. Figure 4(d) shows that the ethylene FE is strongly anion dependent. The highest Faradaic Efficiency was observed for $\mathrm{KOH}(43.2 \%)$, followed by $\mathrm{KClO}_{4}(36.7 \%)$ and $\mathrm{KHCO}_{3}$ (28.7\%), while the phosphate containing solutions hardly resulted in the formation of ethylene. In Figure 5 the values for the FE are plotted against the $\mathrm{pH}$ of the solution, showing an increasing trendline as a function of increasing $\mathrm{pH}$. Clearly the data for $\mathrm{KClO}_{4}$ do not follow the trendline, 


\section{Chapter 4}

suggesting that for this anion, the local $\mathrm{pH}$ near the surface of the electrode is significantly higher than measured in solution, as indicated by the extrapolation (blue dotted arrows) in Figure 5.

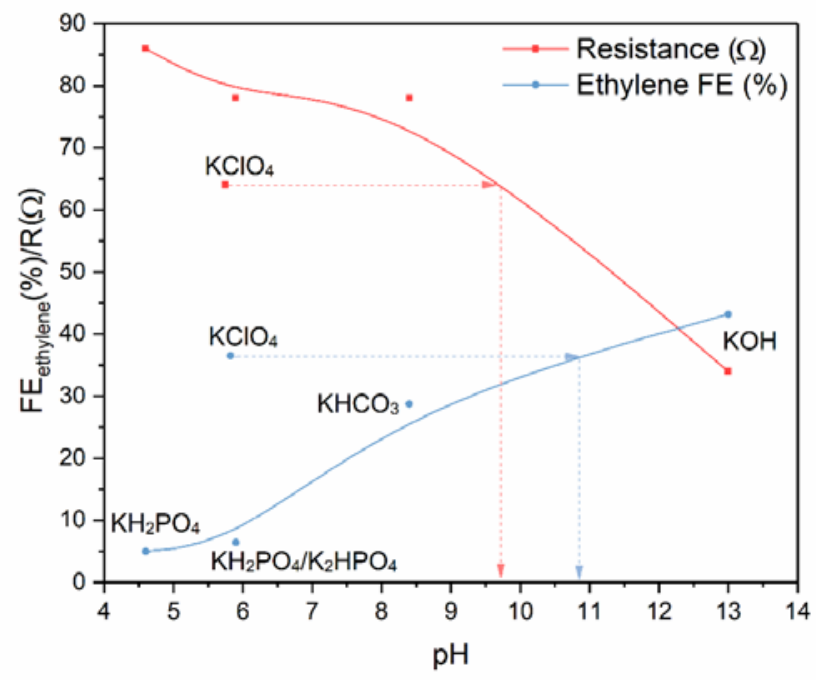

Figure 5. The electrolyte resistance $(\Omega)$, red line, and the highest ethylene faradaic efficiency (\%), blue line, vs. the bulk $\mathrm{pH}$ of various electrolytes. Please note that the $\mathrm{pH}$ near the electrode surface of the $\mathrm{KClO}_{4}$ is likely significantly higher than measured, around 10.8, as indicated by the blue arrows. Furthermore, extrapolation of the resistance value to the trend-line, suggests the $\mathrm{pH}$ is around 9.8 .

The trendline in Figure 5 shows once more how strongly dependent the ethylene formation in $\mathrm{Cu}$-catalyzed reduction is on alkalinity. In addition to electrolyte $\mathrm{pH}$ and buffering capacity, it is necessary to address conductivity as another aspect of the electrolyte. The conductivity may have a significant effect on the total current density $^{84}$. Please note that also the resistance of the solution appears $\mathrm{pH}$ dependent, ranging from 85 to $30 \mathrm{Ohm}$, as shown in Figure 5. What stands out in this graph is that $\mathrm{KClO}_{4}$ did not conform to the overall trend in conductivity, again suggesting that the actual $\mathrm{pH}$ on the electrode surface is higher than the bulk value. Based on 
the relationship between $\mathrm{pH}$, resistance and ethylene efficiency, the actual $\mathrm{pH}$ value can be estimated to be $\sim 9.5-11$.

Hori et al. has suggested that ethylene can be formed by two mechanisms ${ }^{83}$. The first one involves the dimerization of two adsorbed $\mathrm{CH}_{2}$ intermediate species, and in the second one, a Fischer-Tropsch like combination of adsorbed $\mathrm{CH}_{2}$ and $\mathrm{CO}$ plays a role. Recent theoretical and experimental studies have provided strong evidence that ethylene is formed through hydrogenation of surface adsorbed CO to form the CHO intermediate, also a common intermediate in the route towards methane ${ }^{85-86}$. In addition, previous research has established that a $\mathrm{CO}$ dimer is the first intermediate towards ethylene formation ${ }^{87-88}$. Formation of the ${ }^{*} \mathrm{C}_{2} \mathrm{O}_{2}$ dimer consists of CO coupling, mediated by electron transfer. The overall reaction to form ethylene is:

$$
2 \mathrm{CO}+8\left(\mathrm{H}^{+}+e^{-}\right) \rightarrow \mathrm{C}_{2} \mathrm{H}_{4}+2 \mathrm{H}_{2} \mathrm{O}
$$

In conclusion, the effect of the anion can be correlated to the (local) $\mathrm{pH}$; when this is highest, the activity of $\mathrm{C}_{2}$ products is most abundant, consistent with other reports that demonstrate that $\mathrm{OH}^{-}$promotes $\mathrm{C}-\mathrm{C}$ coupling ${ }^{82}$.

Ethane: To date, a few studies have investigated ethane formation which is only observed on very rough copper surfaces. Surface defects associated with roughness most likely favor the reaction of adsorbed hydrogen species crucial for ethane formation ${ }^{83}$. Ethane can be formed through two proposed mechanisms. One pathway involves dimerization of $\mathrm{CO}$ followed by hydrogenation of the ethylene intermediate ${ }^{43,89}$, while the second pathway suggests dimerization of $\mathrm{CH}_{3}$ species ${ }^{90}$ which is also a proposed intermediate for methane formation ${ }^{88}$.

Figure $4 \mathrm{~b}$ compares ethane formation in various electrolytes. From this figure we can see that production of ethane is suppressed in highly alkaline as well as very acidic electrolytes. The highest faradaic efficiency is observed in $0.1 \mathrm{M} \mathrm{KHCO}_{3}$ $\left(\mathrm{pH}=8.4\right.$ ) followed by $0.1 \mathrm{M} \mathrm{KClO}_{4}$ (solution $\mathrm{pH}=5.9$ ). It should be noted that the 


\section{Chapter 4}

local $\mathrm{pH}$ of the latter is likely higher and is possibly moderately basic, supported by experimental evidence of this study. Besides, comparing Figs. 4a,b also revealed a smaller overpotential for the ethane production as opposed to maximum ethylene selectivity, similar to a previous study ${ }^{90}$.

Formation of ethane is highly dependent on adsorbed hydrogen species. High concentrations of adsorbed hydrogen are expected at lower $\mathrm{pH}$. On the other hand, ethane formation also requires dimerization of $\mathrm{CO}\left(\right.$ or $\left.\mathrm{CH}_{3}\right)$, which is enhanced at high $\mathrm{pH}$. As a result, ethane was not significantly formed at the lower $\mathrm{pH}$ range and was inhibited at very high $\mathrm{pH}$.

Turning to Fig 4e, it is apparent that formation of ethane is $\mathrm{pH}$ dependent on the RHE scale but $\mathrm{pH}$ independent on SHE scale, similar to ethylene. It is therefore likely that a shared mechanism exists between ethane and ethylene. However, further studies need to be undertaken to further analyze the formation of ethane, the hydrogenation of ethylene.

Methane: During CORR at low pH, the copper surface is enriched with adsorbed hydrogen species. The availability of protons or hydrogen species favors the formation of methane. As a result, methane formation and hydrogen evolution are major reactions in acidic electrolytes. The hydrogen evolution reaction and formation of adsorbed hydrogen proceeds as follows ${ }^{91-92}$ :

$$
\begin{aligned}
& H^{+}+e \rightarrow H_{a d s} \\
& 2 H_{a d s} \rightarrow H_{2} \\
& H_{a d s}+H^{+}+e \rightarrow H_{2}
\end{aligned}
$$

The methane formation route proceeds through protonation of adsorbed CO to form $\mathrm{CHO}$ or $\mathrm{COH}$ intermediates ${ }^{83}, 93-94$. Previous research has established that breaking of the $\mathrm{C}-\mathrm{O}$ band occurs after protonation of $\mathrm{CO}$ to produce $\mathrm{CHO}$ or $\mathrm{COH}^{83 \text {, }}$ 88 . 
Formation of methane was fully suppressed in basic electrolytes with the exception of $0.1 \mathrm{M} \mathrm{KHCO}_{3}$ where a minor amount of methane was formed (see Figure 4c). Methane formation is correlated with the concentration of adsorbed hydrogen species on the electrode surface. Hence, at lower $\mathrm{pH}$, the enrichment of electrode surface with adsorbed hydrogen makes methane the dominant product. The large amount of methane and small amount of ethylene produced at low $\mathrm{pH}$ values demonstrates that the protonation of CO is favored over the CO dimerization.

Interestingly, solutions of $0.1 \mathrm{M} \mathrm{KClO}_{4}$ and $0.1 \mathrm{M} \mathrm{KH}_{2} \mathrm{PO}_{4} / \mathrm{K}_{2} \mathrm{HPO}_{4}$ buffer have similar $\mathrm{pH}$ of 5.9, yet the local $\mathrm{pH}$ close to the electrode surface of these two differs significantly. As a results, formation of methane was not observed in $\mathrm{KClO}_{4}$, providing further evidence for a rise of local $\mathrm{pH}$ at the electrode surface.

A comparison of the figures $4 \mathrm{c}$ and $\mathrm{f}$ reveals that the onset potential for formation of methane takes place on the same potential on the RHE and SHE scale. However, since we did not carry out further experiments at more negative potentials, the peak of methane formation was not observed and hence we could not derive any conclusions.

\section{In-situ ATR-SEIRAS to study CO adsorption}

To further understand effect of electrolyte anion on the CORR mechanism, ATRSEIRAS was used to investigate $\mathrm{CO}$ adsorption on the $\mathrm{Cu}$ electrode. Figure 6 represents in-situ ATR-SEIRA spectra during CVs from -0.7 to $-1.5 \mathrm{~V}$ vs. Ag/AgCl in $0.1 \mathrm{M}$ solutions of $\mathrm{KH}_{2} \mathrm{PO}_{4}, \mathrm{KClO}_{4}, \mathrm{KHCO}_{3}$ and $\mathrm{KOH}$. Due to the $\mathrm{pH}$ dependence of the RHE, the potentials in this section are reported vs. the Ag/AgCl reference electrode. The reference spectra were taken at $-0.8 \mathrm{~V}$. Figure 7 shows the corresponding integrated areas of $\mathrm{CO}_{\text {atop }}$ bands taken from Figure 6. 


\section{Chapter 4}
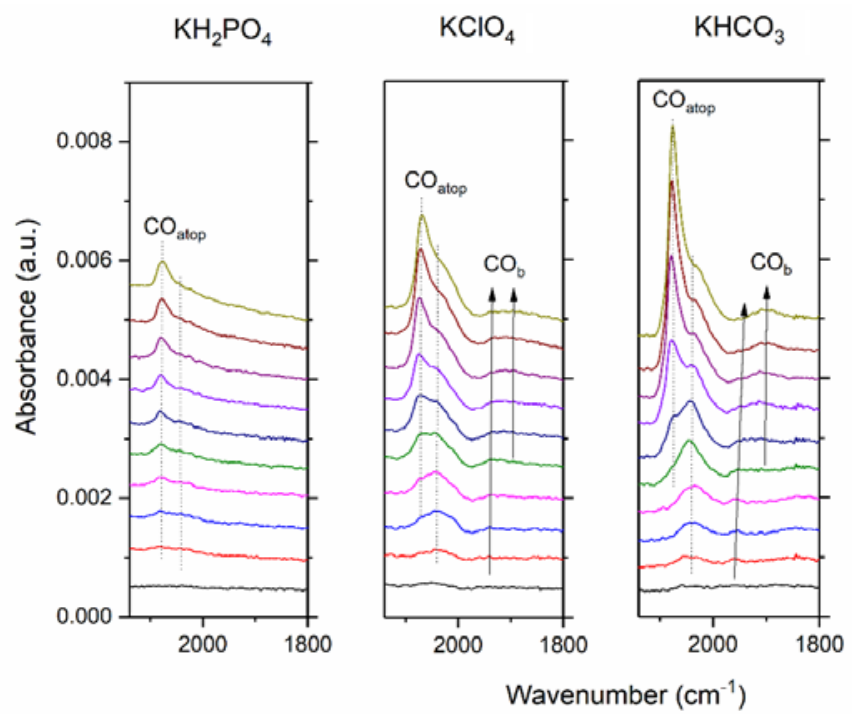

$\mathrm{KOH}$

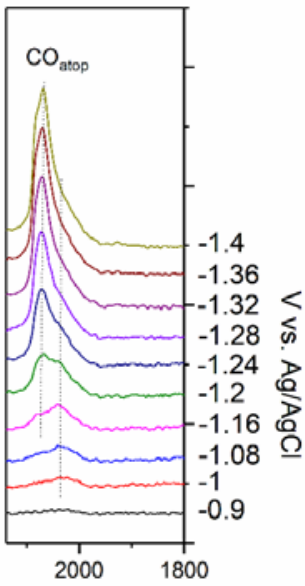

Figure 6. In-situ ATR-SEIRA spectra of $\mathrm{CO}_{\text {atop }}$ and $\mathrm{CO}_{\mathrm{b}}$ as a function of applied potential in CO-saturated $0.1 \mathrm{M} \mathrm{KH}_{2} \mathrm{PO}_{4}, \mathrm{KClO}_{4}, \mathrm{KHCO}_{3}$ and $\mathrm{KOH}$ in $\mathrm{H}_{2} \mathrm{O}$. The reference spectrum was recorded at $-0.8 \mathrm{~V}$.

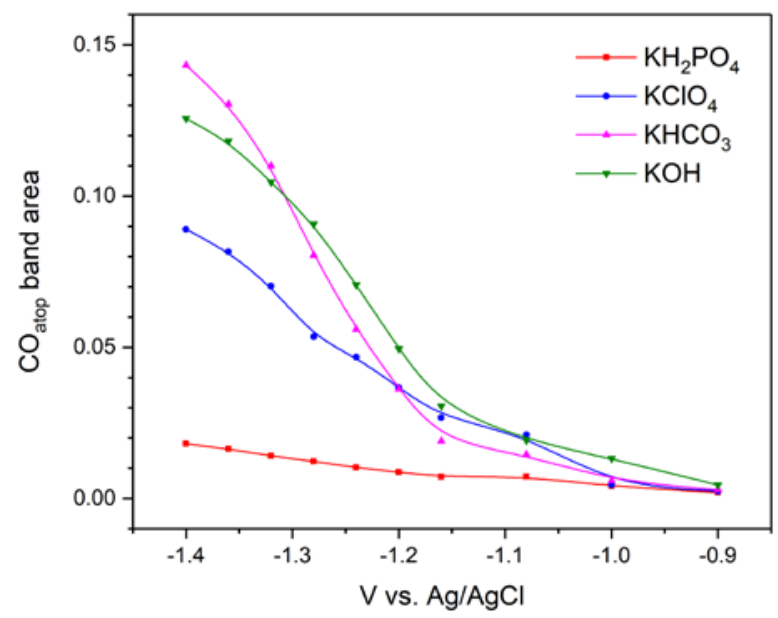

Figure 7. Integrated band area of $\mathrm{CO}_{\text {atop }}$ as a function of applied potential in CO-saturated $0.1 \mathrm{M} \mathrm{KH}_{2} \mathrm{PO}_{4}, \mathrm{KClO}_{4}, \mathrm{KHCO}_{3}$ and $\mathrm{KOH}$ in $\mathrm{H}_{2} \mathrm{O}$, respectively. 
As shown in Figure 6, the band corresponding to linearly bound $\mathrm{CO}$ at an atop site $\left(\mathrm{CO}_{\text {atop }}\right)$ appears at $\sim-1 \mathrm{~V}$ and then gradually increases until the highest value at $-1.4 \mathrm{~V}$. The $\mathrm{CO}_{\text {atop }}$ band consists of two bands at 2040 and $2075 \mathrm{~cm}^{-1}$ attributed to the low frequency band (LFB) and high frequency band (HFB), respectively ${ }^{95}$. The sharp HFB is assigned to CO adsorbed on weakly coordinated defect sites, while the more narrow LFB is attributed to CO adsorption on highly coordinated sites. In $\mathrm{KClO}_{4}$ and $\mathrm{KHCO}_{3}$, bridge-bonded $\mathrm{CO}\left(\mathrm{CO}_{\mathrm{b}}\right)$ can also be observed at 1900 and 1940 $\mathrm{cm}^{-1}$. Based on previous studies, $\mathrm{CO}_{\mathrm{b}}$ is unreactive and predominantly appears under alkaline conditions ${ }^{96-97}$. Analysis of figure 6 further reveals that the onset potential of CO adsorption is not dependent on anion identity, again consistent with literature ${ }^{98}$. In addition, a significant difference between the adsorption intensity of the CO bands is observed as a function of anion.

In the previous section we illustrated the effect of electrolyte anion on catalytic performance and showed that an increasing ethylene FE was achieved in the order of $\mathrm{KH}_{2} \mathrm{PO}_{4}<\mathrm{KHCO}_{3}<\mathrm{KClO}_{4}<\mathrm{KOH}$. Turning to the spectroscopic evidence from Figure 7, it can be seen that the integrated band areas are also strongly dependent on anion identity and increase in the order of $\mathrm{KH}_{2} \mathrm{PO}_{4}<\mathrm{KClO}_{4}<\mathrm{KHCO}_{3}<\mathrm{KOH}$. It is now well established from a variety of studies that the integrated band area of $\mathrm{CO}$ is proportional to $\mathrm{CO}$ coverage ${ }^{99-101}$. Based on this, observing the lowest $\mathrm{CO}_{\text {atop }}$ band area (and consequently the $\mathrm{CO}$ coverage) for $\mathrm{KH}_{2} \mathrm{PO}_{4}$ is consistent with the low formation of $\mathrm{C}_{2}$ products and relatively high methane production. At low $\mathrm{CO}$ coverage and high coverage of adsorbed hydrogen (associated with the low $\mathrm{pH}$ ), protonation of $\mathrm{CO}$ is favored over $\mathrm{CO}$ dimerization. On the other hand, the highest $\mathrm{CO}$ coverage in $\mathrm{KOH}$ can explain the high ethylene $\mathrm{FE}$ of $43.2 \%$, since a high $\mathrm{CO}$ coverage on the surface, kinetically favors C-C coupling and ethylene formation ${ }^{102}$. Interestingly, $\mathrm{KClO}_{4}$ showed a relatively low $\mathrm{CO}$ coverage compared to $\mathrm{KHCO}_{3}$ despite having higher ethylene FE. This discrepancy has been proposed to be related to competitive adsorption of the perchlorate anion ${ }^{98}$, but given the high FE towards 


\section{Chapter 4}

ethylene, this appears not very likely. Alternatively, the combination of a low surface coverage with $\mathrm{CO}$ and a superior production of ethylene, could be explained by an enhanced stimulated rate of CO dimerization in perchlorate environment, although the origin of this phenomenon is not yet known ${ }^{103}$.

\subsection{Conclusions}

In summary, we have shown that a high FE towards ethylene in the electrochemical reduction of CO is depending on a delicate balance of the ratio of $\mathrm{CO}$ and $\mathrm{H}$ on the surface of the copper electrodes. This ration can be manipulated by the applied potential, partial pressure of $\mathrm{CO}$ in inert gas, or $\mathrm{CO}_{2}$, and the anion determined (local) $\mathrm{pH}$ near the electrode surface. An optimized FE towards ethylene was obtained using an applied potential of $-1.25 \mathrm{~V}$ vs SHE, a partial pressure of 1.0 atm of $\mathrm{CO}$, and using $\mathrm{KOH}$ as electrolyte. When $\mathrm{CO}_{2}$ is present, a ratio of $0.4 \mathrm{~atm}$ of $\mathrm{CO}$ in $0.6 \mathrm{~atm}$ of $\mathrm{CO}_{2}$ appears optimal, at an applied potential of $-1.1 \mathrm{~V}$ vs RHE.

Further experiments on electrolyte anions confirmed that the concentration of adsorbed hydrogen is associated with the formation of the dominant hydrocarbon. At lower $\mathrm{pH}$ where adsorbed hydrogen is abundant, methane formation is prevalent. At higher $\mathrm{pH}$ where less adsorbed hydrogen is available and C-C coupling is enhanced, ethylene formation is predominant over ethane formation. Moreover, insitu ATR-SEIRAS studies revealed that anions play an important role in determining the $\mathrm{CO}$ surface coverage. It was revealed that with increase in $\mathrm{pH}$, $\mathrm{CO}$ coverage was significantly increased, favoring the CO dimerization pathway towards ethylene. Taken together, these results highlight the significant role of $\mathrm{CO}\left(\mathrm{CO}_{2}\right)$ partial pressure and electrolyte anions in the selective production of hydrocarbons. 


\subsection{Appendix}
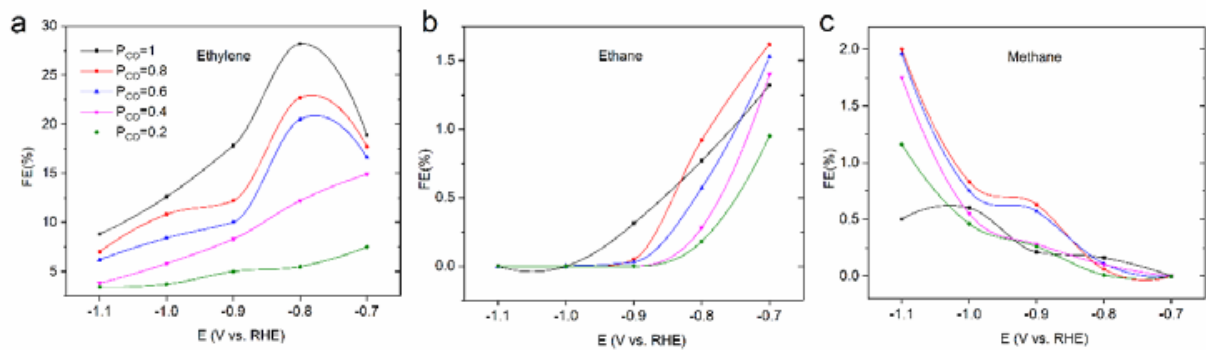

Figure S1. Faradaic efficiency vs. E (V vs. RHE) of a) ethylene, b)ethane and c)methane under varying applied potentials in $0.1 \mathrm{M} \mathrm{KHCO}_{3}$.
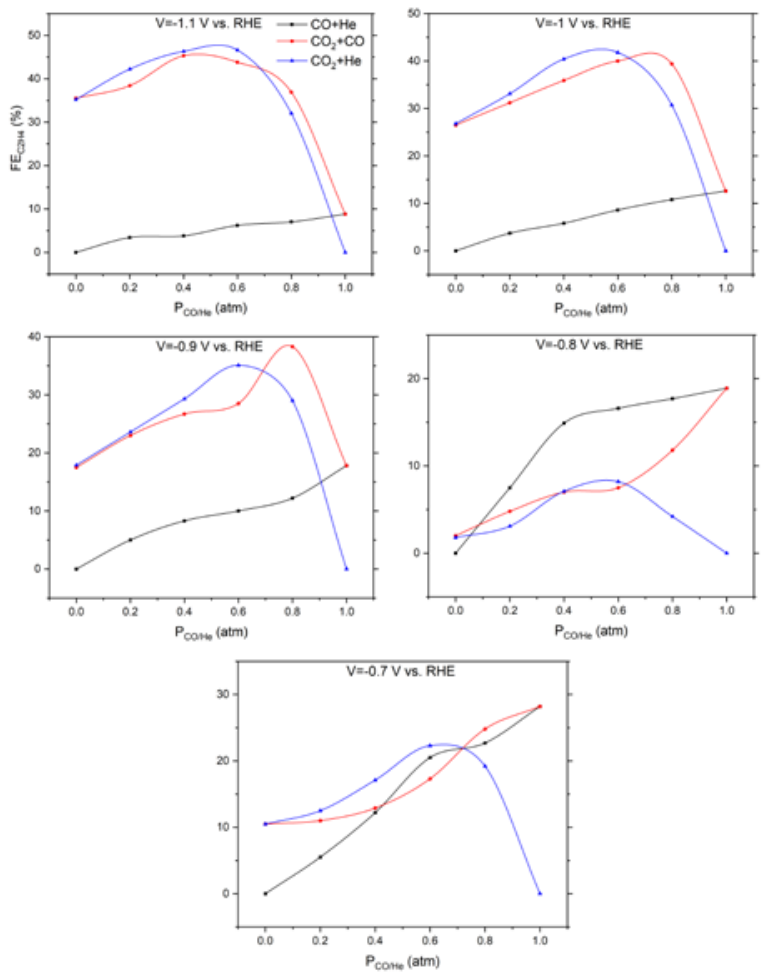

Figure S2. Comparison of Faradaic efficiency of ethylene vs. $\mathrm{P}_{\mathrm{CO}}$ (for $\mathrm{CO} / \mathrm{He}$ and $\mathrm{CO} / \mathrm{CO}_{2}$ mixtures) or $\mathrm{P}_{\mathrm{He}}$ (for $\mathrm{CO}_{2} / \mathrm{He}$ mixtures) at various potentials. 


\section{Chapter 4}
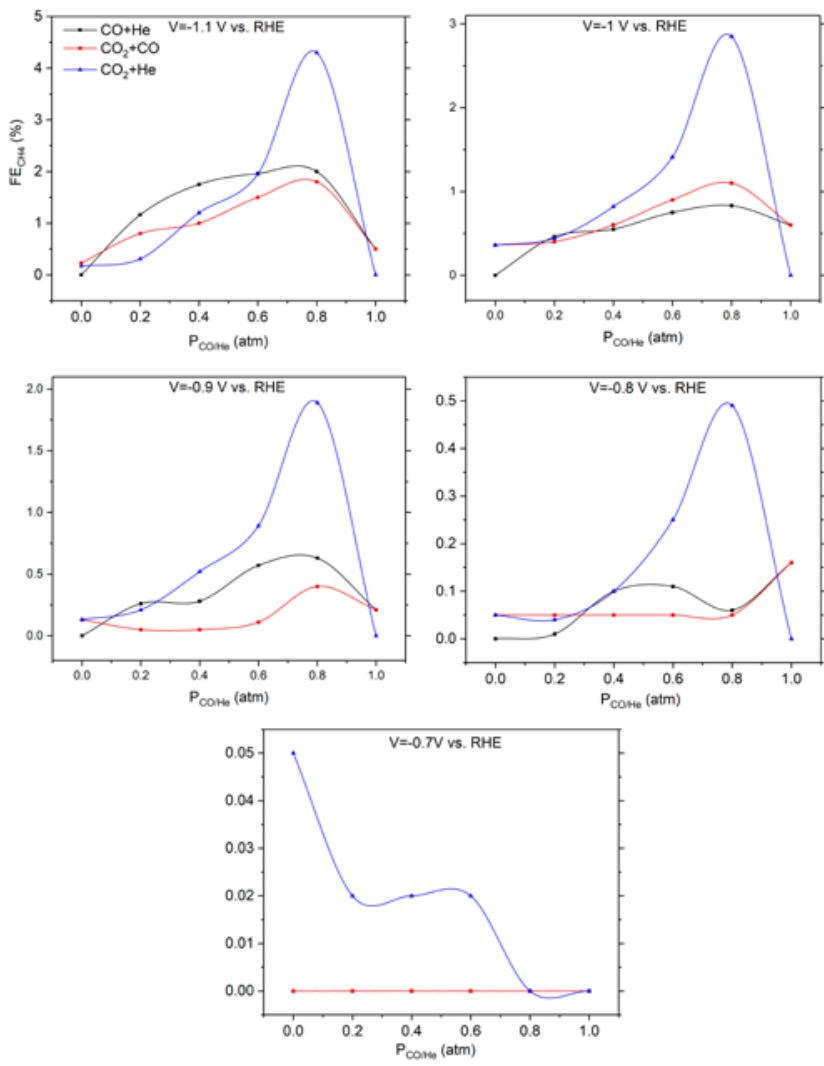

Figure S3. Comparison of Faradaic efficiency of methane vs. $\mathrm{P}_{\mathrm{CO}}$ (for $\mathrm{CO} / \mathrm{He}$ and $\mathrm{CO} / \mathrm{CO}_{2}$ mixtures) or $\mathrm{P}_{\mathrm{He}}$ (for $\mathrm{CO}_{2} / \mathrm{He}$ mixtures) at various potentials.

a

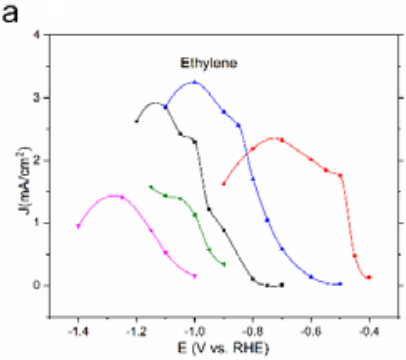

b

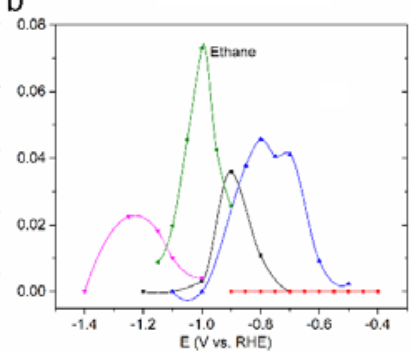

C

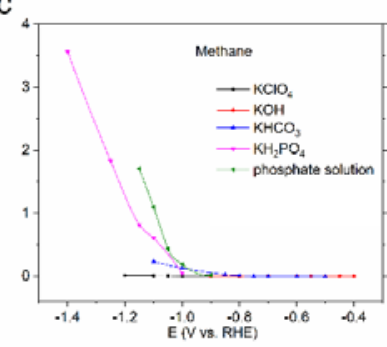

Figure S4. (a, b and c) partial current densities of ethylene, ethane and methane as a function of applied potential in various electrolytes. 
Optimizing CO coverage on rough copper electrodes: Effect of the partial ...
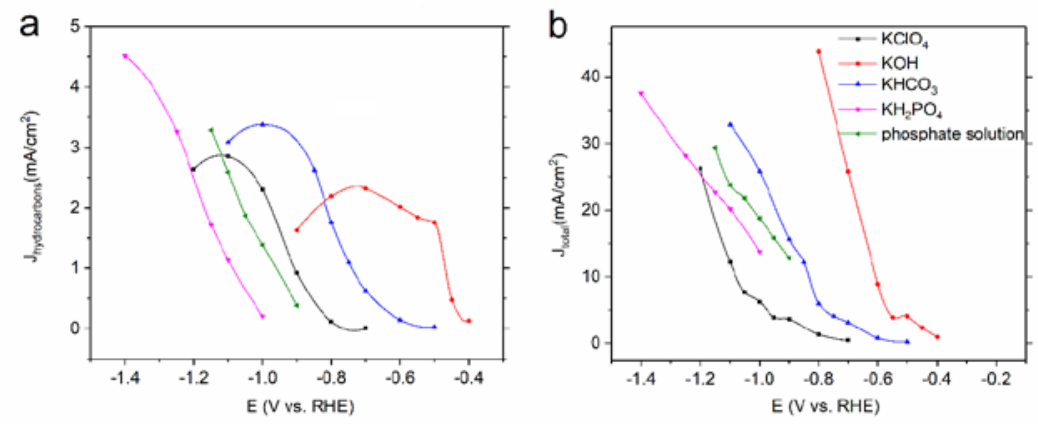

Figure S5. (a) Sum of hydrocarbons partial current densities and (b) total current densities as a function of applied potential in various electrolytes 
Chapter 4 


\title{
Chapter 5.
}

\section{Infrared analysis of interfacial}

\section{phenomena during electrochemical}

\section{reduction of $\mathrm{CO}_{2}$ over polycrystalline}

\author{
copper electrodes
}

\begin{abstract}
Using ATR infrared spectroscopy and $\sim 10 \mathrm{~nm}$ thick, sputtered Cu-films on single bounce Si-ATR-crystals, we have analyzed the electrochemical conversion of $\mathrm{CO}_{2}$ in $\mathrm{NaOH} / \mathrm{D}_{2} \mathrm{O}$ solutions. By using cyclic voltammetry, transitions in selectivity of surface-adsorbed species could be identified. At highly negative potential (more negative than $-1.2 \mathrm{~V}$ (vs. RHE)) the formation of $\mathrm{OD}^{-}$and $\mathrm{D}_{2}$ is dominant, resulting in a relatively high concentration of carbonate in solution near the interface, with a maximum in IR intensity at $\sim 1410 \mathrm{~cm}^{-1}$. When the potential is less negative than -
\end{abstract}




\section{Chapter 5}

$1.2 \mathrm{~V}$, spectroscopically resolved interconversion of carbonate $\left(\mathrm{CO}_{3}^{2-}\right)$ to bicarbonate (D) $\mathrm{CO}_{3}^{-}$is evident, explained by a decrease in local $\mathrm{pH}$. Furthermore, in a potential range of -1.2 to $-0.5 \mathrm{~V}$ (vs RHE), using $\mathrm{D}_{2} \mathrm{O}$, the recently proposed $\mathrm{CO}_{2}$ Dimer-Radical-Anion was observed on polycrystalline copper films. We also assign a previously unresolved band at $\sim 1610 \mathrm{~cm}^{-1}$ to this species. The dimer disproportionates to $\mathrm{CO}$ and $\mathrm{CO}_{3}^{2-}$, the latter being converted to bi-carbonate. Adsorbed CO is sensitive to a Stark shift. i.e. a shift as function of applied potential. Eventually, CO disappears, and the infrared signature of (dissolved) formate at $\sim 1590 \mathrm{~cm}^{-1}$ appears at $\sim-0.5 \mathrm{~V}$. We discuss the spectra and chemistry in detail, based on reference spectra of carbonate, bicarbonate and formate, and using ${ }^{13} \mathrm{CO}_{2}$ to substantiate the formation of the dimer. The results are discussed and compared to recent literature on infrared analysis of electrochemical reduction of $\mathrm{CO}_{2}$.

\subsection{Introduction}

Surface enhanced infrared absorption spectroscopy (SEIRAS) combined with attenuated total reflection (ATR) FTIR, is a very sensitive method for investigation of electrocatalytically active surfaces ${ }^{104}$. One of the applications of this technique is the operando study of the electrochemical reduction of $\mathrm{CO}_{2}\left(\mathrm{ER}-\mathrm{CO}_{2}\right)^{99,105-112}$. The mechanism of ER- $\mathrm{CO}_{2}$ on $\mathrm{Cu}$ is quite complex, and includes various, voltagedependent reaction intermediates and products ${ }^{23}$, 52, 113. In addition, the electrochemical potential is known to induce significant changes in interfacial $\mathrm{pH}$ values, as well as spectroscopic shifts due to the so-called Stark effect, which predicts that spectral lines of molecules shift due to the presence of an external electric field. SEIRAS is responsive to these changes, and surface-adsorbed molecules relevant to $\mathrm{ER}-\mathrm{CO}_{2}$ such as $\mathrm{CO}, \mathrm{HCO}_{3}^{-}, \mathrm{CO}_{3}^{2-}$ and $\mathrm{HCOO}^{-}$, can be distinguished, since these exhibit different, highly IR active vibrational modes ${ }^{114}$. It should, however, be mentioned that all previous studies applying SEIRAS predominantly identified final products in various concentrations as a function of electrolyte, $\mathrm{CO}_{2}$ partial pressure, and applied voltage, while (short-lived) 
intermediates have not been clearly identified. Furthermore, while spectral assignments have been made, these are often ambiguous as a result of overlap of the $\mathrm{O}-\mathrm{H}$ bending mode of water with vibrations of products and intermediates in the critical wavenumber region between $1700-1550 \mathrm{~cm}^{-1115}$. Besides, extreme care must be taken not to mistake commonly occurring (local pH dependent) bicarbonate bands for developing adsorbed intermediates. Fortunately, several assignments have been corroborated by isotopic labeling using ${ }^{13} \mathrm{CO}_{2}{ }^{108,116-117}$.

In this study, further clarity in spectral development has been achieved by using $\mathrm{D}_{2} \mathrm{O}$ solutions. Combination of ATR-SEIRAS, isotopic labeling of $\mathrm{CO}_{2}\left({ }^{13} \mathrm{CO}_{2}\right)$ and use of $\mathrm{D}_{2} \mathrm{O}$ enabled a thorough investigation of voltage dependent dynamic chemical changes at the electrode-electrolyte interface in alkaline conditions. We will demonstrate that both, surface adsorbed species and species present at the interface in solution, can be monitored. This study makes several original contributions to a more detailed interpretation of spectra, in comparison to the existing literature. Most importantly, the present research explores the presence of the $\mathrm{CO}_{2}$ dimer-radicalanion on roughened copper surfaces in protic conditions. This dimer is commonly advocated in the literature for reduction of $\mathrm{CO}_{2}$ in aprotic conditions, and was only previously proposed in protic (aqueous) conditions to explain the behavior of $\mathrm{Cu}$ nanoparticles in visible light sensitized ER- $\mathrm{CO}_{2}{ }^{117}$. In addition, we identify (qualitatively) local pH changes in the boundary layer near the electrode surface, by analysis of the interconversion of carbonate to bicarbonate, and formic acid to formate. Finally, we show that at relatively small negative potentials, formation of formate is accompanied by formation of adsorbed carbonate species. 


\section{Chapter 5}

\subsection{Experimental Section}

\section{Thin film preparation and characterization}

$\mathrm{Cu}$ thin-film electrodes were prepared by magnetron sputtering from a copper source, directly onto the reflecting plane of a $45^{\circ}$ silicon ATR crystal. The sputtering was carried out using an argon flow of $25 \mathrm{ml} / \mathrm{min}$, and applying a power of $30 \mathrm{~W}$. These relatively mild conditions result in a sputtering rate of $0.044 \mathrm{~nm} / \mathrm{s}$. Since the time of sputtering was set at $270 \mathrm{~s}$, a film thickness of $12 \mathrm{~nm}$ was produced after 270 s. The resistance of each film tested across a $1.5 \mathrm{~cm}$ length of the layer was around $8 \Omega$. Surface characterization of the copper film was carried out using atomic force microscopy (AFM). The working mode of the applied AFM system (Cypher, Oxford Instruments), was amplitude modulation, with a NSC36 double side probe coated cantilever, and the measurements were carried out in air.

\section{Electrochemical Measurements}

All electrochemical experiments were performed in a custom-made threeelectrode cell, with the Cu film being used as the working electrode. A graphite rod, rather than a Pt wire, was used as counter electrode to eliminate any possible Pt contaminations on the working electrode, while a $\mathrm{Ag} / \mathrm{AgCl}$ electrode $(3 \mathrm{M} \mathrm{NaCl}$, BASi) was used as reference electrode. A VersaSTAT 3 potentiostat was used to perform electrochemical measurements. The experiments were conducted in a Bruker Vertex 70 spectrometer equipped with a liquid nitrogen-cooled MCT detector and a Veemax III ATR accessory. The electrolyte consisted of $0.1 \mathrm{M} \mathrm{NaOH}$ in $\mathrm{D}_{2} \mathrm{O}$ (Sigma, 99.9 atom \% D) and prior to each experiment, $\mathrm{CO}_{2}\left(\right.$ or ${ }^{13} \mathrm{CO}_{2}$ ) was bubbled through for 15 minutes to saturate the solution. The $\mathrm{Cu}$ films were activated by three cycles between 0.6 and $-0.6 \mathrm{~V}$ in the $0.1 \mathrm{M} \mathrm{NaOH}$ in $\mathrm{D}_{2} \mathrm{O}$ electrolyte, in order to improve the signal. During these cycles the development of large peaks ranging from 1500 to $1553 \mathrm{~cm}^{-1}$ (the position was dependent on potential) was observed, together with a peak at around $1230 \mathrm{~cm}^{-1}$. These peaks can be assigned to adsorbed carbonate, as will be discussed in the following section. These species thus 
already existed on the electrode surface before the (spectroscopically monitored) cyclic voltammetry (CV) was carried out. A reference spectrum was recorded and spectra were taken with $4 \mathrm{~cm}^{-1}$ resolution during a $\mathrm{CV}$ with a typical scan rate of 3 $\mathrm{mV} / \mathrm{sec}$, under continuous purge of $\mathrm{CO}_{2}$ (or ${ }^{13} \mathrm{CO}_{2}$ ).

The reason for choosing $\mathrm{NaOH}$ over bicarbonate, was to allow experiments in a ${ }^{13} \mathrm{CO}_{2}$ atmosphere. In bicarbonate solutions, rapid scrambling of ${ }^{13} \mathrm{CO}_{2}$ with $\mathrm{H}^{12} \mathrm{CO}_{3}{ }^{-}$ can be expected, which reduces the spectral intensity of ${ }^{13} \mathrm{C}$-labeled products and intermediates, complicating interpretation. The spectra are shown in (reflectance) absorbance units, where positive bands represent the formation, and negative bands the decomposition of interfacial species. All the potentials were converted to the Reversible Hydrogen Electrode (RHE) scale by $\mathrm{V}_{\text {vs. } \mathrm{RHE}}=\mathrm{V}_{\text {measured vs. } \mathrm{Ag} / \mathrm{AgCl}}+0.198+$ $0.059 *$ ( $\mathrm{pH}$ of solution).

\subsection{Results and Discussion}

\section{Surface characterization of copper films}

In order to estimate the thickness and to study the morphology of the sputtered copper films on ATR crystals, Atomic Force Microscopy (AFM) was used. Figures 1 and S1 illustrate some main characteristics of the film. As can be seen in Figure $1 \mathrm{a}$, a rough landscape of metallic copper was formed during the sputtering process. AFM images also reveal a diameter of elevated areas of approximately $\sim 30 \mathrm{~nm}$ and a film thickness of $\sim 12 \mathrm{~nm}$. This rough structure provides strong surface IR enhancement effects, crucial for SEIRAS studies, and allowed us to probe chemical changes during cyclic voltammetry of the $\mathrm{ER}-\mathrm{CO}_{2}$ with high sensitivity. The observed film thickness of $\sim 12 \mathrm{~nm}$, is in good agreement with the theoretically calculated film thickness on the basis of the rate and time of the sputtering procedure. 


\section{Chapter 5}

(a)

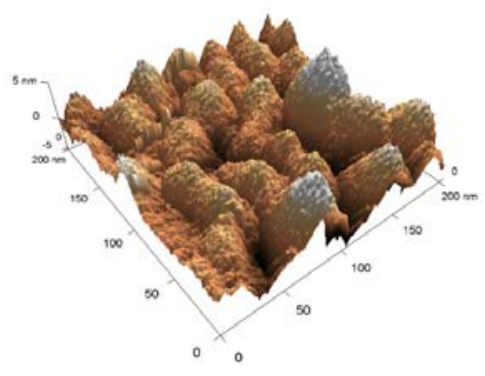

(b)

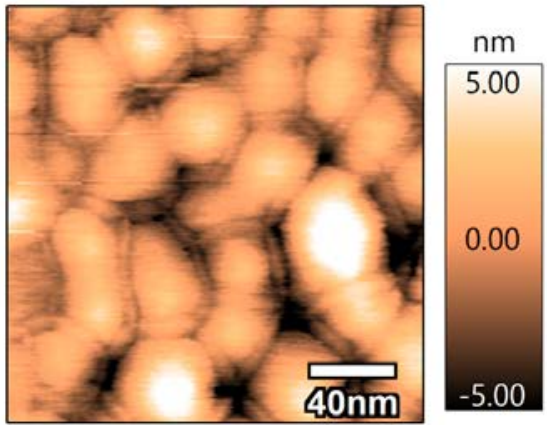

Figure 1. $200 \mathrm{~nm} \times 200 \mathrm{~nm}$ AFM images of the Cu film sputtered on the applied Si crystal in (a) three-dimensional and (b) two-dimensional view.

\section{Cathodic scans (to more negative potential)}

The potential dependent spectra of species interacting with the $\mathrm{Cu}$ surface in $\mathrm{CO}_{2}$ saturated $0.1 \mathrm{M} \mathrm{NaOH}$ from -0.24 (at which potential the background was recorded) to $-1.18 \mathrm{~V}$ can be seen in Figure 2. While scanning towards more negative potentials, various bands can be identified in the range of 2200-1200 $\mathrm{cm}^{-1}$. Initially, a negative band develops around $1517 \mathrm{~cm}^{-1}$, accompanied by formation of a positive peak around $1592 \mathrm{~cm}^{-1}$. In the fourth spectrum and-up, several bands appear in the 2100 $\mathrm{cm}^{-1}$ to $1800 \mathrm{~cm}^{-1}$ region, accompanied by a negative shoulder on the $1592 \mathrm{~cm}^{-1}$ band $\left(1610 \mathrm{~cm}^{-1}\right)$, and formation of two dominant bands at $1627 \mathrm{~cm}^{-1}$ and $1366 \mathrm{~cm}^{-1}$. The latter peak position is likely affected by a few negative contributions. The bands in the $2100 \mathrm{~cm}^{-1}$ to $1800 \mathrm{~cm}^{-1}$ region maximize and disappear, while the $1627 \mathrm{~cm}^{-1}$ and $1366 \mathrm{~cm}^{-1}$ show continuous growth. Several minor changes in the spectra can also be observed, but these are better resolved in anodic scans (to more positive potential), and will be addressed accordingly. In the following we will interpret the observations during negative scans based on decreasing wavenumber. 


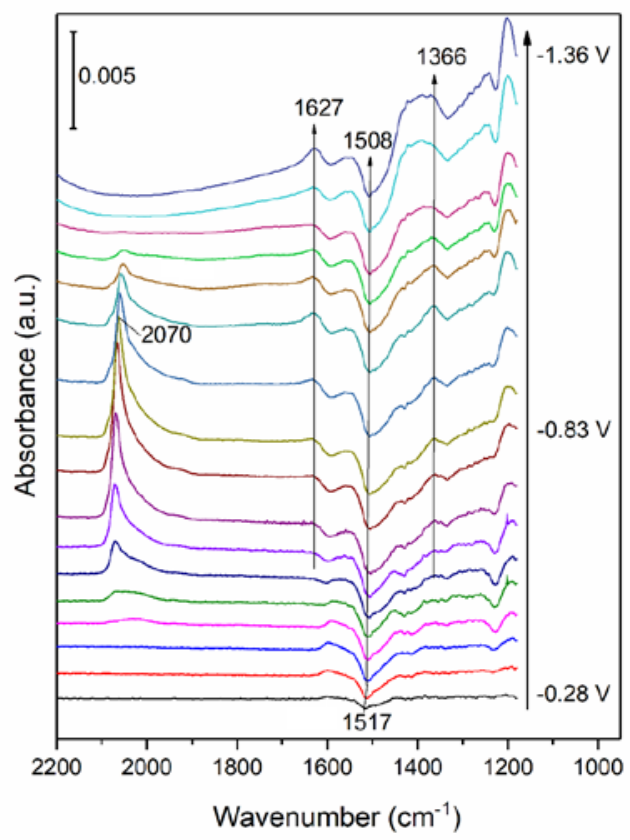

Figure 2. ATR spectra of the $\mathrm{Cu}$ thin film during a negative scan in $\mathrm{CO}_{2}$ saturated in 0.1 $\mathrm{M} \mathrm{NaOH}$-containing $\mathrm{D}_{2} \mathrm{O}$ solution. The applied reference spectrum was recorded at $-0.24 \mathrm{~V}$. The potential interval between spectra is $\sim 0.07 \mathrm{mV}$.

\section{$2200-1800 \mathrm{~cm}^{-1}$ : Formation of CO}

In the higher range of wavenumbers a shouldered band apparent in a relatively large range of potentials, can be assigned to various configurations of adsorbed CO. A sharp band maximizing at $2070 \mathrm{~cm}^{-1}$ developed next to a shoulder at around 2040 $\mathrm{cm}^{-1}$. These peaks have been interpreted as the low frequency band (LFB) and the high frequency band (HFB) of atop-bound CO, respectively ${ }^{95}$. Figure 3 shows an overview of the development in intensity (height), as well as peak position of these two bands as a function of applied potential. From this graph it is evident that the HFB position, which was initially observed at $2070 \mathrm{~cm}^{-1}$, red-shifts to lower 


\section{Chapter 5}

wavenumber, when the potential is swept negatively, consistent with previous findings ${ }^{108,118-119}$. This shift is related to the so-called Stark effect, which predicts that spectral lines of molecules shift due to the presence of an external electric field. An oscillating dipole will have different resonant frequencies when immersed in different electric fields, here obvious by a decreasing wavenumber if the potential becomes increasingly more negative. In addition, a broad band at $1935 \mathrm{~cm}^{-1}$ simultaneously develops. This band can be attributed to bridge-bound CO, as previously reported for copper to show vibrations in the $1800-2000 \mathrm{~cm}^{-1}$ region ${ }^{96,120 \text { - }}$ ${ }^{121}$. The broadness, and much lower intensity of this band, makes the correlation between applied potential and position in the spectrum, less evident.

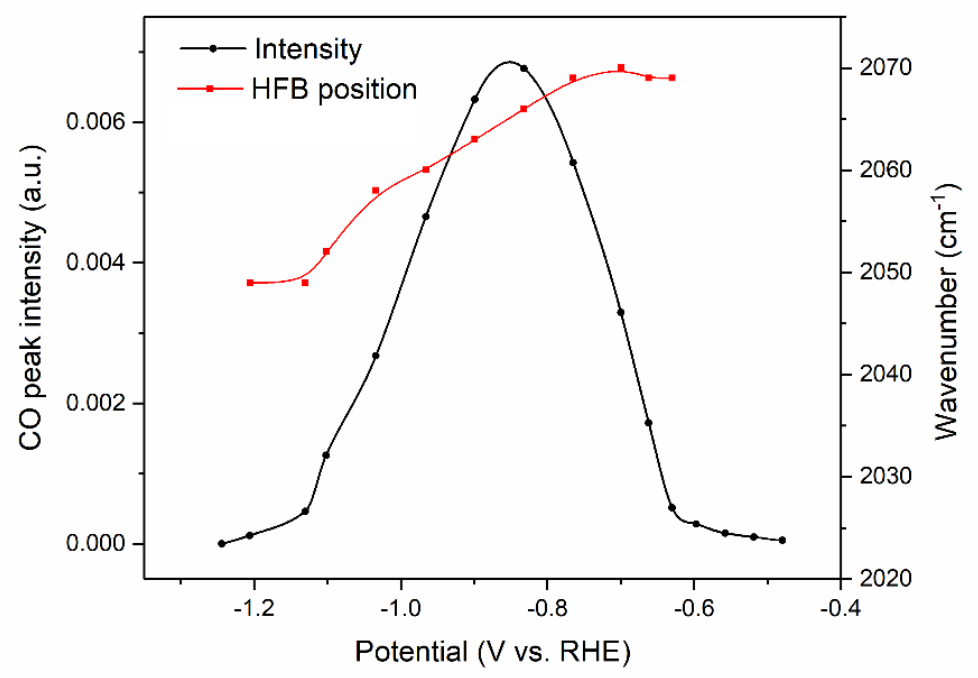

Figure 3. Peak intensity (height) of the shifting maximum of the HFB of CO. The LFB position is difficult to determine, due to the low intensity of this band (not shown).

\section{$1700-1300 \mathrm{~cm}^{-1}$ : Carbonate and bicarbonate}

Turning to lower wavenumbers, the two simultaneously rising bands at 1627 and $1363 \mathrm{~cm}^{-1}$ formed from $-0.7 \mathrm{~V}$ and developing at more negative potentials, are 
assigned to bicarbonate. This agrees with reference spectra recorded for $\mathrm{D}_{2} \mathrm{O}$ and $\mathrm{NaHCO}_{3}$ in $\mathrm{D}_{2} \mathrm{O}$ on a bare Si crystal surface (Figures S2 and S3). After saturation with $\mathrm{CO}_{2}$, the $0.1 \mathrm{M} \mathrm{NaOH}$ electrolyte has converted significantly to bicarbonate (See Figure S4).The negative band with minima in the range of $1517-1508 \mathrm{~cm}^{-1}$ (depending on potential) was previously assigned to desorption of surface-adsorbed carbonate anions. A brief overview of the bicarbonate and carbonate band assignments in recent literature ${ }^{108,119,122-123}$, is summarized in Table 1 . The peak is rather asymmetric, and the (negative) intensity increases at more negative potentials, likely due to increasing electric repulsions, inducing carbonate desorption ${ }^{108}$.

Table 1. Vibrational assignments of bicarbonate and carbonate anions

\begin{tabular}{|c|c|c|c|c|}
\hline Surface & Method & $\begin{array}{c}\text { Band } \\
\text { center }\left(\mathbf{c m}^{-1}\right)\end{array}$ & Species & Assignment \\
\hline $\operatorname{Pt}(111) \quad$ and & IR & 1530 & Adsorbed $\mathrm{CO}_{3}^{2-}$ & \\
\hline $\operatorname{Pt}(110)^{122}$ & & 1410 & Solution $\mathrm{CO}_{3}^{2-}$ & \\
\hline \multirow[t]{4}{*}{$\mathrm{Au}(111)^{123}$} & IRAS & 1397 & Solution $\mathrm{CO}_{3}^{2-}$ & $v_{a(C O 2)}$ \\
\hline & & $1450-1511$ & Adsorbed $\mathrm{CO}_{3}^{2-}$ & \\
\hline & & 1629 & $\mathrm{HCO}_{3}^{-}$ & $v_{a(\mathrm{CO} 2)}$ \\
\hline & & 1362 & $\mathrm{HCO}_{3}^{-}$ & $v_{\mathrm{s}(\mathrm{CO} 2)}$ \\
\hline $\begin{array}{l}\quad \mathrm{Cu}(100) \text { and } \\
\text { polycrystalline } \\
\mathrm{Cu}^{119}\end{array}$ & FTIR & 1545 & Adsorbed $\mathrm{CO}_{3}^{2-}$ & \\
\hline \multirow[t]{2}{*}{$\mathrm{Cu}^{108}$} & ATR- & $1544-1517$ & Adsorbed $\mathrm{CO}_{3}^{2-}$ & \\
\hline & SEIRAS & 1394 & Solution $\mathrm{CO}_{3}^{2-}$ & \\
\hline $\mathrm{NaCO}_{3}$ and & ATR & 1626 & $\mathrm{HCO}_{3}^{-}$ & $v_{a(\mathrm{CO} 2)}$ \\
\hline $\mathrm{NaHCO}_{3}$ as a & & 1365 & $\mathrm{HCO}_{3}^{-}$ & $v_{\mathrm{s}(\mathrm{CO} 2)}$ \\
\hline $\begin{array}{l}\text { reference for this } \\
\text { study }\end{array}$ & & 1410 & Solution $\mathrm{CO}_{3}^{2-}$ & $\mathrm{V}_{\mathrm{a}(\mathrm{CO} 2)}$ \\
\hline
\end{tabular}




\section{Chapter 5}

Further examination of Figure 2 reveals a clear shift in wavenumber from 1517 to $1508 \mathrm{~cm}^{-1}$, a trend which was also observed in previous studies ${ }^{103,108}$. To further probe this behavior, the starting position of the band as a function of initially applied potential was studied and the obtained frequency (wavenumber) at which the peak minimizes at $0.04 \mathrm{mV}$ more negative potential (spectra not shown) is presented in Figure 4. Upon increasing the starting potential of the negative scan, the (negative) band position dramatically shifts to higher wavenumbers. A possible explanation for this red-shift might again be found in the Stark tuning effect ${ }^{118,124}$. Interestingly, there is a significant difference in the slope of the curves in the potentials more negative and more positive than $0 \mathrm{~V}$, which suggests a significant change in electrical field when the voltage turns positive. It should also be mentioned that changes in local $\mathrm{pH}$ as a function of potential, might affect the peak position of adsorbed carbonate. Protonation or deprotonation (upon increasing basicity) of surface adsorbed carbonate is likely, and the degree of protonation will determine the peak position. Finally, the nature of the adsorbed state (monodentate or bidentate) of carbonate might also be potential dependent and determine the observed wavenumber. 


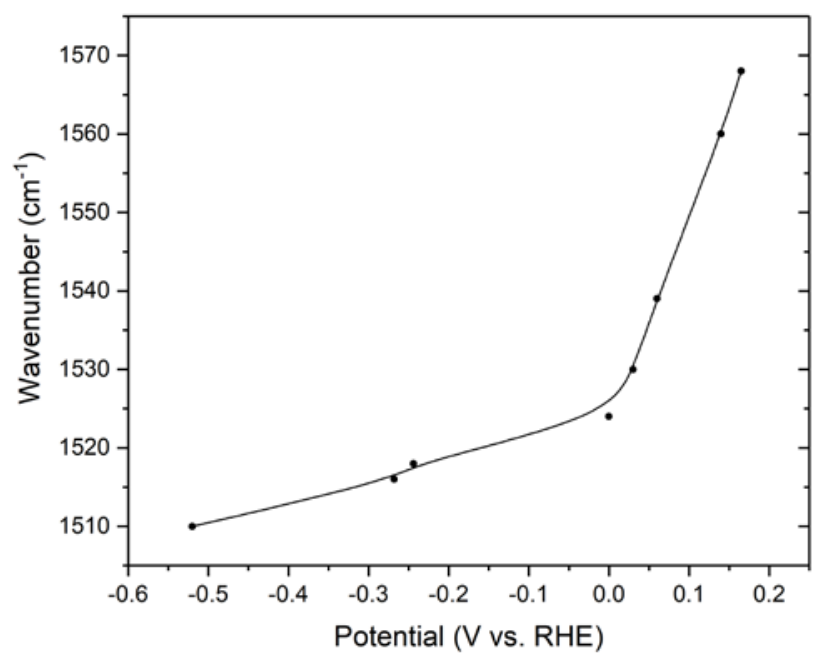

Figure 4. Band position of adsorbed carbonate as a function of potential. The peak position was determined on the basis of changes in peak intensity as follows. First a reference spectrum was recorded at the potential, which is indicated on the x-axis. Then the potential was swept in the direction of (more negative) values at $3 \mathrm{mV} / \mathrm{sec}$, resulting typically in negative contributions in intensity of the adsorbed carbonate. The position of the peak intensity was determined at $0.04 \mathrm{mV}$ more negative than the potential used for recording of the background (and indicated on the $\mathrm{x}$-axis).

In addition to the bicarbonate-carbonate bands, complicated transients in negative intensity of the band around $1592 \mathrm{~cm}^{-1}$ (adjacent to the positive band at $1627 \mathrm{~cm}^{-1}$ ) are apparent in Figure 2. The spectral changes are better resolved in Figure S5, showing spectra in a negative scan direction starting at $0 \mathrm{~V}$. It is apparent from this figure that the position of the band seems potential dependent and also red-shifts if the potential becomes more negative. This band (moving from 1610 to $1584 \mathrm{~cm}^{-1}$ in Figure S5) is likely related to formate, and should not be mistaken for the $\mathrm{O}-\mathrm{H}$ bending mode of water, since we performed experiments in $\mathrm{D}_{2} \mathrm{O}$. Besides, based on reference spectra taken for $\mathrm{H}_{2} \mathrm{O}$ (Figure S2), the bending mode of water is expected around $1640 \mathrm{~cm}^{-1}$. The peak eventually disappears at $-0.63 \mathrm{~V}$, concurrently with 


\section{Chapter 5}

formation of bicarbonate (bands at 1627 and $1365 \mathrm{~cm}^{-1}$ ), in agreement with a shift in selectivity of copper electrodes from formate to CO. The assignment to a vibrational mode of (adsorbed) formate is not straight forward. It cannot be the asymmetric mode of bidentate adsorbed formate, because it is forbidden by the surface selection rule. Assignment to the $\mathrm{C}=\mathrm{O}$ stretching vibration of monodentate adsorbed formate is also unlikely since, (i) this mode has never been observed even in solutions containing large concentrations of formate/formic acid, (ii) formate (anion) adsorption at negative potentials appears unlikely, and (iii) the $\mathrm{C}=\mathrm{O}$ stretching mode of monodentate adsorbed formate would be close to the same mode of formic acid $\left(1710 \mathrm{~cm}^{-1}\right)$. It is more likely that this band corresponds to the asymmetric O-C-O stretching of formate in solution (see Fig S8), and the apparent shift is related to changes in intensity of adjacent spectral features, e.g. due to formation and adsorption of (bi)carbonate.

In the next section, ATR spectra obtained during a positive scan are revealing similar, but more detailed dynamic changes (Figure 5).

\section{Positive (anodic) scans:}

We will now further identify the potential ranges in which the various species appear and disappear in a reverse scan, again in the order of appearance in the spectra. The background (reference) spectrum was recorded at the starting, negative value of the potential.

\section{$2200-1800 \mathrm{~cm}^{-1}$ : Formation of CO}

Figure 5 shows a series of spectra recorded during a scan towards more positive potentials (an anodic scan), for which the reference spectrum was taken at $-1.2 \mathrm{~V}$. At the initial potential of the scan $(-1.2 \mathrm{~V})$, adsorbed $\mathrm{CO}$ was not present, in agreement with Figure 2. The atop-bound CO band grows in as the potential is swept towards more positive values, and then disappears again. The broad peak from $\sim 1900$ to $2000 \mathrm{~cm}^{-1}$ representing the bridge-bound CO is also observed, which did 
not disappear until the end of the scan at $0 \mathrm{~V}$. A strong Stark shift is now also apparent.

\section{$1700-1300 \mathrm{~cm}^{-1}$ : Carbonate and bicarbonate}

In the most interesting region, the pair of bands at 1627 and $1363 \mathrm{~cm}^{-1}$ attributed to bicarbonate develops, while a band at $1410 \mathrm{~cm}^{-1}$ grows in negatively. According to the ATR-IR spectra of $\mathrm{Na}_{2} \mathrm{CO}_{3}$ (Figure S6) and $\mathrm{NaHCO}_{3}$ (Figure S3), as well as the assignments proposed in a number of earlier reports summarized in Table 1 , the band at $1410 \mathrm{~cm}^{-1}$ is assigned to solution-based carbonate anions. This is also in agreement with the absence of a stark shift as a function of increasing (less negative) potential. A possible explanation for the negative growth of this band is a change in the equilibrium composition of $\mathrm{CO}_{2}, \mathrm{HCO}_{3}^{-}$and $\mathrm{CO}_{3}^{2-}$ at the interface (solution boundary layer), which shifts towards bicarbonate if less $\mathrm{OH}^{-}$is formed, induced by reduction in rate of water consuming reductive processes occurring on the surface at more positive potentials (the exact opposite of what was observed in Figure 2) ${ }^{125}$. Previous studies also indicate that carbonate in solution only exists at very negative potentials when the local $\mathrm{pH}$ is high ${ }^{122}$. Starting at $-1.2 \mathrm{~V}$ and during the sweep to more positive potentials, carbonate converts to bicarbonate and $\mathrm{CO}_{2}$. The band at $2342 \mathrm{~cm}^{-1}$ was previously assigned to $\mathrm{CO}_{2}$ dissolved in the electrolyte. The increase in $\mathrm{CO}_{2}$ concentration during the scan is apparent in Figure 5, and is observed due to mass transfer limitations ${ }^{125}$. To further elucidate the interchange of carbonate and bicarbonate, necessary to facilitate the interpretation of the dynamic changes shown in Figure 5, the potential was initiated at $-1.7 \mathrm{~V}$, and scanned towards $-0.9 \mathrm{~V}$. 


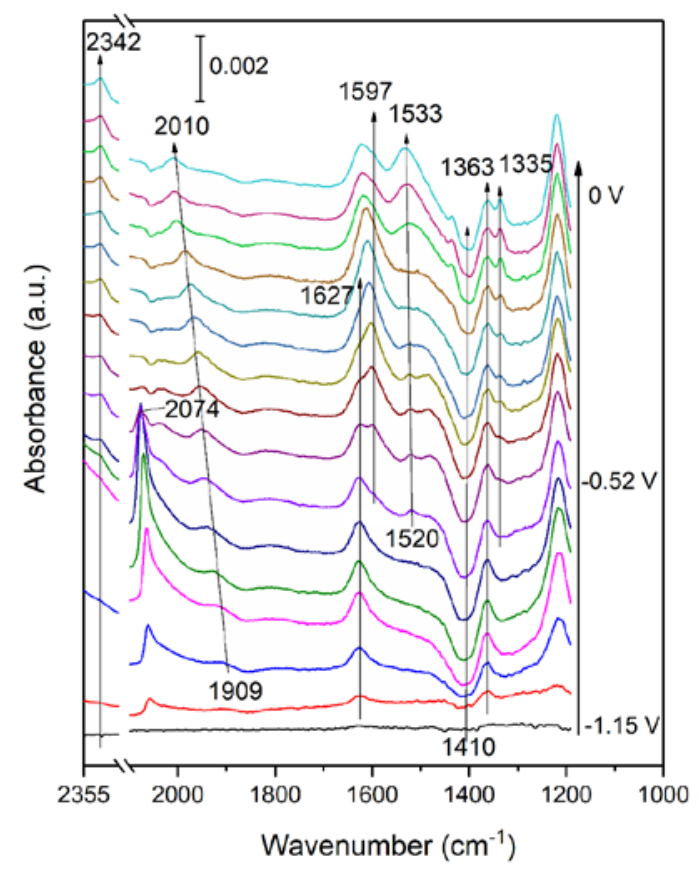

Figure 5. ATR spectra of the $\mathrm{Cu}$ thin film during anodic scan in $\mathrm{CO}_{2}$ saturated $0.1 \mathrm{M}$ $\mathrm{NaOH}$ in $\mathrm{D}_{2} \mathrm{O}$ solution with reference spectrum taken at $-1.2 \mathrm{~V}$.

\section{Interfacial phenomena at potentials ranging from -1.7 to $-0.9 \mathrm{~V}$ :}

At the potential of $-1.7 \mathrm{~V}$, chemistry is dominated by hydrogen $\left(\mathrm{D}_{2}\right)$ evolution, and conversion of $\mathrm{CO}_{2}$ is limited. Starting at this potential, and scanning more positively, allowed us to evaluate changes in local $\mathrm{pH}$ by monitoring the carbonate/bicarbonate equilibrium. The results of the positive scan from -1.7 to -0.9 $\mathrm{V}$ followed by a negative scan back to $-1.7 \mathrm{~V}$ are presented in Figure 6. At $-1.7 \mathrm{~V}$ the local $\mathrm{pH}$ is very basic. Since solution-based carbonate is the dominant species, this suggests that the $\mathrm{pH}$ is at least 11 . Evaluation of the intensity changes of the bicarbonate band at $1627 \mathrm{~cm}^{-1}$ reveals a decrease in $\mathrm{pH}(\mathrm{pK}=10.32)$ at potentials more positive than $-1.7 \mathrm{~V}$, suggesting that transport is not fast enough to cancel any $\mathrm{pH}$ decrease. At potentials more positive than $-1.45 \mathrm{~V}$, the interfacial $\mathrm{pH}$ and the interfacial concentration of bicarbonate will gradually approach that in the bulk, 
which is what Figure 7 is showing. Additionally, the ration in intensity of bicarbonate-carbonate is again changing during a reverse, negative sweep, resulting in a baseline spectrum at $-1.55 \mathrm{~V}$, where hydrogen evolution ( $\mathrm{D}_{2}$ in this case) is again dominant. During the negative scan, the concentration of bicarbonate will decrease, and that of carbonate will increase, showing $\mathrm{pH}$ changes are close to reversible (see Figure 6b). These results confirm the change in equilibrium composition of bicarbonate and carbonate anions in the potential range where $\mathrm{ER}-\mathrm{CO}_{2}$ takes place $^{108}$.

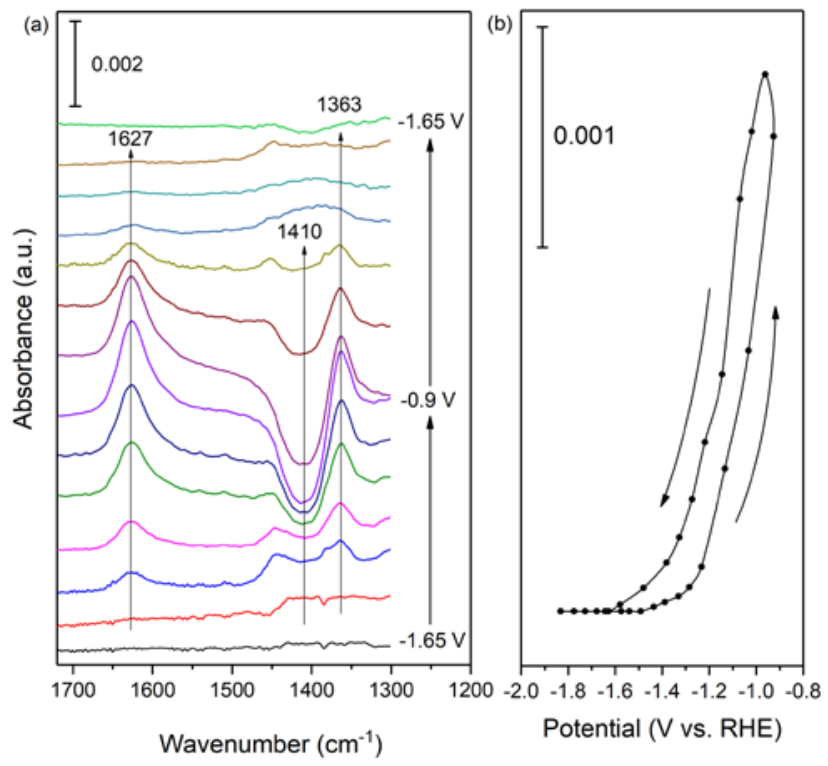

Figure 6. (a) ATR studies of bicarbonate and carbonate during scan from $-1.7 \mathrm{~V}$ to -0.9 $\mathrm{V}$ and back to $-1.7 \mathrm{~V}$ in $\mathrm{CO}_{2}$ saturated $0.1 \mathrm{M} \mathrm{NaOH}$ in $\mathrm{D}_{2} \mathrm{O}$ solution with the reference spectrum taken at $-1.7 \mathrm{~V}$ and (b) $1627 \mathrm{~cm}^{-1}$ band intensity during the $\mathrm{CV}$. The potential interval between spectra is $\sim 0.11 \mathrm{mV}$. Please note that the frequency of the maxima of the various peaks does not shift as a function of applied potential.

Formate and other intermediates 


\section{Chapter 5}

Revisiting Figure 5 and returning to the lower wavenumber region at more positive potentials $(\sim-0.52 \mathrm{~V})$, three additional bands need further interpretation, located at $1597 \mathrm{~cm}^{-1}, 1520-1533 \mathrm{~cm}^{-1}$, and $1335 \mathrm{~cm}^{-1}$. The band at $1597 \mathrm{~cm}^{-1}$ can be assigned to the $\mathrm{C}=\mathrm{O}$ stretching vibration of formate (see Figure S7). The other features of formate at 1351 and $1383 \mathrm{~cm}^{-1}$, assigned to the $v_{\mathrm{s}(\mathrm{OCO})}$ and $\delta_{(\mathrm{CH})}$, respectively, cannot not be easily resolved, due to overlap with the (negative) carbonate band at $1410 \mathrm{~cm}^{-1}$ and overlap with the $1363 \mathrm{~cm}^{-1}$ band of bicarbonate. Table 2 provides an overview of formate band assignments from previous studies ${ }^{126-}$ ${ }^{132}$. In addition, Figures S8 show dynamic changes in formic acid/formate peak positions when a potential is applied. These data are also included in Table 2. The band at $1520-1533 \mathrm{~cm}^{-1}$ has been extensively discussed (see Figure 4) and can be assigned to (protonated) surface adsorbed carbonate, now appearing as a positive band due the potential at which the background was recorded. The band at $1335 \mathrm{~cm}^{-}$ ${ }^{1}$ is the most difficult to assign. To demonstrate this band is related to reduction of $\mathrm{CO}_{2}$, we will now discuss spectra obtained by isotopic labeling.

\section{Isotopic labeling}

The spectra shown in Figure 7 were obtained by purging ${ }^{13} \mathrm{CO}_{2}$ gas in the electrolyte for 30 minutes, to ensure saturation, and carrying out a scan in the positive direction starting from $-1.2 \mathrm{~V}$ to $0 \mathrm{~V}$. Comparing the spectra obtained in ${ }^{13} \mathrm{CO}_{2}$ (Figure 7) to the spectra shown in Figure 5, reveals several band shifts. The adsorbed ${ }^{13} \mathrm{CO}$ band is located at $2023 \mathrm{~cm}^{-1}$. The interchange of solution based carbonate to bicarbonate is clearly evident by the negative band at $1376 \mathrm{~cm}^{-1}$, accompanied by the positive bicarbonate bands at $1575 \mathrm{~cm}^{-1}$ and $1333 \mathrm{~cm}^{-1}$. The surface carbonate band at $1520-1533 \mathrm{~cm}^{-1}$ is evident at $1468-1488 \mathrm{~cm}^{-1}$ using ${ }^{13} \mathrm{CO}_{2}$. Most likely, the unknown band at $1335 \mathrm{~cm}^{-1}$ has shifted to $1294 \mathrm{~cm}^{-1}$, demonstrating this is $\mathrm{CO}_{2}$ related. In particular for carbonate species on oxide surfaces, various modes of interaction have been proposed, including monodentate and bidentate interaction. Table 3 provides additional assignments of IR bands to various 
carbonate species ${ }^{79,132-134}$, indicating that the 1335 (1294 for ${ }^{13} \mathrm{CO}_{2}$ ), might be related to bidentate carbonate, as proposed for Ag-based catalysts ${ }^{38}$. Indeed there appears a similarity in growth-rate of the 1533 and $1335 \mathrm{~cm}^{-1}$ band in Figure 5. In the following we discuss potential additional contributions to the $\mathrm{CO}_{2}$-associated features in the spectra.

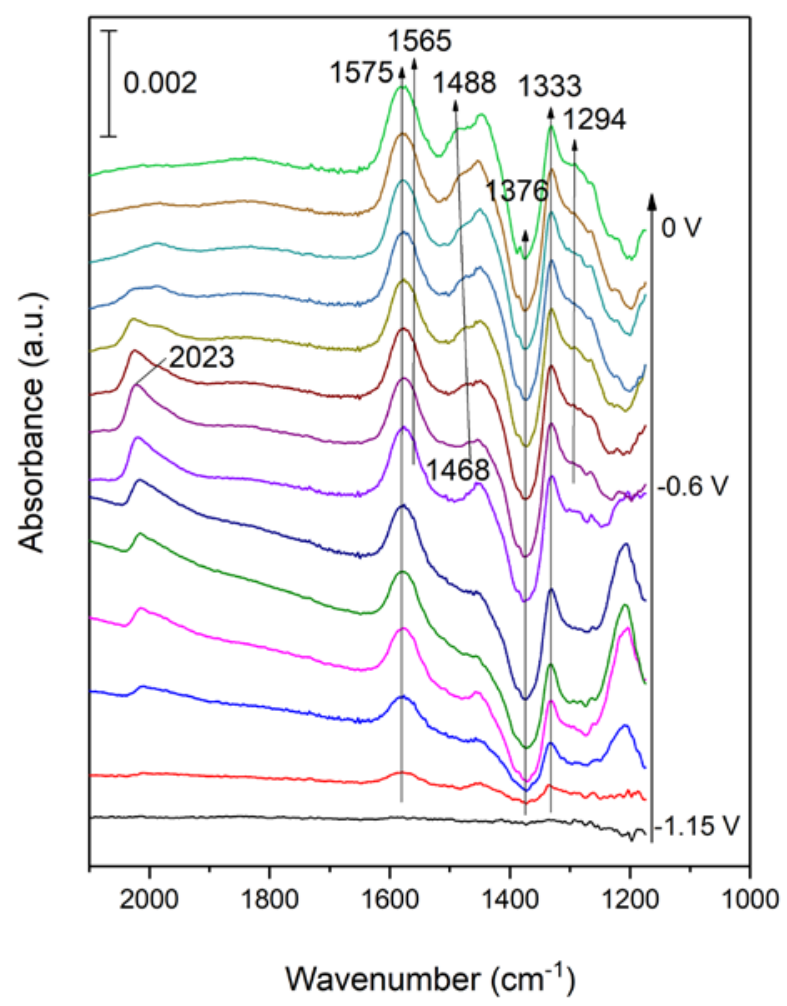

Figure 7. ATR spectra of the $\mathrm{Cu}$ thin film during positive scan in ${ }^{13} \mathrm{CO}_{2}$ saturated $0.1 \mathrm{M}$ $\mathrm{NaOH}$ in $\mathrm{D}_{2} \mathrm{O}$ solution with reference spectrum taken at $-1.2 \mathrm{~V}$. The potential interval between spectra is $\sim 0.08 \mathrm{mV}$. 


\section{Chapter 5}

Table 2. Vibrational assignments of the formate ion

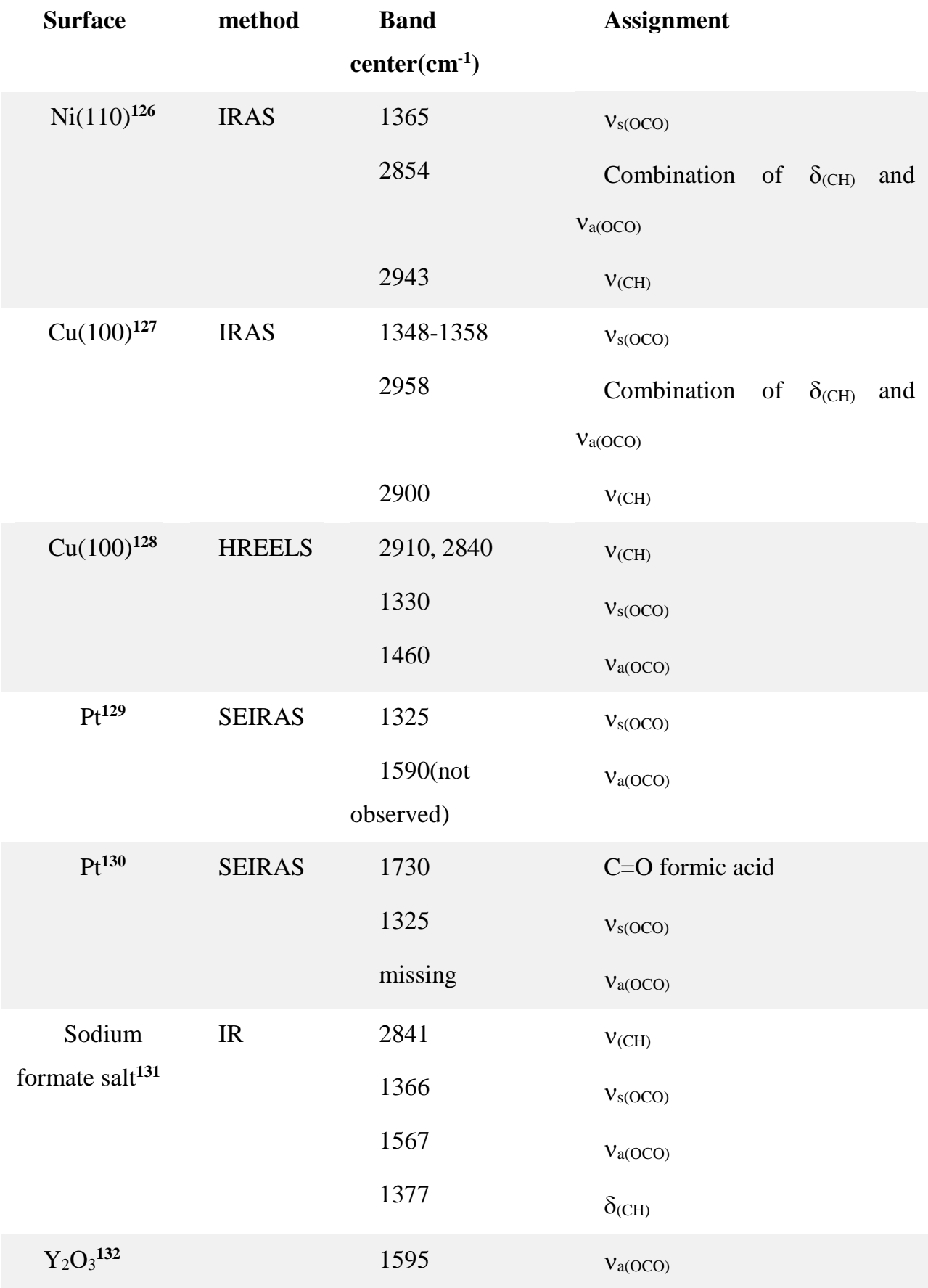


Infrared analysis of interfacial phenomena during electrochemical reduction...

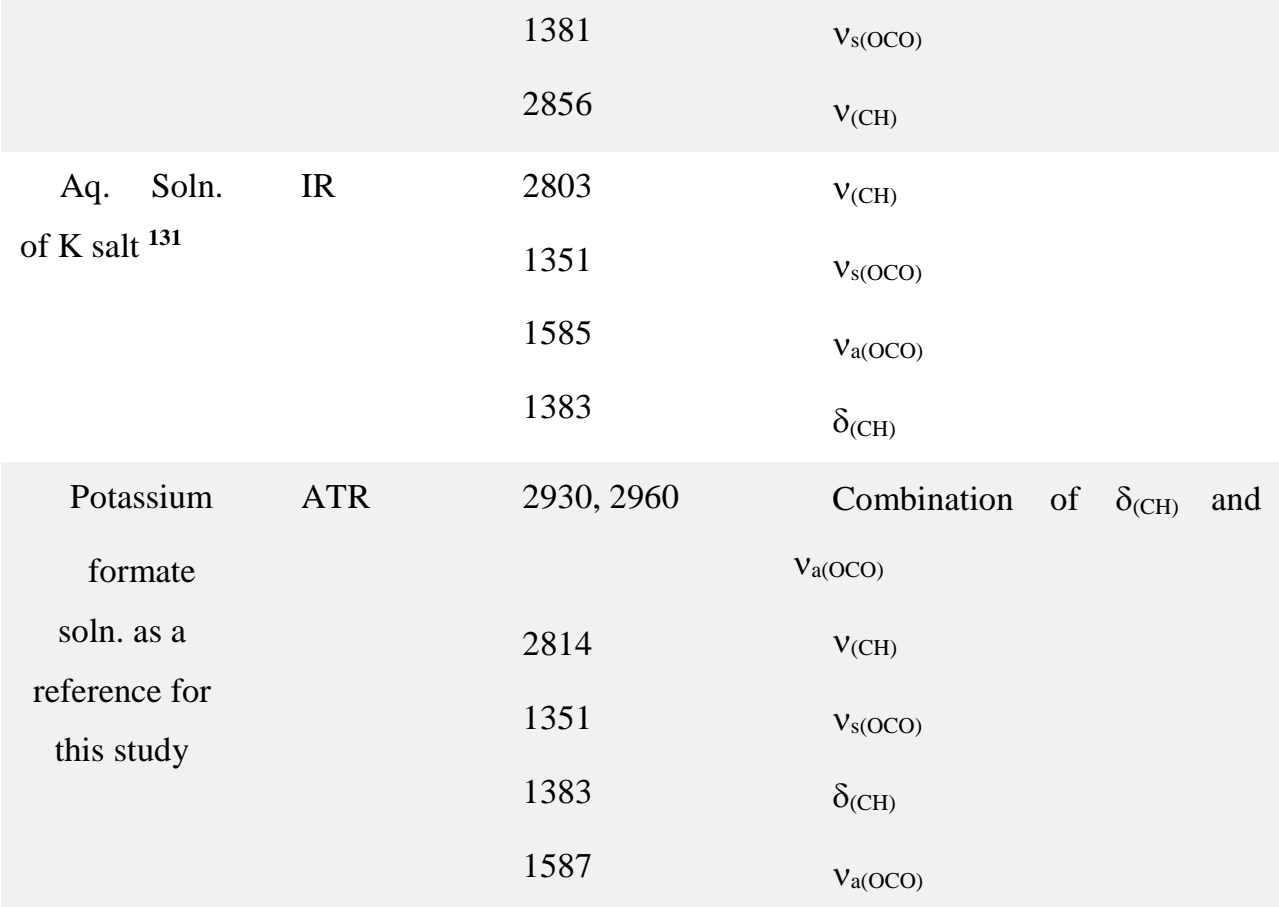

Table 3. Vibrational assignments of carbonate species

\begin{tabular}{|c|c|c|c|}
\hline surface & method & $\begin{array}{c}\text { Band } \\
\text { center }\left(\mathbf{c m}^{-1}\right)\end{array}$ & assignment \\
\hline Tin(IV) Oxide ${ }^{133}$ & IR & $\begin{array}{l}1630-1590 \\
1270-1260\end{array}$ & Bidentate \\
\hline & & $\begin{array}{l}1530-1470 \\
1370-1300\end{array}$ & Monodentate \\
\hline $\mathrm{Cu}(111)^{79}$ & DFT & 1533 & $v_{\mathrm{s}}$ bidentate \\
\hline $\mathrm{Cu}(100)$ & $\begin{array}{l}\text { DFT } \\
\text { ATR-SEIRAS }\end{array}$ & $\begin{array}{l}1540 \\
1495\end{array}$ & \\
\hline $\mathrm{Ag} / \mathrm{MgO}^{135}$ & FTIR & $\begin{array}{l}1530 \\
1390\end{array}$ & $\begin{array}{l}v_{\text {as }} \text { monodentate } \\
v_{\mathrm{s}} \text { monodentate }\end{array}$ \\
\hline $\mathrm{Ag} / \mathrm{Ga}_{2} \mathrm{O}_{3}$ & & 1590 & $v_{\text {as }}$ bidentate \\
\hline
\end{tabular}




\section{Chapter 5}

$\begin{array}{lccc} & & 1320 & v_{\text {s }} \text { bidentate } \\ \mathrm{Y}_{2} \mathrm{O}_{3}{ }^{\mathbf{1 3 2}} & \text { FTIR } & 1585 & v_{\text {as }} \text { bridged } \\ & & 1334 & v_{\text {s }} \text { bridged } \\ \mathrm{KMG30*134} & \text { IR } & 1570 & v_{\text {as }} \text { bidentate } \\ & 1335 & v_{\text {s }} \text { bidentate } \\ \text { *potassium-promoted hydrotalcite } & & \end{array}$

\section{Additional spectral contributions: the Dimer}

Very recently, rapid scan ATR FTIR spectroscopic studies have provided indications for a $\mathrm{CO}_{2}$ dimer radical anion intermediate at an aqueous interface of $\mathrm{Cu}$ nanoparticles ${ }^{117}$. To verify the formation of the dimer on roughened copper surfaces in our study using ATR-SEIRAS, an anodic scan with a rate of $2 \mathrm{mV} / \mathrm{sec}$ from a significantly negative potential of $-1.3 \mathrm{~V}$ (used as reference spectrum) was performed. The potential was selected based on the potential dependent appearance of observed species in this study. The absence of previously discussed bands except for bicarbonate and carbonate anions, allowed for precise deconvolution and spectral analysis as shown in Figure 8.

Development of the $1363 \mathrm{~cm}^{-1}$ band while scanning towards more positive potentials is illustrated in Figure 8a. Further analysis by deconvolution of the bands reveals maxima at 1369, 1361 and $1351 \mathrm{~cm}^{-1}$. Analysis of the time-dependent intensity of these bands reveals noticeable discrepancy in the growth kinetics of the 1369, compared to the 1361 and $1351 \mathrm{~cm}^{-1}$ bands (Figure 8c). The potential (time) dependent relative intensity of the 1361 and $1351 \mathrm{~cm}^{-1}$ bands was measured to be fixed at a value of $2 \pm 0.05$, suggesting they belong to a single species. In order to ensure that this set of bands originated from carbon-containing species, the experiment was also carried out using ${ }^{13} \mathrm{CO}_{2}$. The results (figure 8b) reveal potential (time) dependent development of a set of bands at 1335, 1324 and $1315 \mathrm{~cm}^{-1}$. Similar to ${ }^{12} \mathrm{CO}_{2}$ studies, the relative intensity of 1324 and $1315 \mathrm{~cm}^{-1}$ bands was measured 
to be a fixed value of $2.15 \pm 0.05$, suggesting they belong to a single species. Based on a previous report of Frei and coworkers ${ }^{117}$, the pair of bands at 1361 and 1351 $\mathrm{cm}^{-1}$ (1324 and $1315 \mathrm{~cm}^{-1}$ for ${ }^{13} \mathrm{CO}_{2}$ ) together with a potential dependent asymmetric stretch at $1627 \mathrm{~cm}^{-1}\left(1575 \mathrm{~cm}^{-1}\right.$ for ${ }^{13} \mathrm{CO}_{2}$, see Figure 7) could be assigned to the $\mathrm{C}_{2} \mathrm{O}_{4}{ }^{-}$radical anion, which is then apparently a relatively stable intermediate.

$\mathrm{C}_{2} \mathrm{O}_{4}{ }^{-}$is the product of coupling of $\mathrm{CO}_{2}$ and the $\mathrm{CO}_{2}{ }^{-}$radical by forming a $\mathrm{C}-\mathrm{O}$ bond (see structure in Figure 9), the $\mathrm{CO}_{2}^{-}$being the first and most frequently cited intermediate for hydrocarbons and $\mathrm{C} 1$ products $^{14,136}$. In the pathway towards $\mathrm{CO}$, adsorbed $\mathrm{CO}_{2}^{-}$is believed to react with physisorbed $\mathrm{CO}_{2}$ and form the more stable $\mathrm{CO}_{2}$ dimer radical anion ${ }^{137-138}$. While this dimer has been predominantly proposed for reduction of $\mathrm{CO}_{2}$ in aprotic conditions, it is recently also believed to play a mechanistic role in ER-CO $\mathrm{CO}_{2}$ in aqueous solutions ${ }^{139-140}$. Generally the dimer is proposed to disproportionate into $\mathrm{CO}$ and $\mathrm{CO}_{3}{ }^{2-}$ :

$$
\begin{aligned}
& \mathrm{CO}_{2}+\mathrm{e}^{-} \rightarrow \mathrm{CO}_{2}^{--} \\
& \mathrm{CO}_{2}^{--}+\mathrm{CO}_{2} \rightarrow\left(\mathrm{CO}_{2}\right)_{2}^{-} \\
& \left(\mathrm{CO}_{2}\right)_{2}^{--}+\mathrm{e}^{-} \rightarrow \mathrm{CO}+\mathrm{CO}_{3}^{2-}
\end{aligned}
$$

If this intermediate would play a major role, a decreasing intensity of the spectral features of the dimer, should be accompanied by increasing intensity of the bands due to (surface adsorbed) CO and carbonate. However, this correlation is affected by other processes which simultaneously occur, such as protonation of the carbonate, and reaction of $\mathrm{CO}$ to form ethylene. In protic conditions, generally proton assisted formation of products is proposed, such as the following reactions leading to formate ((4), (5)), while also the formation of CO can be explained by proton assisted reduction of $\mathrm{CO}_{2}$, yielding water (6):

$$
\begin{aligned}
& \mathrm{CO}_{2}^{-}+\mathrm{H}^{+} \rightarrow \mathrm{HCOO} \\
& \mathrm{HCOO}+\mathrm{e}^{-} \rightarrow \mathrm{HCOO}^{-}
\end{aligned}
$$




\section{Chapter 5}

$$
\mathrm{CO}_{2}+2 \mathrm{H}^{+}+2 \mathrm{e}^{-} \rightarrow \mathrm{CO}+\mathrm{H}_{2} \mathrm{O}
$$

The formation of formate is evident from several spectra in this study, as previously discussed. The relative contribution of reaction (6) as compared to reaction (3) will determine spectral dynamics, and this is likely potential dependent. An accurate overview of the results discussed so far on the formation of $\mathrm{CO}$, revealed that the $\mathrm{CO}$ peak was observed at potentials as negative as $-1.24 \mathrm{~V}$. At more negative potentials the $\mathrm{CO}$ peak disappears, which can be due to competitive binding of hydrogen, in addition to accelerated CO dimerization to form hydrocarbons. As previously discussed extensively, the dynamics of the carbonate bands as a function of applied potential, besides being the consequence of reaction (3), can also be largely affected by changes in local (surface) $\mathrm{pH}$, orientation of the molecule (monovs bidentate) on the surface, and/or desorption of adsorbed carbonate, which influences the so-called collective vibrations in the adlayer. 

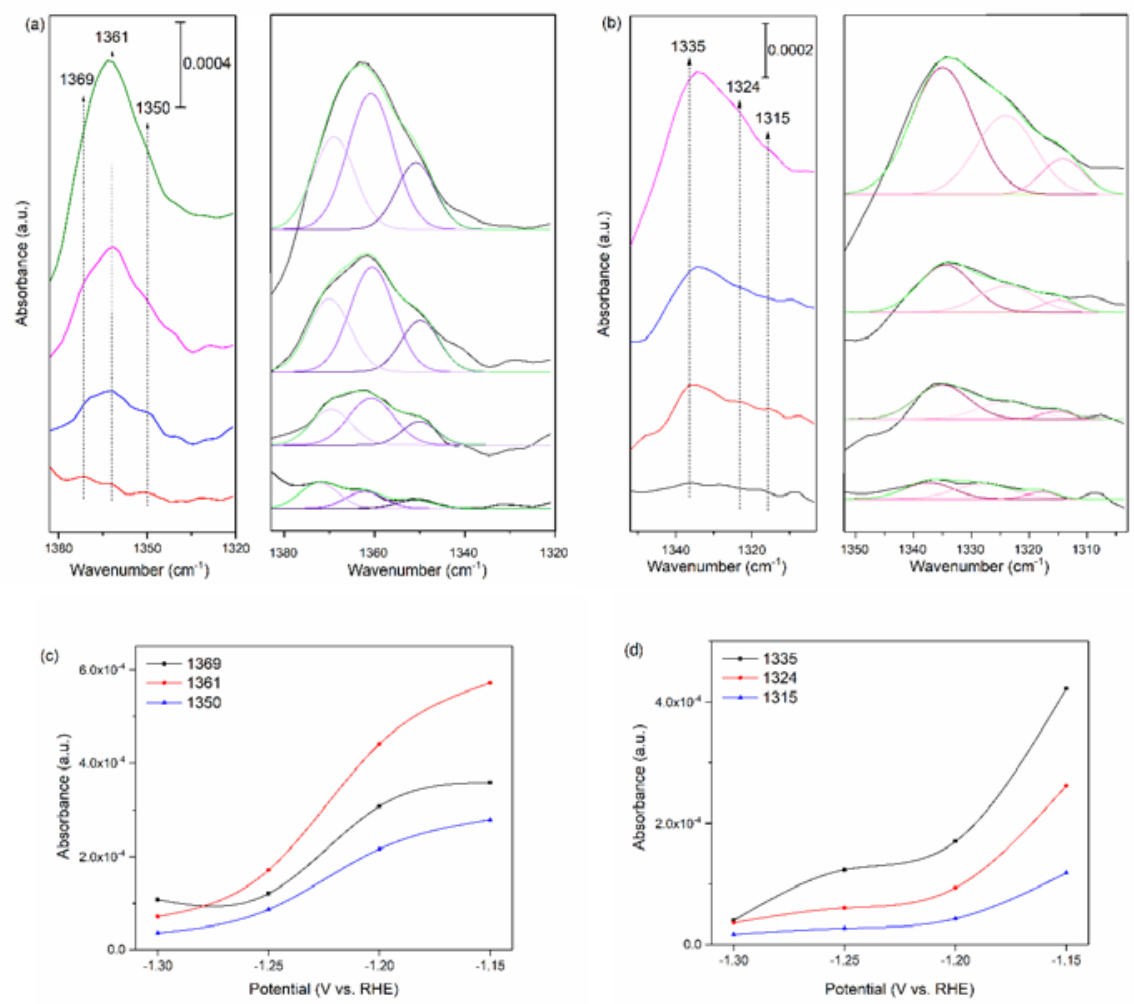

Figure 8. Spectral deconvolution of bands during positive scans from $-1.3 \mathrm{~V}$ to $-1.15 \mathrm{~V}$ with a scan rate of $2 \mathrm{mV} / \mathrm{sec}$ in (a) $\mathrm{CO}_{2}$ and (b) ${ }^{13} \mathrm{CO}_{2}$, saturated in $0.1 \mathrm{M} \mathrm{NaOH}$ in $\mathrm{D}_{2} \mathrm{O}$ solution, with the reference spectrum taken at -1.3 V. (c) Growth kinetics of the 1369, 1361 and $1350 \mathrm{~cm}^{-1}$ bands and (d) 1335, 1324 and $1315 \mathrm{~cm}^{-1}$ bands during a positive scan. The potential interval between spectra is $\sim 0.05 \mathrm{mV}$.

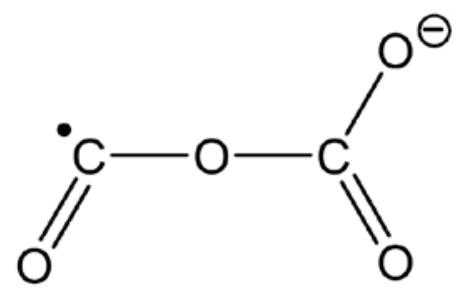

Figure 9. Structure of the carbon dioxide dimer radical anion $\left(\mathrm{C}_{2} \mathrm{O}_{4}{ }^{-}\right)$. 


\section{Chapter 5}

\subsection{Conclusions}

This study set out to probe possible reaction intermediates and products of ER$\mathrm{CO}_{2}$ on $\mathrm{Cu}$ by employing in situ ATR-SEIRAS and isotopic labeling. The following observations have made and can be interpreted as follows. At relatively small negative applied potential, formate is formed in the presence of adsorbed carbonate, likely in the bidentate form. At more negative potential, the selectivity shifts towards $\mathrm{CO}$ and (solution-based) bicarbonate. Local pH changes largely influence the ration of bicarbonate vs adsorbed, and solution-based carbonate ${ }^{107-108}$. One of the more significant findings to emerge from this study was detection of the $\mathrm{CO}_{2}$ dimer radical anion, which we propose to contribute to the formation of $\mathrm{CO}$ by disproportionation. To the best of our knowledge, this is the first observation of this dimer using ATRSEIRAS on $\mathrm{Cu}$ electrodes and in aqueous conditions ${ }^{117}$. At potentials more negative than $-1.4 \mathrm{~V}, \mathrm{CO}$ is no longer adsorbed, the dimer concentration is low, and the spectra only reveal solution-based carbonate with residual bi-carbonate. Intermediates for ethylene formation have not been revealed, likely due their short

lifetimes. Transient ultrafast IR spectroscopy (microsecond timescales) will be attempted in order to elucidate mechanistic pathways towards ethylene in ER-CO 2 . 


\subsection{Appendix}

(a)

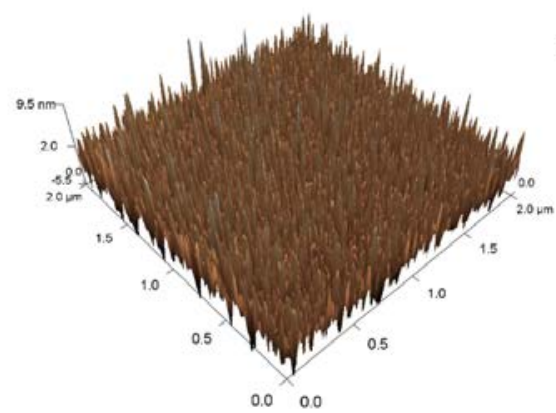

(b)
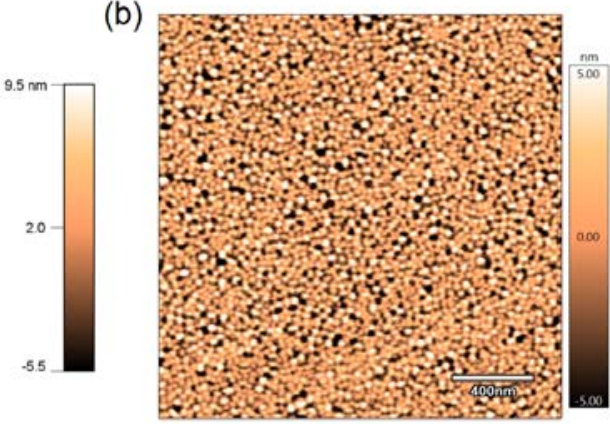

Figure S1. $2 \mu \mathrm{m} \times 2 \mu \mathrm{m}$ AFM images of the $\mathrm{Cu}$ film sputtered on Si crystal in (a) threedimensional and (b) two-dimensional view.

\section{Reference spectra:}

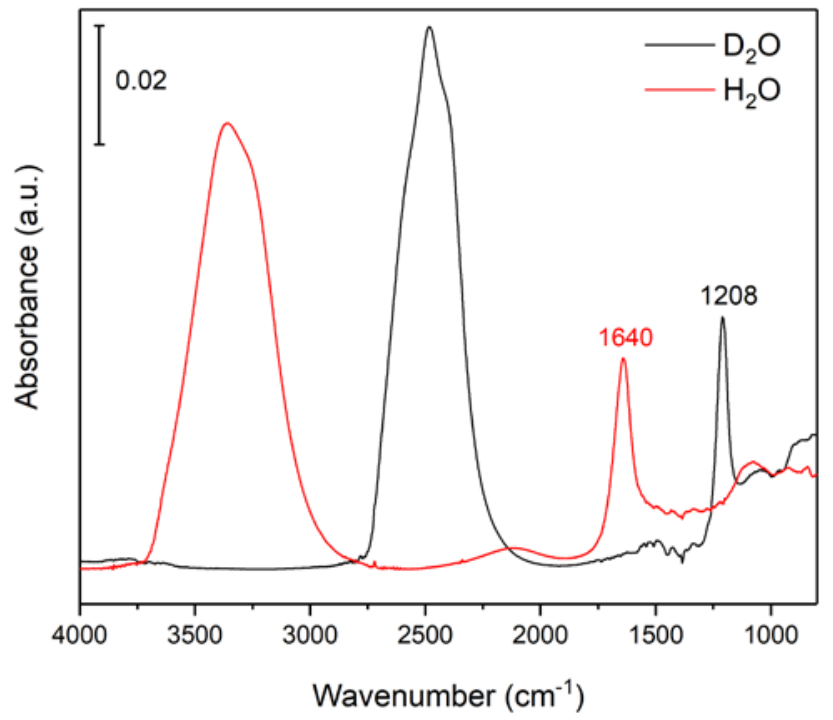

Figure S2. Infrared spectrum of $\mathrm{H}_{2} \mathrm{O}$ and $\mathrm{D}_{2} \mathrm{O}$. 


\section{Chapter 5}

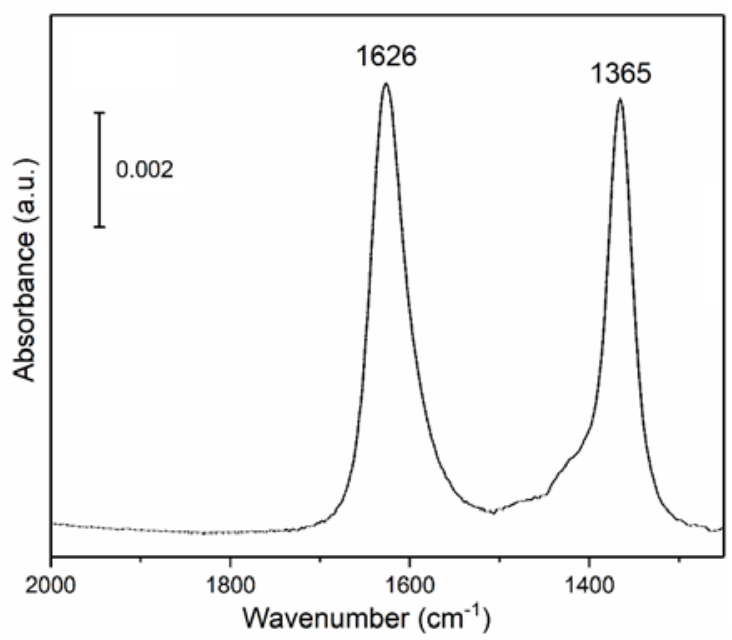

Figure S3. Infrared spectrum of $0.5 \mathrm{M}$ sodium bicarbonate in $\mathrm{D}_{2} \mathrm{O}$.

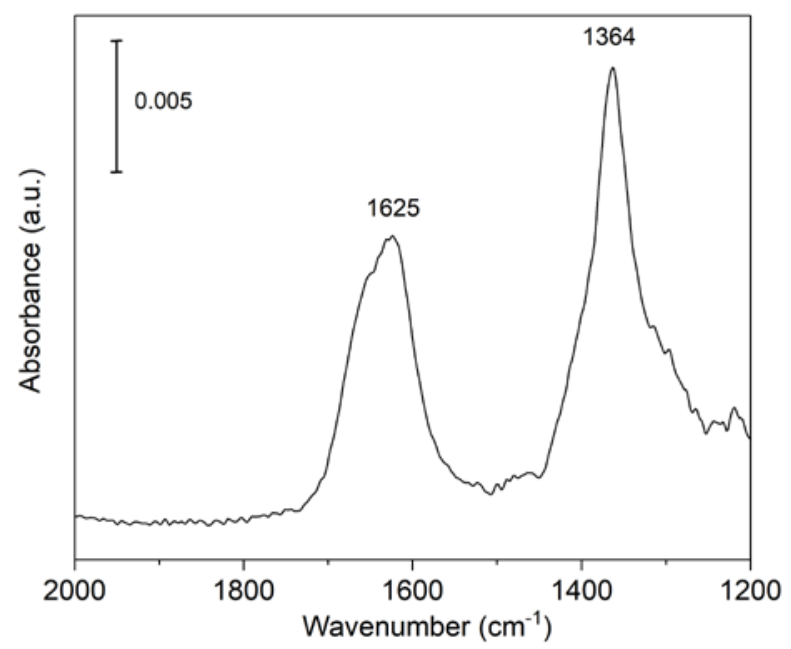

Figure S4. Development of bicarbonate peaks after purging $0.1 \mathrm{M} \mathrm{NaOH}$ solution (in $\mathrm{H}_{2} \mathrm{O}$ ) with $\mathrm{CO}_{2}$. 


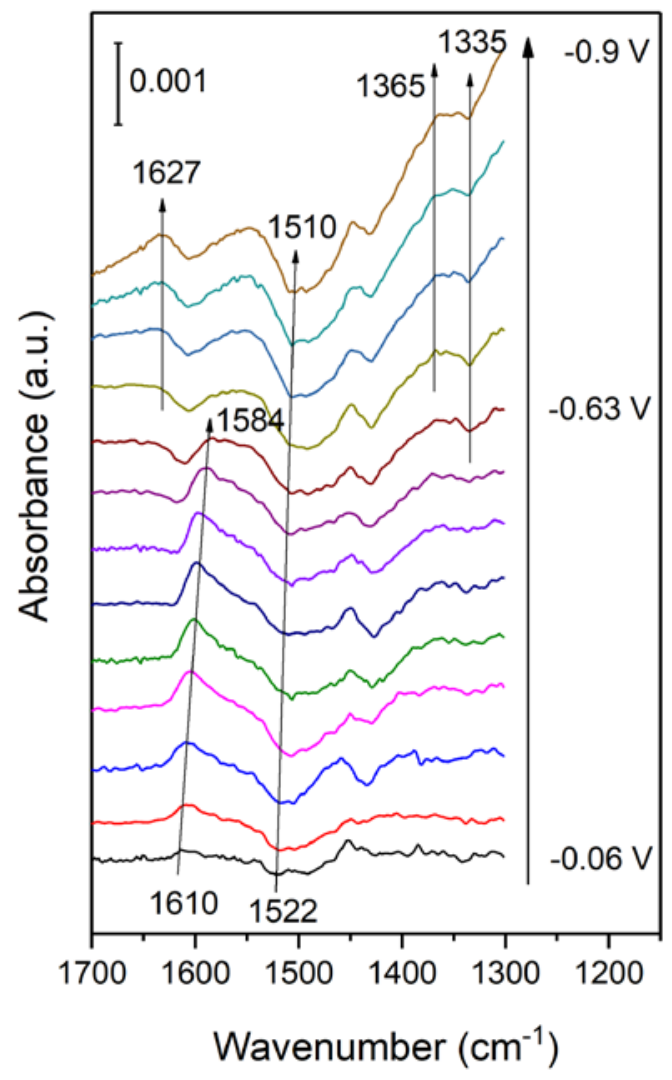

Figure S5. ATR spectra of the $\mathrm{Cu}$ thin film during negative scan in $\mathrm{CO}_{2}$ saturated $0.1 \mathrm{M}$ $\mathrm{NaOH}$ in $\mathrm{D}_{2} \mathrm{O}$ solution in $1700-1300 \mathrm{~cm}^{-1}$ region with reference spectrum taken at $0 \mathrm{~V}$. 


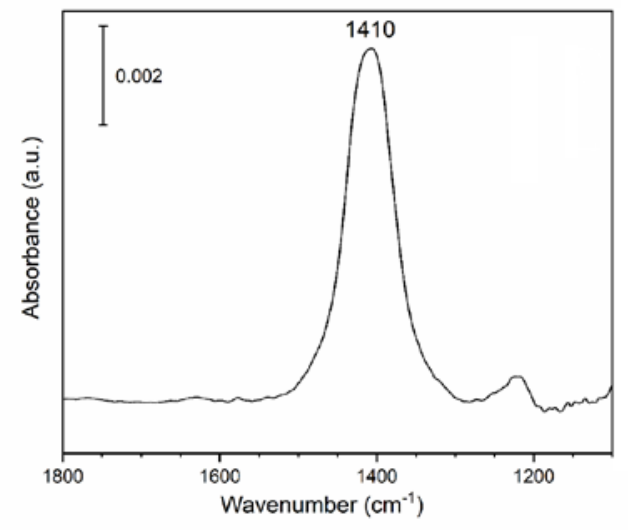

Figure S6. Infrared spectrum of $0.5 \mathrm{M}$ sodium carbonate in $\mathrm{D}_{2} \mathrm{O}$.

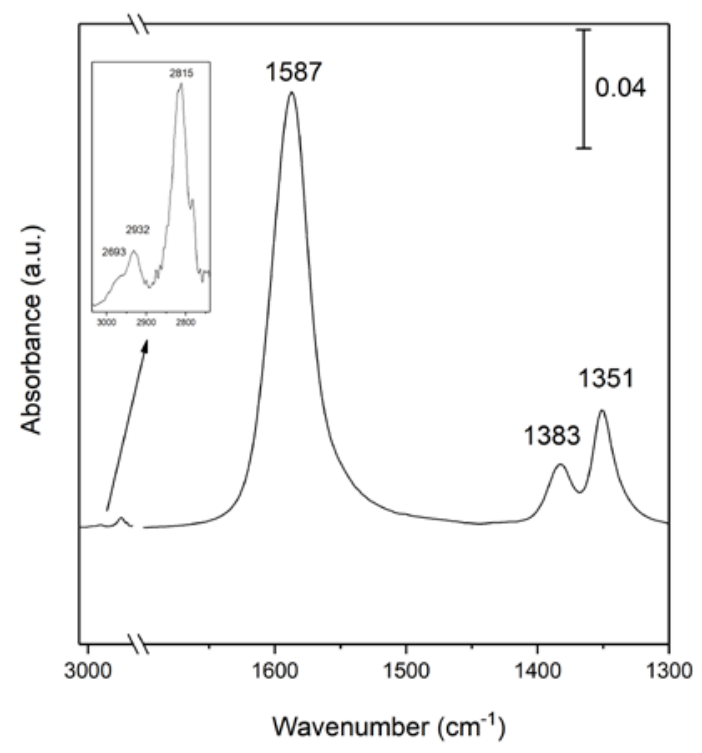

Figure S7. Infrared spectrum of Potassium formate $(1 \mathrm{M})$ in $\mathrm{D}_{2} \mathrm{O}$. The $\mathrm{C}-\mathrm{H}$ stretch vibration is present at $2815 \mathrm{~cm}^{-1}$, while the $\mathrm{CO}_{(2)}$ stretch vibration is present at $1587 \mathrm{~cm}^{-1}$. 


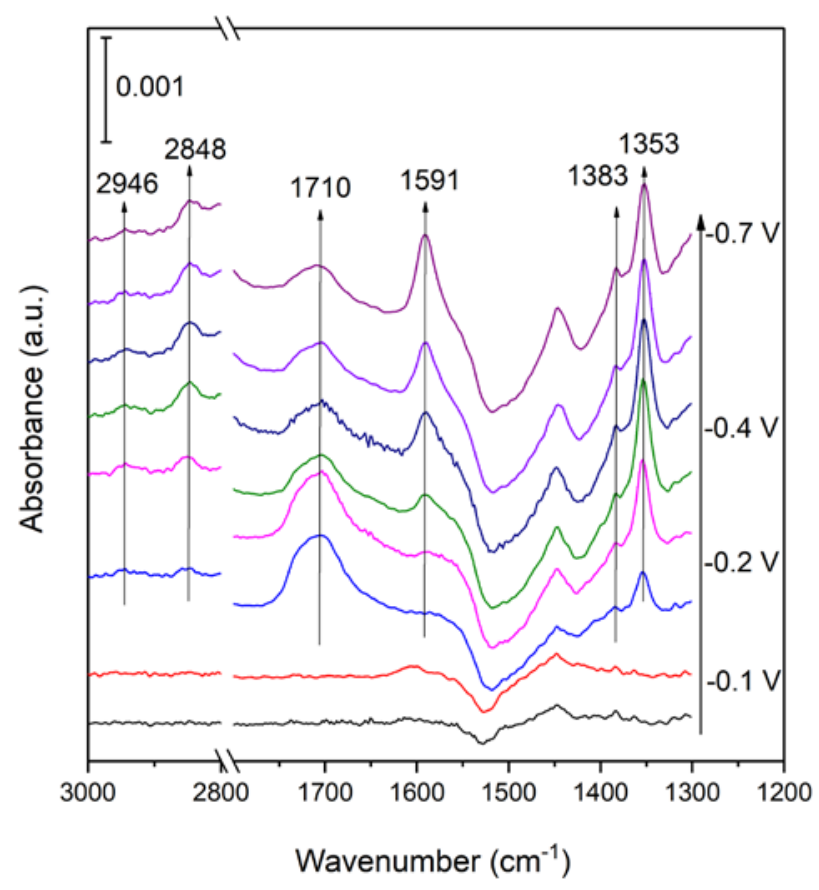

Figure S8. Infrared spectra of $0.1 \mathrm{M} \mathrm{NaOH}$ in $\mathrm{D}_{2} \mathrm{O}$, in contact with a $\mathrm{Cu}$ film. Formic acid was added at $-0.2 \mathrm{~V}$ (with applied potential on). The background spectrum taken at $0 \mathrm{~V}$ prior to addition of formic acid. The peak at $1710 \mathrm{~cm}^{-1}$ is attributed to $\mathrm{C}=\mathrm{O}$ stretch vibrations of formic acid. The C-H stretch vibrations at 2946 and $2848 \mathrm{~cm}^{-1}$ are relatively weak. In the potential range of -0.3 to $-0.7 \mathrm{~V}$ the height of the $1710 \mathrm{~cm}^{-1}$ band decreases, while the increasing bands at 2848, 1591, 1383 and $1353 \mathrm{~cm}^{-1}$ are associated with formate. 
Chapter 5 


\section{Chapter 6.}

\section{Correlating the surface structure and composition of copper to high}

selectivity towards ethylene in reduction of $\mathrm{CO}_{2}$

\section{Abstract}

Development of a selective Cu-based electrocatalyst for electrochemical reduction of $\mathrm{CO}_{2}$ for production of $\mathrm{C}_{2+}$ hydrocarbons requires understanding of the effect of the electrode structure on i) the nature of surface adsorbed intermediates and ii) the final composition of the product-gas. In this study, the electrode structure of electropolished $\mathrm{Cu}$ was manipulated by addition of variable concentration of 0.1$1 \mathrm{mM}$ of $\mathrm{CuSO}_{4}$ to $0.1 \mathrm{M}$ or $0.5 \mathrm{M}$ of $\mathrm{KHCO}_{3}$ electrolyte. The faradaic efficiency (FE) of electropolished $\mathrm{Cu}$ towards ethylene increased from $\sim 30$ to $\sim 40 \%$ by the 


\section{Chapter 6}

incorporation of $0.1 \mathrm{mM}$ of $\mathrm{CuSO}_{4}$ in $0.1 \mathrm{M} \mathrm{KHCO}_{3}$ solution, while larger quantities up to $1 \mathrm{mM}$ lead to lower $\mathrm{FE}$ and favor $\mathrm{H}_{2}$ formation, in particular at $0.5 \mathrm{M} \mathrm{KHCO}_{3}$ concentration. Based on the study of the surface morphology, the added $\mathrm{CuSO}_{4}$ causes in-situ electrodeposition of $\mathrm{Cu}$ microstructures, enhancing the roughness of the electrode, the highest for the $1 \mathrm{mM} \mathrm{CuSO}_{4}$ concentration as determined by capacitance measurements. The key result of this study is the demonstration using SERS, that addition of $0.1-1 \mathrm{mM} \mathrm{CuSO}_{4}$ significantly enhances the surface coverage of $\mathrm{CO}$ in $0.1 \mathrm{M} \mathrm{KHCO}_{3}$, as well as the potential range at which adsorbed $\mathrm{CO}$ is present, facilitating CO dimerization and selective formation of ethylene. In addition, SERS reveals a lower intensity and stability of surface $\mathrm{Cu}-\mathrm{OH}$ bands by addition of $\mathrm{CuSO}_{4}$, suggesting too high coverage with $\mathrm{Cu}-\mathrm{OH}$ might be detrimental for ethylene selectivity. These observations are significantly less pronounced in 0.5 $\mathrm{M} \mathrm{KHCO}_{3}$ and discussed and compared to recently postulated hypotheses on the surface composition during $\mathrm{CO}_{2}$ reduction.

\subsection{Introduction}

The electrochemical reduction of $\mathrm{CO}_{2}$ is a technology presently under development to mitigate high $\mathrm{CO}_{2}$ concentrations in the atmosphere, and to produce renewable fuels and feedstock. $\mathrm{Cu}$ uniquely converts $\mathrm{CO}_{2}$ to a wide range of hydrocarbons ${ }^{23}$. The surface morphology and roughness of $\mathrm{Cu}$ electrodes have previously been proven to greatly influence the activity and product selectivity during $\mathrm{CO}_{2} \mathrm{RR}$. The selectivity towards ethylene can be significantly enhanced by the use of foam like structures ${ }^{141}$, nanowires ${ }^{106,142-143}$, mesocrystals ${ }^{144}$, nanocubes ${ }^{145}$, nanoparticles ${ }^{28}$, thick deposited $\mathrm{Cu}$ oxide films ${ }^{28,43,146}$ and sputtering ${ }^{28}$. All these methods lead to enhanced roughness and an enhanced active surface area of the electrodes. A possible explanation for the observed enhanced ethylene selectivity is that the higher current densities obtained on roughened electrodes lead to higher local $\mathrm{pH}$ values, favoring formation of ethylene $\mathrm{e}^{57,147-148}$. Another explanation is that surface roughening introduces surface defects such as steps, edges, terraces and 
vacancies. Higher density of such surface adsorption sites of low-coordination favors adsorption properties of the catalyst ${ }^{28,63,83}$. Abundance of these active surface sites resolves the preference towards $C_{1}$ or $C_{2}$ reaction pathways as compared to the production of hydrogen. In addition to ex-situ methods to enhance the roughness, few studies exist which discuss in-situ electrodeposition of $\mathrm{Cu}^{149-150}$ and in-situ deposition of nickel ${ }^{151}$. In such an approach, in addition to the electrolyte composition, i.e. the alkali (bi)carbonate concentration, $\mathrm{Cu}$ cations are added, which influence the electrode performance $e^{45,147,152}$.

To identify the catalytically active sites under operating conditions, in-situ spectroscopic techniques have gained attention in recent years. Under cathodic conditions, copper oxides are quickly reduced and as a result, it is difficult to employ ex-situ methods to identify the oxidation state of $\mathrm{Cu}$ during $\mathrm{CO}_{2} \mathrm{RR}$. Consequently, in-situ SERS has been used to monitor the oxidation state of the catalyst surface ${ }^{106}$, ${ }^{153-156}$. In addition, SERS is a powerful tool for examining adsorbed intermediates.

In this report, in-situ electrodeposition was employed to effectively obtain highly active sites showing high electrocatalytic selectivity towards ethylene. Surface characterization of the electrodeposited $\mathrm{Cu}$ reveals significant enhancement in roughness. We also try to unravel the oxidation state of $\mathrm{Cu}$ in action, and to identify adsorbed species at highly negative potentials where $\mathrm{CO}_{2} \mathrm{RR}$ is dominant, using the in-situ SERS technique. We show that increasing surface roughness significantly increases surface coverage of CO, a key intermediate in the formation of ethylene, while the surface coverage is also dependent on the concentration of the applied $\mathrm{KHCO}_{3}$ solution. The resulting enhanced probability for $\mathrm{CO}$ dimerization explains the highly selective formation of ethylene. This work also reveals that $\mathrm{Cu}-\mathrm{OH}$ species are present during $\mathrm{CO}_{2} \mathrm{RR}$, even at negative potential, and decrease in relative intensity by the presence of $\mathrm{Cu}^{2+}$-ions in solution. Based on these results, we establish a deeper understanding of how the electrode morphology can lead to selective ethylene formation pathways. 


\section{Chapter 6}

\subsection{Experimental section}

\section{Materials and Film Deposition}

$\mathrm{Cu}$ foils used as working electrode were prepared by mechanical polishing, followed by electropolishing in $85 \%$ phosphoric acid, potentiostatically at $3 \mathrm{~V}$ vs. a graphite foil counter electrode. Finally the electrodes were cleaned ultrasonically in ethanol and water.

The electrolyte solutions of $\mathrm{KHCO}_{3}$ (Sigma Aldrich, 99.99\% metals basis), $\mathrm{NaHCO}_{3}$ (Sigma Aldrich, 99.7\%), $\mathrm{Li}_{2} \mathrm{CO}_{3}$ (Sigma Aldrich, 99\%), $\mathrm{CsHCO}_{3}$ (Alfa Aesar, 99.99\%), $\mathrm{KCl}$ (Sigma Aldrich, 99\%), $\mathrm{Cu}\left(\mathrm{CH}_{3} \mathrm{COO}\right)_{2}$ (Sigma Aldrich, 99.99\%), $\mathrm{CuCl}_{2} \cdot 2 \mathrm{H}_{2} \mathrm{O}$ (Sigma Aldrich, 99\%) and $\mathrm{CuSO}_{4}$ (Sigma Aldrich, 99\%) were prepared using deionized water (Millipore MilliQ, $18.2 \mathrm{M} \Omega \mathrm{cm}$ ). For preparation of $0.1 \mathrm{M} \mathrm{LiHCO}_{3}, 0.05 \mathrm{M} \mathrm{Li}_{2} \mathrm{CO}_{3}$ was purged overnight with a flow of $20 \mathrm{ml} / \mathrm{min}$. of $100 \% \mathrm{CO}_{2}$.

The morphology of the surface of the electrode was examined using scanning electron microscopy (JEOL JSM-6010LA).

\section{Electrochemical Measurements}

All electrochemical measurements were carried out using a Bio-Logic VSP Potentiostat. A home-made, two-compartment electrochemical cell using a three electrode assembly was used to carry out the $\mathrm{CO}_{2}$ electrochemical reduction. Various concentrations (0.1-1 mM) of $\mathrm{Cu}$ salts were added to $0.1 \mathrm{M} \mathrm{KHCO}_{3}$ as electrolyte. Glassy carbon (SIGRADUR ${ }^{\circledR}$ G) was used as the counter electrode and was separated from the working electrode using an anion exchange membrane (Selemion AMV, AGC, Inc.). Ag/AgCl in $3 \mathrm{M} \mathrm{NaCl}$ was used as a reference electrode and potentials were converted to the Reversible Hydrogen Electrode (RHE) scale by $\mathrm{V}_{\text {vs. }}$ $\mathrm{RHE}=\mathrm{V}_{\text {measured vs. } \mathrm{Ag} / \mathrm{AgCl}}+0.198+0.059 *(\mathrm{pH}$ of solution $)$.

The $\mathrm{CO}_{2}$ gas was continuously purged through a glass frit at a rate of $20 \mathrm{ml} \mathrm{min}{ }^{-1}$ for 30 minutes before each experiment, using a mass flow controller. The flow rate 
was then decreased to $5 \mathrm{ml} \mathrm{min}{ }^{-1}$ during the electrochemical reduction. The reactor effluent was vented directly into the gas sampling loop of a micro-gas chromatograph (micro-GC) equipped with a pulsed discharge detector (PDD) every 4 minutes. The micro-GC was equipped with two different columns (Molsieve plot and Rt-Q Bond) for separation of $\mathrm{H}_{2}, \mathrm{CO}, \mathrm{CO}_{2}$ and hydrocarbons. The data were averaged from four individual injections after 1 hour of electrochemical reduction to ensure steady state conditions. During chronoamperometry (CA) measurements, the current continuously increased and the current densities are reported according to the selected GC injections.

Raman spectroscopy was carried out using an Avantes AvaRaman spectrometer with an Intertec laser as excitation source at $\lambda=785 \mathrm{~nm}$. In-situ experiments were performed in a homemade flow cell with Pt mesh as counter electrode and $\mathrm{Ag} / \mathrm{AgCl}$ in $3 \mathrm{M} \mathrm{NaCl}$ as a reference electrode. The electrolyte was continuously purged with $\mathrm{CO}_{2}$ throughout the experiment. The Raman probe was separated from the electrolyte by a quartz window. An acquisition time of 10 seconds was selected to record each spectrum.

\section{Electrochemical surface area measurements}

The relative surface roughness factors of the electrodes after $\mathrm{CO}_{2} \mathrm{RR}$ in $0.1 \mathrm{M}$ $\mathrm{KHCO}_{3}+\mathrm{x} \mathrm{mM} \mathrm{CuSO}_{4}(\mathrm{x}=0,0.1,0.5$ and 1 ) were calculated by measuring the double layer capacitance values in $0.1 \mathrm{M} \mathrm{KCl}$. Pt mesh was used as a counter electrode and $\mathrm{Ag} / \mathrm{AgCl}$ was used as reference electrode. Cyclic voltammetry (CV) was performed with different scan rates $\left(5,20,40,60,80,100 \mathrm{mVs}^{-1}\right)$ in the potential range in which no Faradaic processes occur. The slope of the current density (the absolute values of the forward and backward scans were quite comparable) vs. scan rate gave the capacitance value which was normalized to smoothened copper, to obtain relative surface roughness factors. 


\section{Chapter 6}

\subsection{Results and discussion}

\section{Surface characterization of in-situ electrodeposited $\mathrm{Cu}$}

To explore whether addition of $\mathrm{CuSO}_{4}$ to the electrolyte affects the morphology of the electrode, the surface morphology of the $\mathrm{Cu}$ deposits during the electroreduction in $0.1 \mathrm{M} \mathrm{KHCO}_{3}+0.1 \mathrm{mM} \mathrm{CuSO}_{4}$ was investigated by scanning electron microscopy (SEM) (See Figure 1 and Figure S1). To evaluate development of the electrode morphology, samples were studied after $5 \mathrm{~min}, 30 \mathrm{~min}$ and $1 \mathrm{hr}$ of electrodeposition. Electropolished $\mathrm{Cu}$ foil (Figure 1a) shows an almost uniform flat surface with no significant features. As can be seen from Figure 1b, after 5 minutes of electroreduction, dandelion-like structures with an average diameter of 20 microns were formed. After 30 minutes, a more complex microstructure was revealed. The dandelions slightly grew in size and newly formed, smaller and horizontally oriented dendrite structures with the length of a few microns are visible, as well as nanoparticles. After 1 hour of electrolysis, the complex dandelion + surface dendrite morphology was retained and only slightly further developed, still leaving significant areas of the electrode void of dandelion structures. Figure S2 provides different magnifications from significant features of the surface structure after 1 hour of electroreduction. These images confirm that the average size of the dandelion-like microstructures was around 30 microns and dendrites consist of central backbones with the length of few microns and sharp secondary branches. Increasing the concentration of the added $\mathrm{CuSO}_{4}$ to $1 \mathrm{mM}$ resulted in highly porous integrated, three-dimensional dendritic microstructures (See Figure S2). Contrary to the $0.1 \mathrm{mM}$ concentration in which dandelion coverage appears to consist of highly crystalline structures, the continuous integrated network of dendrites is less crystalline and structures reveal similar morphology as the few dendrites in the 0.1 $\mathrm{mM}$ solution. 

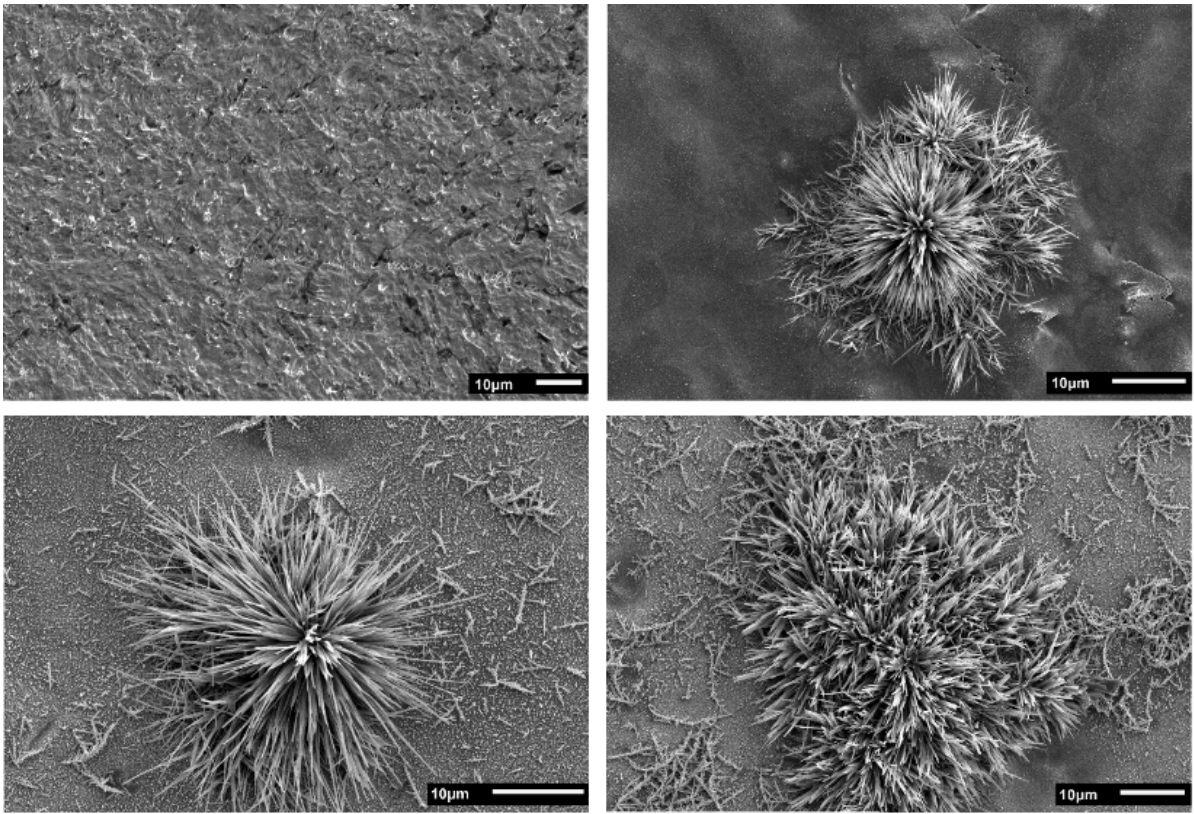

Figure 1. SEM images showing development of microstructures electrodeposited on electropolished $\mathrm{Cu}$ after (a) $0 \mathrm{~min}$, (b) $5 \mathrm{~min}$, (c) $30 \mathrm{~min}$ and (d) 1 hour of reduction at -1.1 $\mathrm{V}$ vs RHE in $0.1 \mathrm{M} \mathrm{KHCO}_{3}+0.1 \mathrm{mM} \mathrm{CuSO}_{4}$.

In the next section, the significant impact of these morphological characteristics on the resulting $\mathrm{CO}_{2} \mathrm{RR}$ product distribution will be discussed.

\section{Effect of $\mathrm{Cu}$ salt additive on selectivity and activity}

To assess the effect of $\mathrm{Cu}$ salt and its concentration, appropriate amounts of copper sulfate, acetate and chloride were incorporated into a $0.1 \mathrm{M} \mathrm{KHCO}_{3}$ solution to adjust the concentration from 0 to $1 \mathrm{mM}$. The performance in electrochemical reduction of $\mathrm{CO}_{2}$ was subsequently assessed (See Figures 2 (using sulfate as anion) and S3 (using acetate and chloride as anion)). Increasing the added salt up to a concentration of $0.1 \mathrm{mM}$ leads to a rise in FE of ethylene from 29 to $42 \%$, consistent with significant loss in methane FE from 18 to 6\% and suppression of hydrogen evolution. Higher concentrations of salt did not favor ethylene formation and instead, favored hydrogen evolution to the expense of ethylene and methane. The methane 


\section{Chapter 6}

FE was slightly decreased as more salt was incorporated. The formation of CO was nearly unaffected by salt concentration. The anion composition of the copper salt did not significantly affect the results, with $\mathrm{CuSO}_{4}$ leading to slightly higher FEs towards ethylene. Interestingly, the highest $\mathrm{FE}$ of ethylene and lowest methane and $\mathrm{H}_{2}$ formation were observed at an optimum value of salt concentration of $0.1 \mathrm{mM}$.

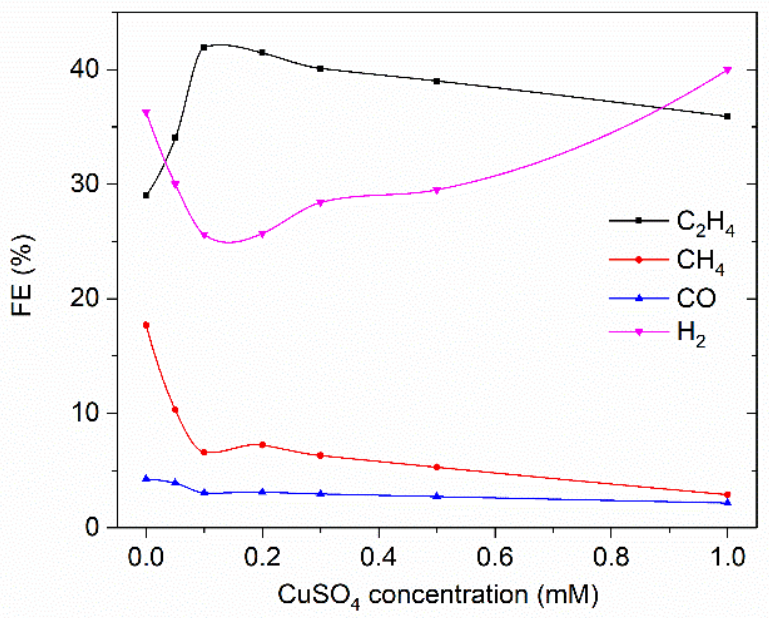

Figure 2. Faradaic efficiency of $\mathrm{C}_{2} \mathrm{H}_{4}, \mathrm{CH}_{4}, \mathrm{CO}$ and $\mathrm{H}_{2}$ vs. added $\mathrm{CuSO}_{4}$ concentration to $0.1 \mathrm{M} \mathrm{KHCO}_{3}$ at $-1.1 \mathrm{~V}$ vs. RHE.

Table 1. The capacitance values and surface roughness factors of the electrodes as a function of added $\mathrm{CuSO}_{4}$ concentration to $0.1 \mathrm{M} \mathrm{KHCO}_{3}$ electrolyte after 1 hour of electrochemical $\mathrm{CO}_{2}$ reduction at $-1.1 \mathrm{~V}$ vs. RHE.

Catalyst (added $\mathrm{CuSO}_{4} \quad$ Capacitance $(\mathrm{mF}) \quad$ Roughness factor concentration)

$\begin{array}{rrr}\text { Electropolished Cu } & 0.192 & 1 \\ \mathbf{+ 0 . 1} \mathbf{~ m M} & 1.007 & 5.25 \\ \mathbf{+ 0 . 5} \mathbf{~ m M} & 2.079 & 10.82 \\ \mathbf{+ 1} \mathbf{m M} & 3.454 & 17.99\end{array}$


On the basis of the above experimental evidence and morphological observations, the selectivity might be altered towards formation of ethylene and suppression of formation of methane and $\mathrm{H}_{2}$ as the result of the improved surface roughness, and associated higher reactivity and local $\mathrm{pH}$. To quantify the roughness, the roughness factors of post-reduction $\mathrm{Cu}$ electrodes were estimated by the double layer capacitance method, and the results are represented in Table 1 (see Figure S4 for the CVs at different scan rates). The results indicate that an increase in additive concentration leads to higher surface roughness factors, while the highest selectivity towards ethylene is obtained at an optimum roughness factor value of $\sim 5$ times higher than of electropolished copper. To offer an explanation for this optimum value, we need to examine other effects of improved roughness.

There are two likely causes for the enhanced catalytic performance of the roughened surface. Firstly, roughened surfaces have significantly greater density of low-coordinated sites such as steps, edges and terraces, particularly given the dendritic shape of the copper structures. Compared to terraces, steps are known to facilitate high coverage of $\mathrm{CO}$, and therefore a shift in selectivity towards $\mathrm{C}_{2+}$ hydrocarbons can be expected ${ }^{39,63}$. On the other hand, edges promote the coverage of $* \mathrm{CHO}$ and ${ }^{*} \mathrm{CH}_{2} \mathrm{O}$. At highly elevated surface roughness $(>5$ times of electropolished copper), a very large population of low-coordinate sites strongly bind $\mathrm{H}$ atoms and favor the hydrogen evolution reaction compared to $\mathrm{CO}_{2} \mathrm{RR}^{40}$. Interestingly, this is in agreement with the results presented in Figure 2, showing elevated values of $\mathrm{H}_{2}$ formation at the highest $\mathrm{CuSO}_{4}$ concentration (correlated with highest roughness factor). It is worth noting that a smooth surface mostly made of low index crystal facets, such as $\mathrm{Cu}(100)$ and $\mathrm{Cu}(111)$ is more selective towards methane and hydrogen.

Secondly, the higher active surface area of the roughened electrode leads to higher current densities and consequently, an increase in local $\mathrm{pH}$, which is known to alter the reaction pathway towards formation of ethylene $\mathrm{e}^{70,80,147-148}$. The rise of local $\mathrm{pH}$ 


\section{Chapter 6}

at high current densities occurs due to fast proton consumption at the surface. To assess the influence of roughness on current density of $\mathrm{Cu}$ electrodes, I-t curves were examined.

(a)

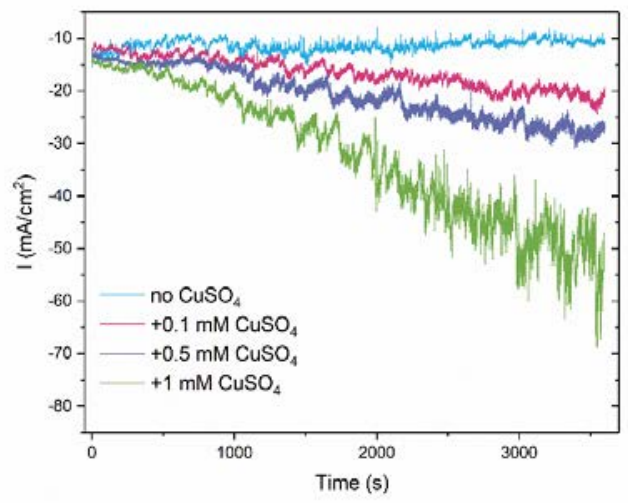

(b)

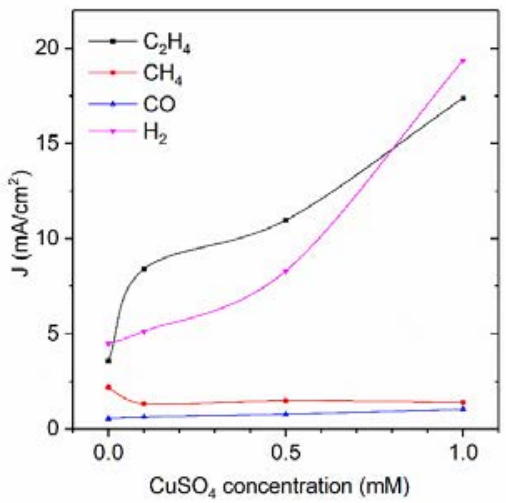

Figure 3. (a) $\mathrm{CO}_{2} \mathrm{RR}$ activity (chronoamperometry) of electropolished $\mathrm{Cu}$ foil in $\mathrm{CO}_{2}$ saturated $0.1 \mathrm{M} \mathrm{KHCO}_{3}+0,0.1,0.5$ and $1 \mathrm{mM} \mathrm{CuSO}_{4}$ electrolytes at $-1.1 \mathrm{~V}$ vs. RHE and (b) partial current density of products as a function of $\mathrm{CuSO}_{4}$ concentration.

The current density at rough $\mathrm{Cu}$ electrode (in $0.1 \mathrm{M} \mathrm{KHCO}_{3}+0.1 \mathrm{mM} \mathrm{CuSO}_{4}$ ) increased gradually from 12.2 to $20 \mathrm{~mA} . \mathrm{cm}^{-2}$ during $1 \mathrm{hr}$ of electroreduction (Fig. 3). The current density was improved more significantly as the concentration of $\mathrm{CuSO}_{4}$ was increased. In contrast, the electropolished $\mathrm{Cu}$ electrodes experienced a slight decrease in current density over time under identical conditions in the absence of $\mathrm{CuSO}_{4}$, as shown in Fig 3a. Hence, the activity of the rough electrode is superior to that of the smooth surface. Moreover, the rate of ethylene formation was notably increased as the concentration of $\mathrm{CuSO}_{4}$ in the electrolyte was increased (Fig. 3b), consistent with the effect of local $\mathrm{pH}$.

Taken together, the above discussion and our observations suggest that both, changes in surface orientation and site coordination, and the increased local $\mathrm{pH}$ at the rough electrode surface dictate the selectivity towards ethylene. This finding 
supports the work of other studies demonstrating that the highest ethylene selectivity was achieved at an optimum surface roughness factor ${ }^{40,43}$ or a balanced ratio of edge sites to plane sites in cube-shaped nanoparticles ${ }^{157}$. To establish whether addition of $\mathrm{CuSO}_{4}$ is generally enhancing performance, this was tested at variable bicarbonate concentration and electrolyte anion.

\section{Effect of bicarbonate concentration}

The effect of $\mathrm{KHCO}_{3}$ concentration on product distribution using different $\mathrm{KHCO}_{3}$ electrolytes $(0.05,0.1,0.2,0.3,0.5 \mathrm{M})$ in the presence of $0.1 \mathrm{mM} \mathrm{CuSO}_{4}$ at $-1.1 \mathrm{~V}$ vs RHE was investigated. Figure 4 provides an overview of the FE of the main products as a function of $\mathrm{KHCO}_{3}$ concentration, determined after $1 \mathrm{~h}$ of operation. As can be seen, product distribution is greatly affected by electrolyte concentration, of which the trend is generally in agreement with trends reported by others in the absence of $\mathrm{CuSO}_{4}$ in solution ${ }^{52,147,158}$. However, at the concentration of $0.5 \mathrm{M} \mathrm{KHCO}_{3}$, formation of ethylene was significantly suppressed, and the increasing trend in methane $\mathrm{FE}$ interrupted. Apparently, at $0.5 \mathrm{M} \mathrm{KHCO}_{3}$, formation of hydrocarbons is significantly inhibited by the addition of $\mathrm{CuSO}_{4}$. It seems likely that this result is due to deactivation of the $\mathrm{Cu}$ electrode against $\mathrm{CO}_{2}$ reduction. In a previous study by Kas et al., it was established that the oxide derived $\mathrm{Cu}$ electrode was deactivated in $0.5 \mathrm{M} \mathrm{KHCO}_{3}$ electrolyte at significantly higher rates as compared to in $0.1 \mathrm{M}$ electrolyte ${ }^{147}$. To gain more insight, in the final section we employ in-situ SERS to investigate the interfacial phenomena at $0.5 \mathrm{M} \mathrm{KHCO}_{3}$. 


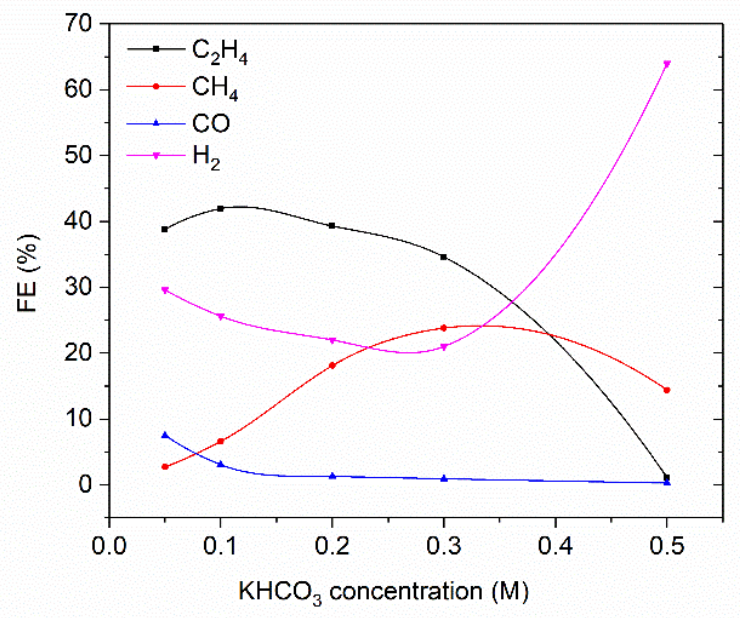

Figure 4. Faradaic efficiency of $\mathrm{C}_{2} \mathrm{H}_{4}, \mathrm{CH}_{4}, \mathrm{CO}$ and $\mathrm{H}_{2}$ vs. $\mathrm{KHCO}_{3}$ concentration with $0.1 \mathrm{mM} \mathrm{CuSO}_{4}$ at $-1.1 \mathrm{~V}$ vs. RHE.

\section{Effect of electrolyte cation}

The effect of alkali-metal cations on product distribution in the presence of 0.1 $\mathrm{mM} \mathrm{CuSO}_{4}$ was studied at $-1.1 \mathrm{~V}$ vs RHE as shown in Figure 5. Increasing the alkalimetal cation size in the order of $\mathrm{Li}^{+}<\mathrm{Na}^{+}<\mathrm{K}^{+}<\mathrm{Cs}^{+}$significantly enhances ethylene formation, consistent with the literature ${ }^{46,152,159-161}$, and the presence of $\mathrm{CuSO}_{4}$ does not seem to affect the trend. Quantitatively the ethylene partial current density is somewhat larger in the presence of $\mathrm{CuSO}_{4}$, particularly for the $\mathrm{K}^{+}$and $\mathrm{Na}^{+}$ electrolytes. DFT calculations by Gao et al. attributed the promoting effect of $\mathrm{K}^{+}$and $\mathrm{Cs}^{+}$on ethylene production to formation of intermediates ( $\mathrm{CO}^{*}$, OCCO*, $\mathrm{OCCOH}^{*}$ ) favoring the $\mathrm{C}_{2}+$ pathway ${ }^{159}$. Furthermore, Frumkin proposed that larger cations influence surface reactions by stabilizing anion intermediates on the cathode surface, enabling higher current densities ${ }^{162}$, in accordance with the present results. Smaller cations on the other hand, have large hydrating shells and hence lower propensity for adsorption on the electrode surface. This causes increase of $\mathrm{Cu}-\mathrm{H}$ coverage and 
favors hydrogen evolution ${ }^{161}$. Methane formation was most predominant in the $\mathrm{Na}^{+}$ electrolyte.

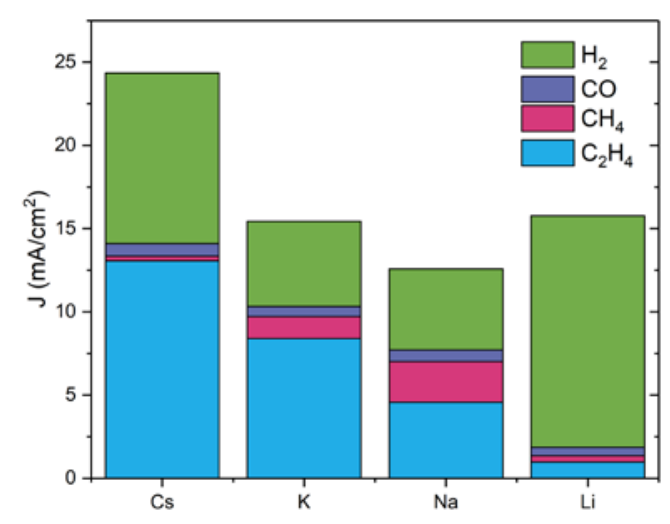

Figure 5. Partial current density of $\mathrm{C}_{2} \mathrm{H}_{4}, \mathrm{CH}_{4}, \mathrm{CO}$ and $\mathrm{H}_{2}$ in $\mathrm{CO}_{2}$-saturated $0.1 \mathrm{M} \mathrm{MHCO}_{3}$ ( $\mathrm{M}=\mathrm{Li}, \mathrm{Na}, \mathrm{K}, \mathrm{Cs})+0.1 \mathrm{mM} \mathrm{CuSO}_{4}$ electrolyte at $-1.1 \mathrm{~V}$ vs. RHE.

\section{In situ Raman spectroscopy of $\mathrm{Cu}^{2+}$-mediated reduction of $\mathrm{CO}_{2}$}

SERS was performed on a $\mathrm{Cu}$ electrode in $\mathrm{CO}_{2}$-saturated $0.1 \mathrm{M} \mathrm{KHCO}_{3}$ electrolyte in the absence or presence of a flowing solution of $1 \mathrm{mM} \mathrm{CuSO}_{4}$, at a constant potential of $-1.1 \mathrm{~V}$ vs. RHE. The time dependent in-situ Raman spectra of the $\mathrm{Cu}$ electrode at $-1.1 \mathrm{~V}$ are presented in Figure 6 (each spectrum, bottom to top, was recorded after 10 consecutive minutes). The first measurement was collected at open circuit potentials and clearly revealed the characteristics of $\mathrm{Cu}_{2} \mathrm{O}$ at 150,400 , 525 and $620 \mathrm{~cm}^{-1} 163$. After applying the $-1.1 \mathrm{~V}$ vs. RHE, $\mathrm{Cu}_{2} \mathrm{O}$ peaks rapidly disappear, and major peaks at 310, 380 and $518 \mathrm{~cm}^{-1}$ develop. These peaks can be assigned to surface oxide/hydroxides $\left(\mathrm{Cu}(\mathrm{O})_{\mathrm{x}} /(\mathrm{OH})_{\mathrm{y}}\right){ }^{164}$. Based on our previous study ${ }^{165}$, we assign the peaks at 310 and $380 \mathrm{~cm}^{-1}$ to $\mathrm{CuO}$ and the one at $518 \mathrm{~cm}^{-1}$ to $\mathrm{Cu}-\mathrm{OH}$. Initially, the 380 and $518 \mathrm{~cm}^{-1}$ bands dominate, while the $380 \mathrm{~cm}^{-1}$ decreases, the $310 \mathrm{~cm}^{-1}$ peak appears, and the $518 \mathrm{~cm}^{-1}$ band increases and broadens as a function of time, suggesting compositional changes in the $\mathrm{CuO} / \mathrm{OH}$ deposit. 


\section{Chapter 6}

Nevertheless, the persistence of these bands suggest that the surface of the copper electrode is not fully reduced, and oxide/hydroxide species cover the surface when at potentials where $\mathrm{CO}_{2}$ is reduced to ethylene. In accordance with the present results, a number of previous studies have confirmed the presence of $\mathrm{Cu}^{+}$at negative potentials with the help of in-situ techniques ${ }^{166-170}$. Generally this has been proposed as being favorable for the ethylene FE, but in the following we will demonstrate that in fact the intensity of $\mathrm{Cu}^{+}$(identified by $\mathrm{Cu}-\mathrm{OH}$ ) inversely correlates with the surface coverage of $\mathrm{CO}$, which positively correlates with the FE towards ethylene.

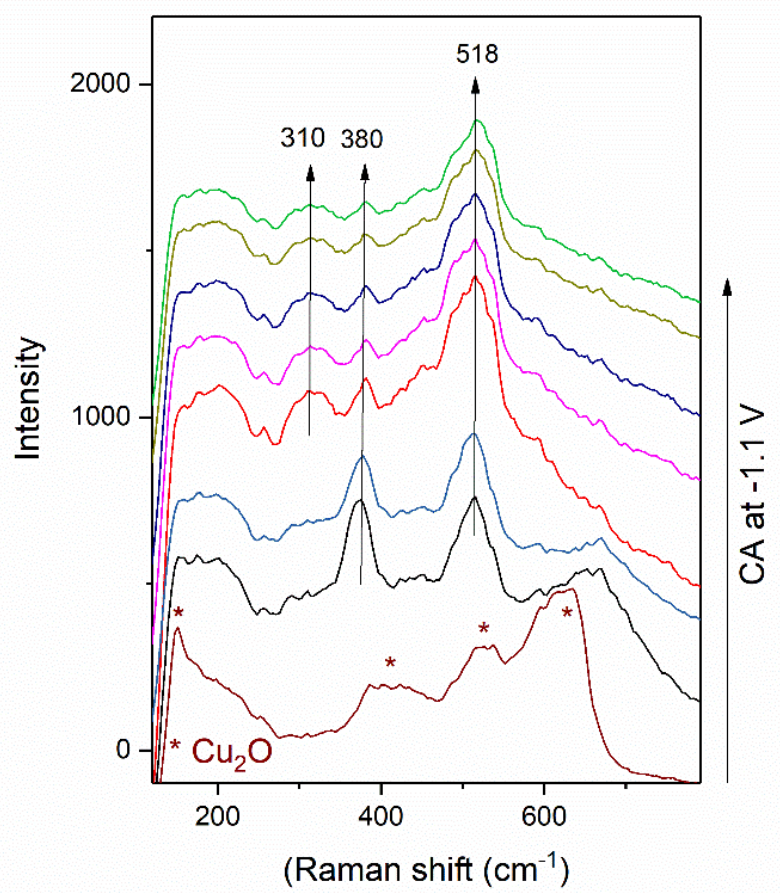

Figure 6. In-situ SERS of a Cu surface in $\mathrm{CO}_{2}$ saturated $0.1 \mathrm{M} \mathrm{KHCO}_{3}+1 \mathrm{mM} \mathrm{CuSO}_{4}$ during $1 \mathrm{hr}$ of CA at $-1.1 \mathrm{~V}$. 
(a)

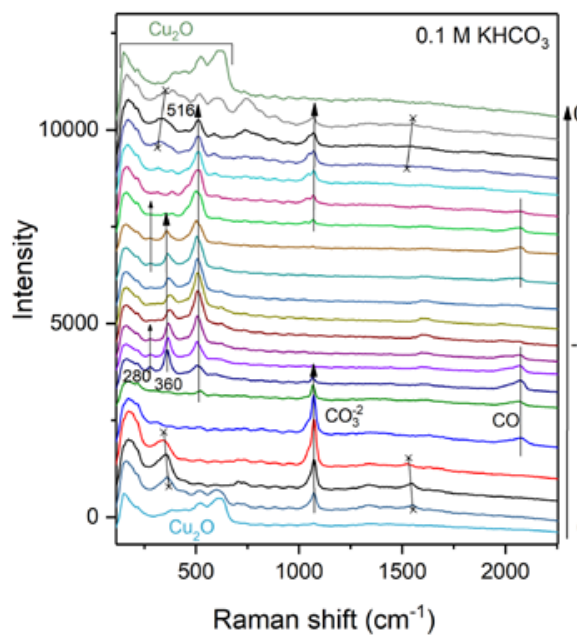

(b)

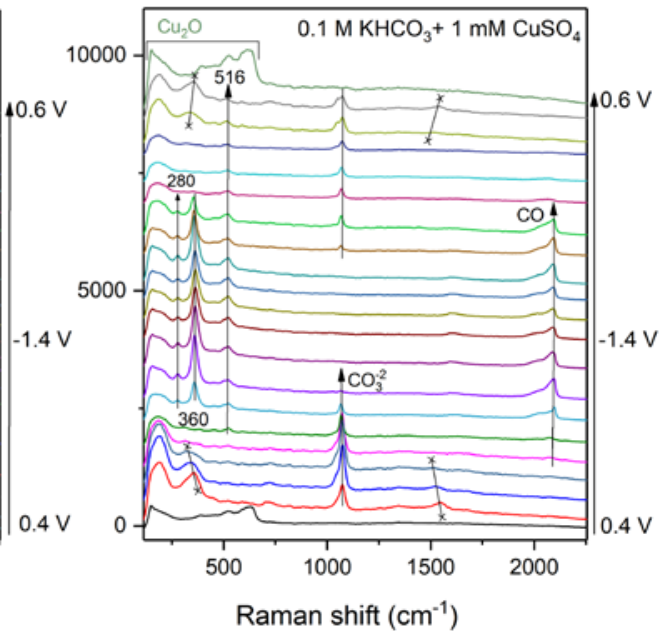

Figure 7. In-situ SERS of Cu surface in $\mathrm{CO}_{2}$ saturated (a) $0.1 \mathrm{M} \mathrm{KHCO}_{3}$ and (b) $0.1 \mathrm{M}$ $\mathrm{KHCO}_{3}+1 \mathrm{mM} \mathrm{CuSO}_{4}$ (already subjected to $1 \mathrm{hr}$ of CA in the same electrolyte). Spectra were collected during a CV with the rate of $10 \mathrm{mV} / \mathrm{sec}$ and the potential interval between spectra is $0.2 \mathrm{~V}$.

First we show in Figure 7 the spectra of the electropolished and rough $\mathrm{Cu}$ electrodes during the $\mathrm{CV}$ in $\mathrm{CO}_{2}$ saturated $0.1 \mathrm{M} \mathrm{KHCO}_{3}$ and $0.1 \mathrm{M} \mathrm{KHCO}_{3}+1 \mathrm{mM}$ $\mathrm{CuSO}_{4}$ electrolyte, respectively. During a negative scan, on electropolished $\mathrm{Cu}$, adsorbed CO starts to develop at the potential of $-0.4 \mathrm{~V}$, identified by the Raman intensity at $\sim 2080 \mathrm{~cm}^{-1}$. Also the peak at $280 \mathrm{~cm}^{-1}$ can be assigned to adsorbed CO, while adsorbed CO is most clearly revealed by the growth of peak at $360 \mathrm{~cm}^{-1}$, showing similar dynamics, but more clearly resolved, as observed for the $\sim 2080 \mathrm{~cm}^{-}$ ${ }^{1}$ band. As the potential was swept more negatively, these peaks disappeared, while these re-appeared (but less intensively) during the positive scan in a similar potential range (Figure 7a). If we now turn to the spectra in the presence of $\mathrm{CuSO}_{4}$ (Fig. 7b), the same set of bands not only do not disappear at highly negative potentials, but are also generally more pronounced, indicative of a larger concentration of adsorbed $\mathrm{CO}^{171-174}$. These peaks correspond to libration, frustrated translation, and the 


\section{Chapter 6}

stretching vibration of the adsorbed CO molecule, respectively. To validate this assignment and correlation between these peaks, in-situ SERS of $\mathrm{Cu}$ electrode in $\mathrm{CO}_{2}$ saturated $0.1 \mathrm{M} \mathrm{KHCO}_{3}+1 \mathrm{mM} \mathrm{CuSO}_{4}$ during $1 \mathrm{hr}$ of CA at $-0.8 \mathrm{~V}$ was carried out (See Figure S7). This potential was chosen to assure CO is formed, as is confirmed by the presence of the $2080 \mathrm{~cm}^{-1}$ band. The simultaneous development of these peaks validates their assignment to a single species (CO). It has been suggested that a high surface coverage of CO is a key factor in selectivity towards ethylene ${ }^{74}$, 76, 101-102, 159. Building on our earlier discussions, we hypothesize that on roughened $\mathrm{Cu}$ electrodes by $\mathrm{Cu}$ deposition, the abundance of low-coordinated sites induces a high CO coverage. The increased CO coverage enhances CO dimerization and shifts the selectivity towards formation of ethylene. This finding broadly supports the work of other studies demonstrating that a CO coupling mechanism was enhanced at a high local $\mathrm{pH}^{85,147-148}$. On the other hand, on the electropolished electrode with lower CO coverage, hydrogenation of adsorbed $\mathrm{CO}$ forms $* \mathrm{COH}$ and promotes reaction pathways toward $\mathrm{C}_{1}$ products.

Turning back to Figure 7, at the potential of $-0.6 \mathrm{~V}$, a peak was developed at 518 $\mathrm{cm}^{-1}$ which can be assigned to $\mathrm{Cu}-\mathrm{OH}$, indicative of $\mathrm{Cu}^{+}$. What is striking about this peak is that it coexists with the series of bands assigned to $\mathrm{CO}$ and is present at highly negative potentials where hydrocarbons are dominant products. However, by comparing Figs. 7a and b, it can be seen that in Fig 7b the peak at $518 \mathrm{~cm}^{-1}$ is significantly suppressed. This was consistent through all the swept potentials and suggests that the surface hydroxide is less abundant, and indeed inversely correlates with the surface coverage of CO. 


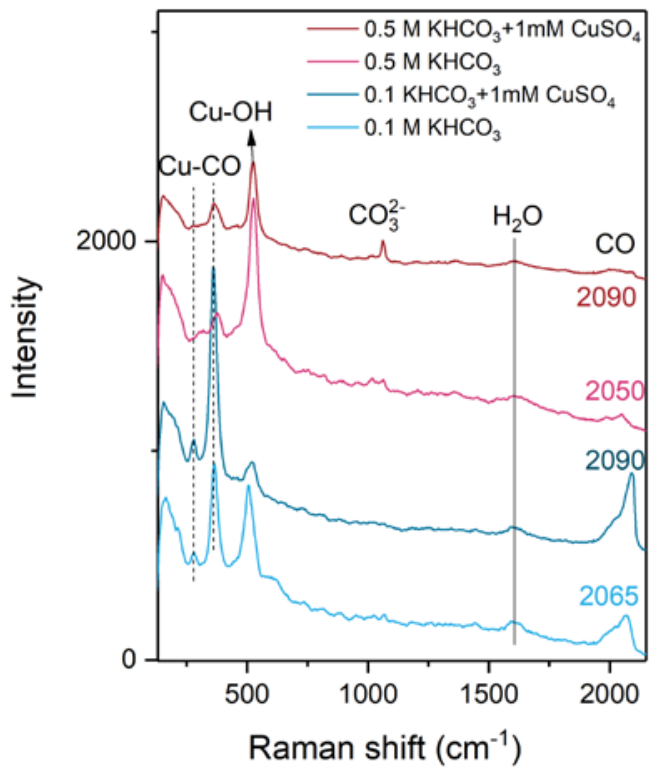

Figure 8. Comparison of in-situ SER spectra of $\mathrm{Cu}$ surface in $\mathrm{CO}_{2}$ saturated $0.1 \mathrm{M}$ $\mathrm{KHCO}_{3}, 0.1 \mathrm{M} \mathrm{KHCO}_{3}+1 \mathrm{mM} \mathrm{CuSO}_{4}, 0.5 \mathrm{M} \mathrm{KHCO}_{3}$ and $0.5 \mathrm{M} \mathrm{KHCO}_{3}+1 \mathrm{mM} \mathrm{CuSO}_{4}$ at $-1 \mathrm{~V}$.

To support the inverse correlation, SERS was performed on $\mathrm{Cu}$ electrodes in $\mathrm{CO}_{2}$ saturated $0.5 \mathrm{M} \mathrm{KHCO}_{3}$ and $0.5 \mathrm{M} \mathrm{KHCO}_{3}+1 \mathrm{mM} \mathrm{CuSO}_{4}$ electrolytes during $\mathrm{CVs}$ from +0.4 to $-1.4 \mathrm{~V}$ (See figures S8 and S9). To compare the results with the results of $0.1 \mathrm{M} \mathrm{KHCO}_{3}$ experiments (Fig. 7), spectra taken at $-1 \mathrm{~V}$ are presented in Figure 8.

What is striking about this figure is that when using $0.1 \mathrm{M} \mathrm{KHCO}_{3}$ electrolyte, all three peaks of CO at 275, 360 and $2090 \mathrm{~cm}^{-1}$ (blue spectra) show significantly higher intensities compared to $0.5 \mathrm{M} \mathrm{KHCO}_{3}$ conditions (red spectra). In addition, at $0.1 \mathrm{M}$ $\mathrm{KHCO}_{3}$, the intensities of the $\mathrm{Cu}-\mathrm{OH}$ peaks at $520 \mathrm{~cm}^{-1}$ were much lower than the peaks at $360 \mathrm{~cm}^{-1}$ (representing $\mathrm{CO}$ ). This indicates that in $0.1 \mathrm{M} \mathrm{KHCO}_{3}$ electrolytes, the surface coverage of $\mathrm{CO}$ is higher and the surface composition contains less hydroxide (hence more metallic $\mathrm{Cu}$ ) compared to $0.5 \mathrm{M} \mathrm{KHCO}_{3}$. These 


\section{Chapter 6}

observations accords well with the results of product distribution, showing correlations between CO coverage and formation of ethylene.

Another important finding was revealed by comparing the spectra in $0.5 \mathrm{M}$ $\mathrm{KHCO}_{3}$ and $0.5 \mathrm{M} \mathrm{KHCO}_{3}+1 \mathrm{mM} \mathrm{CuSO}_{4}$ electrolytes. In the latter, the intensity of CO band is extremely low and the carbonate band at $1070 \mathrm{~cm}^{-1}$ indicates that the electrode surface is still partially occupied by this species even at highly negative potentials (See figure S9). It can thus be suggested that the adsorbed carbonate has limited the formation of $\mathrm{CO}$ intermediate, in agreement with the suppression of ethylene formation on the same surface as shown in figure 4. It is interesting to note that in both $\mathrm{KHCO}_{3}$ concentrations with $\mathrm{CuSO}_{4}$ present in the electrolyte, the same CO band position was observed at $2090 \mathrm{~cm}^{-1}$ which suggests that similar linearly bonded CO adsorption sites were occupied.

The results of this study indicate that a combination of both high CO coverage and relatively small intensity of $\mathrm{Cu}-\mathrm{OH}$ band is crucial to high selectivity towards ethylene.

Several studies have employed in-situ techniques to reveal the catalytically active sites in $\mathrm{CO}_{2} \mathrm{RR}$. The majority has demonstrated that metallic $\mathrm{Cu}$ sites are responsible for $\mathrm{CO}_{2}$ activation while others attributed the activity to $\mathrm{Cu}^{+}$species or the $\mathrm{Cu}^{+} / \mathrm{Cu}^{0}$ interface. In accordance with the present results, previous mechanistic studies revealed that $\mathrm{CO}$ dimerization is stabilized at the interface between surface of metallic $\mathrm{Cu}$ and $\mathrm{Cu}^{+175-176}$. They concluded that the synergy between $\mathrm{Cu}^{0}$ and $\mathrm{Cu}^{+}$ promoted both $\mathrm{CO}_{2}$ activation and $\mathrm{CO}$ dimerization, while blocking $\mathrm{C}_{1}$ pathways. Therefore, we conclude that the presence of both $\mathrm{Cu}^{0}$ and $\mathrm{Cu}^{+}$assist $\mathrm{C}-\mathrm{C}$ bond formation and is responsible for ethylene production.

Another key results is the correlation between the set of peaks at $360-320 \mathrm{~cm}^{-1}$ and $1550-1510 \mathrm{~cm}^{-1}$ which appear at potentials from +0.2 to $-0.4 \mathrm{~V}$ on the negative scan and from +0.2 to $+0.6 \mathrm{~V}$ on the positive scan. The correlation can be easily 
noticed by looking at crossed arrows in figure 8b. Several reports have assigned the $1540 \mathrm{~cm}^{-1}$ band to adsorbed carbonate ${ }^{73,99,110,165,177}$. Based on these reports on peak position and observed potentials range, we assign this set of peaks to adsorbed carbonate.

Together these spectroscopic evidence showed that increased roughness promotes selectivity towards ethylene. The shift of reaction pathway due to high density of non-coordinated sites stabilizing CO adsorbed species was confirmed by in-situ SERS spectroscopy. Besides, we concluded that both metallic $\mathrm{Cu}$ and oxide/hydroxides are stable at $\mathrm{CO}_{2} \mathrm{RR}$ potentials and are key for controlling selectivity. Our study has demonstrated that both morphological effect and local $\mathrm{pH}$ effect are crucial for activating ethylene pathways on $\mathrm{Cu}$ electrodes.

\subsection{Conclusion}

In this work, we report the highly selective and stable electroreduction of $\mathrm{CO}_{2}$ to ethylene. In situ electrodeposition process was used to modify the surface of electropolished $\mathrm{Cu}$ foils to generate microstructured morphology. The insitu formation of this electrocatalyst resulted in highly roughened surface areas and higher availability of active sites. An optimized population of surface defects in addition to local $\mathrm{pH}$ effects were found to be determining factors for the enhanced selectivity towards ethylene. Based on our in-situ SERS measurements, we showed that high CO coverage on rough electrodes is responsible for selectivity towards formation of ethylene. We also provided direct evidence that $\mathrm{Cu}$ oxide/hydroxide species are stable at highly negative potentials during $\mathrm{CO}_{2} \mathrm{RR}$ and likely diminish selectivity. This work provides a strategy for in situ modification of surface morphology on $\mathrm{Cu}$ electrodes to improve the selectivity towards ethylene. 


\subsection{Appendix}
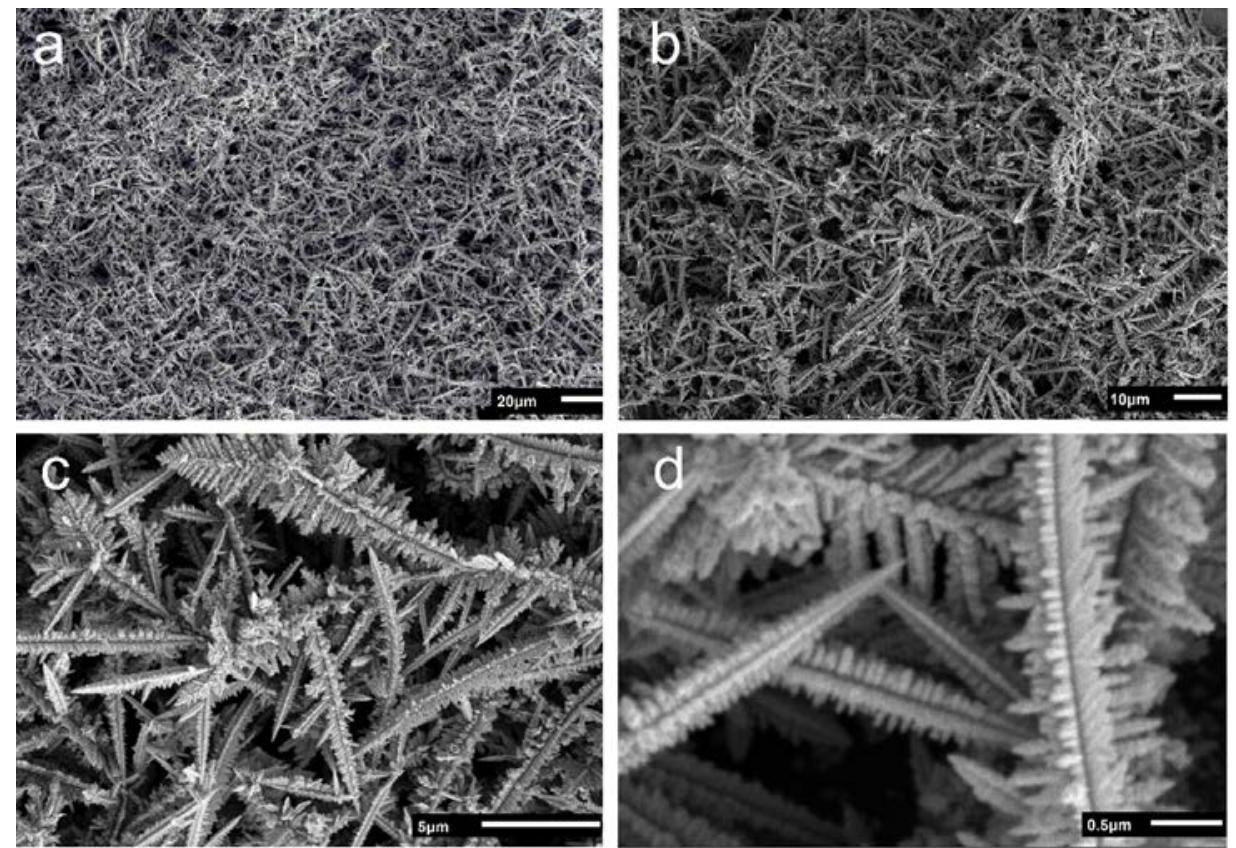

Figure S2. SEM images showing the morphology of the film after1 hour of reduction at $1.1 \mathrm{~V}$ vs RHE in $0.1 \mathrm{M} \mathrm{KHCO}_{3}+1 \mathrm{mM} \mathrm{CuSO}_{4}$ at different magnifications.

(a)

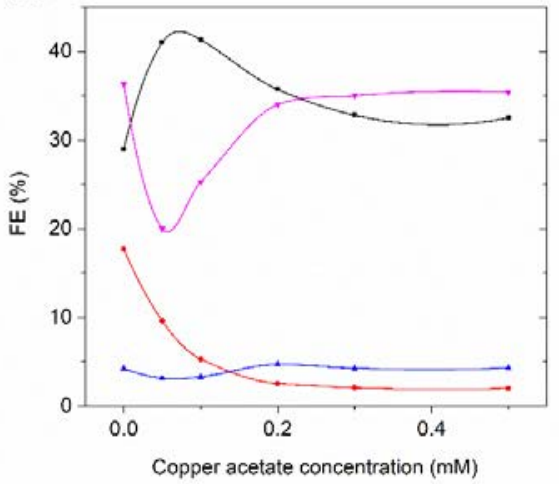

(b)

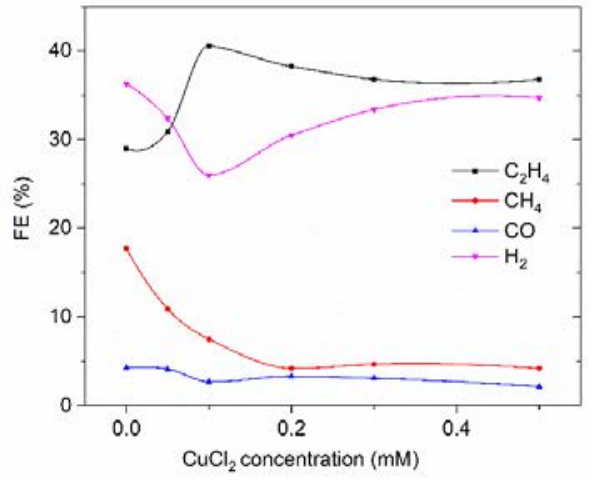

Figure S3. Faradaic efficiency of $\mathrm{C}_{2} \mathrm{H}_{4}, \mathrm{CH}_{4}, \mathrm{CO}$ and $\mathrm{H}_{2}$ vs. added (a) copper acetate and (b) $\mathrm{CuCl}_{2}$ concentration to $0.1 \mathrm{M} \mathrm{KHCO}_{3}$ at $-1.1 \mathrm{~V}$ vs. RHE. 
(a)

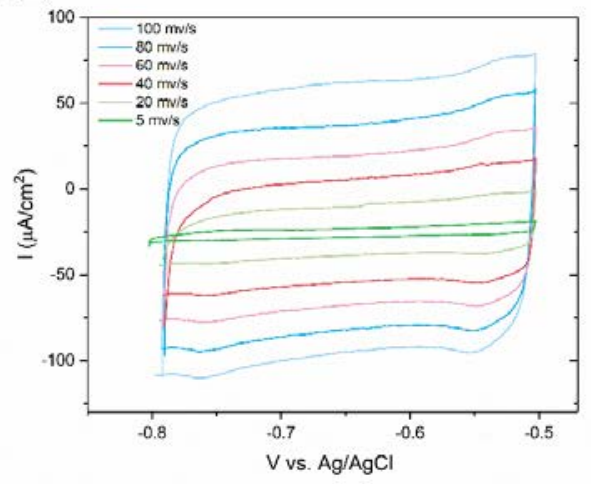

(b)

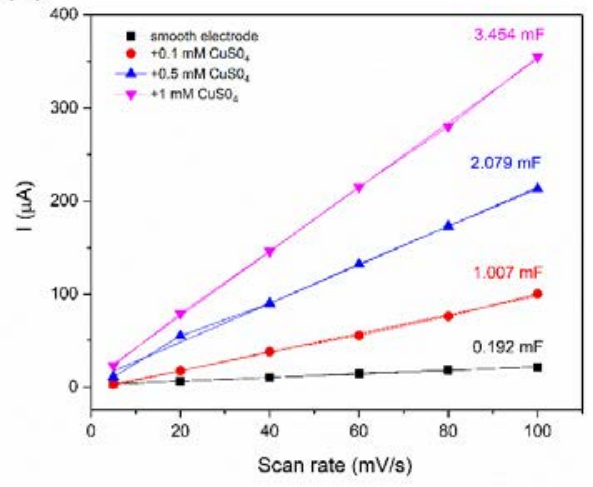

Figure S4. (a) Cyclic voltammograms of the $\mathrm{Cu}$ electrode in $0.1 \mathrm{M} \mathrm{KHCO}_{3}+0.1 \mathrm{mM}$ $\mathrm{CuSO}_{4}$ subjected to $1 \mathrm{hr}$ electrochemical reduction, followed by various scan rates in a potential window where only double-layer charging and discharging is relevant, (b) Double layer capacitance values of a smooth $\mathrm{Cu}$ electrode and the rough electrodes after $1 \mathrm{hr}$ of electroreduction in $0.1 \mathrm{~m} \mathrm{KHCO}_{3}+0.1,0.5$ and $1 \mathrm{mM} \mathrm{CuSO}_{4}$. The slopes have been calculated by linear fitting in Origin Pro.

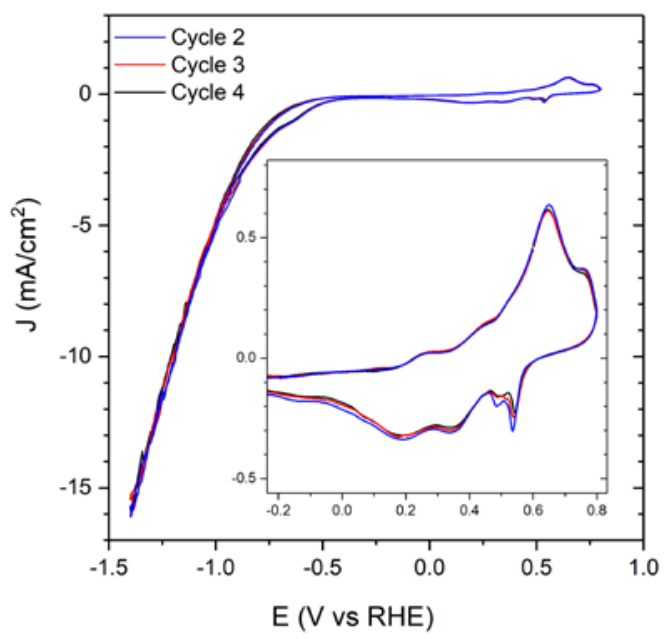

Figure S5. Cyclic voltammograms of $\mathrm{Cu}$ electrodes in $0.1 \mathrm{M} \mathrm{KHCO}_{3}$ electrolyte with scan rate of $10 \mathrm{mV} / \mathrm{sec}$. 


\section{Chapter 6}

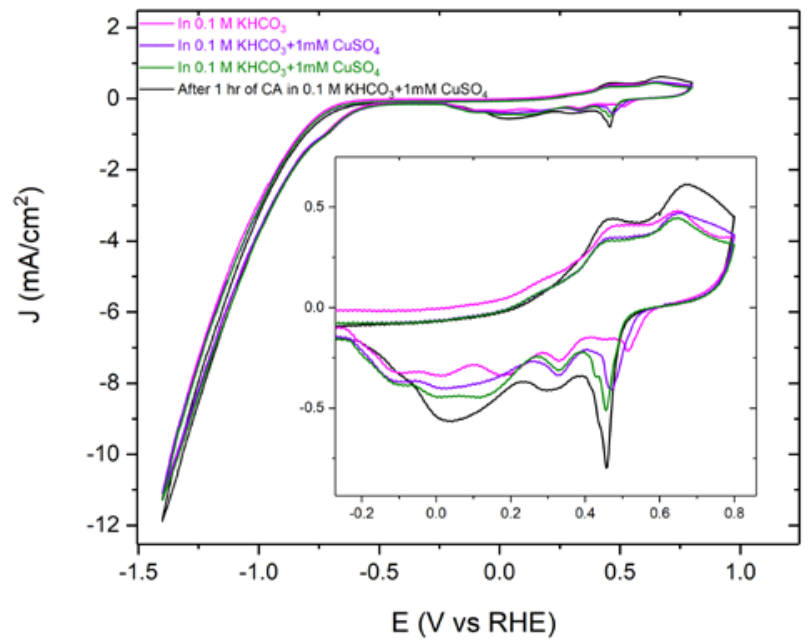

Figure S6. Cyclic voltammograms of $\mathrm{Cu}$ electrodes in $0.1 \mathrm{M} \mathrm{KHCO}_{3}, 0.1 \mathrm{M} \mathrm{KHCO}_{3}+1$ $\mathrm{mM} \mathrm{CuSO}_{4}$ and after $1 \mathrm{hr}$ of CA in the same electrolyte with scan rate of $50 \mathrm{mV} / \mathrm{sec}$.

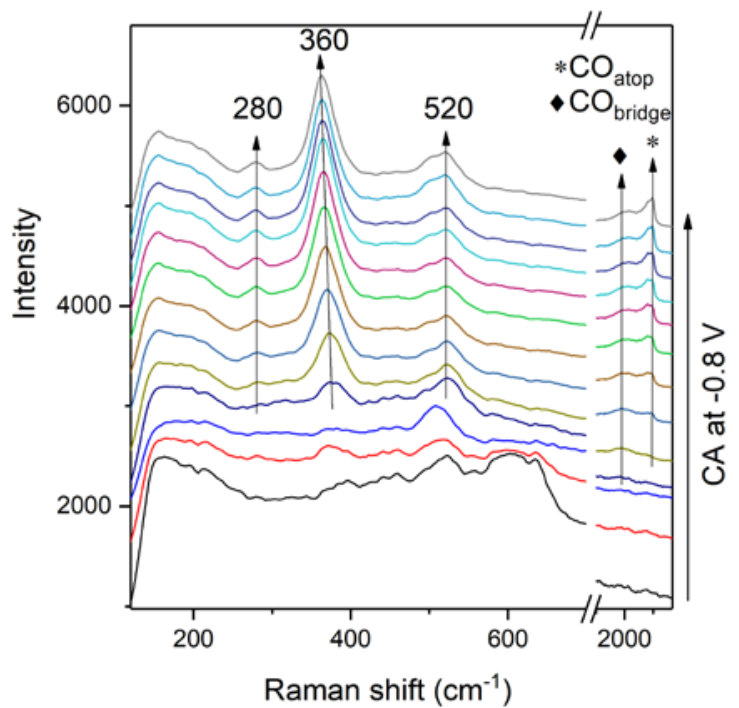

Figure S7. In-situ SERS of $\mathrm{Cu}$ surface in $\mathrm{CO}_{2}$ saturated $0.1 \mathrm{M} \mathrm{KHCO}_{3}+1 \mathrm{mM} \mathrm{CuSO}_{4}$ during $1 \mathrm{hr}$ of CA at $-0.8 \mathrm{~V}$. 


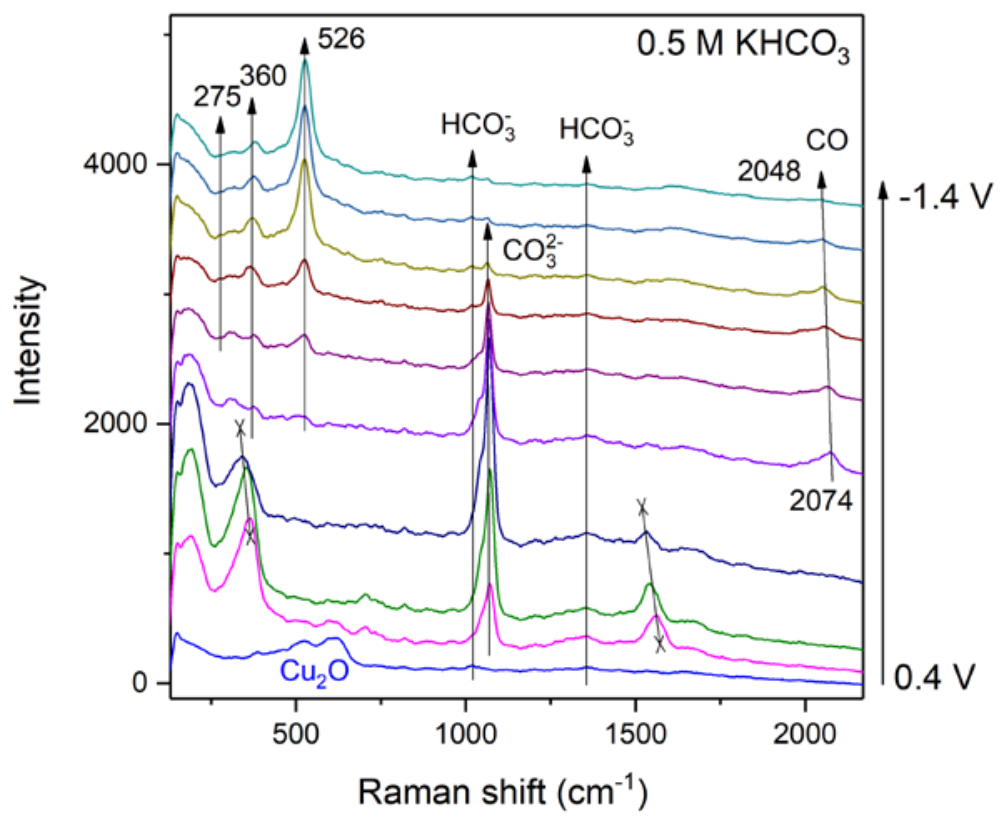

Figure S8. In-situ SERS of $\mathrm{Cu}$ surface in $\mathrm{CO}_{2}$ saturated $0.5 \mathrm{M} \mathrm{KHCO}_{3}$. Spectra were collected during a $\mathrm{CV}$ with the rate of $10 \mathrm{mV} / \mathrm{sec}$ and the potential interval between spectra is $0.2 \mathrm{~V}$. 


\section{Chapter 6}

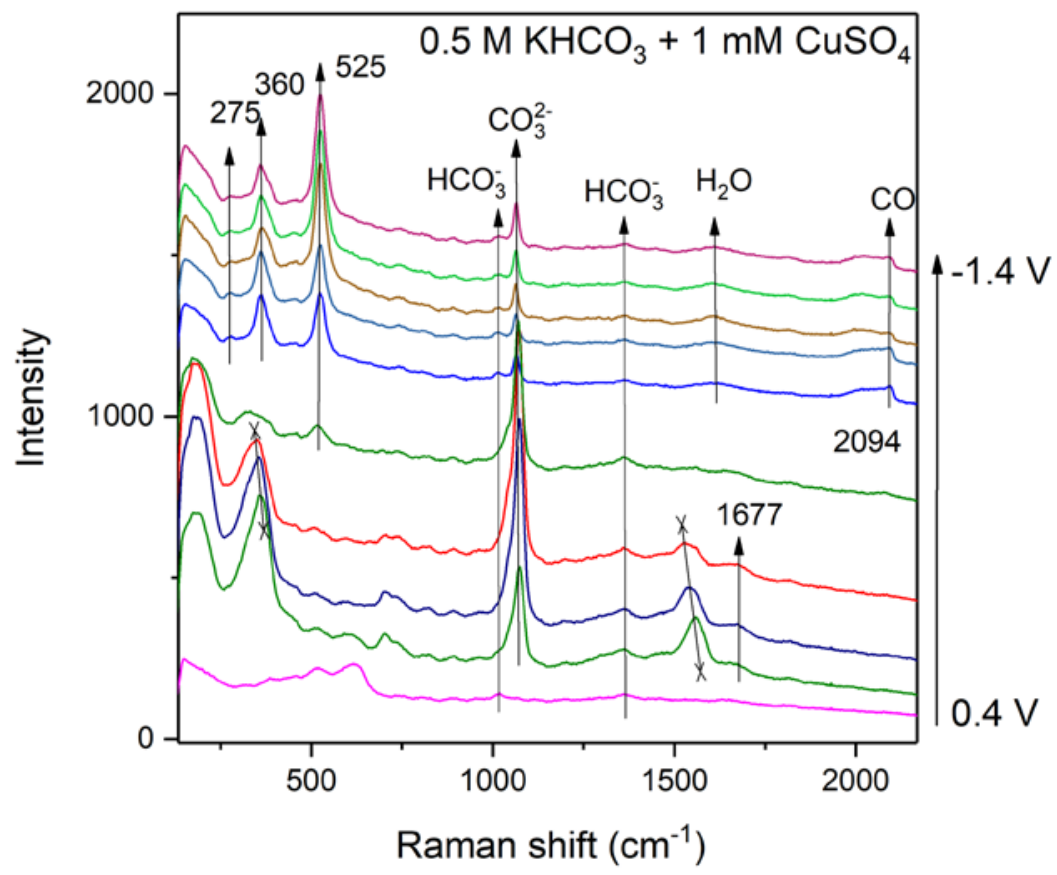

Figure S9. In-situ SERS of $\mathrm{Cu}$ surface in $\mathrm{CO}_{2}$ saturated $0.5 \mathrm{M} \mathrm{KHCO}_{3}+1 \mathrm{mM} \mathrm{CuSO}_{4}$ (already subjected to $1 \mathrm{hr}$ of CA in the same electrolyte). Spectra were collected during a CV with the rate of $10 \mathrm{mV} / \mathrm{sec}$ and the potential interval between spectra is $0.2 \mathrm{~V}$. 


\section{Chapter 7.}

\section{In situ Raman study of potential dependent surface adsorbed carbonate, $\mathrm{CO}, \mathrm{OH}$ and $\mathrm{C}$-species on Cu-electrodes during electrochemical reduction of $\mathrm{CO}_{2}$}

\section{Abstract}

Using In-situ Surface-enhanced Raman spectroscopy (SERS) to study Cucatalyzed electrochemical reduction of $\mathrm{CO}_{2}$ in carbonate solution, and ${ }^{13} \mathrm{C} /{ }^{12} \mathrm{C}$ and $\mathrm{D}_{2} \mathrm{O} / \mathrm{H}_{2} \mathrm{O}$ isotopic labeling for assignment, we show reduction of $\mathrm{Cu}(\mathrm{I})$ oxide is accompanied by adsorption of predominantly monodentate carbonate starting at $\sim 1067 \mathrm{~cm}^{-1}$ in the potential range from $[+0.2 \mathrm{~V} \rightarrow-0.2 \mathrm{~V}]$. While the presence of a band at $\sim 1540 \mathrm{~cm}^{-1}$ has been previously assigned to adsorbed carboxylate $\left({ }^{*} \mathrm{CO}_{2}{ }^{-}\right)$, we alternatively assign this to bidentate carbonate, with a strong Stark tuning effect with a rate of $\sim 60 \mathrm{~cm}^{-1} / \mathrm{V}$. As expected, appearance of surface CO was observed in 


\section{Chapter7}

the range of $\left[-0.4 \mathrm{~V} \rightarrow-1.0 \mathrm{~V}\right.$ ], clearly identified by the $\mathrm{Cu}-\mathrm{CO}$ vibration at $360 \mathrm{~cm}^{-}$ 1 . At the more negative end of this potential range, we identified the formation of copper hydroxide, and for the first time a surface-carbon species, showing Raman bands at $\sim 525 \mathrm{~cm}^{-1}(\mathrm{Cu}-\mathrm{OH})$ and $\sim 500$ (Cu-C), respectively. In the potential range of $[-1.0 \mathrm{~V} \rightarrow-1.4 \mathrm{~V}]$, surface $\mathrm{CO}$ disappeared, but the $\mathrm{Cu}-\mathrm{OH}$ and $\mathrm{Cu}-\mathrm{C}$ species were persistent. Interestingly positive polarization at $>0.1 \mathrm{~V}$ converts these species and restores surface $\mathrm{Cu}(\mathrm{I})$ oxide, rendering the surface processes completely repeatable.

\subsection{Introduction}

The reduction of $\mathrm{CO}_{2}$ to value-added chemicals such as hydrocarbons and alcohols has received a great deal of attention in the scientific literature. Copper is the most promising electrocatalyst for this reaction ${ }^{23,80}$. However, tuning the catalyst to achieve high energy efficiency and product selectivity, is still a significant challenge. To this purpose, understanding of the nature of the catalytically active site(s), rate determining steps, and interfacial phenomena is critical. Despite major scientific advances, these are still not fully resolved.

In general, it is well established that native, crystalline $\mathrm{Cu}$ oxides $\left(\mathrm{Cu}_{2} \mathrm{O}, \mathrm{CuO}\right)$ are reduced to crystalline metallic $\mathrm{Cu}$ at the negative potentials required for $\mathrm{CO}_{2} \mathrm{RR}$. However, residual (hydr)oxide, either subsurface or surface-adsorbed, as well as carbonates, have also been proposed to play a major role in controlling reaction selectivity. In oxide-derived copper electrocatalysts, existence of subsurface oxygen is believed to play a role in selectivity towards multicarbon products ${ }^{178}$. Alternatively, $\mathrm{Cu}^{+}$sites remaining on the catalyst surface during the reaction have also been considered as active sites ${ }^{179-180}$.

Electrochemical surface-enhanced vibrational spectroscopy has already established itself as a powerful tool to examine the presence of adsorbed species and related surface phenomena. For instance, in our recent study, we explored surface 
adsorbed products and intermediates of $\mathrm{CO}_{2} \mathrm{RR}$ on $\mathrm{Cu}$ using in-situ surfaceenhanced infrared absorption spectroscopy (SEIRAS), and demonstrated the presence of a variety of species, including adsorbed carbonates, adsorbed CO, and possibly a carbon dioxide dimer radical anion ${ }^{73}$. However, due to limitations in the spectral range of the SEIRAS technique, the presence of surface (hydro)oxides during $\mathrm{CO}_{2} \mathrm{RR}$ is difficult to identify.

Compared to SEIRAS, which does not provide sufficient throughput in the lowwavenumber region, Surface Enhanced Raman Spectroscopy (SERS) lowers the accessible range well below $1000 \mathrm{~cm}^{-1}$, where metal-oxide/hydroxide vibrations can be observed. In addition, while SEIRAS spectra are dependent on reference spectra, sometimes leading to complicated band patterns in in situ measurements, SERS spectra show absolute, real-time intensities. Based on this, besides detection of adsorbed species ${ }^{181-182}$, in-situ SERS is used to monitor the oxidation state of catalyst surface ${ }^{106,154,156,163,174}$. Surprisingly, to the best of our knowledge, the number of studies that employed in-situ techniques to demonstrate the presence of surface $\mathrm{Cu}^{+}$species during $\mathrm{CO}_{2} \mathrm{R}$ is quite limited ${ }^{166-170}$.

Herein, we report an in situ SERS investigation of electrochemical reduction of $\mathrm{CO}_{2}$ on electropolished, polycrystalline $\mathrm{Cu}$ at a wide range of potentials. We consistently used $0.1 \mathrm{M} \mathrm{KHCO}_{3}$ as electrolyte, which we previously demonstrated to lead to locally high $\mathrm{pH}$ values, which promote formation of ethylene ${ }^{3}$. Although highly SERS-active substrates normally suffer from instability, causing poor reversibility ${ }^{183}$, our electrodes showed excellent activity and reversibility in the potential region chosen for this study. In other words, compared to previous studies, we could obtain spectra with high intensity of adsorbed species even at highly negative potentials and during the anodic scan. We observed potential-dependent features associated with carbonates, bicarbonates, CO, and most importantly hydroxide species and a stable C-containing species on $\mathrm{Cu}$ using a combination of SERS and ${ }^{13} \mathrm{C} /{ }^{12} \mathrm{C}$ and $\mathrm{D} / \mathrm{H}$ isotopic labeling. Most importantly, we provide evidence 


\section{Chapter7}

that not only $\mathrm{Cu}-\mathrm{OH}$, but also a $\mathrm{Cu}-\mathrm{C}$ species remain persistent on the surface of the copper electrode, when active in the formation of $\mathrm{CO}$, ethylene and methane, likely deactivating the surface.

\subsection{Experimental Section}

\section{Materials and electrode preparation}

Polycrystalline $\mathrm{Cu}$ electrodes were prepared by mechanical polishing, followed by anodic treatment (in $85 \%$ phosphoric acid, potentiostatically at $3 \mathrm{~V}$ vs. a graphite foil counter electrode), and cleaning ultrasonically in ethanol and water.

The electrolyte solutions of $\mathrm{KHCO}_{3}$ (Sigma Aldrich, 99.99\% metals basis) and $\mathrm{KH}^{13} \mathrm{CO}_{3}$ (Sigma Aldrich, 99 atom $\%{ }^{13} \mathrm{C}$ ) were prepared using deionized water (Millipore MilliQ, 18.2 $\mathrm{M} \Omega \mathrm{cm}$ ). Solution of $0.1 \mathrm{M} \mathrm{KDCO}_{3}$ was prepared by purging $\mathrm{CO}_{2}$ in $0.05 \mathrm{M} \mathrm{K}_{2} \mathrm{CO}_{3}$ (Sigma Aldrich, ACS reagent, $\geq 99 \%$ ) in $\mathrm{D}_{2} \mathrm{O}$ (Sigma Aldrich, 99.9 atom \% D).

\section{Electrochemical Measurements}

All in-situ electrochemical experiments were performed in a custom-made threeelectrode cell, with the $\mathrm{Cu}$ film being used as the working electrode. A Pt mesh was used as counter electrode, while a $\mathrm{Ag} / \mathrm{AgCl}$ electrode (3 $\mathrm{M} \mathrm{NaCl}, \mathrm{BASi}$ ) was used as reference electrode. A Bio-Logic VSP potentiostat was used to perform the electrochemical measurements. The reversibility and reproducibility of the spectra when applying multiple oxidation-reduction cycles, demonstrates Pt contamination of the $\mathrm{Cu}$ electrode is negligible.

The $\mathrm{Cu}$ films were activated by three oxidation-reduction cycles between 0.6 and $-0.6 \mathrm{~V}$ in the $0.1 \mathrm{M} \mathrm{KHCO}_{3}$ in $\mathrm{H}_{2} \mathrm{O}$ electrolyte, in order to achieve a desirable level of Raman signal enhancement. In other words, electrochemical roughening of the $\mathrm{Cu}$ electrode was achieved through dissolution and redeposition reactions. The electrolyte was continuously purged with $\mathrm{CO}_{2}$ or ${ }^{13} \mathrm{CO}_{2}$ throughout the experiment with flow rates of 20 and $0.5 \mathrm{ml} / \mathrm{min}$, respectively. 
Raman spectroscopy was carried out using an Avantes AvaRaman spectrometer, equipped with an Intertec $\lambda=785 \mathrm{~nm}$ laser as excitation source. The Raman probe was focused on the electrode/electrolyte through a quartz window. An acquisition time of 10 seconds was selected to record each spectrum.

All reported potentials were converted to the Reversible Hydrogen Electrode (RHE) scale by using the equation:

$$
\mathrm{V}_{\text {vs. RHE }}=\mathrm{V}_{\text {measured vs. Ag/AgCl }}+0.198+0.059 *(\mathrm{pH} \text { of solution }) \text {. }
$$

\subsection{Results}

The potential dependent results of in-situ SERS of the $\mathrm{Cu}$ surface in $\mathrm{CO}_{2}$ saturated $0.1 \mathrm{M} \mathrm{KHCO}_{3}$ from 0.4 to $-1.4 \mathrm{~V}$ can be seen in Figure 1 . In this Figure, characteristic spectral features strongly depend on the applied potential, confirming that the $\mathrm{Cu}$ film is SERS active. Besides, during an anodic scan (from -1.4 to +0.4 V), strong SERS signals were also recorded (See Figure S1 and S2-3 for reproducibility) and cycling of the potentials lead to stable and reproducible SERS spectra. We will address the most likely surface composition at each potential, with variable concentration of carbonate, bicarbonate, adsorbed $\mathrm{CO}, \mathrm{Cu}(\mathrm{OH})_{\mathrm{x}}, \mathrm{Cu}-\mathrm{C}$, and water, and discuss spectra of isotopically labeled conditions subsequently to corroborate the assignments. 
(a)

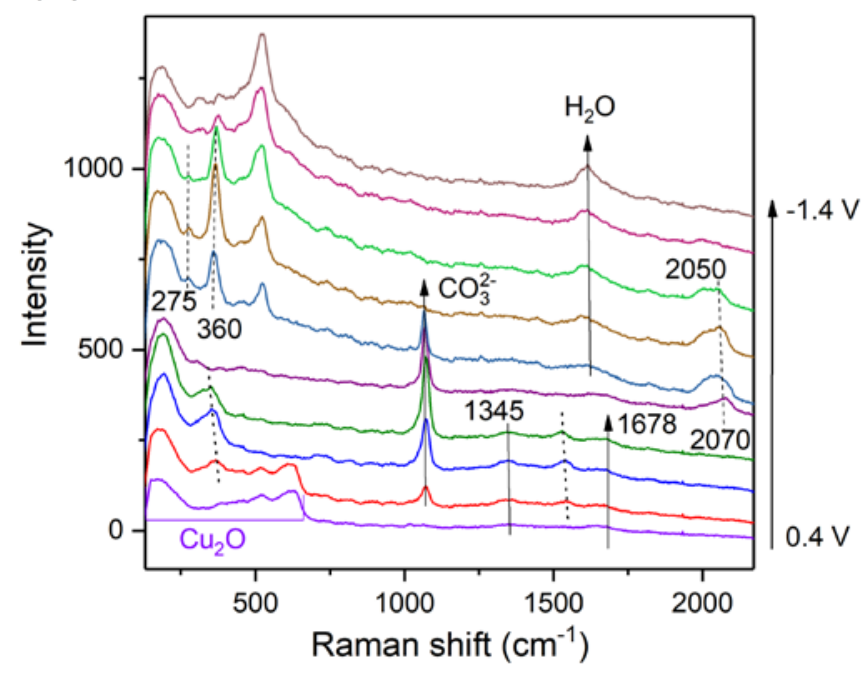

(b)

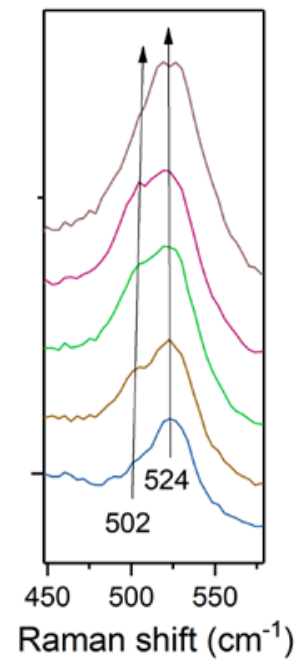

Figure 1. In-situ SERS of a $\mathrm{Cu}$ surface in $\mathrm{CO}_{2}$ saturated $0.1 \mathrm{M} \mathrm{KHCO}_{3}$ and (b) development of the bands at 502 and $524 \mathrm{~cm}^{-1}$ during a cathodic scan. Spectra were collected using a CV rate of $10 \mathrm{mV} / \mathrm{sec}$. The potential interval between spectra is $0.2 \mathrm{~V}$. Spectra were vertically shifted to facilitate comparison.

The first spectra at $+0.4 \mathrm{~V}$ and $+0.2 \mathrm{~V}$ clearly reveal the characteristics of (native), surface $\mathrm{Cu}_{2} \mathrm{O}$ at 150, 400, 525 and $620 \mathrm{~cm}^{-1} 163$. This set of bands was also observed when reaching positive potentials in the anodic scan, explained by surface oxidation of $\mathrm{Cu}$ to $\mathrm{Cu}_{2} \mathrm{O}$ (Figure S1). Very little spectral features are visible at higher wavenumbers at these potentials. Consequent to applying a more negative potential, $\mathrm{Cu}_{2} \mathrm{O}$ was reduced, and as the potential was swept more negatively, new features in the range of 200-600 $\mathrm{cm}^{-1}$ appeared. Particularly interesting is the pair of bands located at 524 and $502 \mathrm{~cm}^{-1}$ (Figure 1b), which are likely related to Cu-hydroxide and Cu-carbon species (see also Figure S1b). Definitive assignment of these peaks is complicated, as the spectral overlap was not reported in recent publications, nor accounted for in theoretical predictions for copper oxide/hydroxide species. Therefore, we employed ${ }^{13} \mathrm{C} /{ }^{12} \mathrm{C}$ and $\mathrm{D} / \mathrm{H}$ isotope exchange to identify the origin of 
these bands more precisely. The results are presented in detail in the "oxide/hydroxide" section. We will first address the development of carbonate and bicarbonate features, and the dynamics of CO.

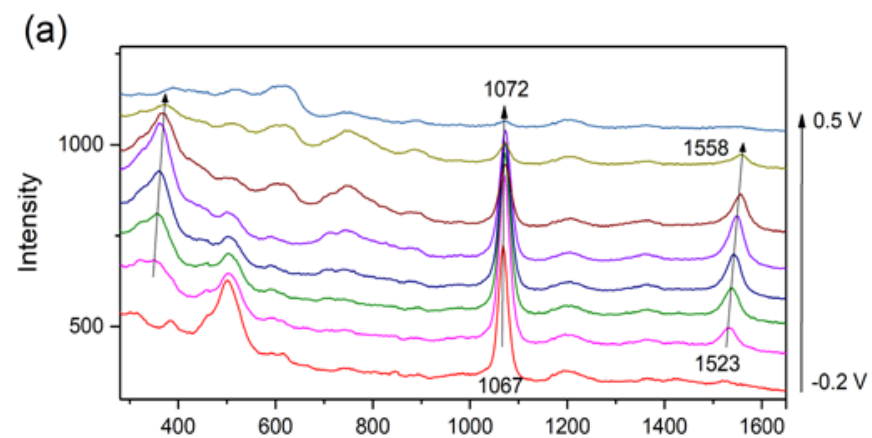

(b)

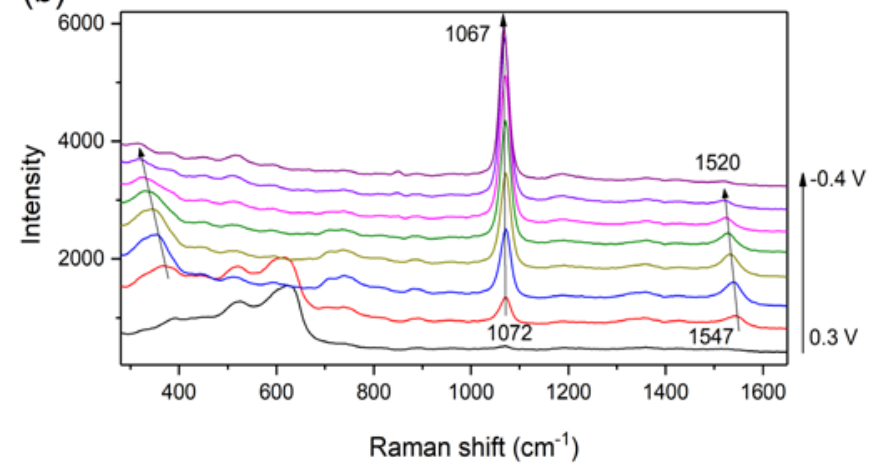

Figure 2. In-situ SERS of the Cu surface in $\mathrm{CO}_{2}$ saturated $0.1 \mathrm{M} \mathrm{KDCO}_{3}$ in $\mathrm{D}_{2} \mathrm{O}$ showing potential-dependent development of the adsorbed and in solution carbonate during (a) a positive and (b) a negative potential scan. Spectra were collected during a CV with a rate of $10 \mathrm{mV} / \mathrm{sec}$ and the potential interval between spectra is $0.1 \mathrm{~V}$.

\section{Carbonate and bicarbonate bands}

As shown in Figures 1 and 2, a dominant feature in the in situ spectra is a strong band at 1072-1067 $\mathrm{cm}^{-1}$, showing a Stark tuning effect with a rate of $\sim 7 \mathrm{~cm}^{-1} / \mathrm{V}$. The band rises and then falls, and is visible up to a potential of approximately $-0.8 \mathrm{~V}$. To assign this band, a reference spectrum of formate as a possible reaction product at 


\section{Chapter7}

low overpotentials was recorded (Figure S4). Clearly, the dominant band of formate is located at $1359 \mathrm{~cm}^{-1}$ and not at $\sim 1070 \mathrm{~cm}^{-1}$, so this assignment can be discarded. On the basis of evidence from other studies ${ }^{175,182,184-185}$, this band can be attributed to the $\mathrm{C}-\mathrm{O}$ symmetric stretching mode of (weakly adsorbed) monodentate carbonate. In principle this assignment can be corroborated by changing ${ }^{12} \mathrm{C}$ for ${ }^{13} \mathrm{C}$ in the carbonate, which should lead to a shift in band position.

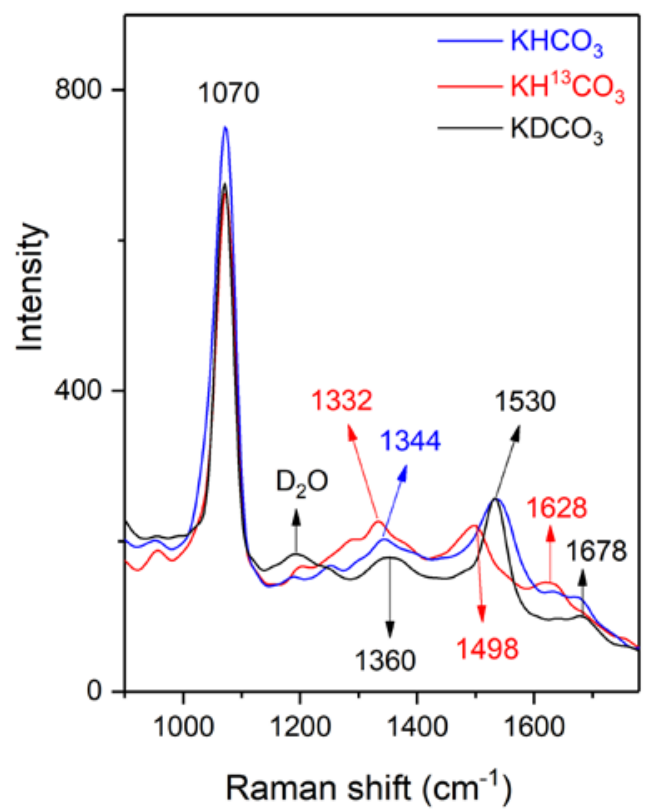

Figure 3. In-situ SERS of $\mathrm{Cu}$ surface in $\mathrm{CO}_{2}$ saturated $0.1 \mathrm{M} \mathrm{KHCO}_{3}$ in $\mathrm{H}_{2} \mathrm{O},{ }^{13} \mathrm{CO}_{2}$ saturated $0.1 \mathrm{M} \mathrm{KH}^{13} \mathrm{CO}_{3}$ in $\mathrm{H}_{2} \mathrm{O}$ and $\mathrm{CO}_{2}$ saturated $0.05 \mathrm{M} \mathrm{K}_{2} \mathrm{CO}_{3}$ in $\mathrm{D}_{2} \mathrm{O}$ at $0 \mathrm{~V}$ vs. RHE showing the effect of isotope exchange on adsorbed species.

However, as shown in Figure 3, the position of the $1070 \mathrm{~cm}^{-1}$ peak is very little affected by ${ }^{13} \mathrm{C} /{ }^{12} \mathrm{C}$ or $\mathrm{D} / \mathrm{H}$ isotope exchange. This is consistent with recent findings in the literature, also reporting a negligible shift upon ${ }^{13} \mathrm{C} /{ }^{12} \mathrm{C}$ exchange, which is explained by the centrosymmetric movements of the oxygen atoms with respect to the central carbon atom ${ }^{182,186}$. To further confirm this assignment to carbonate, $\mathrm{CO}_{2}$ - 
free solutions were used to ensure elimination of $\mathrm{CO}_{2} / \mathrm{HCO}_{3}{ }^{-}$-derived carbonaceous adsorbates. In agreement with literature, comparison of the spectra measured in $\mathrm{CO}_{2}$ saturated and $\mathrm{N}_{2}$-saturated $0.1 \mathrm{M} \mathrm{KClO}_{4}$ (See figure S5) reveals the absence of the $1070 \mathrm{~cm}^{-1}$ band in $\mathrm{CO}_{2}$-free conditions.

An additional observation regarding the peak position is the following. As indicated previously, the peak position is dependent on the applied potential, and therefore likely due to an adsorbed carbonate species. Principally the electrolyte was prepared by dissolution of bicarbonate, which is apparently deprotonated to a large extent at reductive potentials, due to the basicity of the interfacial region near the electrode. Two different configurations can be proposed for adsorbed carbonate, namely bidentate and monodentate. Here we follow the previously, well supported and discussed assignment of the $\sim 1070 \mathrm{~cm}^{-1}$ band to monodentate carbonate, in agreement with the centrosymmetric movements of the oxygen atoms. ${ }^{11,15}$

As shown in Figure 2, in the potential range of +0.2 to $-0.3 \mathrm{~V}$, when performing a negative scan (and from -0.1 to $+0.4 \mathrm{~V}$ when performing a positive scan), two bands at 1547 and $350 \mathrm{~cm}^{-1}$ concurrently appear or disappear. The similarity in Stark shift of this pair of bands (Figure S6) furthermore indicates that these belong to the same chemisorbed species on the catalyst surface.

To assign this pair to a vibrational mode, it is useful to track the existing literature. Based on experimental evidence, the $1540 \mathrm{~cm}^{-1}$ band has been assigned to the vibration of adsorbed carbonate $\mathrm{e}^{108,119,122,177}$ or more precisely, the asymmetric C-O stretching mode of strongly adsorbed bidentate carbonate ${ }^{184}$. This assignment is also consistent with our previous findings measuring similar electrodes using SEIRAS ${ }^{73}$, showing a strong resemblance in peak position as a function of applied potential. To further examine this assignment, the results of isotopic labeling experiments can be considered, as shown in Figures S7-9 (using $\mathrm{KH}^{13} \mathrm{CO}_{3}$ and ${ }^{13} \mathrm{CO}_{2}$ ) and $\mathrm{S} 10\left(\right.$ in $\mathrm{D}_{2} \mathrm{O}$ )). The red-shift of the band from 1547 to $1524 \mathrm{~cm}^{-1}$ due to ${ }^{13} \mathrm{C} /{ }^{12} \mathrm{C}$ isotope exchange, 


\section{Chapter7}

and immunity to $\mathrm{D} / \mathrm{H}$ isotope exchange as shown in figures S7 and S10, further confirms this assignment.

It should be mentioned, however, that in a recent study ${ }^{182}$ this assignment was discarded and the pair of peaks at 1540 and $350 \mathrm{~cm}^{-1}$ were attributed to carboxylate, as the first intermediate in $\mathrm{CO}_{2} \mathrm{RR}$. Looking back to Figure 2a, it is evident that during the anodic scan, the pair of bands persists in the potential range of -0.1 to $+0.4 \mathrm{~V}$, which is associated with a positive current (see Fig. 5). As a result, it is highly unlikely that these bands are associated with $\mathrm{CO}_{2} \mathrm{RR}$. Based on this assumption, we discard the assignment to carboxylate, and confidently assign this pair to adsorbed carbonate species, in the bidentate form.

Next, as shown in Figure 1 in the potential range of +0.4 to $-0.2 \mathrm{~V}$, another feature at $1345 \mathrm{~cm}^{-1}$ (1344 $\mathrm{cm}^{-1}$ in Figure 3) is revealed, albeit significantly smaller in intensity than the $\sim 1070 \mathrm{~cm}^{-1}$ band. Isotopic labeling experiments were employed and revealed that the band originally at $1344 \mathrm{~cm}^{-1}$ shifted to 1332 , or $1360 \mathrm{~cm}^{-1}$ due to ${ }^{13} \mathrm{C} /{ }^{12} \mathrm{C}$ or $\mathrm{D} / \mathrm{H}$ isotope exchange, respectively (See figure 3). This implies that the vibratory chemical bonds are associated with both $\mathrm{H}$ and $\mathrm{C}$ atoms. According to the above analysis, and in agreement with the literature ${ }^{181,187}$, we assign this band to bicarbonate vibrational modes. The isotopic labeling results are also in good agreement with band assignments from a recent study ${ }^{117}$.

Interestingly, we also detected a weak band at $1678 \mathrm{~cm}^{-1}$ between $\sim+0.4$ and -0.2 $\mathrm{V}$. While this band was unaffected by $\mathrm{D}_{2} \mathrm{O} / \mathrm{H}_{2} \mathrm{O}$ isotope exchange, it shifted to 1629 $\mathrm{cm}^{-1}$ as a result of ${ }^{13} \mathrm{C} /{ }^{12} \mathrm{C}$ isotope exchange. This band has recently been attributed to the asymmetric stretch of the carbonyl group associated with a ${ }^{*} \mathrm{COOH}$ intermediate ${ }^{188}$. However, there is no convincing evidence to prove this assignment. Therefore, as suggested by another study ${ }^{182}$, further research should be undertaken to identify the origin of this band.

\section{Adsorbed CO}


Starting from higher frequencies, the band corresponding to adsorption of $\mathrm{CO}$ on atop sites (linearly adsorbed, $\mathrm{CO}_{\text {atop }}$ ) appeared at $2070 \mathrm{~cm}^{-1}$ at $-0.4 \mathrm{~V}$ and shifted to $2050 \mathrm{~cm}^{-1}$ at more negative potentials, which is consistent with the literature ${ }^{73,108}$. This shift with potential is again due to the Stark effect, and is indicative of chemisorbed species. Besides this band, two low-frequency metal-adsorbate bands at 360 and $275 \mathrm{~cm}^{-1}$ also appeared simultaneously and thus in the same potential

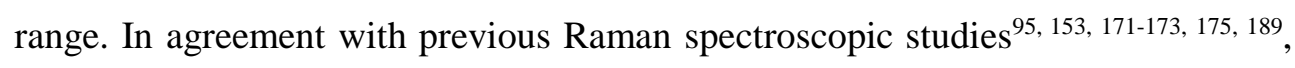
these are also assigned to adsorbed $\mathrm{CO}$ on $\mathrm{Cu}$.

At $1617 \mathrm{~cm}^{-1}$, a broad band was developed at highly negative potentials. This peak could be assigned to the bending mode of $\mathrm{H}-\mathrm{O}-\mathrm{H}$ vibrations of interfacial water ${ }^{177}$, ${ }^{188,}{ }^{190}$. Consistent with this assignment, this band was unaffected by ${ }^{13} \mathrm{C} /{ }^{12} \mathrm{C}$ isotope exchange in carbonate, and was observed at $1200-1187 \mathrm{~cm}^{-1}$ when $\mathrm{D}_{2} \mathrm{O}$ was used as solvent (See Figure S6). The observation of interfacial water at negative potentials is in agreement with previous studies ${ }^{79,164,191}$.

\section{$\mathrm{Cu}\left(\mathrm{OH}_{\mathrm{x}} / \mathrm{O}_{\mathrm{y}} / \mathrm{C}\right)$}

To shine more light on the identity of the bands at $200-600 \mathrm{~cm}^{-1}$ and gain insight into the chemical state of the active $\mathrm{Cu}$ species during $\mathrm{CO}_{2} \mathrm{RR},{ }^{13} \mathrm{C} /{ }^{12} \mathrm{C}$ and $\mathrm{D} / \mathrm{H}$ isotope exchange experiments were carried out and the results are presented in Figure 4. We will now demonstrate that the pair of bands located at 524 and $502 \mathrm{~cm}^{-}$ ${ }^{1}$ (Figure 1b, (see also Figure S1b)), are related to hydroxide and a copper-carbon species. In $\mathrm{KHCO}_{3}$ (Figure 4, left) at $-0.5 \mathrm{~V}$ and more negative potentials, a band centered at $522 \mathrm{~cm}^{-1}$ with an apparent shoulder at $502 \mathrm{~cm}^{-1}$ was developed (see also Figure 1b, and Figure S1b). 

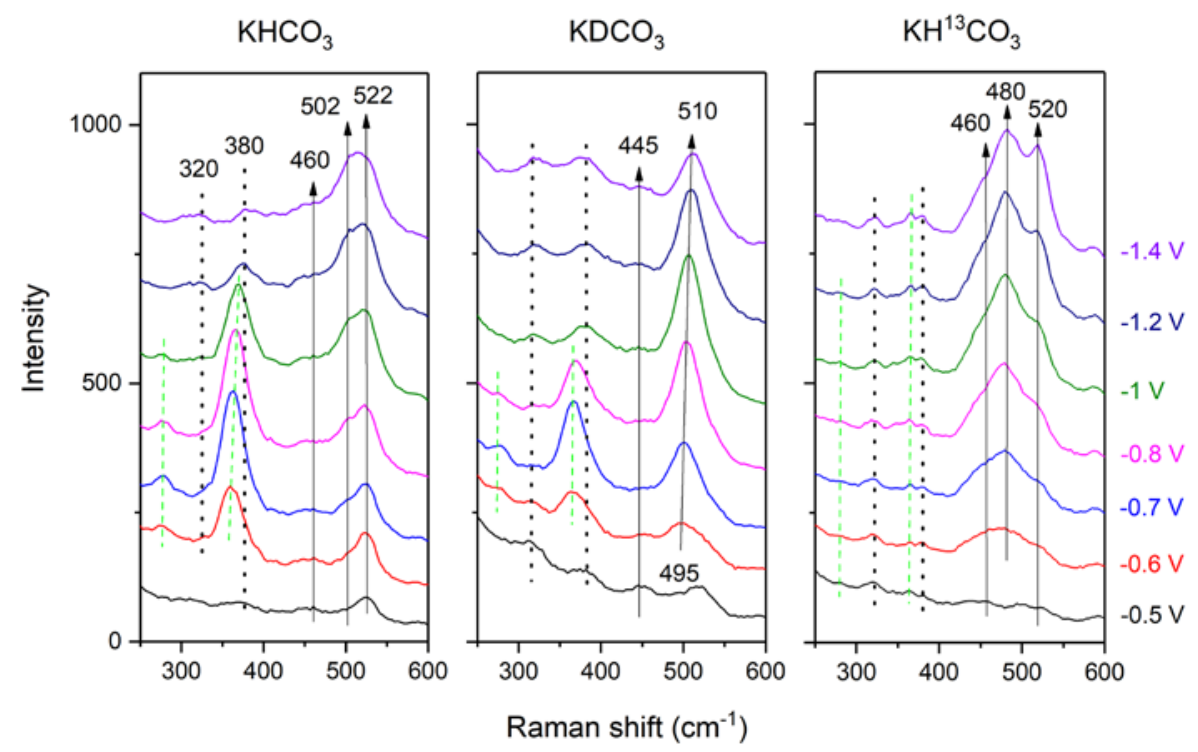

Figure 4. In-situ SERS of the $\mathrm{Cu}$ surface in $\mathrm{CO}_{2}$ saturated $0.1 \mathrm{M} \mathrm{KHCO}_{3}$ in $\mathrm{H}_{2} \mathrm{O}, \mathrm{CO}_{2}$ saturated $0.05 \mathrm{M} \mathrm{K}_{2} \mathrm{CO}_{3}$ in $\mathrm{D}_{2} \mathrm{O}$ and ${ }^{13} \mathrm{CO}_{2}$ saturated $0.1 \mathrm{M} \mathrm{KH}^{13} \mathrm{CO}_{3}$ in $\mathrm{H}_{2} \mathrm{O}$ showing development of bands in the region of 250-600 $\mathrm{cm}^{-1}$ during a cathodic scan. Spectra were collected during a CV with the rate of $10 \mathrm{mV} / \mathrm{sec}$. The black dotted lines at 320 and $380 \mathrm{~cm}^{-}$ , while the green dashed lines at 275 and $365 \mathrm{~cm}^{-1}$ represent adsorbed CO.

By substituting $\mathrm{D}$ for $\mathrm{H}$, features associated with surface $\mathrm{CuO}_{\mathrm{y}}$ should not exhibit a frequency shift, while spectral features correlated to adsorbed $\mathrm{Cu}(\mathrm{OH})_{\mathrm{x}}$ should display a downshift. Turning to the spectral evidence in $\mathrm{KDCO}_{3}$, a single band at 495-510 $\mathrm{cm}^{-1}$ was observed. We identified this peak as a deuterium monoxide (OD) associated vibration. Apparently, by replacing $H$ with D, SERS bands are shifted towards lower frequencies from 522 to $495 \mathrm{~cm}^{-1}$, with the frequency ratio of $\sim 0.96$ from $\mathrm{Cu}-\mathrm{OD}$ versus $\mathrm{Cu}-\mathrm{OH}$ vibrations being in close accordance with earlier studies ${ }^{192-193}$. Interestingly, due to the absence of a band at $\sim 470-480 \mathrm{~cm}^{-1}$, the band at $502 \mathrm{~cm}^{-1}$ did not exhibit any shifts as the result of $\mathrm{D} / \mathrm{H}$ isotope exchange, and is likely located underneath the dominant O-D band at $495-510 \mathrm{~cm}^{-1}$. If we now turn to results of ${ }^{13} \mathrm{C} /{ }^{12} \mathrm{C}$ isotope exchange in $\mathrm{KH}^{13} \mathrm{CO}_{3}$, we observe a significant 
difference compared to $\mathrm{KHCO}_{3}$. While the band at $522 \mathrm{~cm}^{-1}$, assigned to adsorbed hydroxide species based on the above discussion, remained unchanged, the shoulder originally at $502 \mathrm{~cm}^{-1}$ is now shifted to $\sim 480 \mathrm{~cm}^{-1}$. This ${ }^{13} \mathrm{C}$ isotopic shift, reveals the C-containing origin of this band. To the best of our knowledge, this is the first report on finding such species. Due to the complexity of possible species that could bond to the $\mathrm{Cu}$ surface, a more accurate assignment than "Cu-C" of this band is challenging and remains to be elucidated.

Another minor feature in the spectra, is the band at $460 \mathrm{~cm}^{-1}$, which only displays sensitivity to $\mathrm{H} / \mathrm{D}$ exchange and shifted to $445 \mathrm{~cm}^{-1}$ in $\mathrm{KDCO}_{3}$, while this contributes to the spectrum in ${ }^{13} \mathrm{C}$-labeled carbonate as a non-shifted shoulder on the band at 480 $\mathrm{cm}^{-1}$. We assign this band to $\mathrm{Cu}$ hydroxide species. The previous assignments of hydroxide species are in accordance with the two different states of adsorbed $\mathrm{OH}^{-}$ ions, $\mathrm{OH}-\mathrm{Cu}-\mathrm{OH}$ and $\mathrm{Cu}(\mathrm{OH})_{2}$ at 450 and $488-520 \mathrm{~cm}^{-1}$ reported in the literature 164, 192-195.

Turning now to the wavenumbers below $400 \mathrm{~cm}^{-1}$ in Figure 4, the bands at 275 and $360 \mathrm{~cm}^{-1}$ attributed to $\mathrm{Cu}-\mathrm{CO}$ are marked with green dashed lines. At highly negative potentials at which $\mathrm{Cu}-\mathrm{CO}$ bands are suppressed, two bands at 320 and 380 $\mathrm{cm}^{-1}$, marked with black dotted lines concurrently appeared. This pair is also present during the anodic scan, until eventually disappearing at $-0.4 \mathrm{~V}$ (See Figure S1). These two bands are tentatively assigned to features of surface $\mathrm{CuO}$, in good agreement with calculated frequencies of $\mathrm{CuO}$ and previously observed positions at $~ 300$ and $\sim 350 \mathrm{~cm}^{-1} 196$.

Based on the above discussions, three types of surface species were resolved in our SER spectra: oxides at 320 and $380 \mathrm{~cm}^{-1}$, hydroxides at 460 and $520 \mathrm{~cm}^{-1}$, and a C-containing compound at $502 \mathrm{~cm}^{-1}$. Thus, counter-intuitively, $\mathrm{Cu}^{+}$species exist at relatively deep negative potentials, and are potentially inhibiting $\mathrm{CO}_{2} \mathrm{RR}$. 


\section{Chapter7}

\subsection{Discussion}

To gain further insights into the dynamics of the adsorbed species, we analyzed the adsorption/desorption intensities as a function of potential, including carbonates, $\mathrm{CO}$ and hydroxide on the $\mathrm{Cu}$ electrode, and compare these to the electrochemical response in a cyclic voltammogram in Figure 5. To produce Figure 5a, specific band intensities were derived from figure S3, and were plotted against applied potential. An illustration of the cycle, with the adsorbed species present in several potential ranges can be found in Figure 6.

(a)

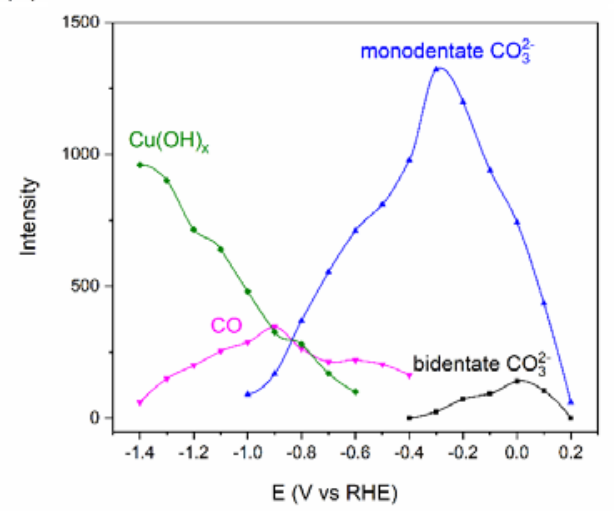

(b)

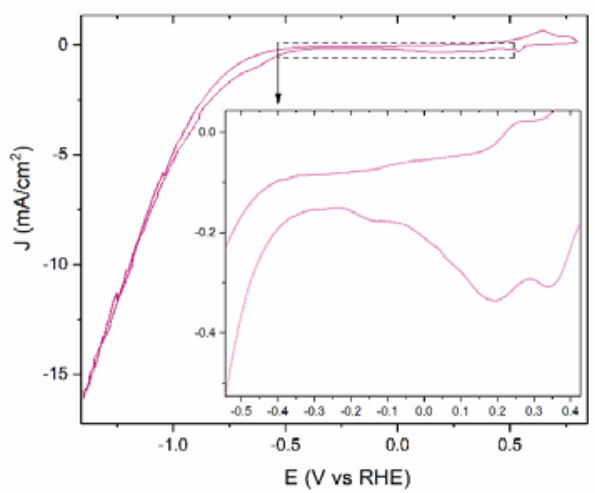

Figure 5. (a) Effect of electrode potential on intensities of $\mathrm{Cu}(\mathrm{OH})_{\mathrm{x}}, \mathrm{CO}$, and adsorbed $\mathrm{CO}_{3}{ }^{2-}$ bands and (b) Cyclic voltammograms of the $\mathrm{Cu}$ electrode in $\mathrm{CO}_{2}$-saturated $0.1 \mathrm{M}$ $\mathrm{KHCO}_{3}$ with a scan rate of $10 \mathrm{mV} / \mathrm{sec}$. Clearly, between $0.4 \mathrm{~V} \rightarrow 0.0 \mathrm{~V}$ two reductive waves are apparent, likely due to reduction of (surface) $\mathrm{Cu}(\mathrm{I})$ oxide to $\mathrm{Cu}(\mathrm{m})$. 


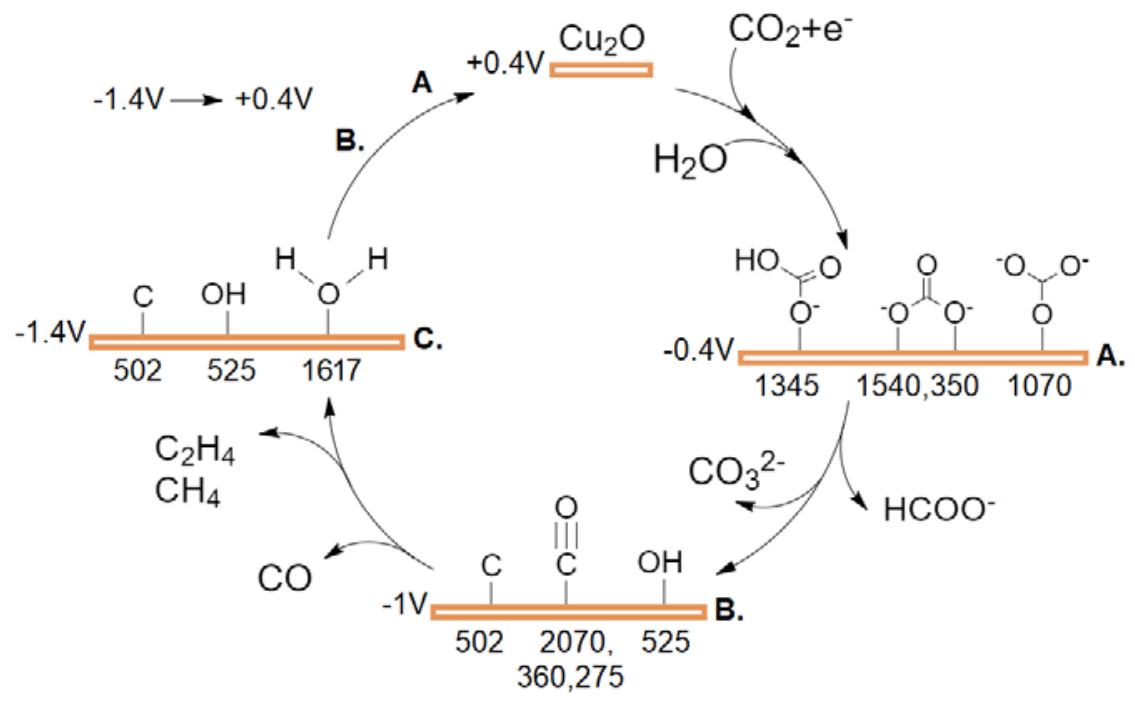

Figure 6. Simplified scheme of the adsorbed species present at different potentials in a cyclic voltammogram. A., B., and C. indicate different stages at $-0.4 \mathrm{~V},-1.0 \mathrm{~V}$, and $-1.4 \mathrm{~V}$. The products indicated to be formed from the surface are known from multiple previous studies on electrochemical reduction of $\mathrm{CO}_{2}$. Desorption of $\mathrm{CO}_{3}{ }^{2-}$ is assumed to explain the large change in intensity between stages A. and B., while formate production is in agreement with the reductive current observed below $\sim-0.5 \mathrm{~V}$ in Figure 5 (b).

As shown in figure 5 (a), at a potential of $+0.2 \mathrm{~V}$, adsorption of both configurations of carbonate, i.e. monodentate and bidentate takes place. At $0 \mathrm{~V}$, the adsorption of the carbonate band at $1540 \mathrm{~cm}^{-1}$ is the highest, and as the potential is swept more negatively, it desorbs until finally disappearing at $\sim-0.4 \mathrm{~V}$. Then, the intensity of the monodentate carbonate band reaches a maximum. Next, what is striking is that this potential also coincides with the appearance of a CO band on the electrode surface. As evident from Figure 5a, CO adsorption is accompanied by dramatic desorption of specifically adsorbed anions ${ }^{95,197}$. It is noteworthy that desorption of pre-adsorbed anions has significant activation barriers, and can be overcome by applying negative potentials ${ }^{198}$, consistent with our findings. Finally, 


\section{Chapter7}

as $\mathrm{CO}$ is adsorbed on the surface and displaces the adsorbed anions, a sharp increase in cathodic current is observed (Figure 5b), which besides to the reductive formation of $\mathrm{CO}$, might be associated with the production of formate, as indicated in the cycle displayed in Figure 6.

Further increase in $\mathrm{CO}$ population on the surface of the electrode is achieved until CO reaches its highest intensity at $\sim-0.9 \mathrm{~V}$ upon complete removal of monodentate carbonate in accordance with literature ${ }^{73,95,108}$. At more cathodic potentials, desorption of $\mathrm{CO}$ from the electrode surface is probably due to the displacement of adsorbed CO by adsorbed hydrogen atoms, and is accompanied by the formation of hydrocarbons (Figure 6) ${ }^{107}$.

As the potential is scanned even more negatively, approximately at $-0.6 \mathrm{~V}$, the hydroxide band emerges at $520 \mathrm{~cm}^{-1}$. This band continues to grow in intensity as the potential is swept more negatively. It is obvious that $\mathrm{Cu}^{+}$species (specifically hydroxide in this case) persists even below the potentials at which adsorbed CO and carbonates are present. As illustrated in Figure 6, the presence of hydroxide is accompanied by the presence of a $\mathrm{Cu}-\mathrm{C}$ species, of which the exact origin remains to be elucidated. Figure 6 implies the reversibility of the process, although the adsorbed carbonate and CO bands are less intense in an anodic scan, than observed in a cathodic scan. When the potential reaches $+0.4 \mathrm{~V}$ vs $\mathrm{RHE}$, the $\mathrm{Cu}-\mathrm{OH}$ and $\mathrm{Cu}-$ $\mathrm{C}$ species disappear, and the surface is oxidized to create the surface oxide $\mathrm{Cu}_{2} \mathrm{O}$.

\subsection{Conclusions}

In summary, we investigated the $\mathrm{CO}_{2} \mathrm{RR}$ process on a $\mathrm{Cu}$ electrode by the powerful in-situ SERS technique. Employing isotopic labeling enabled us to reveal the identity of detected species and verify the assignments. Several novel observations have been made. First, this study identified two configurations of adsorbed carbonates, i.e. bidentate and monodentate, and disproves a previous assignment of the 1540 and $360 \mathrm{~cm}^{-1}$ bands to carboxylate. Then, another major 
finding is the direct observation of displacement of electrolyte anions by $\mathrm{CO}$, a crucial intermediate towards hydrocarbons. Most importantly, Raman spectroscopy resolved the presence of surface species including oxides and hydroxides during $\mathrm{CO}_{2} \mathrm{RR}$ at highly negative potentials, which were surprisingly stable against reduction. In addition, another Cu-related compound containing carbon was observed for the first time. On the basis of these results, we propose that $\mathrm{Cu}-\mathrm{OH}$ and/or Cu-C species might constitute the active site in $\mathrm{CO}_{2} \mathrm{RR}$ towards ethylene and methane. To comprehend the role of $\mathrm{Cu}^{+}$species as catalytically active sites for $\mathrm{CO}_{2} \mathrm{RR}$, more experimental and theoretical work is crucial. 


\subsection{Appendix}
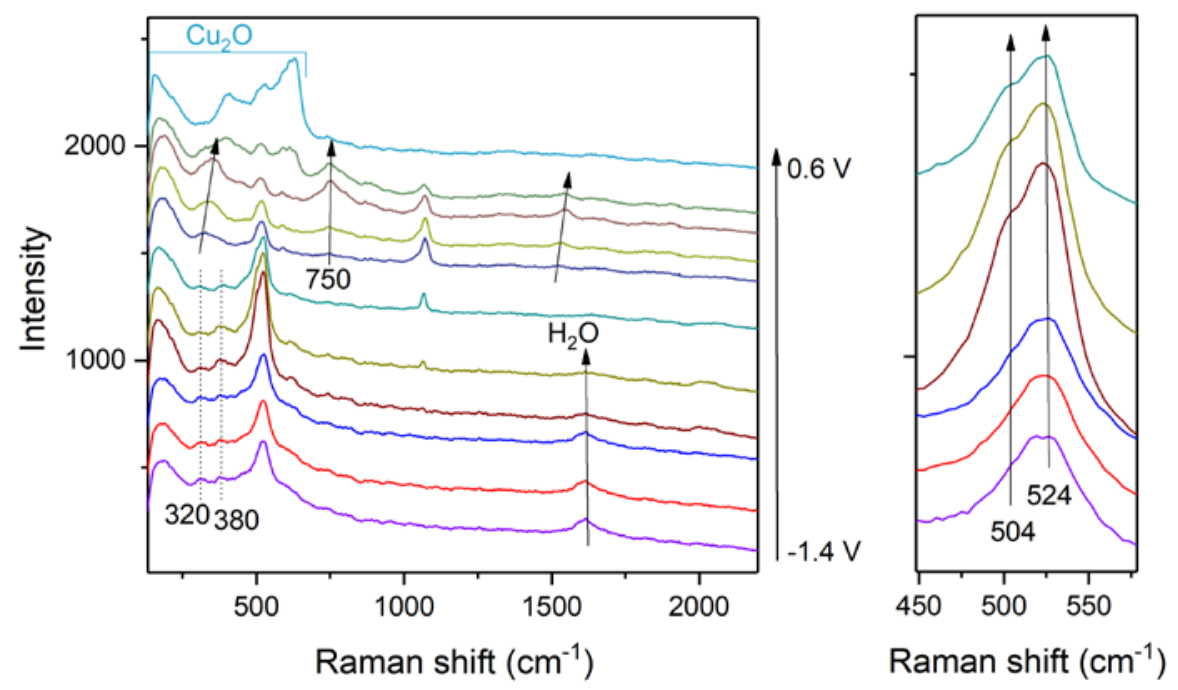

Figure S1. In-situ SERS of the Cu surface in $\mathrm{CO}_{2}$ saturated $0.1 \mathrm{M} \mathrm{KHCO}_{3}$, increasing the potential from $-1.4 \mathrm{~V}$ to $+0.6 \mathrm{~V}$. Spectra were collected using a scan-rate of $10 \mathrm{mV} / \mathrm{sec}$, and the potential interval between spectra is $0.2 \mathrm{~V}$. The zoomed area shows the development of bands at 504 and $524 \mathrm{~cm}^{-1}$ during an anodic scan and represents the spectra recorded at -1.4 , $-1.2,-1.0,-0.8,-0.6$, and $-0.4 \mathrm{~V}$ (bottom to top), respectively. A band at $750 \mathrm{~cm}^{-1}$ is observed only during the anodic scan at positive current densities, suggesting that it does not belong to any reactive species for $\mathrm{CO}_{2} \mathrm{RR}$. To this date, no research has addressed this band and its origin remains to be elucidated. Furthermore, it is evident that the intensity of adsorbed species in the anodic scan is weaker compared to cathodic scan. This is most possibly due to the fact that at highly negative potential of $-1.4 \mathrm{~V}$, significant amount of gaseous products are released from the electrode surface, blocking the Raman probe. Some bubbles remain on the electrode surface and negatively influence the intensity of the spectra during the rest of scan. 


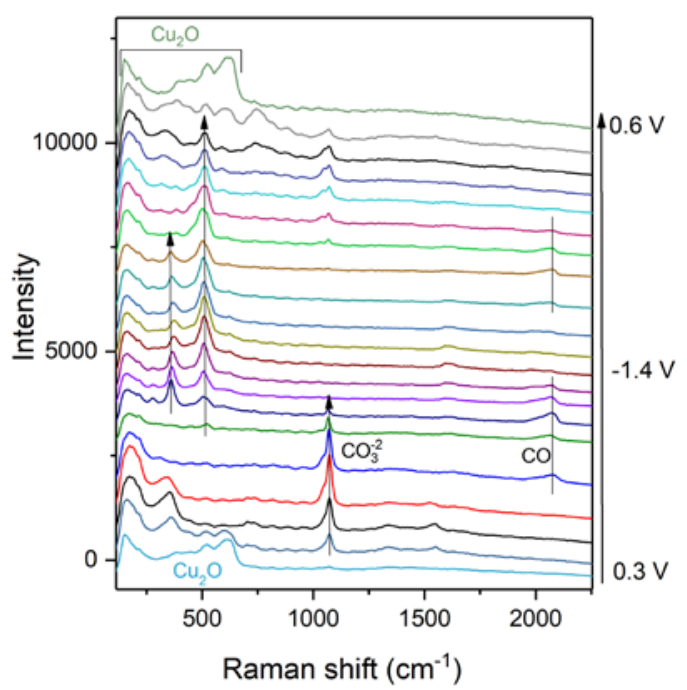

Figure S2. In-situ SERS of the $\mathrm{Cu}$ surface in $\mathrm{CO}_{2}$ saturated $0.1 \mathrm{M} \mathrm{KHCO}_{3}$, in CV from 0.3 to -1.4 to $0.6 \mathrm{~V}$. Spectra were collected using a scan-rate of $10 \mathrm{mV} / \mathrm{sec}$, and the potential interval between spectra is $0.2 \mathrm{~V}$.

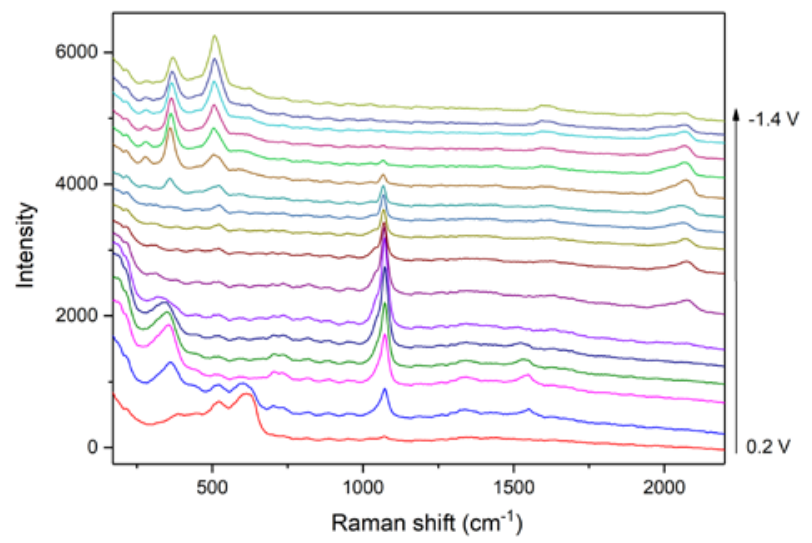

Figure S3. In-situ SERS of the $\mathrm{Cu}$ surface in $\mathrm{CO}_{2}$ saturated $0.1 \mathrm{M} \mathrm{KHCO}_{3}$, during cathodic scan from +0.2 to $-1.4 \mathrm{~V}$. Spectra were collected using a scan-rate of $10 \mathrm{mV} / \mathrm{sec}$, and the potential interval between spectra is $0.1 \mathrm{~V}$. 


\section{Chapter7}

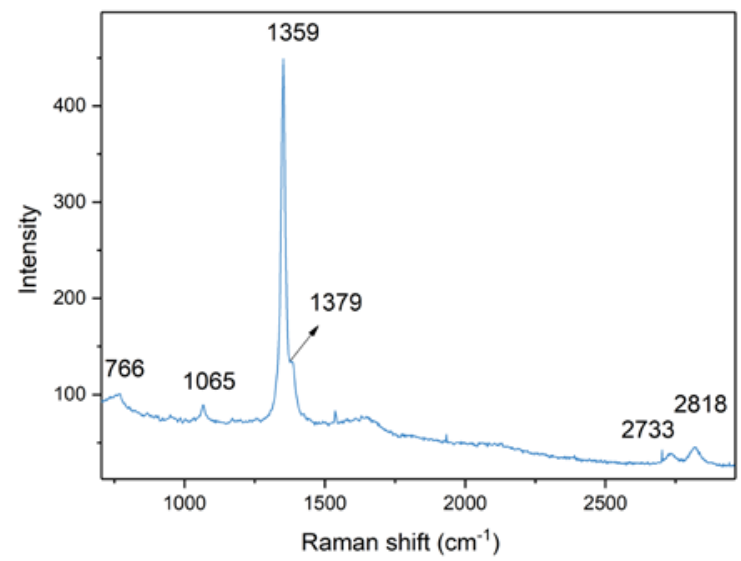

Figure S4. Raman Spectrum of $1 \mathrm{M}$ Potassium formate in $\mathrm{H}_{2} \mathrm{O}$.
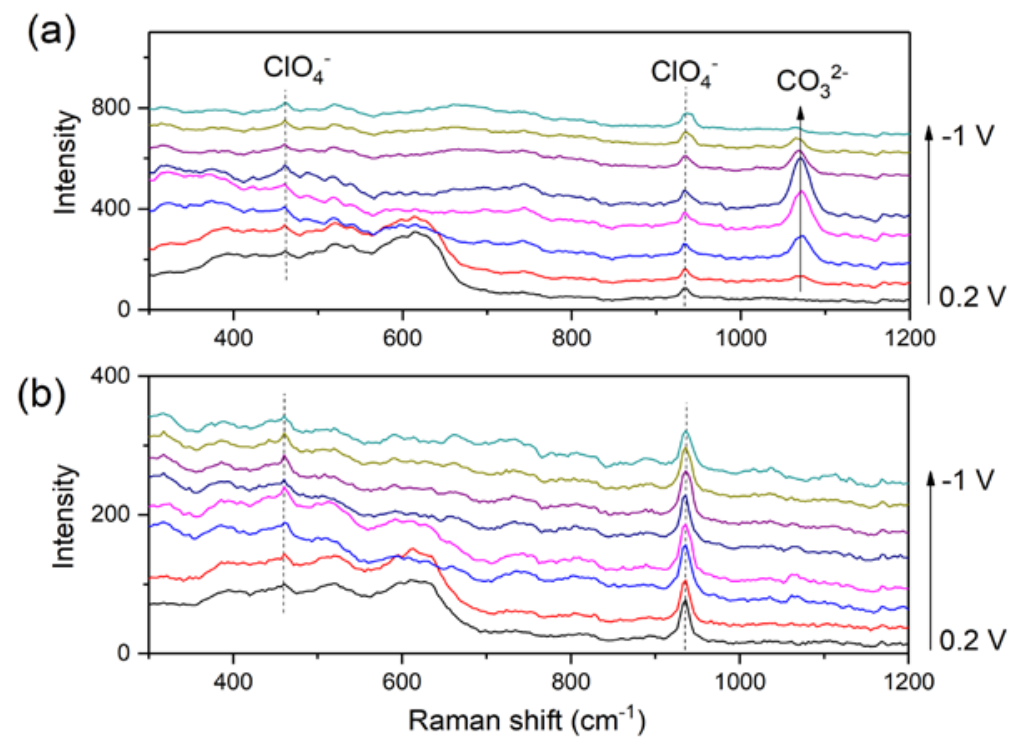

Figure S5. In-situ SERS of the Cu surface in (a) $\mathrm{CO}_{2}$ saturated and (b) $\mathrm{N}_{2}$ saturated 0.1 $\mathrm{M} \mathrm{KClO}_{4}$ showing potential-dependent development of a carbonate band in (a) during a negative scan. The peaks at 460 and $934 \mathrm{~cm}^{-1}$ are indicative of the $\mathrm{ClO}_{4}{ }^{-}$anion. Spectra were collected during a $\mathrm{CV}$ with a scan-rate of $10 \mathrm{mV} / \mathrm{sec}$. 


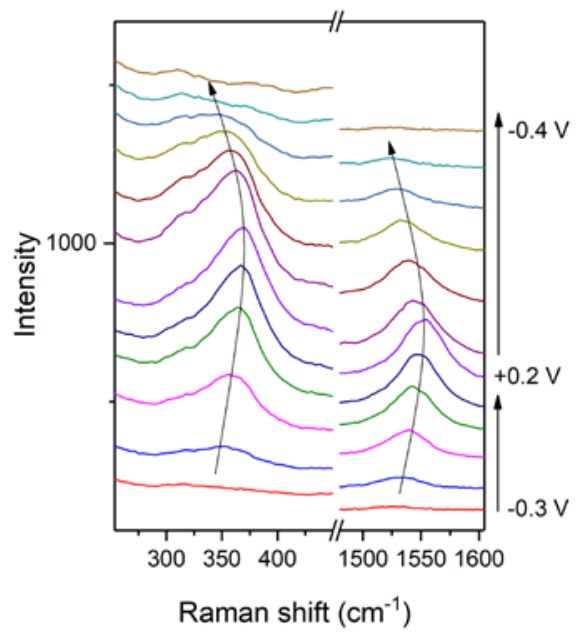

Figure S6. In-situ SERS of $\mathrm{Cu}$ surface in $\mathrm{CO}_{2}$ saturated $0.1 \mathrm{M} \mathrm{KHCO}_{3}$ showing potentialdependent development of the pair of adsorbed carbonate bands during scan from $-0.3 \mathrm{~V}$ to $+0.2 \mathrm{~V}$ and back to $-0.4 \mathrm{~V}$. Spectra were collected during a CV with the rate of $10 \mathrm{mV} / \mathrm{sec}$ and the potential interval between spectra is $0.1 \mathrm{~V}$.

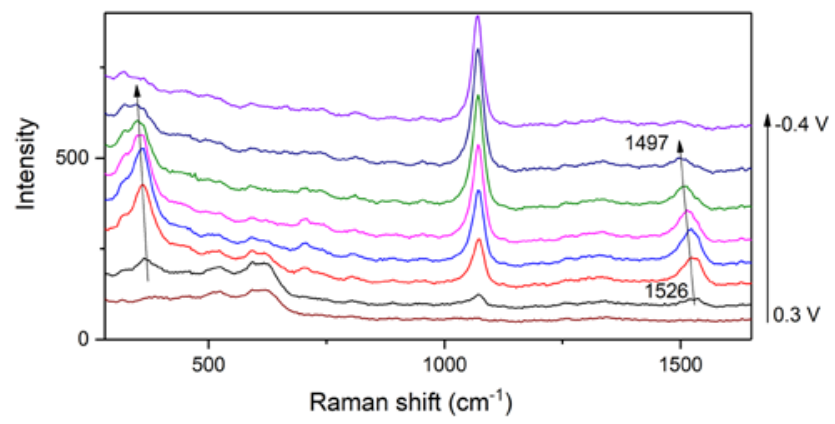

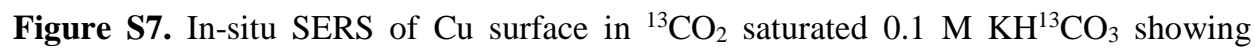
potential-dependent development of the adsorbed and in solution carbonate during a negative scan. Spectra were collected during a CV with a scan-rate of $10 \mathrm{mV} / \mathrm{sec}$ and the potential interval between spectra is $0.1 \mathrm{~V}$, ranging from $+0.3 \mathrm{~V}$ to $-0.4 \mathrm{~V}$. 


\section{Chapter7}
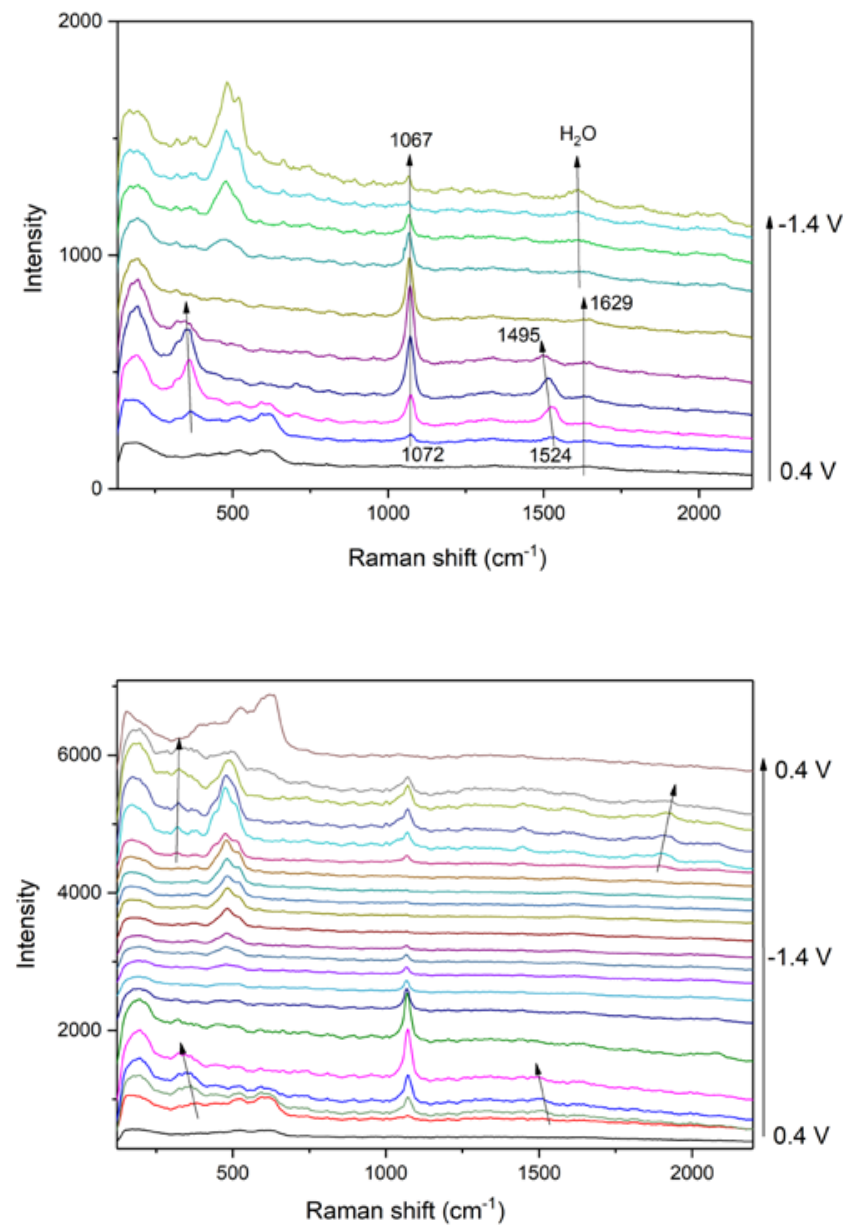

Figure S8 and S9. Broad range spectra of in-situ SERS of the $\mathrm{Cu}$ surface in ${ }^{13} \mathrm{CO}_{2}$ saturated $0.1 \mathrm{M} \mathrm{KH}^{13} \mathrm{CO}_{3}$. Spectra were collected during a $\mathrm{CV}$ with a scan-rate of $10 \mathrm{mV} / \mathrm{sec}$. On this electrode the adsorbed CO features are less obvious. 


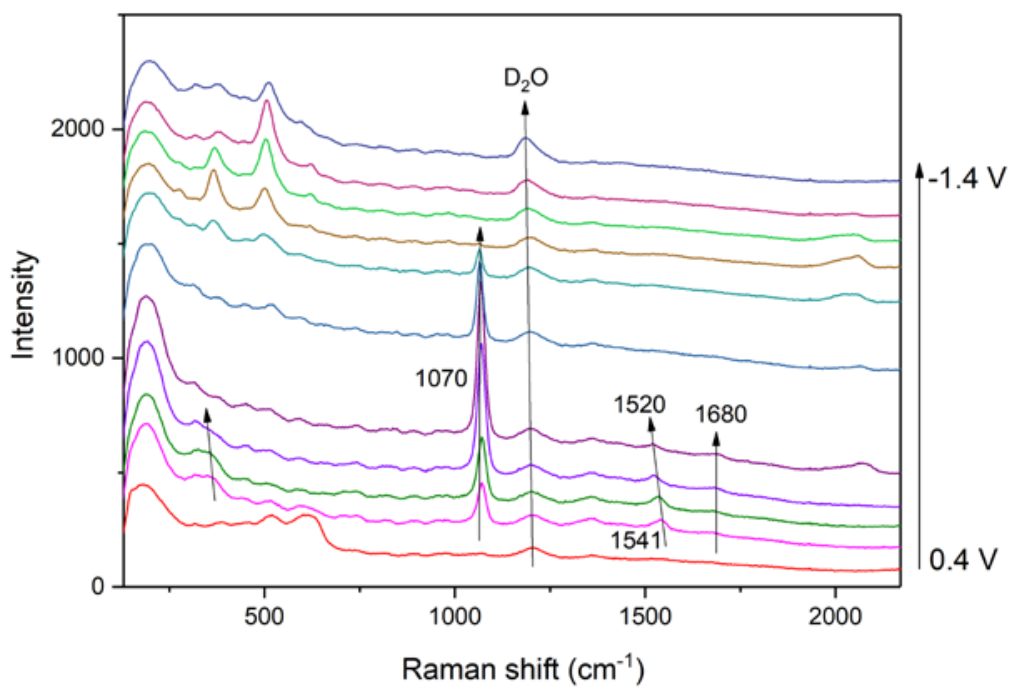

Figure S10. In-situ SERS of the $\mathrm{Cu}$ surface in $\mathrm{CO}_{2}$ saturated $0.1 \mathrm{M} \mathrm{KDCO}_{3}$ in $\mathrm{D}_{2} \mathrm{O}$. Spectra were collected during a CV with a scan-rate of $10 \mathrm{mV} / \mathrm{sec}$. 
Chapter7 


\section{Bibliography}

1.Davis, S. J.; Caldeira, K.; Matthews, H. D., Science 2010, 329 (5997), 1330-1333.

2.Keeling, R.; Piper, S.; Bollenbacher, A.; Walker, J. Atmospheric Carbon Dioxide Record from Mauna Loa (1958-2008); Environmental System Science Data Infrastructure for a Virtual Ecosystem: 2009.

3.Pachauri, R. K.; Allen, M. R.; Barros, V. R.; Broome, J.; Cramer, W.; Christ, R.; Church, J. A.; Clarke, L.; Dahe, Q.; Dasgupta, P., Climate change 2014: synthesis report. Contribution of Working Groups I, II and III to the fifth assessment report of the Intergovernmental Panel on Climate Change. Ipcc: 2014.

4.Hoegh-Guldberg, O.; Mumby, P. J.; Hooten, A. J.; Steneck, R. S.; Greenfield, P.; Gomez, E.; Harvell, C. D.; Sale, P. F.; Edwards, A. J.; Caldeira, K.; Knowlton, N.; Eakin, C. M.; Iglesias-Prieto, R.; Muthiga, N.; Bradbury, R. H.; Dubi, A.; Hatziolos, M. E., Science 2007, 318 (5857), 1737-1742.

5.Wigley, T. M. L., Science 2005, 307 (5716), 1766-1769.

6.Appel, A. M.; Bercaw, J. E.; Bocarsly, A. B.; Dobbek, H.; DuBois, D. L.; Dupuis, M.; Ferry, J. G.; Fujita, E.; Hille, R.; Kenis, P. J., Chemical reviews 2013, 113 (8), 6621-6658.

7.Scibioh, M. A.; Viswanathan, B. In Carbon Dioxide to Chemicals and Fuels, Scibioh, M. A., Viswanathan, B., Eds. Elsevier: 2018; pp 255-306.

8.Habisreutinger, S. N.; Schmidt-Mende, L.; Stolarczyk, J. K., Angewandte Chemie International Edition 2013, 52 (29), 7372-7408.

9.Azuma, M.; Hashimoto, K.; Hiramoto, M.; Watanabe, M.; Sakata, T., Journal of the Electrochemical Society 1990, 137 (6), 1772.

10.Jajesniak, P.; Ali, H.; Wong, T. S., J Bioprocess Biotech 2014, 4 (3), 1-15.

11.Endrődi, B.; Bencsik, G.; Darvas, F.; Jones, R.; Rajeshwar, K.; Janáky, C., Progress in Energy and Combustion Science 2017, 62, 133-154.

12.Yaashikaa, P. R.; Senthil Kumar, P.; Varjani, S. J.; Saravanan, A., Journal of CO2 Utilization 2019, 33, 131-147.

13.Shaftel, H.; Jackson, R.; Callery, S., 2017.

14.Hori, Y. In Modern Aspects of Electrochemistry, Vayenas, C. G., White, R. E., Gamboa-Aldeco, M. E., Eds. Springer New York: New York, NY, 2008; pp 89-189. 15.Sun, Z.; Ma, T.; Tao, H.; Fan, Q.; Han, B., Chem 2017, 3 (4), 560-587.

16.Whipple, D. T.; Kenis, P. J. A., The Journal of Physical Chemistry Letters 2010, 1 (24), 3451-3458.

17.Oloman, C.; Li, H., ChemSusChem: Chemistry \& Sustainability Energy \& Materials 2008, 1 (5), 385-391. 


\section{Bibliography}

18.Francke, R.; Schille, B.; Roemelt, M., Chemical Reviews 2018, 118 (9), 46314701.

19.Zhang, S.; Fan, Q.; Xia, R.; Meyer, T. J., Accounts of Chemical Research 2020, 53 (1), 255-264.

20.Grills, D. C.; Matsubara, Y.; Kuwahara, Y.; Golisz, S. R.; Kurtz, D. A.; Mello, B. A., The Journal of Physical Chemistry Letters 2014, 5 (11), 2033-2038.

21.Hori, Y.; Kikuchi, K.; Suzuki, S., Chemistry Letters 1985, 14 (11), 1695-1698.

22.Somorjai, G., Catalysis Reviews Science and Engineering 1978, 18 (2), 173-197.

23.Kuhl, K. P.; Cave, E. R.; Abram, D. N.; Jaramillo, T. F., Energy \& Environmental Science 2012, 5 (5), 7050-7059.

24.Benson, E. E.; Kubiak, C. P.; Sathrum, A. J.; Smieja, J. M., Chemical Society Reviews 2009, 38 (1), 89-99.

25.Dean, J. A., Lange's handbook of chemistry. McGraw-Hill New York: 1992; Vol. 15.

26.Hori, Y., Modern Aspects of Electrochemistry. 42 New York. Springer: 2008.

27.Lu, Q.; Rosen, J.; Jiao, F., ChemCatChem 2015, 7 (1), 38-47.

28.Tang, W.; Peterson, A. A.; Varela, A. S.; Jovanov, Z. P.; Bech, L.; Durand, W. J.; Dahl, S.; Nørskov, J. K.; Chorkendorff, I., Physical Chemistry Chemical Physics 2012, 14 (1), 76-81.

29.Kim, D.; Kley, C. S.; Li, Y.; Yang, P., Proceedings of the National Academy of Sciences 2017, 114 (40), 10560-10565.

30.Lu, Q.; Rosen, J.; Zhou, Y.; Hutchings, G. S.; Kimmel, Y. C.; Chen, J. G.; Jiao, F., Nature communications 2014, 5 (1), 1-6.

31.Osawa, M.; Ikeda, M., The Journal of Physical Chemistry 1991, 95 (24), 99149919.

32.Kretschmann, E.; Raether, H., Z. Naturforsch. a 1968, 23 (12), 2135-2136.

33.Stiles, P. L.; Dieringer, J. A.; Shah, N. C.; Duyne, R. P. V., Annual Review of Analytical Chemistry 2008, 1 (1), 601-626.

34.Golden, T. D.; Shumsky, M. G.; Zhou, Y.; VanderWerf, R. A.; Van Leeuwen, R.

A.; Switzer, J. A., Chemistry of Materials 1996, 8 (10), 2499-2504.

35.Lewis, N. S.; Nocera, D. G., Proceedings of the National Academy of Sciences 2006, 103 (43), 15729-15735.

36.Hori, Y.; Kikuchi, K.; Murata, A.; Suzuki, S., Chemistry Letters 1986, 15 (6), 897-898.

37.Hori, Y. i. In Modern aspects of electrochemistry, Springer: 2008; pp 89-189.

38.Shibata, H.; Moulijn, J. A.; Mul, G., Catalysis letters 2008, 123 (3-4), 186. 
39.Hori, Y.; Takahashi, I.; Koga, O.; Hoshi, N., Journal of Molecular Catalysis A: Chemical 2003, 199 (1), 39-47.

40.Ren, D.; Deng, Y.; Handoko, A. D.; Chen, C. S.; Malkhandi, S.; Yeo, B. S., ACS Catalysis 2015, 5 (5), 2814-2821.

41.Handoko, A. D.; Ong, C. W.; Huang, Y.; Lee, Z. G.; Lin, L.; Panetti, G. B.; Yeo, B. S., The Journal of Physical Chemistry C 2016, 120 (36), 20058-20067.

42.Li, C. W.; Kanan, M. W., Journal of the American Chemical Society 2012, 134 (17), 7231-7234.

43.Kas, R.; Kortlever, R.; Milbrat, A.; Koper, M. T. M.; Mul, G.; Baltrusaitis, J., Physical Chemistry Chemical Physics 2014, 16 (24), 12194-12201.

44.Kim, B.; Ma, S.; Jhong, H.-R. M.; Kenis, P. J., Electrochimica Acta 2015, 166, 271-276.

45.Kyriacou, G.; Anagnostopoulos, A., Journal of applied electrochemistry 1993, 23 (5), 483-486.

46.Lum, Y.; Yue, B.; Lobaccaro, P.; Bell, A. T.; Ager, J. W., The Journal of Physical Chemistry C 2017, 121 (26), 14191-14203.

47.Li, J.; Wang, Z.; McCallum, C.; Xu, Y.; Li, F.; Wang, Y.; Gabardo, C. M.; Dinh, C.-T.; Zhuang, T.-T.; Wang, L.; Howe, J. Y.; Ren, Y.; Sargent, E. H.; Sinton, D., Nature Catalysis 2019, 2 (12), 1124-1131.

48.Schreier, M.; Yoon, Y.; Jackson, M. N.; Surendranath, Y., Angewandte Chemie International Edition 2018.

49.Li, J.; Chang, K.; Zhang, H.; He, M.; Goddard, W. A.; Chen, J. G.; Cheng, M.-J.; Lu, Q., ACS Catalysis 2019, 9 (6), 4709-4718.

50.Wang, L.; Nitopi, S. A.; Bertheussen, E.; Orazov, M.; Morales-Guio, C. G.; Liu, X.; Higgins, D. C.; Chan, K.; Nørskov, J. K.; Hahn, C., ACS Catalysis 2018, 8 (8), 7445-7454.

51.Gupta, N.; Gattrell, M.; MacDougall, B., Journal of applied electrochemistry 2006, 36 (2), 161-172.

52.Hori, Y.; Murata, A.; Takahashi, R., Journal of the Chemical Society, Faraday Transactions 1: Physical Chemistry in Condensed Phases 1989, 85 (8), 2309-2326.

53.Duan, Z.; Sun, R., Chemical Geology 2003, 193 (3), 257-271.

54.Schumpe, A., Chemical Engineering Science 1993, 48 (1), 153-158.

55.Joseph, S.; Kamath, P. V., Journal of The Electrochemical Society 2007, 154 (7), E102-E106.

56.Goodpaster, J. D.; Bell, A. T.; Head-Gordon, M., The Journal of Physical Chemistry Letters 2016, 7 (8), 1471-1477. 


\section{Bibliography}

57.Varela, A. S.; Kroschel, M.; Reier, T.; Strasser, P., Catalysis Today 2016, 260, 8-13.

58.Kas, R.; Kortlever, R.; Yılmaz, H.; Koper, M. T.; Mul, G., ChemElectroChem 2015, 2 (3), 354-358.

59.Raciti, D.; Mao, M.; Park, J. H.; Wang, C., Journal of The Electrochemical Society 2018, 165 (10), F799-F804.

60.Spurgeon, J. M.; Kumar, B., Energy \& Environmental Science 2018, 11 (6), 1536-1551.

61.von der Assen, N.; Müller, L. J.; Steingrube, A.; Voll, P.; Bardow, A., Environmental Science \& Technology 2016, 50 (3), 1093-1101.

62.Wang, L.; Nitopi, S. A.; Bertheussen, E.; Orazov, M.; Morales-Guio, C. G.; Liu, X.; Higgins, D. C.; Chan, K.; Nørskov, J. K.; Hahn, C.; Jaramillo, T. F., ACS Catalysis 2018, 8 (8), 7445-7454.

63.Hori, Y.; Takahashi, I.; Koga, O.; Hoshi, N., The Journal of Physical Chemistry B 2002, 106 (1), 15-17.

64.Dinh, C.-T.; Burdyny, T.; Kibria, M. G.; Seifitokaldani, A.; Gabardo, C. M.; García de Arquer, F. P.; Kiani, A.; Edwards, J. P.; De Luna, P.; Bushuyev, O. S.; Zou, C.; Quintero-Bermudez, R.; Pang, Y.; Sinton, D.; Sargent, E. H., Science 2018, 360 (6390), 783-787.

65. Jouny, M.; Luc, W.; Jiao, F., Nature Catalysis 2018, 1 (10), 748-755.

66.Xiao, H.; Cheng, T.; Goddard, W. A.; Sundararaman, R., Journal of the American Chemical Society 2016, 138 (2), 483-486.

67.Liu, X.; Schlexer, P.; Xiao, J.; Ji, Y.; Wang, L.; Sandberg, R. B.; Tang, M.; Brown, K. S.; Peng, H.; Ringe, S.; Hahn, C.; Jaramillo, T. F.; Nørskov, J. K.; Chan, K., Nature Communications 2019, 10 (1), 32.

68.Calle-Vallejo, F.; Koper, M. T., Angewandte Chemie International Edition 2013, 52 (28), 7282-7285.

69.Garza, A. J.; Bell, A. T.; Head-Gordon, M., ACS Catalysis 2018, 8 (2), 14901499.

70.Moradzaman, M.; Martínez, C. S.; Mul, G., Sustainable Energy \& Fuels 2020, 4 (10), 5195-5202.

71.Wang, X.; de Araújo, J. F.; Ju, W.; Bagger, A.; Schmies, H.; Kühl, S.; Rossmeisl, J.; Strasser, P., Nature Nanotechnology 2019, 14 (11), 1063-1070.

72. Lum, Y.; Ager, J. W., Nature Catalysis 2019, 2 (1), 86-93.

73.Moradzaman, M.; Mul, G., ACS Catalysis 2020, 10 (15), 8049-8057.

74.Sandberg, R. B.; Montoya, J. H.; Chan, K.; Nørskov, J. K., Surface Science 2016, 654, 56-62. 
75.Montoya, J. H.; Shi, C.; Chan, K.; Nørskov, J. K., The Journal of Physical Chemistry Letters 2015, 6 (11), 2032-2037.

76.Huang, Y.; Handoko, A. D.; Hirunsit, P.; Yeo, B. S., ACS Catalysis 2017, 7 (3), 1749-1756.

77.Cheng, T.; Xiao, H.; Goddard, W. A., Proceedings of the National Academy of Sciences 2017, 114 (8), 1795-1800.

78.Sanchez-Sanchez, C. M.; Exposito, E.; Batanero, B.; Montiel, V.; Barba, F.; Aldaz, A., ChemInform 2005, 36 (28).

79.Katayama, Y.; Nattino, F.; Giordano, L.; Hwang, J.; Rao, R. R.; Andreussi, O.; Marzari, N.; Shao-Horn, Y., The Journal of Physical Chemistry C 2019, 123 (10), 5951-5963.

80.Hori, Y.; Murata, A.; Takahashi, R., J. Chem. Soc., Faraday Trans. 1 1989, 85.

81.Koper, M. T. M., Chemical Science 2013, 4 (7), 2710-2723.

82.Schouten, K. J. P.; Pérez Gallent, E.; Koper, M. T. M., Journal of Electroanalytical Chemistry 2014, 716, 53-57.

83.Hori, Y.; Takahashi, R.; Yoshinami, Y.; Murata, A., The Journal of Physical Chemistry B 1997, 101 (36), 7075-7081.

84.Lv, J.-J.; Jouny, M.; Luc, W.; Zhu, W.; Zhu, J.-J.; Jiao, F., Advanced Materials 2018, 30 (49), 1803111.

85.Schouten, K. J. P.; Qin, Z.; Pérez Gallent, E.; Koper, M. T. M., Journal of the American Chemical Society 2012, 134 (24), 9864-9867.

86.Peterson, A. A.; Abild-Pedersen, F.; Studt, F.; Rossmeisl, J.; Nørskov, J. K., Energy \& Environmental Science 2010, 3 (9), 1311-1315.

87.Gattrell, M.; Gupta, N.; Co, A., Journal of Electroanalytical Chemistry 2006, 594 (1), 1-19.

88.Schouten, K. J. P.; Kwon, Y.; van der Ham, C. J. M.; Qin, Z.; Koper, M. T. M., Chemical Science 2011, 2 (10), 1902-1909.

89.Chen, C. S.; Wan, J. H.; Yeo, B. S., The Journal of Physical Chemistry C 2015, 119 (48), 26875-26882.

90.Handoko, A. D.; Chan, K. W.; Yeo, B. S., ACS Energy Letters 2017, 2 (9), 21032109.

91.Gerischer, H.; Mehl, W., Zeitschrift für Elektrochemie, Berichte der Bunsengesellschaft für physikalische Chemie 1955, 59 (10), 1049-1059.

92.Horiuti, J.; Keii, T.; Hirota, K., JOURNAL OF THE RESEARCH INSTITUTE FOR CATALYSIS HOKKAIDO UNIVERSITY 1951, 2 (1), 1-72.

93.Kortlever, R.; Shen, J.; Schouten, K. J. P.; Calle-Vallejo, F.; Koper, M. T. M., The Journal of Physical Chemistry Letters 2015, 6 (20), 4073-4082. 


\section{Bibliography}

94.Cheng, T.; Xiao, H.; Goddard, W. A., Proceedings of the National Academy of Sciences 2017, 114 (8), 1795-1800.

95.Gunathunge, C. M.; Li, X.; Li, J.; Hicks, R. P.; Ovalle, V. J.; Waegele, M. M., The Journal of Physical Chemistry C 2017, 121 (22), 12337-12344.

96.Gunathunge, C. M.; Ovalle, V. J.; Li, Y.; Janik, M. J.; Waegele, M. M., ACS Catalysis 2018, 8 (8), 7507-7516.

97.Couto, A.; Rincón, A.; Pérez, M. C.; Gutiérrez, C., Electrochimica Acta 2001, 46 (9), 1285-1296.

98.Ovalle, V. J.; Waegele, M. M., The Journal of Physical Chemistry C 2020, 124 (27), 14713-14721.

99.Wuttig, A.; Liu, C.; Peng, Q.; Yaguchi, M.; Hendon, C. H.; Motobayashi, K.; Ye, S.; Osawa, M.; Surendranath, Y., ACS Central Science 2016, 2 (8), 522-528.

100.Koga, O.; Teruya, S.; Matsuda, K.; Minami, M.; Hoshi, N.; Hori, Y., Electrochimica Acta 2005, 50 (12), 2475-2485.

101.Lee, S.; Lee, J., ChemElectroChem 2018, 5 (3), 558-564.

102.Eilert, A.; Cavalca, F.; Roberts, F. S.; Osterwalder, J.; Liu, C.; Favaro, M.; Crumlin, E. J.; Ogasawara, H.; Friebel, D.; Pettersson, L. G. M.; Nilsson, A., The Journal of Physical Chemistry Letters 2017, 8 (1), 285-290.

103.Sartin, M. M.; Yu, Z.; Chen, W.; He, F.; Sun, Z.; Chen, Y.-X.; Huang, W., The Journal of Physical Chemistry C 2018, 122 (46), 26489-26498.

104.Wuttig, A.; Yaguchi, M.; Motobayashi, K.; Osawa, M.; Surendranath, Y., Proceedings of the National Academy of Sciences 2016, 113 (32), E4585-E4593.

105.Baruch, M. F.; Pander, J. E.; White, J. L.; Bocarsly, A. B., ACS Catalysis 2015, 5 (5), 3148-3156.

106.Dutta, A.; Kuzume, A.; Rahaman, M.; Vesztergom, S.; Broekmann, P., ACS Catalysis 2015, 5 (12), 7498-7502.

107.Dunwell, M.; Lu, Q.; Heyes, J. M.; Rosen, J.; Chen, J. G.; Yan, Y.; Jiao, F.; Xu, B., Journal of the American Chemical Society 2017, 139 (10), 3774-3783.

108.Zhu, S.; Jiang, B.; Cai, W.-B.; Shao, M., Journal of the American Chemical Society 2017, 139 (44), 15664-15667.

109.Papasizza, M.; Cuesta, A., ACS Catalysis 2018, 8 (7), 6345-6352.

110.Heyes, J.; Dunwell, M.; Xu, B., The Journal of Physical Chemistry C 2016, 120 (31), 17334-17341.

111.Yang, K.; Kas, R.; Smith, W. A., Journal of the American Chemical Society 2019, 141 (40), 15891-15900.

112.Delgado, J. M.; Orts, J. M.; Pérez, J. M.; Rodes, A., Journal of Electroanalytical Chemistry 2008, 617 (2), 130-140. 
113.Yoshio, H.; Katsuhei, K.; Akira, M.; Shin, S., Chemistry Letters 1986, 15 (6), 897-898.

114.Wain, A. J.; O’Connell, M. A., Advances in Physics: X 2017, 2 (1), 188-209.

115.Kas, R.; Ayemoba, O.; Firet, N. J.; Middelkoop, J.; Smith, W. A.; Cuesta, A., ChemPhysChem 2019, 20(22), 2904-2925.

116.Pérez-Gallent, E.; Figueiredo, M. C.; Calle-Vallejo, F.; Koper, M. T. M., Angewandte Chemie International Edition 2017, 56 (13), 3621-3624.

117.Sheng, H.; Oh, M. H.; Osowiecki, W. T.; Kim, W.; Alivisatos, A. P.; Frei, H., Journal of the American Chemical Society 2018, 140 (12), 4363-4371.

118.Hori, Y.; Koga, O.; Yamazaki, H.; Matsuo, T., Electrochimica Acta 1995, 40 (16), 2617-2622.

119.Hori, Y.; Koga, O.; Watanabe, Y.; Matsuo, T., Electrochimica Acta 1998, 44 (8), 1389-1395.

120.Salimon, J.; Hernández-Romero, R. M.; Kalaji, M., Journal of Electroanalytical Chemistry 2002, 538-539, 99-108.

121.Shaw, S. K.; Berná, A.; Feliu, J. M.; Nichols, R. J.; Jacob, T.; Schiffrin, D. J., Physical Chemistry Chemical Physics 2011, 13 (12), 5242-5251.

122. Iwasita, T.; Rodes, A.; Pastor, E., J. Electroanal. Chem. 1995, 383 (1), 181189.

123.Arihara, K.; Kitamura, F.; Ohsaka, T.; Tokuda, K., Journal of Electroanalytical Chemistry 2001, 510 (1), 128-135.

124. Lambert, D. K., Solid State Communications 1984, 51 (5), 297-300.

125.Singh, M. R.; Clark, E. L.; Bell, A. T., Physical Chemistry Chemical Physics 2015, 17 (29), 18924-18936.

126.Yamakata, A.; Kubota, J.; Kondo, J. N.; Domen, K.; Hirose, C., The Journal of Physical Chemistry 1996, 100 (46), 18177-18182.

127.Hayden, B. E.; Prince, K.; Woodruff, D. P.; Bradshaw, A. M., Surface Science 1983, 133 (2), 589-604.

128.Sexton, B. A., Surface Science 1979, 88 (2), 319-330.

129.Joo, J.; Uchida, T.; Cuesta, A.; Koper, M. T. M.; Osawa, M., Electrochimica Acta 2014, 129, 127-136.

130.Miki, A.; Ye, S.; Osawa, M., Chemical Communications 2002, (14), 15001501.

131.Ito, K.; Bernstein, H. J., Canadian Journal of Chemistry 1956, 34 (2), 170-178. 132.Köck, E.-M.; Kogler, M.; Bielz, T.; Klötzer, B.; Penner, S., The Journal of Physical Chemistry C 2013, 117 (34), 17666-17673. 
133.Thornton Edward, W., J. Chem. Soc., Faraday Trans. 1 1975, 71 (0), 461-472. 134.Coenen, K.; Gallucci, F.; Mezari, B.; Hensen, E.; van Sint Annaland, M., Journal of CO2 Utilization 2018, 24, 228-239.

135.Kato, Y.; Yamamoto, M.; Akatsuka, M.; Ito, R.; Ozawa, A.; Kawaguchi, Y.; Tanabe, T.; Yoshida, T., Surface and Interface Analysis 2019, 51 (1), 40-45.

136.Bartos, B.; Freund, H. J.; Kuhlenbeck, H.; Neumann, M.; Lindner, H.; Müller, K., Surface Science 1987, 179 (1), 59-89.

137.Freund, H. J.; Roberts, M. W., Surface Science Reports 1996, 25 (8), 225-273.

138.Amatore, C.; Saveant, J. M., Journal of the American Chemical Society 1981, 103 (17), 5021-5023.

139.Manthiram, K.; Beberwyck, B. J.; Alivisatos, A. P., Journal of the American Chemical Society 2014, 136 (38), 13319-13325.

140.Tryk, D. A.; Yamamoto, T.; Kokubun, M.; Hirota, K.; Hashimoto, K.; Okawa, M.; Fujishima, A., Applied Organometallic Chemistry 2001, 15 (2), 113-120.

141.Sen, S.; Liu, D.; Palmore, G. T. R., ACS Catalysis 2014, 4 (9), 3091-3095.

142.Ma, M.; Djanashvili, K.; Smith, W. A., Angewandte Chemie International Edition 2016, 55 (23), 6680-6684.

143.Raciti, D.; Cao, L.; Livi, K. J. T.; Rottmann, P. F.; Tang, X.; Li, C.; Hicks, Z.; Bowen, K. H.; Hemker, K. J.; Mueller, T.; Wang, C., ACS Catalysis 2017, 7 (7), 4467-4472.

144.Chen, C. S.; Handoko, A. D.; Wan, J. H.; Ma, L.; Ren, D.; Yeo, B. S., Catalysis Science \& Technology 2015, 5 (1), 161-168.

145.Roberts, F. S.; Kuhl, K. P.; Nilsson, A., Angewandte Chemie International Edition 2015, 54 (17), 5179-5182.

146.Li, C. W.; Ciston, J.; Kanan, M. W., Nature 2014, 508 (7497), 504-507.

147.Kas, R.; Kortlever, R.; Y1lmaz, H.; Koper, M. T. M.; Mul, G., ChemElectroChem 2015, 2 (3), 354-358.

148.Schouten, K. J. P.; Gallent, E. P.; Koper, M. T., Journal of Electroanalytical Chemistry 2014, 716, 53-57.

149.Cook, R. L., Journal of The Electrochemical Society 1988, 135 (6), 1320.

150.Kim, D.; Kley, C. S.; Li, Y.; Yang, P., Proceedings of the National Academy of Sciences 2017, 114 (40), 10560-10565.

151.Lain, M. J.; Pletcher, D., Electrochimica Acta 1987, 32 (1), 99-107.

152.Murata, A.; Hori, Y., Bulletin of the Chemical Society of Japan 1991, 64 (1), 123-127.

153.Ren, D.; Fong, J.; Yeo, B. S., Nature Communications 2018, 9 (1), 925. 
154.Mandal, L.; Yang, K. R.; Motapothula, M. R.; Ren, D.; Lobaccaro, P.; Patra, A.; Sherburne, M.; Batista, V. S.; Yeo, B. S.; Ager, J. W.; Martin, J.; Venkatesan, T., ACS Applied Materials \& Interfaces 2018, 10 (10), 8574-8584.

155.Ren, D.; Ang, B. S.-H.; Yeo, B. S., ACS Catalysis 2016, 6 (12), 8239-8247.

156.Kwon, Y.; Lum, Y.; Clark, E. L.; Ager, J. W.; Bell, A. T., ChemElectroChem 2016, 3 (6), 1012-1019.

157.Loiudice, A.; Lobaccaro, P.; Kamali, E. A.; Thao, T.; Huang, B. H.; Ager, J. W.; Buonsanti, R., Angewandte Chemie International Edition 2016, 55 (19), 5789-5792.

158.Zhong, H.; Fujii, K.; Nakano, Y., Journal of The Electrochemical Society 2017, 164 (9), F923-F927.

159.Gao, D.; McCrum, I. T.; Deo, S.; Choi, Y.-W.; Scholten, F.; Wan, W.; Chen, J. G.; Janik, M. J.; Roldan Cuenya, B., ACS Catalysis 2018, 8 (11), 10012-10020.

160.Singh, M. R.; Kwon, Y.; Lum, Y.; Ager, J. W.; Bell, A. T., Journal of the American Chemical Society 2016, 138 (39), 13006-13012.

161.Thorson, M. R.; Siil, K. I.; Kenis, P. J., Journal of the Electrochemical Society 2012, 160 (1), F69.

162. Frumkin, A., Transactions of the Faraday Society 1959, 55, 156-167.

163.Deng, Y.; Handoko, A. D.; Du, Y.; Xi, S.; Yeo, B. S., ACS Catalysis 2016, 6 (4), 2473-2481.

164.Niaura, G., Electrochimica Acta 2000, 45 (21), 3507-3519.

165.Moradzaman, M.; Mul, G., In situ Raman study of Potential Dependent Surface Adsorbed Carbonate, $\mathrm{CO}, \mathrm{OH}$ and C-species on Cu-electrodes during electrochemical reduction of $\mathrm{CO}_{2}$. ChemElectroChem (2021).

166.Kim, D.; Lee, S.; Ocon, J. D.; Jeong, B.; Lee, J. K.; Lee, J., Physical Chemistry Chemical Physics 2015, 17 (2), 824-830.

167.Mistry, H.; Varela, A. S.; Bonifacio, C. S.; Zegkinoglou, I.; Sinev, I.; Choi, Y.W.; Kisslinger, K.; Stach, E. A.; Yang, J. C.; Strasser, P., Nature communications 2016, 7 (1), 1-9.

168.De Luna, P.; Quintero-Bermudez, R.; Dinh, C.-T.; Ross, M. B.; Bushuyev, O. S.; Todorović, P.; Regier, T.; Kelley, S. O.; Yang, P.; Sargent, E. H., Nature Catalysis 2018, 1 (2), 103-110.

169.Chou, T.-C.; Chang, C.-C.; Yu, H.-L.; Yu, W.-Y.; Dong, C.-L.; Velasco-Vélez, J.-J.; Chuang, C.-H.; Chen, L.-C.; Lee, J.-F.; Chen, J.-M., Journal of the American Chemical Society 2020, 142 (6), 2857-2867.

170.Chu, S.; Yan, X.; Choi, C.; Hong, S.; Robertson, A.; Masa, J.; Han, B.; Jung, Y.; Sun, Z., Green Chemistry 2020.

171.Akemann, W.; Otto, A., Surface Science 1993, 287-288, 104-109. 


\section{Bibliography}

172.Pohl, M.; Otto, A., Surface Science 1998, 406 (1), 125-137.

173.Smith, B.; Irish, D.; Kedzierzawski, P.; Augustynski, J., Journal of the Electrochemical Society 1997, 144 (12), 4288.

174.Deng, Y.; Huang, Y.; Ren, D.; Handoko, A. D.; Seh, Z. W.; Hirunsit, P.; Yeo, B. S., ACS Applied Materials \& Interfaces 2018, 10 (34), 28572-28581.

175.Jiang, S.; Klingan, K.; Pasquini, C.; Dau, H., The Journal of Chemical Physics 2019, 150 (4), 041718.

176.Favaro, M.; Xiao, H.; Cheng, T.; Goddard, W. A.; Yano, J.; Crumlin, E. J., Proceedings of the National Academy of Sciences 2017, 201701405.

177.Oda, I.; Ogasawara, H.; Ito, M., Langmuir 1996, 12 (4), 1094-1097.

178.Eilert, A.; Cavalca, F.; Roberts, F. S.; Osterwalder, J. r.; Liu, C.; Favaro, M.; Crumlin, E. J.; Ogasawara, H.; Friebel, D.; Pettersson, L. G., The journal of physical chemistry letters 2017, 8 (1), 285-290.

179.Mistry, H.; Varela, A. S.; Bonifacio, C. S.; Zegkinoglou, I.; Sinev, I.; Choi, Y.W.; Kisslinger, K.; Stach, E. A.; Yang, J. C.; Strasser, P.; Cuenya, B. R., Nature Communications 2016, 7 (1), 12123.

180.Nie, X.; Griffin, G. L.; Janik, M. J.; Asthagiri, A., Catalysis Communications 2014, 52, 88-91.

181.Klingan, K.; Kottakkat, T.; Jovanov, Z. P.; Jiang, S.; Pasquini, C.; Scholten, F.; Kubella, P.; Bergmann, A.; Roldan Cuenya, B.; Roth, C.; Dau, H., ChemSusChem 2018, 11 (19), 3449-3459.

182.Chernyshova, I. V.; Somasundaran, P.; Ponnurangam, S., Proceedings of the National Academy of Sciences 2018, 115 (40), E9261-E9270.

183.Tian, Z.-Q.; Ren, B., Annual Review of Physical Chemistry 2004, 55 (1), 197229.

184.Chernyshova, I. V.; Ponnurangam, S.; Somasundaran, P., Physical Chemistry Chemical Physics 2013, 15 (18), 6953-6964.

185.Smith, B. D.; Irish, D. E.; Kedzierzawski, P.; Augustynski, J., Journal of The Electrochemical Society 2019, 144 (12), 4288-4296.

186.Shan, W.; Liu, R.; Zhao, H.; He, Z.; Lai, Y.; Li, S.; He, G.; Liu, J., ACS Nano 2020.

187.Frantz, J. D., Chemical Geology 1998, 152 (3), 211-225.

188.Vasileff, A.; Zhi, X.; Xu, C.; Ge, L.; Jiao, Y.; Zheng, Y.; Qiao, S.-Z., ACS Catalysis 2019, 9 (10), 9411-9417.

189.Kim, Y.; Park, S.; Shin, S.-J.; Choi, W.; Min, B. K.; Kim, H.; Kim, W.; Hwang, Y. J., Energy \& Environmental Science 2020, 13 (11), 4301-4311. 
190.Ross, M. B.; Dinh, C. T.; Li, Y.; Kim, D.; De Luna, P.; Sargent, E. H.; Yang, P., Journal of the American Chemical Society 2017, 139 (27), 9359-9363.

191.Chen, Y. X.; Tian, Z. Q., Chemical Physics Letters 1997, 281 (4), 379-383.

192.Desilvestro, J.; Weaver, M. J., Journal of Electroanalytical Chemistry and Interfacial Electrochemistry 1986, 209 (2), 377-386.

193.Zhang, Y.; Gao, X.; Weaver, M. J., The Journal of Physical Chemistry 1993, 97 (33), 8656-8663.

194.Reyter, D.; Odziemkowski, M.; Bélanger, D.; Roué, L., Journal of the Electrochemical Society 2007, 154 (8), K36.

195.Chan, H. Y. H.; Takoudis, C. G.; Weaver, M. J., The Journal of Physical Chemistry B 1999, 103 (2), 357-365.

196.Debbichi, L.; Marco de Lucas, M. C.; Pierson, J. F.; Krüger, P., The Journal of Physical Chemistry C 2012, 116 (18), 10232-10237.

197.Hori, Y.; Koga, O.; Watanabe, Y.; Matsuo, T., Electrochimica acta 1998, 44 (89), 1389-1395.

198.Salimon, J.; Hernandez-Romero, R.; Kalaji, M., Journal of Electroanalytical Chemistry 2002, 538, 99-108. 


\section{Summary}

In this thesis, the selective formation of ethylene on $\mathrm{Cu}$ electrodes by electrochemical reduction of $\mathrm{CO}_{2} / \mathrm{CO}$ was investigated. I propose strategies to more selectively form ethylene on rough $\mathrm{Cu}$ electrodes. Fundamental spectroscopic studies were also employed to help understand the formation mechanism of hydrocarbons on $\mathrm{Cu}$ electrodes. Chapter 1 provides motivation and background information on utilization of $\mathrm{CO}_{2}$. Electrochemical reduction of $\mathrm{CO}_{2}$ into hydrocarbons could be a promising way to close the carbon cycle.

In chapter 2, various experimental setups used in this thesis to evaluate the performance of $\mathrm{Cu}$ electrodes in the reduction of $\mathrm{CO}_{2}$ are described. We also provide brief theoretical background on the main characterization techniques used in this thesis: gas chromatography, ATR-FTIR and Raman spectroscopy.

In chapter 3, the influence of the $\mathrm{CO}_{2}$ partial pressure on the catalytic performance of the oxide-derived copper electrodes in electrochemical reduction reaction is discussed. We observed that the faradaic efficiency of ethylene increased from $\sim 37 \%$ to $45 \%$ as a result of decreasing the $\mathrm{CO}_{2}$ partial pressure from 1 to 0.4 atm. We hypothesized that this is due to the rise in local $\mathrm{pH}$, and to test this theory we investigated the effects of potential, buffer concentration and surface roughness on the product distribution. Based on the observations, we confirmed the significant role of local $\mathrm{pH}$ conditions on the selectivity of rough $\mathrm{Cu}$ electrodes.

In chapter 4, we studied electrochemical reduction of various $\mathrm{CO} / \mathrm{CO}_{2}$ mixtures on rough $\mathrm{Cu}$ electrodes. We discovered that the highest ethylene faradaic efficiency was obtained at a $\mathrm{CO}_{2}$ partial pressure of $\sim 0.6 \mathrm{~atm}$ (CO partial pressure of $0.4 \mathrm{~atm}$ ). Besides, we studied the effect of CO partial pressure on electrochemical CO reduction and concluded that ethylene faradaic efficiency was linearly dependent on the CO partial pressure. Next, we investigated the effect of anion composition of the electrolyte on the product distribution of electrochemical CO reduction. Highest 


\section{Summary}

ethylene and lowest methane formation were observed in $\mathrm{KOH}$ with the $\mathrm{pH}$ of 13 , while in phosphate buffer at $\mathrm{pH}$ of 4.6 the opposite was found. Finally, in-situ ATRSEIRAS was employed to help understand the effect of electrolyte anion on the distribution of surface adsorbed species on electrochemically activated $\mathrm{Cu}$ surfaces. The results suggest that the CO coverage is enhanced as the $\mathrm{pH}$ is increased, and the proton concentration is decreased. At high CO coverage on the surface, C-C coupling is favored and ethylene formation is significantly improved.

In chapter 5, we employed ATR-FTIR spectroscopy to investigate electrochemical conversion of $\mathrm{CO}_{2}$ on a rough $\mathrm{Cu}$ electrode fabricated via sputtering. We aimed to obtain insights in the key intermediates and used isotopic labeling to identify the observed peaks. For this purpose, we used $0.1 \mathrm{M} \mathrm{NaOH}$ in $\mathrm{D}_{2} \mathrm{O}$ solution saturated with $\mathrm{CO}_{2}\left({ }^{13} \mathrm{CO}_{2}\right)$. We observed surface-adsorbed species of formate, carbonate, $\mathrm{CO}$ and bicarbonate, respectively, when increasingly more negative potentials were applied. Besides, we hypothesize we were able to detect the $\mathrm{CO}_{2}$ dimer radical anion, the first and most frequently cited intermediate in $\mathrm{CO}_{2} \mathrm{RR}$ in non-aqueous conditions, which we propose to contribute to the formation of CO by disproportionation in aqueous conditions. We were not able to identify any other intermediates, possibly due their short lifetimes.

In chapter 6, we investigated the origin of ethylene selectivity on rough $\mathrm{Cu}$ electrodes. We employed in-situ electrodeposition to form rough $\mathrm{Cu}$ structures and observed enhanced ethylene formation while formation of methane and hydrogen were suppressed. We attributed this to enhanced number of low coordinated sites, as a result of improved roughness. To obtain more insights in the key intermediates that determine the selectivity of $\mathrm{CO}_{2}$ reduction to ethylene, we compared electrochemical reduction of $\mathrm{CO}_{2}$ on smooth and roughened $\mathrm{Cu}$ electrodes. We concluded that on rough $\mathrm{Cu}$ electrodes, a significantly increased $\mathrm{CO}$ coverage leads to high rate of $\mathrm{CO}$ coupling, and consequently shifted the selectivity toward ethylene. Moreover, we 
believe that a high content of $\mathrm{Cu}$ hydroxide on the smooth electrode surface plays a role in inhibiting ethylene formation.

Finally, in chapter 7, we employed Raman spectroscopy and isotopic labeling to identify surface composition including the oxidation state of $\mathrm{Cu}$. For this purpose, we developed highly SERS active electrodes that showed excellent activity and reversibility in the potential region chosen for this study. We were able to identify carbonates, bicarbonates and $\mathrm{CO}$ and their potential dependence. One of the more significant findings to emerge from this study was the presence of $\mathrm{Cu}$ oxides and hydroxides at highly negative potentials. Future experimental and theoretical work is needed to comprehend the role of such $\mathrm{Cu}^{+}$species as catalytically active sites for $\mathrm{CO}_{2} \mathrm{RR}$. 


\section{Samenvatting}

\section{Samenvatting}

In dit proefschrift wordt beschreven hoe procesvariabelen de selectieve vorming van ethyleen in de elektrochemische reductie van $\mathrm{CO}_{2}$ en/of $\mathrm{CO}$ over Cu elektroden beïnvloeden. Het effect van de aangelegde potentiaal, de partiële druk, en de concentratie en chemische samenstelling van het elektrolyt is onderzocht door middel van gedetailleerde gas analyse, aangevuld met inzichten in de chemie die plaats vindt op het oppervlak van koper elektroden, verkregen door middel van Raman en Infrarood spectroscopie.

Hoofdstuk 1 geeft achtergrondinformatie voor de noodzaak om de emissies van $\mathrm{CO}_{2}$ in de atmosfeer terug te dringen. Elektrochemische reductie van $\mathrm{CO}_{2}$ naar koolwaterstoffen zou een veelbelovende manier kunnen zijn om de uitstoot daarvan te beperken en de koolstofcyclus te sluiten, en daardoor opwarming van de aarde tegen te gaan.

In hoofdstuk 2 worden de verschillende toegepaste elektrochemische opstellingen beschreven voor de uitvoering van de reductie van $\mathrm{CO}_{2}$. Ook worden de belangrijkste analyse technieken behandeld, namelijk gas chromatografie, ATRFTIR (en speciale manier om Infrarood spectra op te nemen) en Raman spectroscopie.

In hoofdstuk 3 wordt de invloed van de partiële druk van $\mathrm{CO}_{2}$ op de katalytische activiteit van koper elektroden onderzocht in $\mathrm{KHCO}_{3}$ elektrolyt. De efficiëntie naar de vorming van ethyleen verbetert van $37 \%$ naar $45 \%$ ten gevolge van het verlagen van de partiële druk van $\mathrm{CO}_{2}$ van 1 naar 0.4 Bar. Een verhoging van de $\mathrm{pH}$ op het grensvlak tussen het metaal en het elektrolyt zou een verklaring voor deze observatie kunnen zijn. Om deze hypothese te testen is het effect van potentiaal (en daarmee correlerende stroomdichtheid), de bufferconcentratie en oppervlakteruwheid op de productverdeling onderzocht en gemodelleerd. Op basis van observaties uit deze experimenten wordt bevestigd dat de lokale $\mathrm{pH}$ een significante rol speelt in de product selectiviteit op ruwe koperen elektroden. 
In hoofdstuk 4 is de elektrochemische reductie van verschillende $\mathrm{CO} / \mathrm{CO}_{2}$ mengsels op ruwe koperen elektroden bestudeerd. De hoogste faradische efficiëntie van ethyleen wordt verkregen met een partiële druk van $\mathrm{CO}_{2}$ van 0.6 atm (en samenhangende partiële druk van CO van $0.4 \mathrm{~atm}$ ). Daarnaast is ook het effect van de partiële druk van CO op de elektrochemische reductie van CO onderzocht. De productiviteit naar ethyleen vertoont een oplopend verband met de partiële druk van CO. Vervolgens is het effect van de anion samenstelling van het elektrolyt op de productverdeling tijdens de elektrochemische reductie van $\mathrm{CO}$ onderzocht. In een $\mathrm{KOH}$ oplossing met een $\mathrm{pH}$ van 13 werd de hoogste productie van ethyleen en de laagste productie van methaan waargenomen, terwijl in de aanwezigheid van een fosfaat buffer met pH 4.6, de vorming van koolwaterstoffen beperkt is. Tot slot, is gebruik gemaakt van in-situ ATR-SEIRAS om het effect van het elektrolyt anion op product selectiviteit te begrijpen. De resultaten doen vermoeden dat de bedekking van de elektrode met $\mathrm{CO}$ verhoogd wordt bij toenemende lokale $\mathrm{pH}$, waardoor de vorming van ethyleen wordt bevorderd.

In hoofdstuk 5 wordt gebruik gemaakt van ATR-FTIR spectroscopie om de elektrochemische reductie van $\mathrm{CO}_{2}$ op ruwe koperen elektroden nader te onderzoeken. Deze ruwe koperen oppervlakten zijn gefabriceerd middels een sputtertechniek en aangebracht op een Si kristal. Er is gebruik gemaakt van verschillende isotopen van water $\left(\mathrm{D}_{2} \mathrm{O}\right)$ en $\mathrm{CO}_{2}\left({ }^{13} \mathrm{CO}_{2}\right)$ om verschillende pieken te identificeren. Een $0.1 \mathrm{M} \mathrm{NaOH}$ in $\mathrm{D}_{2} \mathrm{O}$ oplossing verzadigd met $\mathrm{CO}_{2}\left({ }^{13} \mathrm{CO}_{2}\right)$ is gebruikt voor deze experimenten. Bij toenemende negatieve potentialen kan achtereenvolgens geadsorbeerd formiaat, carbonaat, CO en bicarbonaat waar worden genomen. Daarnaast zijn sterke aanwijzingen verkregen voor de vorming van het $\mathrm{CO}_{2}$ dimeer radicaal anion, een mogelijk tussenproduct in de elektrochemische reductie van $\mathrm{CO}_{2}$. Verdere reductie van dit dimeer radicaal anion leidt tot de vorming van $\mathrm{CO}$ en carbonaat anionen $\left(\mathrm{CO}_{3}{ }^{2-}\right)$. 


\section{Samenvatting}

In hoofdstuk 6 wordt de het effect van de morfologie van ruwe koperen elektroden op de selectiviteit naar ethyleen nader onderzocht. In-situ elektrodepositie door toevoeging van koperzouten aan het elektrolyt, werd toegepast om ruwe Cu-structuren te vormen. Dit leidt tot verbeterde ethyleenvorming terwijl de vorming van methaan en waterstof wordt onderdrukt. We hebben dit toegeschreven aan een groter aantal laag gecoördineerde sites als gevolg van verbeterde ruwheid. Raman spectroscopie laat zien dat de oppervlakte concentratie van CO aanzienlijk hoger is op ruwe Cu-elektroden, wat leidt tot een hoge mate van CO-koppeling, en daardoor hoge selectiviteit naar ethyleen. Verder is de vorming van een hydroxide verbinding bij negatieve potentiaal waargenomen, waarvan de aanwezigheid een negatieve correlatie vertoond met de productiviteit van de elektrode in de vorming van koolwaterstoffen.

In hoofdstuk 7 hebben we Raman-spectroscopie en verschillende isotopen van water $\left(\mathrm{D}_{2} \mathrm{O}\right)$ en $\mathrm{CO}_{2}\left({ }^{13} \mathrm{CO}_{2}\right)$ gebruikt om de belangrijkste tussenproducten en de oxidatietoestand van $\mathrm{Cu}$ tijdens de reactie te identificeren. Voor dit doel hebben we zeer actieve SERS elektroden ontwikkeld die uitstekende activiteit en reproduceerbaarheid vertoonden in het toegepaste bereik van de elektrochemische potentiaal. De potentiaal afhankelijkheid van geadsorbeerde carbonaten, bicarbonaten en $\mathrm{CO}$ zijn geïdentificeerd. Een belangrijke bevinding was de aanwezigheid van $\mathrm{Cu}$-oxiden en -hydroxiden, en een mogelijke $\mathrm{Cu}-\mathrm{C}$ verbinding bij zeer negatieve elektrochemische potentialen. Toekomstig experimenteel en theoretisch werk is nodig om de rol van dergelijke $\mathrm{Cu}-\mathrm{OH}$ en $\mathrm{Cu}-\mathrm{C}$ verbindingen in de katalytische conversie van $\mathrm{CO}_{2}$ beter te begrijpen. Zoals beschreven in hoofdstuk 6 , bestaat het vermoeden dat de aanwezigheid van deze verbindingen de activiteit en de stabiliteit van de elektrode negatief beïnvloeden. 


\section{List of Publications}

1. Moradzaman, M., Sánchez-Martínez, C. and Mul, G."Effect of partial pressure on product selectivity in $\mathrm{Cu}$-catalyzed electrochemical reduction of $\mathrm{CO}_{2}$." Sustainable Energy \& Fuels 4 (2020): 5195-5202

2. Moradzaman, M. and Mul, G. "Infrared analysis of interfacial phenomena during electrochemical reduction of $\mathrm{CO}_{2}$ over polycrystalline copper electrodes." ACS Catalysis 10 (2020): 8049-8057.

3. Moradzaman, M. and Mul, G. "In situ Raman study of potential dependent surface adsorbed carbonate, $\mathrm{CO}, \mathrm{OH}$ and $\mathrm{C}$-species on Cu-electrodes during electrochemical reduction of $\mathrm{CO}_{2}$." ChemElectroChem (2021).

4. Moradzaman, M. and Mul, G. "Optimizing CO coverage on rough copper electrodes: effect of the partial pressure of $\mathrm{CO}$ and electrolyte anions $(\mathrm{pH})$ on selectivity toward ethylene". The Journal of Physical Chemistry C (2021).

5. Moradzaman, M. and Mul, G. " Correlating the surface structure and composition of copper to high selectivity towards ethylene in reduction of $\mathrm{CO}_{2}$ ". In preparation. 


\section{Acknowledgements}

Four years have come to an end and it's time to close this chapter of my life. I was only able to complete this thesis with the support and help of several people around me, which I herewith would like to acknowledge.

I would like to start by thanking my supervisor. Guido, I appreciate your great enthusiasm towards my work. I surely enjoyed and learned a lot from our discussions. I could not have done any of this without the support and freedom you offered me. Besides all your valuable feedback, your final touches on my thesis made it a lot better.

I would like to thank Robert Meijer and Dorothy. Robert, your positive attitude towards my issues besides your technical skills greatly helped me during my difficult times. Dorothy, your caring and kind nature made me like you instantly, and I want to thank you for your help and also the personal chats we had.

Furthermore, I would like to thank Annemarie and Bastian. It was a pleasure working with you and witnessing your continuous scientific developments.

My dear colleagues in PCS, thank you all for your help and all the good times we had together. Kai, Nakul, Myles and Kaijian, it was lots of fun sharing an office with you. Ainoa and Piotr, my paranymphs, I really enjoyed spending time with you during these years and would like to thank you for being there for me. Liniker, I will never forget our struggles with the GC and jokes about the leaking reactors. Margot, thanks a lot for helping me with the Dutch summary, and always being nice and caring. Devin, thank you for sometimes pulling me out of the office and shaming me into being more social. Ronald, Yibin, Kasper, Vera and Robert, I enjoyed working alongside you in the labs and having fun activities with you, you certainly made these years more enjoyable. Also thanks to Sobhan, Shri, Sean, Martijn and Anne, it was a great experience to work with you. 
Outside PCS I would like to thank Mike Dikkers for his help with sputtering. I would also like to thank Recep Kas for passing on some of his wisdom regarding infrared spectroscopy to me. I would also like to thank the members of the Solar to Products project for their input during the several progress meetings, and particularly Carlos Sanchez Martinez for the modeling efforts reported in Chapter 3.

In the end, I would like to thank my family for their love and support. Hamid, my husband and great friend for almost 9 years, thank you for all the love and patience. I am looking forward to the next chapter with you. 